\title{
Analysis and Test Results for a Two-Bladed, Passive Cycle Pitch, Horizontal-Axis Wind Turbine in Free and Controlled Yaw
}

Kurt H. Holenemser

Washington University

St. Louis, Missouri

NREL technical monitor: C. Shepard

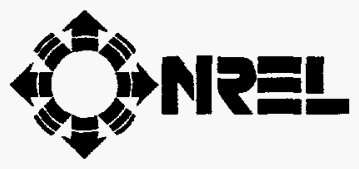

National Renewable Energy Laboratory

1617 Cole Boulevard

Golden, Colorado 80401-3393

A national laboratory of the U.S. Department of Energy Managed by the Midwest Research Institute for the U.S. Department of Energy under Contract No. DE-AC36-83CH10093

Prepared under Subcontract No. XE-2-0254-01

October 1995

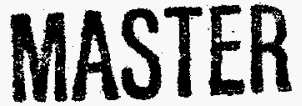


This publication was reproduced from the best available camera-ready copy submitted by the subcontractor and received no editorial review at NREL.

\section{NOTICE}

This report was prepared as an account of work sponsored by an agency of the United States government. Neither the United States government nor any agency thereof, nor any of their employees, makes any warranty, express or implied, or assumes any legal liability or responsibility for the accuracy, completeness, or usefulness of any information, apparatus, product, or process disclosed, or represents that its use would not infringe privately owned rights. Reference herein to any specific commercial product, process, or service by trade name, trademark, manufacturer, or otherwise does not necessarily constitute or imply its endorsement, recommendation, or favoring by the United States government or any agency thereof. The views and opinions of authors expressed herein do not necessarily state or reflect those of the United States government or any agency thereof.

Available to DOE and DOE contractors from:

Office of Scientific and Technical Information (OSTI)

P.O. Box 62

Oak Ridge, TN 37831

Prices available by calling (615) 576-8401

Available to the public from:

National Technical Information Service (NTIS)

U.S. Department of Commerce

5285 Port Royal Road

Springfield, VA 22161

(703) $487-4650$ 


\section{DISCLAIMER}

Portions of this document may be illegible in electronic image products. Images are produced from the best available original document. 


\section{Preface}

The yaw analysis and test results summarized in this report were obtained for a two-bladed, passive cyclic pitch (PCP), horizontal-axis wind turbine at Washington University, St. Louis, Missouri, with Kurt H. Hohenemser as principal investigator. Andrew H.P. Swift developed the yaw analysis methods and the atmospheric testing procedures. Between September 1979 and December 1985, the work was sponsored under various subcontracts by the Solar Energy Research Institute (SERI), now the National Renewable Energy Laboratory (NREL). The Final Subcontract Report SERI/STR-217-3002 of January 1987, included here as Appendix 1, summarizes the analysis and atmospheric test results obtained during this period.

This updated Final Subcontract Report also includes analysis and atmospheric test results obtained after SERI sponsorship was terminated. The extensive modifications to, as well as the maintenance and operation of, the atmospheric test equipment at Washington University's Tyson Research Center were made possible by the support of the university's Mechanical Engineering Department through Eugene F. Bulfin. Robert Short, retired from the McDonnell-Douglas Corporation in St. Louis, made important voluntary contributions. Andrew H.P. Swift carefully reviewed the draft report and made many valuable suggestions for improving it.

In 1993, a somewhat different version of the latest Washington University atmospheric test equipment began operating at the University of Texas at El Paso (UTEP), with Andrew H.P. Swift as principal investigator. The State of Texas and NREL were the cosponsors. The UTEP

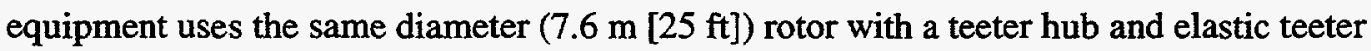
restraints, the same type of yaw control system with remotely operated clutch, and the same 18.3-m (60-ft) tower with three cross-braced legs. As at Washington University, the rotor axis uptilt angle and the lateral offset between rotor and yaw axes can be varied. Although the instrumentation at UTEP is much more extensive, the nacelle weight and the rotor overhang are substantially greater than at Washington University; therefore, a direct comparison between Washington University and UTEP test results will not be possible. 


\section{Summary}

This report, which includes five appendices, is a survey of the analysis and tests performed at Washington University in St. Louis, Missouri, on a horizontal-axis, two-bladed wind turbine with teeter hub. The introduction is a brief account of results obtained during the 5-year period ending December 1985. The wind tunnel model and the test turbine $(7.6 \mathrm{~m}[25 \mathrm{ft}]$ in diameter) at Washington University's Tyson Research Center had a $67^{\circ}$ delta-three angle of the teeter axis. The introduction explains why this configuration was selected and named the passive cycle pitch (PCP) wind turbine. Though the analysis was not limited to the PCP rotor, all tests, including those done from 1986 to 1994 , were conducted with the same teetered wind rotor. The blades are rather stiff and have only a small elastic coning angle and no precone.

During the first phase of testing, the wind turbine powered a variable-speed alternator tuned in such a way that rotor power increased with the cube of the rotor speed. In the next phase of testing, a near-constant-speed induction generator was used and was connected to the utility grid. A version of the PCP wind turbine with induction generator, called the "Proof-of-Concept" turbine, was tested at the Rocky Flats Wind Systems Test Center in 1982. The introduction summarizes the draft report on the preliminary results from Rocky Flats. The draft was circulated among interested parties but it was never finalized or published.

The original Washington University upwind turbine, tested through 1986, operated in free yaw and used a vertical tail surface at the end of a tail boom for wind following. Beyond rated wind speed, the nacelle was yawed with respect to the tail boom by a passive yaw system controlled by a combination of rotor thrust and rotor torque. It was found that yaw angle and yaw rate were strongly influenced by the turbulence response of the tail boom. Varying the teeter spring rates and adjusting the yaw spring and yaw damper did not solve the problem. In 1986, a mechanical tail boom yaw damper was installed which, in combination with the optimization of the other parameters, resulted in a substantial reduction of the turbulence-excited yaw oscillations and in an acceptable sensitivity of the passive yaw control. Normal and emergency shutdowns were performed by an electrical yaw actuator. A 1984 failure of this shutdown system suggested that it may be more important to use free yaw for shut-down rather than for normal operation. In 1987 , the vertical tail surface was removed by truncating the tail boom. An electrically powered yaw gear drive was installed that could be disengaged by a remotely controlled clutch that needed electric power to keep it engaged. Shutdown in response to electric power failure and to other failure signals was performed by free yaw of the rotor from upwind toward downwind, with a near $90^{\circ}$ yaw equilibrium. This method worked very well for the upwind configuration, except for a brief period of teeter-stop pounding caused by high yaw rates during shutdown. Wind following and power regulation were achieved using an electronic analog control.

An unpublished analysis showed that shutdown by free yaw would be slower and more benign (no teeter-stop pounding) for a downwind configuration. Washington University's wind turbine operation was changed to downwind mode in 1991. A small vertical tail surface was added and dimensioned in such a way that at the end of the shutdown transient the stopped rotor self-yawed to a near upwind position. The free-yaw shutdown mode was improved as predicted. Wind turbine operation was also smoother than upwind operation without the previously observed 1-P yaw oscillations that had occurred within the play of the yaw gear drive. In the course of these tests, the turbine in the upwind free-yaw shutdown mode was exposed to storms for an entire year 
without ever turning, although the parking brake provided hardly any braking torque. This suggests the possibility of a free-yaw storm survival mode for fixed-pitch rotors without the need for a rotor brake.

The final section of this report deals with Washington University's 14 years of experience with the 7.6- $\mathrm{m}$ (25-ft) test wind turbine, and the applicability of this experience to larger production machines.

All configurations tested or considered had a rotor without pitch variation, aerodynamic blade tip brakes, ailerons, or mechanical teeter dampers, all of which are believed to increase maintenance and reduce the economic life of a wind turbine. 


\section{Contents}

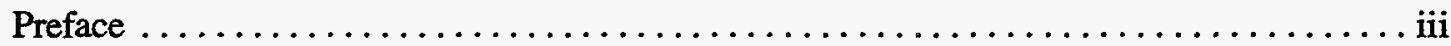

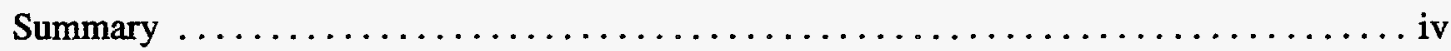

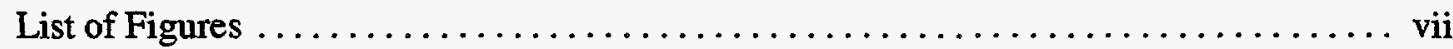

Nomenclature $\ldots \ldots \ldots \ldots \ldots \ldots \ldots \ldots \ldots \ldots \ldots \ldots \ldots \ldots \ldots \ldots \ldots \ldots \ldots \ldots \ldots$ viii

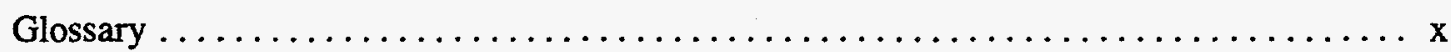

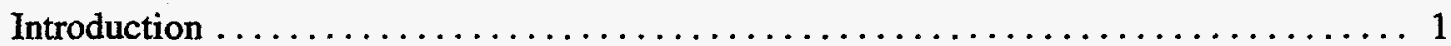

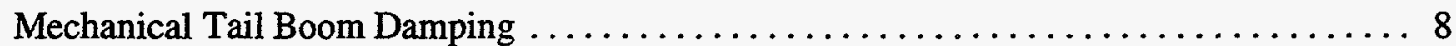

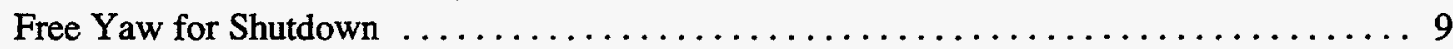

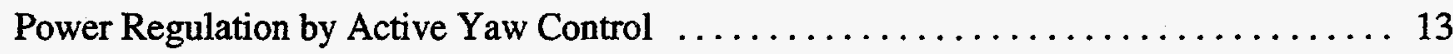

Comparative Tests for Upwind and Downwind Configurations $\ldots \ldots \ldots \ldots \ldots \ldots \ldots$

Storm Survival after Free-Yaw Shutdown . . . . . . . . . . . . . . . . . . . . 15

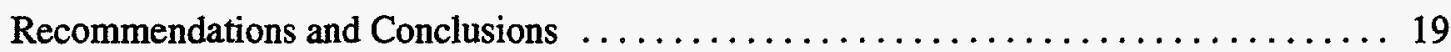

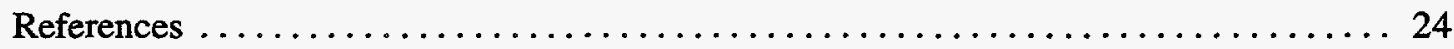

\section{List of Appendices}

Appendix 1. Hohenemser, K.H. (January 1987). Analysis and Test Results for an Improved Constant Speed Passive Cyclic Pitch Wind Turbine. Final Subcontract Report, SERI/STR-217-3002.

Appendix 2. Hohenemser, K.H. (February 1987). "Wind Turbine Yaw Dynamics Analysis for a Teetered Rotor System." Sixth ASME Wind Energy Symposium; Dallas, Texas.

Appendix 3. Hohenemser, K.H. (January 1988). "Wind Turbine Shut-Down by Self Yawing." Seventh ASME Wind Energy Symposium; New Orleans, Louisiana.

Appendix 4. Hohenemser, K.H. (January 1991). "Power Regulation by Active Yaw Control for a Teetered Wind Rotor, Extended Abstract." Tenth ASME Wind Energy Wind Symposium; Houston, Texas.

Appendix 5. Hohenemser, K.H.; Swift, A.H.P. (May 1984). "On the Design of Horizontal Axis Two-Bladed Hinged Wind Turbines." ASME Journal of Solar Energy Engineering, Vol. 106, pp. 171-176. 


\section{List of Figures}

Page

1. Section through rotor shaft in plane of swivel axis $\mathrm{S}-\mathrm{S} \ldots \ldots \ldots \ldots \ldots \ldots \ldots \ldots$

2. a. Upwind, thrust moment has same direction as yaw rate $\dot{\chi} \ldots \ldots \ldots \ldots \ldots 11$

b. Downwind, thrust moment has opposite direction from yaw rate $\dot{x} \ldots \ldots \ldots 11$

3. a. Upwind, $\mathrm{H}$-force moment opposes wind following $\ldots \ldots \ldots \ldots \ldots \ldots \ldots \ldots$

b. Downwind, $\mathrm{H}$-force moment supports wind following $\ldots \ldots \ldots \ldots \ldots \ldots \ldots$

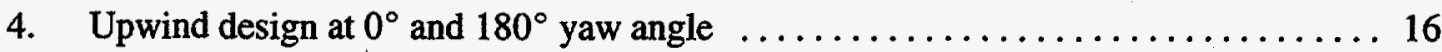

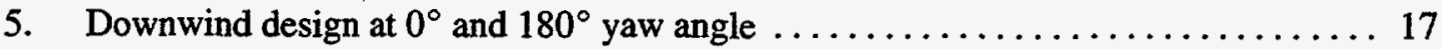




\section{Nomenclature}

$\delta_{3} \quad$ Delta three (see Glossary)

$\beta \quad$ Blade-flapping amplitude, defines the tilting of the rotor plane with respect to the perpendicular to the rotor axis. It is equal to $\tau \cos \delta_{3}$.

$\tau \quad$ Rotor teeter amplitude about the teeter or swivel axis (see Figure 1)

$\Delta \theta \quad$ Blade-pitch change amplitude caused by delta three. It is equal to $\tau \sin \delta_{3}$.

$\Omega \quad$ Rotor angular speed

V Wind speed

$\mathrm{R} \quad$ Rotor radius

V/SR Wind speed ratio, or nondimensional wind speed (or inverse tip speed ratio)

Q Rotor torque

T Rotor thrust

p Air density

$\mathrm{C}_{\mathrm{Q}} \quad$ Torque coefficient $=\mathrm{Q} / \rho \pi \Omega^{2} \mathrm{R}^{5}$

$\sigma \quad$ Rotor solidity ratio $=\mathrm{Bc} / \pi \mathrm{R}$

$(B$, No. of Blades $c=$ Chord at $0.7 R$ )

$C_{p} \quad$ Power Coefficient $=Q \Omega / 0.5 \rho \pi R^{2} V^{3}$

$\chi \quad$ Yaw angle

$\mathrm{d} \chi / \mathrm{dt} \quad$ Yaw rate

$\mathrm{H}$ Aerodynamic force produced in the plane of the rotor due to yawed flow

p Ratio of teeter frequency due to teeter springs over rotational frequency. $\mathrm{p}^{2}=1+\mathrm{K}_{\mathrm{sp}} / \mathrm{I}_{\mathrm{b}}$ $\Omega^{2}$

$\mathrm{K}_{\mathrm{sp}} \quad$ Teeter spring stiffness in the blade-flapping direction 
Airfoil chord width

$I_{b} \quad$ Blade moment of inertia 


\section{Glossary}

Delta three angle ( $\delta 3):$ Angle between the perpendicular to the blade axes and the teeter or swivel axis (see Figure 1).

Passive cyclic pitch design (PCP): This is a rotor-hub design for a teetered rotor with a high delta-three angle. The high delta-three angle provides a pitch-flap coupling so that motion about the teeter, or swivel, hinge results in mostly a pitching motion, rather than a flapping motion, for zero-delta-three rotors. The 1-P teeter motion about the swivel axis produces a cyclic pitching motion (thus, the designation PCP) (see Figure 1).

Furling: Change of direction of the rotor axis in the horizontal plane with respect to a reference indicating the wind direction, so that the rotor-swept area exposed to the wind is reduced. This reference may be given by a tail vane boom (as in Figure 2-4 of Appendix 1), or in the absence of a tail vane boom the reference may be given by a small pilot vane that indicates the wind direction.

Yaw angle (or furl angle): Angle between the rotor axis and the wind direction in the horizontal plane ( 0 when the rotor axis points in the wind direction).

Yaw drive: Mechanism to change the direction of the rotor axis in the horizontal plane with respect to the tower.

Yaw rate, nondimensional: Ratio of the yaw rate to the rotor speed.

Free yaw: Capability of the nacelle to rotate freely in the horizontal plane with respect to the tower.

Lateral offset: Between rotor axis and yaw axis, produces (in free yaw) a furling of the nacelle caused by rotor thrust.

Uptilt angle of the rotor axis: Produces in free yaw a furling moment caused by the rotor-driving moment; lateral offset and uptilt angle can be selected so that the two effects cancel.

Blade-pitch angle: Angle between the airfoil 0 lift line and the rotor plane. Nose toward wind is considered positive (i.e., positive toward feather).

Blade twist: Blade-pitch angle increases toward the blade root to facilitate rotor starting.

Upwind design: Blade twist is designed for the rotor having a yaw angle of 0 when upwind of the tower.

Downwind design: Blade twist is designed for the rotor having a yaw angle of 0 when downwind of the tower.

Reversed flow through rotor: Condition at $90^{\circ}$ to $180^{\circ}$ yaw angle when blade twist produces aerodynamic rotor braking. 
Free-yaw shutdown design: Nacelle is aerodynamically designed (e.g., with the help of a small vertical tail at the end of a stub boom) to freely yaw after power disconnect toward a $90^{\circ}$ yaw angle so that aerodynamic rotor braking is achieved.

Autorotation: Condition at 0 rotor torque.

Self-starting: Aerodynamic rotor start from zero rotor speed without mechanical power input, usually facilitated by large inboard blade twist.

Motor starting: Use of mechanical power input for starting.

1-P Oscillation: Frequency is equal to that of rotor rotational period.

Fixed-pitch design: Blades are rigidly connected to the hub without pitch change bearings, and without blade-pitch control (although, with delta-three angle, a passive cyclic pitch change caused by teetering can occur).

Rated wind speed: Speed at which, for 0 yaw angle, maximum allowable power is reached.

Lock Number: A nondimensional parameter that is the ratio of aerodynamic to inertia forces for a rotor. Lock Number $=\rho a c R^{4} / I_{b}$. 


\section{Introduction}

This introduction provides a brief account of the work accomplished-and the questions remaining-as of December 1985, at the end of the Solar Energy Research Institute's (SERI's) sponsorship of this project.

First, however, we will clarify the meaning of passive cyclic pitch (PCP) as it has been applied to a two-bladed horizontal-axis wind turbine. Use of this phrase has resulted in some misunderstanding in the past, when it was interpreted to mean something different from its true definition-a teeter rotor with a large delta-three angle of the teeter axis.

Figure 1 shows a section through the rotor shaft in the plane of the swivel axis S-S, sometimes called the "teeter axis." $\mathrm{P}$ is a representative point on the blade axis $\mathrm{B}-\mathrm{B}$, which will move vertically out of the plane for a small angular deflection $\tau$ about the swivel axis $S-S . \Omega$ is the angular rotor speed. The swivel axis $S-S$ is specified by the angles $\delta_{3}$ or $90-\delta_{3}$ in degrees. Associated with a small angular deflection $\tau$ about the swivel axis $S-S$ is the out-of-plane angle $\beta$ of the blade axis B-B and the blade pitch change from $\delta_{3}$ denoted as $\Delta \Theta$, (not shown). It is easy to show from Figure 1 the validity of the kinematics relations

$$
\beta=\tau \sin \left(90-\delta_{3}\right), \Delta \Theta=\tau \cos \left(90-\delta_{3}\right)
$$

For stable teetering, the angle $\left(90-\delta_{3}\right)$ measured from the blade axis must have the same direction as $\Omega$. 


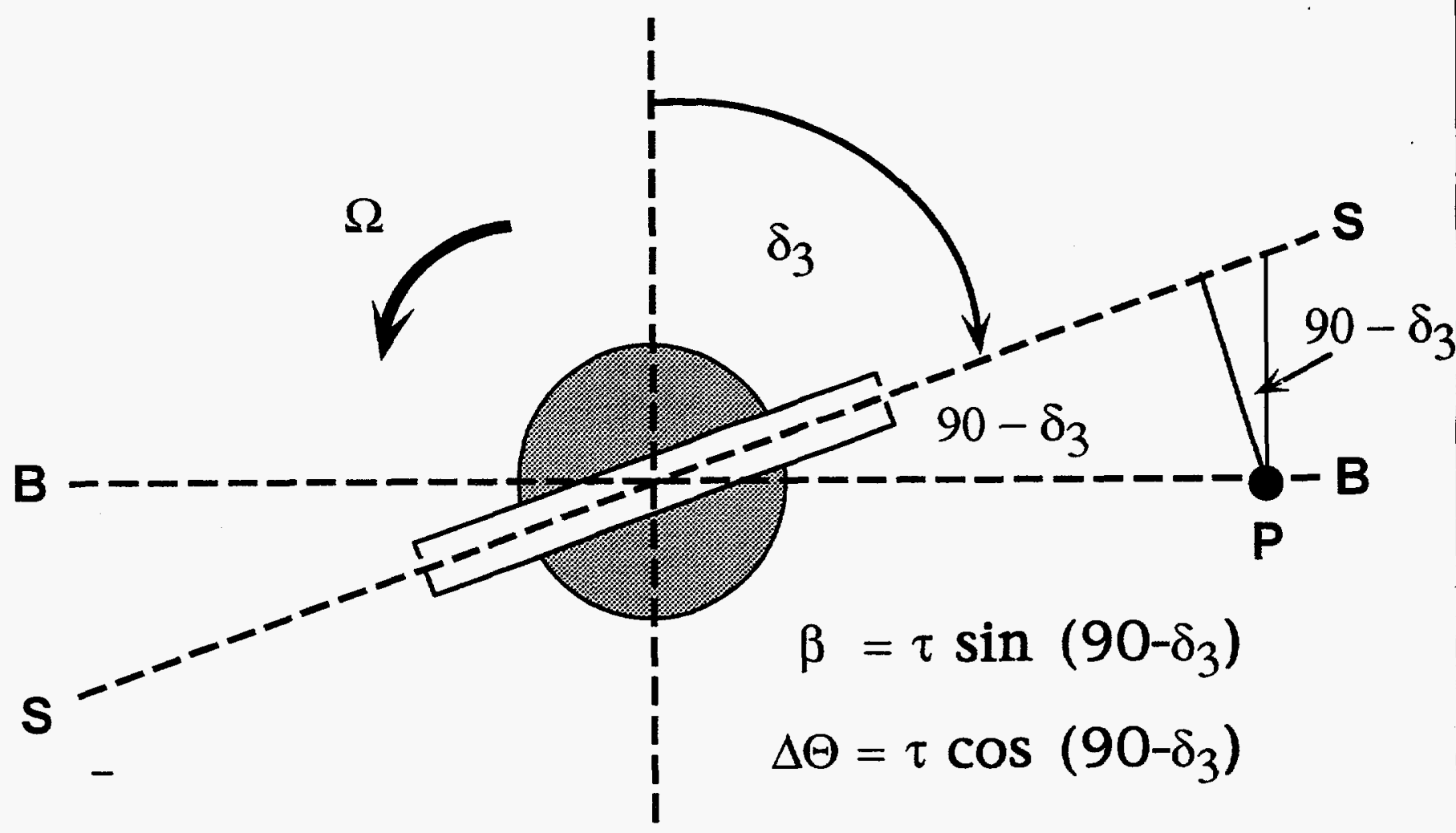

Figure 1. Section through rotor shaft in plane of swivel axis S-S 
One then obtains for the ratios $\beta / \tau$ and $\Delta \Theta / \tau$ as functions of $\delta_{3}$ the following values:

Table 1. The Effect of $\delta_{3}$ on Flap and Pitch Ratios

\begin{tabular}{|c|c|c|}
\hline$\delta_{3}$ & $B / \tau$ & $\Delta \Theta / \tau$ \\
\hline 0 & 1.0 & 0 \\
\hline $30^{\circ}$ & 0.87 & 0.50 \\
\hline $67^{\circ}$ & 0.39 & 0.92 \\
\hline
\end{tabular}

The specific angle of $67^{\circ}$ was the delta-three angle selected for this test rotor because of hub geometry and ease of fit for the teeter bearings. Analyses have indicated that for most operating conditions the angular deflections of $\tau$ are nearly independent of $\delta_{3}$ (see for example Figures 9 and 10 of Appendix 5, applicable for an unstalled wind rotor). As shown in Table 1, moderate delta three values (e.g., $30^{\circ}$ ) result in the out-of-plane angle $\beta$ being not much reduced from its value at 0 delta three. In order to obtain a significant reduction in out-of-plane angle $\beta$, or flap angle, one must select large values of delta three. But then the blade pitch change $\Delta \Theta$ is almost equal to the angular deflection $\tau$ about the swivel axis. It is, therefore, logical to denote a rotor with large $\delta_{3}$ and largely suppressed teeter motions a PCP rotor rather than simply a teeter rotor.

Convention is stronger than logic. For example, codes such as "TEETER@" are also valid for large delta three, and should logically be called (in this regime) "PCP" codes. TEETER is a computer code available from UTEP that models two-bladed teetered rotors in yawed flow (see Reference 4). No matter what terminology is used, the physical effects of parameter variations remain the same.

For brevity, we will continue to use PCP to refer to a rotor with hinged hub or blades, but with substantially suppressed out-of-plane hub or blade motions due to a large pitch-flap coupling (i.e., large $\delta_{3}$ ). As explained in References 1 and 2 of Appendix 1, the three-bladed lifting rotor of the U.S. Army XV-1 convertiplane, developed in the 1950 s, operated in cruising flight as an autorotating fixed-pitch PCP rotor. The hub angle of attack with respect to the relative wind direction was automatically controlled by a rotor speed governor that kept the rotor revolutions per minute (rpm) constant within a small error, even during fast maneuvers and in turbulence. This favorable experience led 25 years later to the proposal to try out the principle of the PCP lifting rotor on a horizontal-axis wind turbine. In this case, the conventional full-, or partial-span blade pitch variation for the purpose of rotor torque and speed control would be replaced by the yaw control for upwind turbines normally required for wind direction following. Appendix 5 also briefly describes the history of the teeter rotor in rotor craft and wind turbines.

The simplest rotor type was a two-bladed rotor with a teeter hub that could easily be made into a PCP rotor by using a large deita-three angle of about $70^{\circ}$ for the swivel pin (see Figure 1). The advantage of using a lifting rotor type wind turbine versus a propeller type with rigid blade-hub and rigid hub-shaft connections was the compensation of gyroscopic and asymmetric blade airloads within the rotating system, without stressing the rotor shaft or other system components. Disadvantages included the out-of-plane blade motions, which required an increased rotor overhang and could lead to teeter-stop pounding with greatly increased system loads. Both of 
these disadvantages were substantially alleviated by the greatly reduced flapping amplitudes of the PCP rotor. The additional teetering degree of freedom could also produce dynamic instabilities, particularly in the nonlinear partial-stall operating regime. Finally, a teeter rotor type, when positioned upwind of the tower, had negative static yaw stability and negative yaw damping, which had to be compensated for by other means such as a tail vane or yaw drive. (When downwind, yaw stability and yaw damping become positive.)

The rotor selected for the study had two blades with a teeter hub, was upwind of the tower, had fixed-blade pitch, and was freely yawing. Below rated wind speed, the negative static yaw stability and negative yaw damping from the rotor were overcompensated by a large vertical tail at the end of a tail boom.

It is interesting to note from Reference 1 that, 13 years later, a near majority of the 25 professional respondents to an inquiry about the preferred horizontal-axis wind turbine configuration selected a similar configuration, except for the large vertical tail, from the five alternatives: three or two blades, rigid or teeter hub, downwind or upwind rotor location, variable- or fixed-blade pitch, and yaw drive or passive yaw.

The sady at Washington University began with a $0.43-\mathrm{m}(1.4-\mathrm{ft})$ diameter wind tunnel model test in autorotation. The PCP wind tunnel model had all the five characteristics listed above, plus a vertical tail surface at the end of a tail boom. The delta-three angle of the swivel axis was $67^{\circ}$. The model was tested in free and in fixed yaw, and in transients from a $20^{\circ}$ initial yaw error. It behaved well and gave support to the design of the 7.6-m (25-ft) diameter atmospheric test rotor. A dynamic instability of the wind tunnel model with teeter-stop pounding and a rapid decay of the rpm occurred at a wind speed of $11 \mathrm{~m} / \mathrm{s}(25 \mathrm{mph}$ ) (speed ratio $\mathrm{V} / \Omega \mathrm{R}=0.21)$. By raising the natural frequency of the coning mode, the onset of dynamic instability could be shifted upward to $13 \mathrm{~m} / \mathrm{s}(29 \mathrm{mph})(\mathrm{V} / \Omega \mathrm{R}=0.25)$. The yaw angle had some effects on the onset of the instability. No attempt was made to analyze the observed instability because partial blade stall occurred for which no applicable code existed. The atmospheric test rotor at Washington University also exhibited dynamic instability and stop pounding when operated at 0 yaw angle at reduced rotor speed in stall. At normal rotor speed and high yaw angles to the wind, it never exhibited any signs of a dynamic instability, though steady winds up to $20 \mathrm{~m} / \mathrm{s}(45 \mathrm{mph})(\mathrm{V} / \Omega \mathrm{R}=0.25)$ and gusts up to $27 \mathrm{~m} / \mathrm{s}(60 \mathrm{mph})$ were encountered.

Today, codes including partial blade stall are available and may succeed in predicting dynamic wind rotor instabilities. One can intuit that the blade coning angle, elastic or built-in, is a sensitive parameter, because it couples blade cyclic pitch with cyclic in-plane blade motions. Preconing, found to be desirable in downwind teeter rotors like the ESI or Carter types, may be detrimental in a PCP rotor. Further analysis is required.

As described in Reference 1 of Appendix 1, the atmospheric 7.6-m (25-ft) diameter test rotor at Washington University was operated in 1980 during a 41-day period for 96 hours with a variablespeed alternator. Yaw angles up to $45^{\circ}$ power-on and up to $80^{\circ}$ power-off were tested. The rotor was automatically furled to near $90^{\circ}$ yaw angle when $228 \mathrm{rpm}$ at $10-\mathrm{kW}$ power was exceeded. Unfurling was performed manually. The variable-speed alternator was connected to a resistance in such a way that the rotor power increased with the cube of the rotor speed, and the torque coefficient $\mathrm{C}_{\mathrm{Q}} / \sigma$ maintained a constant value of 0.008 . Unyawed and between 4 and $10 \mathrm{~m} / \mathrm{s}(9$ and 
$22 \mathrm{mph}$ ) of wind speed, the speed ratio was $V / \Omega R=0.11$ and the power coefficient was $C_{P}=0.38$. At a $40^{\circ}$ yaw angle and between 8 and $13 \mathrm{~m} / \mathrm{s}(18$ and $29 \mathrm{mph})$ of wind speed, the speed ratio was $V / \Omega R=0.15$ and the power coefficient was $C_{P}=0.14$. The machine adapted rapidly to wind direction changes with yaw rates up to $17^{\circ}$ per second, causing cyclic pitch amplitudes up to $\pm 5^{\circ}$. Loads were measured power-on at $15^{\circ}, 30^{\circ}, 45^{\circ}$ yaw angle and power-off at $80^{\circ}$ yaw angle. Blade-root flap bending, in-plane bending, and dynamic rotor shaft torque were far below allowable within the tested operational envelope. Self-starting with the original blades required a gust up to $6 \mathrm{~m} / \mathrm{s}(13 \mathrm{mph})$. Motor starting required a wind speed of $2 \mathrm{~m} / \mathrm{s}(4.5 \mathrm{mph})$.

As described in Reference 2 of Appendix 1, the study was extended in 1981 in four areas. First, an analysis was developed for unstalled operation of the wind rotor in yawed flow, which allowed prediction of the radial and azimuth blade angle-of-attack distributions for constant yaw angles and for constant yaw rates. This made possible an estimate of the onset of blade stall. Second, an active automatic yaw-control system was developed and tested in autorotation, which used rotor speed as input to the yaw control. Third, a passive automatic yaw control was developed and tested that used a combination of rotor thrust and rotor torque inputs to keep rotor speed and rotor power from exceeding rated values. Fourth, the variable-speed alternator was replaced by a nearconstant-speed induction generator connected to the utility grid. The active automatic yawcontrol system with rotor speed as input could not be used in connection with the induction generator, and its further development was discontinued in favor of the passive yaw control system using rotor thrust and rotor torque as inputs.

Researchers at the Washington University site found that energy production was not reduced by the near-constant-speed induction generator versus the variable speed alternator, though the system loads were found to be somewhat higher. However, it was recognized that a substantial redesign of the wind turbine would be required to reduce friction in the passive yaw controls, to reduce the transmission losses due to a belt drive for the induction generator, and to improve the aerodynamics of the wind rotor by extending the airfoil section inboard for improved self-starting.

The work done between 1982 and 1985 with SERI sponsorship is described in detail in Appendix 1. A variant of the Washington University experimental wind turbine, called the "Proof-ofConcept Turbine," was delivered in 1982 to the Rocky Flats Wind Systems Test Center, where the instrumentation was designed and built. The new version incorporated the redesign items mentioned before that led to a substantial reduction in passive-yaw-control friction, in the avoidance of the transmission losses from the induction generator belt drive, and in greatly improved rotor aerodynamics that improved self-starting. The nacelle was made more compact by omitting the set of slip rings which had been used to transfer signals from the rotor to the rotor support. Instead, telemetry was used at Rocky Flats for signal transmission from rotor transducers. In the spring of 1983 the Washington University experimental turbine was changed to the Proof-of-Concept version; however, this was done without telemetry provisions to measure quantities in the rotating system. Instead, a previously established linear relation between the axial acceleration of the nacelle and the blade-flapbending stresses was used to obtain estimates of the blade flap-bending loads and stresses. Although teeter angles could not be measured directly, stop pounding was determined by a vibration sensor on the nacelle.

At Rocky Flats, the Proof-of-Concept turbine was tested for 25 hours at mean wind speed up to 22 $\mathrm{m} / \mathrm{s}(49 \mathrm{mph})$. The four main parameters, including lateral offset between rotor and yaw axis, 
uptilt angle of the rotor axis, spring rate of the yaw spring, and damper rate of the yaw damper, were not varied from their original values, although they were not optimal (as was indicated by later tests at Washington University). Above rated wind speed, the passive yaw control had a turbulence-excited furl oscillation with a period of about 6 seconds, an amplitude of $\pm 15^{\circ}$, and yaw rates of about $20^{\circ}$ per second, whereby the teeter amplitude (cyclic pitch amplitude) varied between near 0 and near maximum, and power output fluctuated between near 0 and $8 \mathrm{~kW}$. The mean power output at a given wind speed was substantially less than at Washington University, which could be explained in part by the difference in air density at the higher altitude of the Rocky Flats facility. There was also the possibility, however, that the generator cut-in and cut-out switch may not have operated properly.

Two structural failures occurred at Rocky Flats. Teeter-stop pounding caused by excessive furl rates probably contributed to both. First, an aluminum hub box beam reinforcement plate failed and had to be replaced. Second, the yaw damper clevis failed and led to a 30-minute period of large, undamped yaw-unyaw oscillations. A draft report by R.M. Osgood and M.P. Schroeder on the preliminary test results was circulated in August 1983. It contained a comparison with the Grumman 8-kW, three-bladed rigid downwind turbine. It was found that the PCP machine could operate at much higher yaw rates without introducing high blade loads, as long as furl-rateinduced teeter-stop pounding was avoided. No further testing was performed at Rocky Flats, and the draft report on the preliminary test results was never finalized.

Initially, the Proof-of-Concept version at Washington University was identical to the one tested at Rocky Flats. Soon a number of changes were made, however, including the addition of a teeter spring restraint, which avoided teeter-stop pounding in gusts at 0 and low rpm. The teeter springs also alleviated the negative rotor yaw damping and the negative rotor yaw stability, as explained in Reference 5 of Appendix 1. Also, a weak rotor parking brake was added. Teeter spring rate, yaw damper rate, and the preload on the unyaw spring were varied and their effects on the yaw dynamics were studied. The optimum combination of these parameters resulted in a maximum power-off rotor speed during yawing of $270 \mathrm{rpm}$ at a wind speed of about $9 \mathrm{~m} / \mathrm{s}(20 \mathrm{mph})$ and lower rotor speeds at higher wind velocities. Although the power-off rotor-speed control was good for protection in case of loss of load, power-on operation in turbulence, though improved by parameter optimization, was still unsatisfactory. Table 4-2 of Appendix 1 shows the effects of the teeter spring rate and the yaw damper rate on the yaw amplitude of the turbulence-excited yaw oscillations and on the maximum yaw rate, together with an estimate of whether or not the yaw control was oversensitive or undersensitive. The yaw-control configurations tested on May 7 , 1983, and May 28, 1984, were considered neither oversensitive nor undersensitive. Above rated wind speed both exhibited turbulence-excited yaw oscillations with $\pm 13^{\circ}$ amplitude. The configuration tested on October 4, 1985, with a much higher teeter spring rate resulted in lower turbulence-excited yaw oscillation amplitudes, but also had a quite sluggish yaw-control response.

The conclusions in Appendix 1 are as follows: first, a yaw-control dynamics analysis (including the effects of partial blade stall) was needed; second, the tested wind turbine configuration was not well suited to verify such an analysis because of the complex and unknown rotor-tail vane interaction; and third, the furl response to wind direction changes should be slowed. The following sections summarize the work performed at Washington University between 1986 and the present. 


\section{Mechanical Tail Boom Damping}

Because yaw angle and yaw rate of the upwind rotor with respect to the tail boom were strongly influenced by the turbulence response of the tail surface (see Figure 4-1 of Appendix 1), it was decided to analyze the coupled tail boom yaw and nacelle yaw dynamics, and to add mechanical damping of the tail boom yawing motions with respect to the tower. In 1986 a simplified linear dynamic analysis of the coupling problem was developed, and a mechanical damping of the tail boom with respect to the tower was added to the Washington University atmospheric test equipment. A commercially available and remotely controllable yaw brake was driven from the tower by chain and sprockets.

Appendix 2 describes the linear analysis and includes test results with and without mechanical yaw damping of the tail boom. Because of the simplifications of the linear analysis, a valid quantitative comparison between analysis and test results could not be expected. However, the analysis should correctly predict the trends of parameter variations. One limitation of the linear analysis was the assumption that the yaw damping moment and the tail boom mechanical yaw moment increased linearly with respect to their individual yaw rates. Actually, the yaw damping moment increased with the square of the yaw rate, whereas the yaw damping moment of the tail boom consisted of a constant friction moment independent of rate. The rotor aerodynamics were also linearized and excluded partial blade stall effects.

Before treating the nacelle and tail boom coupling, the yaw dynamics were analyzed for a fixed tail boom position. It was found that good yaw transients from a $15^{\circ}$ yaw error with little overshoot could be obtained with and without teeter spring restraint. Without such restraint, the yaw damping had to be increased. Next, the yaw dynamics of the tail boom were analyzed for a fixed yaw position. The teeter spring restraint had little effect in raising the low damping ratio of the tail boom. Finally, the coupled tail boom yaw and nacelle yaw motions were analyzed with and without the tail boom mechanical damping. The coupling with nacelle yawing lowered the tail boom damping even further, and it took a sizeable tail boom yaw damping to obtain satisfactory transients (see Figures 8 to 10 of Appendix 2).

The experimental studies were summarized in Table 5 and Figure 14 of Appendix 2. Except for the last two rows, this table is identical with Table 4-2 of Appendix 1. Without tail boom mechanical yaw damping, there was no combination of teeter spring rate and yaw damper rate that reduced the yaw amplitude in turbulence without also reducing the maximum yaw rate, which made the yaw control sluggish. Only with the tail boom mechanical damping was it possible to drastically reduce the turbulence-excited yaw oscillations and retain adequate yaw control sensitivity. The general conclusion of Appendix 2 was that power regulation by rotor yawing called not only for high yaw rates as they are achievable for teeter rotor types, but also for a close to critically damped yaw-control system.

Because of the problem with the large tail vane, and because of the fact that for larger wind turbines the tail vane size becomes impractical, it was decided to replace the tail vane with a mechanical yaw drive. 


\section{Free Yaw for Shutdown}

When incorporating a yaw gear drive in a fixed-pitch turbine, the problem of how to shut down the wind turbine in case of a yaw gear drive failure arises. The need for an emergency shutdown device in case of failure of a mechanical actuator was recognized in April 1984 when, because of an adjustment error, the yaw actuator was blocked and the rotor kept turning for 24 hours before a crane (with bucket) was available to manually remove the blockage (see Section 2.6.1 of Appendix 1).

In April 1987, the vertical tail and most of the tail boom were removed, leaving a short tail boom stub. The yaw mechanism was removed and the nacelle was locked to the tail boom stub in what was previously the unyawed position. The chain and sprockets were retained and an electric motor and worm gear drive were mounted on the tail boom stub to provide an active yaw control via the chain and sprockets. A remotely controlled clutch between the small sprocket and the worm gear needed electric power to remain engaged. It disengaged after power failure or other failure signals to allow free yaw of the nacelle. A small vertical tail surface was added to the tail boom stub and dimensioned in such a way that in free yaw, with stopped rotor, the nacelle would move from the upwind location toward the downwind location and balance at $90^{\circ}$ to the wind. A schematic plan view of the new configuration is shown in Figure 11 of Appendix 3. This configuration allowed free-yaw shutdown of the turbine when the yaw clutch was disengaged.

An analysis of the shutdown process in free yaw for upwind rotor design was performed. For the first few seconds, the analysis agreed quite well with the upwind shutdown tests begun in the spring of 1987. The analysis neglected partial stall effects, assumed a symmetrical airfoil, and neglected blade twist. Because the actual blades had an asymmetrical airfoil and a substantial twist, the assumptions of Appendix 3 were approximately valid only in the upwind quadrant but not in the downwind quadrant. Later atmospheric tests have proven that the rotor is incapable of autorotation for yaw angles of $90^{\circ}$ to $180^{\circ}$. If the asymmetrical blade airfoil and the blade twist were taken into account, Figure 3 of Appendix 3 would have shown for yaw angles beyond $90^{\circ}$ only negative values of $\mathrm{C}_{\mathrm{Q}} \sigma$ for all speed ratios.

Although the shut-down in free yaw for the upwind rotor worked well, the furl rate was rather high and caused a few teeter-stop contacts, as explained in Appendix 3. Therefore, a downwind rotor design was considered. An analysis of the downwind configuration completed in February 1991 indicated that: 1) there is a substantial difference between the autorotation transients from upwind and downwind, whereby the latter produce much lower teeter amplitudes (no teeter-stop pounding) but higher overspeed; 2) the transients for downwind location are not much affected by the delta-three angle; and 3) the higher overspeed of the transient from downwind location can be compensated by a larger horizontal offset between rotor axis and yaw axis. The decisive influence on yawing behavior was the change from negative yaw damping for the upwind configuration to positive yaw damping for the downwind configuration.

The result of the analysis led to the decision in the spring of 1991 to change the Washington University wind turbine to the downwind configuration. As will be discussed later, the usual 1-P turbulence excitation led to a substantially lower accelerometer response of the nacelle for the downwind configuration, so that the reversal in yaw damping affected not only the free-yaw transients but also the high-frequency yaw oscillations and associated loads. 
Freely yawing, rigid-propeller wind rotors with sufficient coning angle have at 0 yaw angle positive static yaw stability and positive yaw damping for both downwind and upwind locations (see Reference 2). The examples analyzed in Reference 2 have flapping frequency ratios, which is the ratio of flapping frequency to rotor speed, of between 3 and 4 . In contrast, this ratio is 1 for a teeter rotor without delta three. For a rigid rotor, the response to a 1-P excitation has only a small phase shift. For a teeter rotor this phase shift is $90^{\circ}$. The negative yaw damping for an upwind teeter rotor is related to this $90^{\circ}$ phase shift of the response to a 1-P excitation.

To further illustrate the differences between upwind and downwind operations, Figure 2 shows schematic top views of (a) an upwind and (b) a downwind configuration during a yaw rate, $\mathrm{d} \chi / \mathrm{dt}$. The tip path plane rotates by an angle opposite to $\mathrm{d} \chi / \mathrm{dt}$. The rotor thrust is approximately perpendicular to the tip path plane and has with respect to the yaw axis, indicated by a cross, a moment in the same sense as $\mathrm{d} \chi / \mathrm{dt}$ (negative yaw damping) for the upwind case (a), and a moment in the opposite direction from $\mathrm{d} \chi / \mathrm{dt}$ (positive yaw damping) for the downwind case.

As indicated in Figure 3, a wind direction change from $\mathrm{V}$ to $\mathrm{V}_{1}$ produces an H-Force. Wind following would mean a counterclockwise rotation of the nacelle. As can be seen from Figure 3 in the upwind case (a), the $\mathrm{H}$-force would rotate the nacelle in the clockwise direction, thus opposing wind following. For the downwind case (b), the $\mathrm{H}$-force would rotate the nacelle in the counterclock wise direction, thus supporting wind following. Teeter springs contribute to positive yaw damping and to positive wind following for both upwind and downwind configurations. The simple relations indicated in Figures 2 and 3 are only approximately correct for slow yaw rates and for slow wind direction changes. Nevertheless, one can conclude that a free-yawing teeter rotor would be unstable upwind and would need compensating devices to avoid instability, while a downwind teeter rotor would be stable.

It is interestung to compare this conclusion with Reference 3, which discusses the experience with the DOENASA 100-kW MOD-O two-bladed teetered wind turbine. This turbine had been operated with an active yaw drive both in the downwind and in the upwind configurations, but which had been tested in free yaw only for the downwind case. Downwind testing used mostly an electric motor and worm gear for the yaw control. Upwind operation used hydraulic yaw drive exclusively. In upwind operation, the blade flapwise cyclic stress was reduced as compared to downwind operation. The cyclic yawing moment upwind was much larger than downwind. Reference 3 reveals that the upwind teetered rotor was less well behaved than the downwind version. The experience with the Washington University wind turbine suggests that the hydraulic yaw drive of the MOD-O provided, for the upwind configuration, insufficient yaw damping to overcompensate for the negative aerodynamic yaw damping inherent in the upwind location of a teeter rotor.

The preceding discussion neglects the coupling between nacelle yawing and tower bending. If the nacelle center of gravity does not coincide with the tower center, instability could also occur for the downwind case. 
(a)
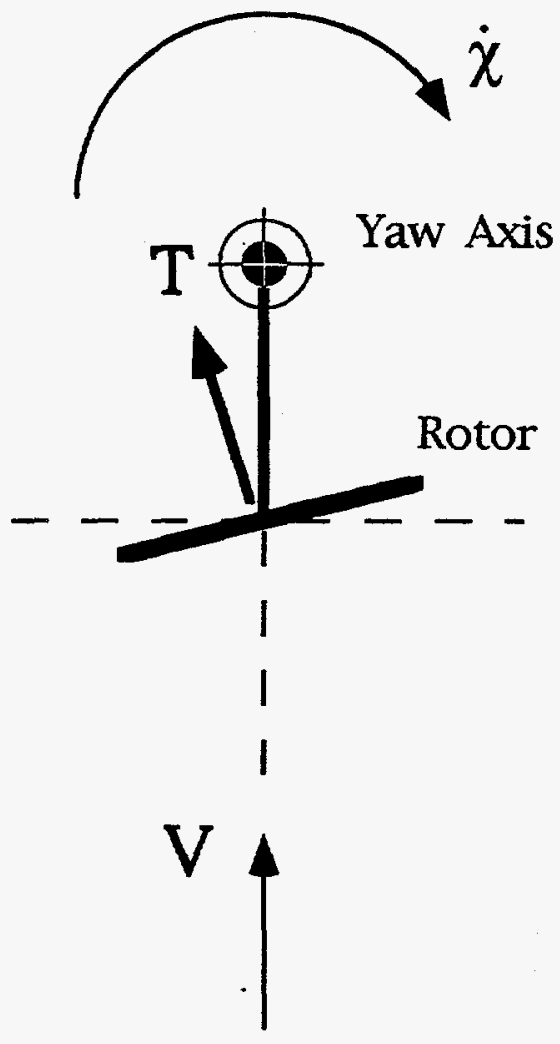

(b)

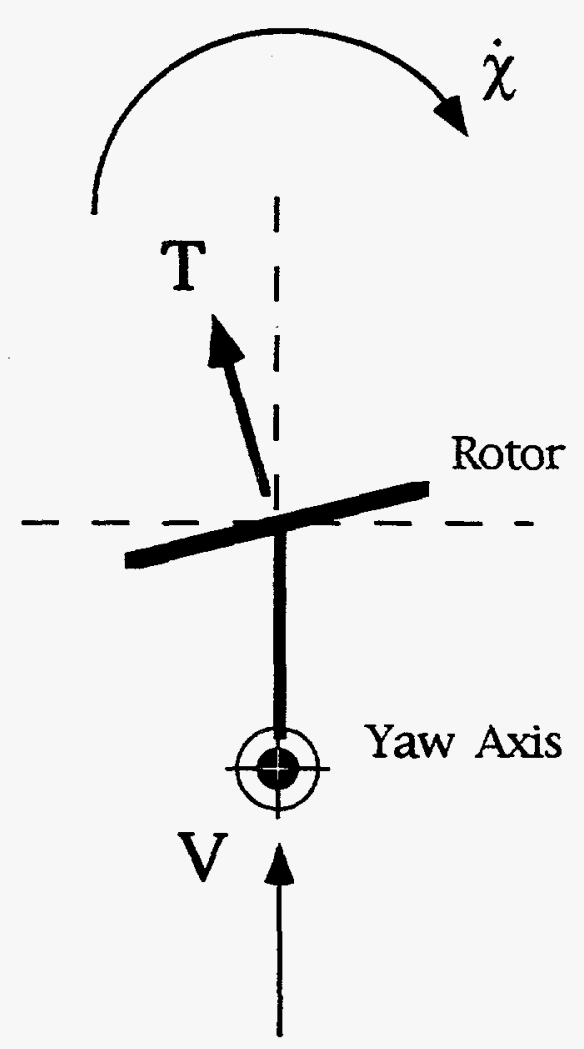

(a) Upwind, thrust moment has same direction as yaw rate $\dot{\chi}$

(b) Downwind, thrust moment has opposite direction from yaw rate $\dot{\chi}$

Figure 2a. Upwind, thrust moment has same direction as yaw rate $\dot{\chi}$

2b. Downwind, thrust moment has opposite direction from yaw rate $\dot{\chi}$ 
(a)

$$
\dot{\chi}=0
$$

Yaw axis

Rotor

$\mathrm{H}$
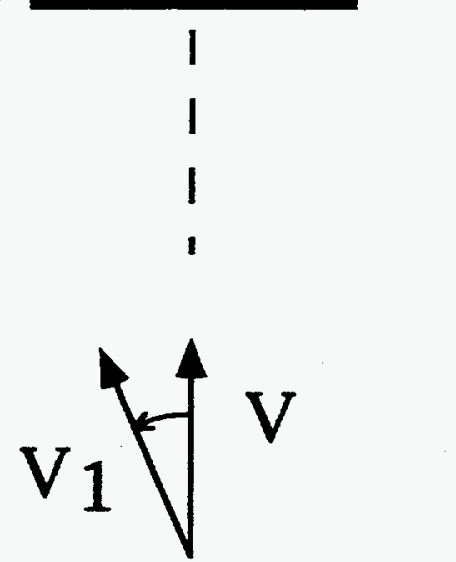

(b)

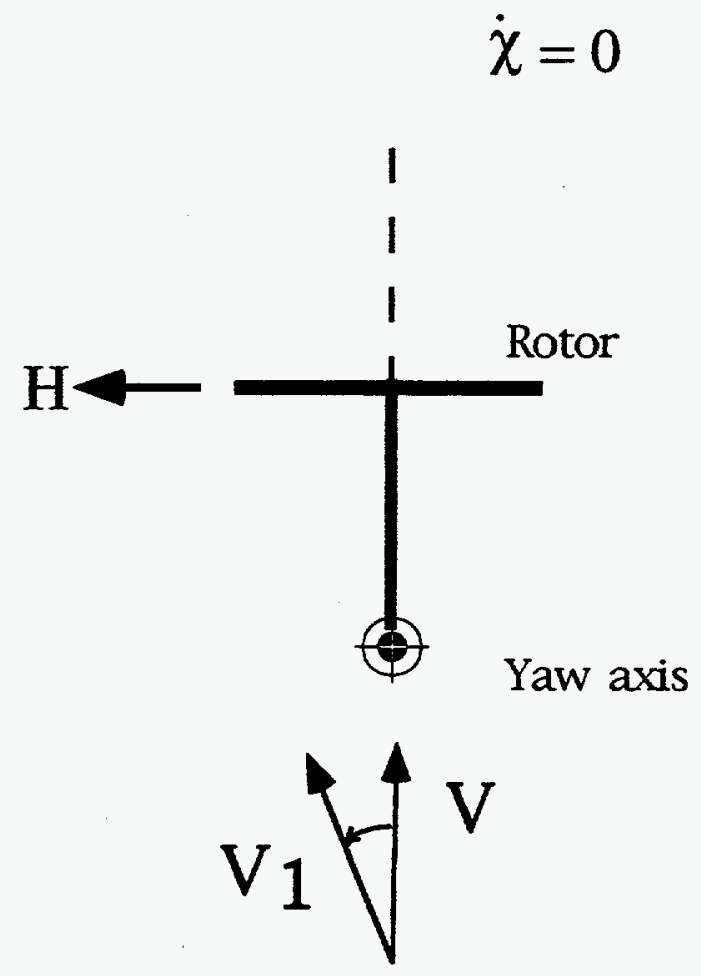

Figure 3a. Upwind, H-force moment opposes wind following 3b. Downwind, $\mathrm{H}$-force moment supports wind following 


\section{Power Regulation by Active Yaw Control}

Experiments with power regulation by active yaw control began in November 1988. Appendix 4 is an extended abstract of a report on the effects of control parameter variations. Analysis and tests gave a limit cycle of a 1.5-second period that was caused by a trigger lag of 0.2 seconds. This was the time it took to reverse the yaw rate after the trigger setting for the generator current was reached. Figure 1 of Appendix 4 is a schematic of the yaw-control circuit. The full report includes the effects of parameter variations in the analog circuitry, which led to satisfactory power regulation. Because this circuitry was tailored to the characteristics of the specific wind turbine at the specific site, it would not be of sufficient general interest to discuss the details here. The more modern approach taken at UTEP was to design a digital fuzzy-logic yaw-control system (see Reference 4). Appendix 4 concludes that the Washington University wind turbine with power regulation by active yaw control was well suited for the substantiation of dynamic yaw codes, if the delta-three angle of the teeter axis could be varied and if downwind rotor operation were used. 


\section{Comparative Tests for Upwind and Downwind Configurations}

The change from the upwind to the downwind configuration of the Washington University wind turbine was completed in October 1991. The induction generator gear unit was retained. The blade pair was rotated about the blade axis by $180^{\circ}$, requiring the generator to operate in the opposite direction as compared to the upwind configuration. During the first downwind test in October 1991, it was noticed that the single-phase generator had been improperly modified for operating in the direction opposite to that before the change. Several equipment and instrumentation failures occurred in 1991 and 1992, which prevented valid testing. A useful test in the downwind configuration was obtained in April 1993 at winds from the west of 10 to $12 \mathrm{~m} / \mathrm{s}$ ( 22 to $27 \mathrm{mph}$ ). The results could be compared to a test in the upwind configuration of May 6 , 1991 , with similar wind conditions and with the same trigger setting for the generator current of 27 amperes.

While the quality of the power control was about the same for these two tests, it was evident both from visually observing the nacelle and from the record that downwind operation was much smoother than upwind operation. The axial nacelle acceleration amplitude was only $\pm 0.04 \mathrm{~g}$ downwind as compared to $\pm 0.12 \mathrm{~g}$ upwind.

The 5.3:1 chain and sprocket transmission and the 60:1 worm gear transmission of the yaw gear drive allowed considerable play in the yaw angle, so that in the upwind case with negative yaw damping, a 1-P nacelle oscillation within this play could develop. The yaw-angle play was the same for the downwind case, but no such 1-P oscillations could be seen.

Most likely, the greatly reduced axial acceleration amplitude measured for the downwind case also implied a corresponding reduction in the blade-flap bending stresses. Originally, these stresses were measured in the upwind case, and a linear relation between blade-flap bending amplitudes and nacelle axial acceleration amplitudes had been found. As mentioned before, after omitting the slip ring unit to obtain a more compact nacelle design, the previously established relation was used to estimate blade-flap bending. Whether or not the same relation was also valid for the downwind configuration is not known.

The comparison between upwind and downwind operation was made with an average yaw angle of more than $30^{\circ}$. For such a yaw angle, the tower wake does not impinge on the blade pair when it is in the vertical position. It is not known how the comparison in axial nacelle acceleration amplitudes would turn out for a zero or small yaw angle. For the downwind case, the visual comparison indicated the absence of 1-P nacelle oscillations for small yaw angles, whereas in the upwind case 1-P nacelle oscillations were prevalent for similar small yaw angles. It is hoped that the UTEP tests with telemetry for the blade-flap bending stresses will make it possible to establish a more reliable comparison between upwind and downwind operation. 


\section{Storm Survival after Free-yaw Shutdown}

For a yaw-controlled, fixed-pitch teeter wind turbine, a practical storm-survival mode without shutdown is an approximately $90^{\circ}$ yaw angle with small blade loads and teeter angles (in spite of power extraction). In extreme conditions, and in case of yaw-control failure, an emergency shutdown is called for. The question then arises as to whether the free-yaw shutdown mode can provide storm survival without a mechanical yaw brake or rotor brake. Observations of the Washington University wind turbine in the free-yaw shutdown mode showed that this mode may be capable of providing storm survival, though probably with higher blade loads than would be encountered for yaw-controlled operation at an approximately $90^{\circ}$ yaw angle.

For the upwind design, the small vertical tail surface on the stub boom has a stabilizing effect at 0 yaw angle, but a destabilizing effect at a $180^{\circ}$ yaw angle (see Figure 4 ). The tail vane cannot be used to obtain a $180^{\circ}$ yaw angle shutdown position. Instead, the tail vane was designed to obtain an approximately $90^{\circ}$ yaw angle where the rotor kept turning below operational rotor speed.

For the downwind design, however, the small vertical tail surface on the stub boom has a destabilizing effect at 0 yaw angle which is quite small compared to the stabilizing rotor effect. It has a stabilizing effect at a $180^{\circ}$ yaw angle (see Figure 5). For this design, the small vertical tail surface on the stub boom could be designed to move the nacelle in the free-yaw shutdown mode to a $180^{\circ}$ yaw angle. In this situation, the rotor (due to the wrong blade twist) will develop a strong aerodynamic braking torque and stop rapidly. This is another advantage of the downwind design over the upwind design. 


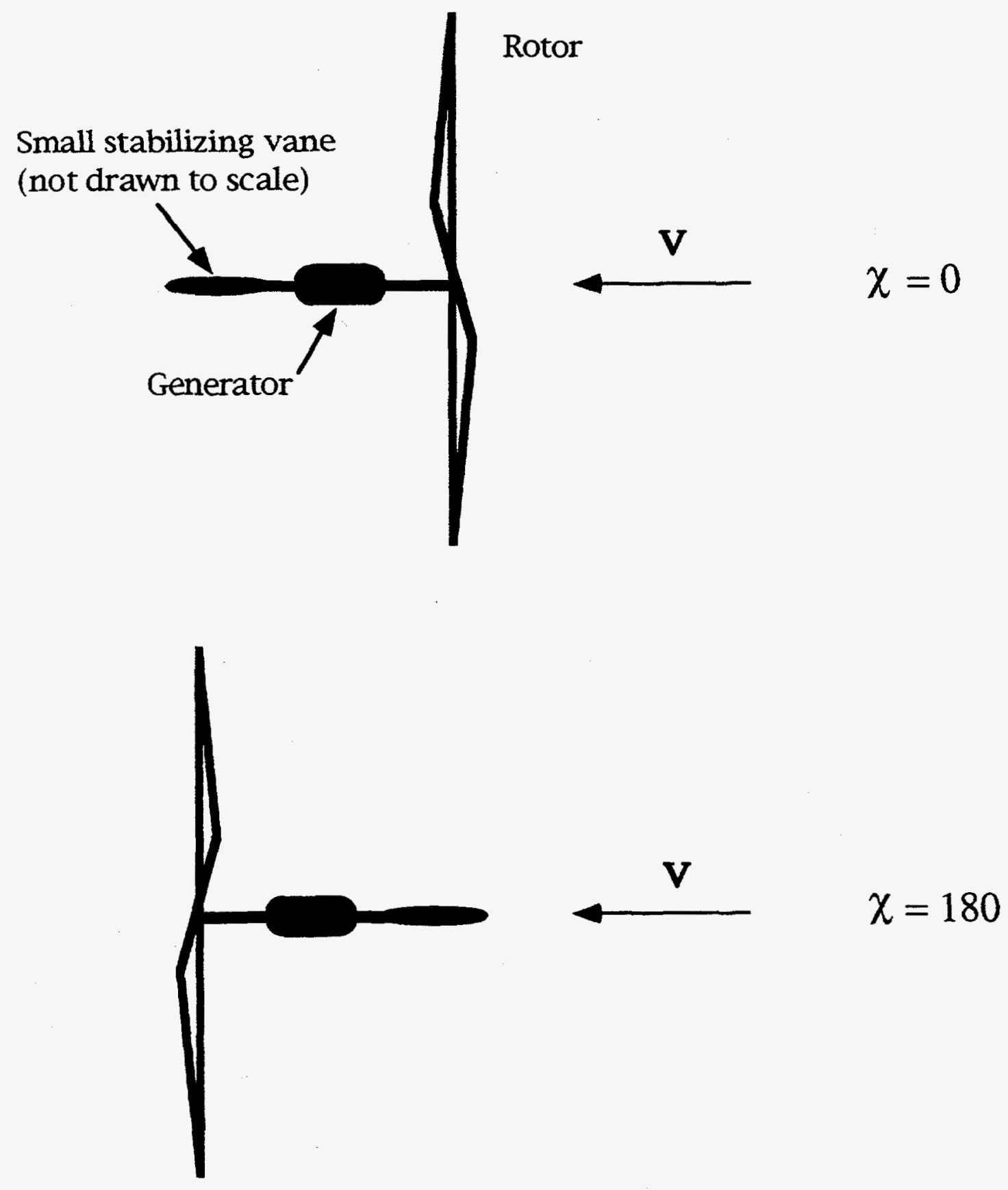

Figure 4. Upwind design at $0^{\circ}$ and $180^{\circ}$ yaw angle 

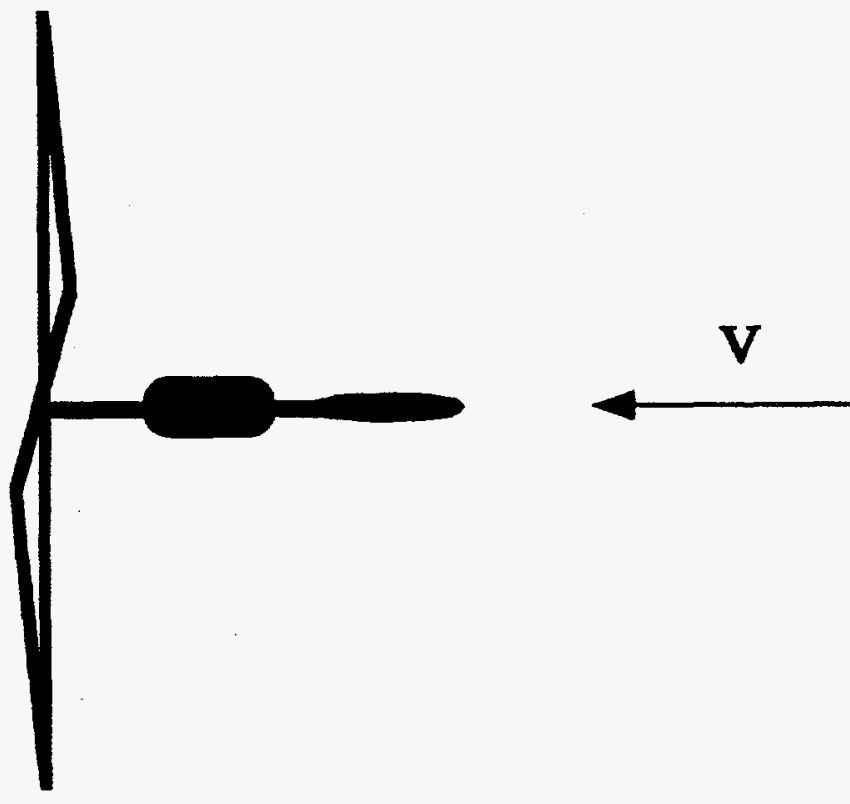

$$
\chi=0
$$
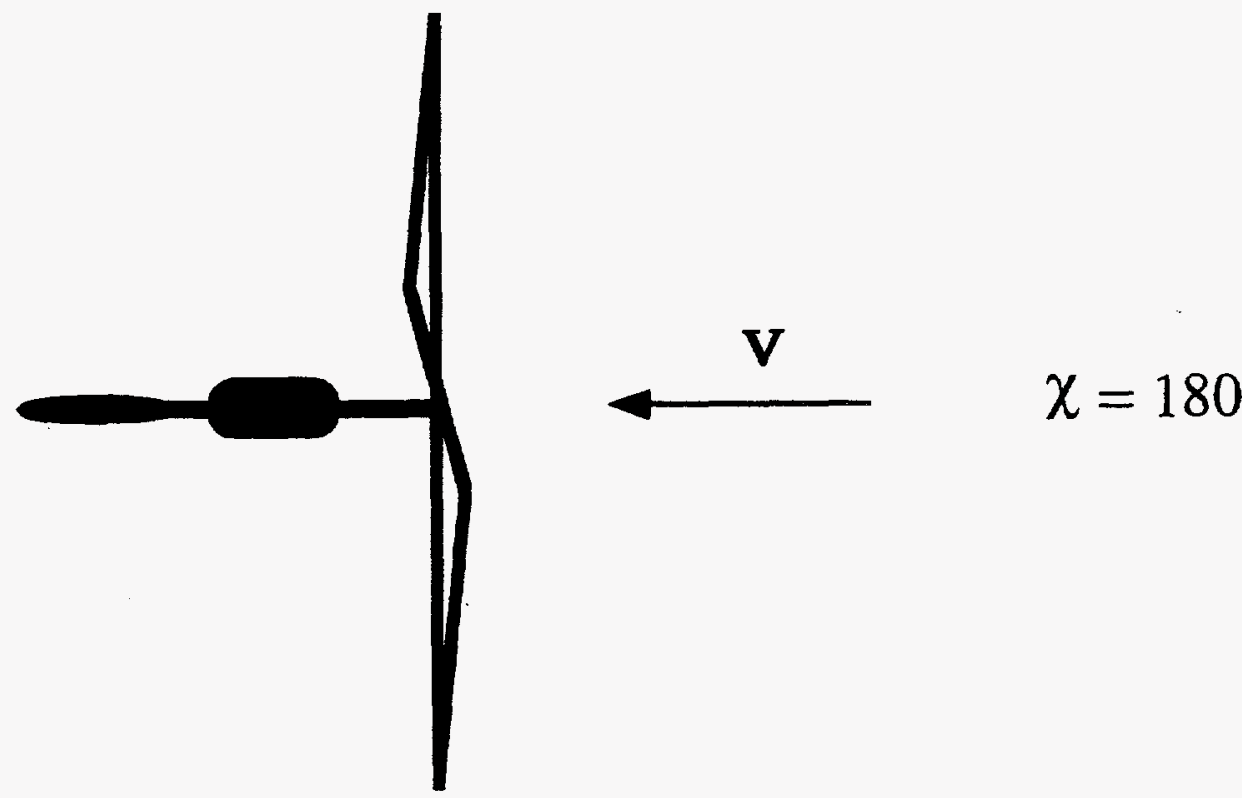

Figure 5. Downwind design at $0^{\circ}$ and $180^{\circ}$ yaw angle 
In both the downwind design and in free-yaw shutdown mode, the Washington University wind turbine was continuously exposed to storms between April 1993 and April 1994. With practically 0 rotor brake moment, the turbine never moved backwards and only occasionally a few degrees forward when a sudden large change in wind direction occurred which could not be compensated for quickly enough by the freely yawing nacelle. Though a record for the wind speeds at the site during the year of exposure was not reached, $27 \mathrm{~m} / \mathrm{s}(60 \mathrm{mph})$ must have been reached or exceeded several times; therefore, the storm-survival characteristics of the free-yaw shutdown mode were demonstrated within this estimated wind speed range.

In normal operation, the teeter springs produce a P-value of about 1.02. The Washington University wind turbine had, at zero rotor speed, a teeter frequency over operational frequency of 0.2 , which yields a P-value of 1.02 . Observations of the free-yaw shutdown mode in very gusty winds indicated that occasional small teeter motions occurred. However, these were far from the angle of teeter-stop bumping. To ensure the absence of teeter-stop contacts at even higher wind speeds, the teeter springs should probably be somewhat stiffer, with a P-value of perhaps 1.03 . The Washington University wind turbine had rigid teeter stops at $6^{\circ}$ out-of-plane motion, which corresponds to an angular motion about the teeter hinge of $15^{\circ}$ (according to Table 1). The combination of a large delta-three angle with elastic teeter restraints gave the Washington University rotor a large margin against teeter-stop bumping at low or 0 rotor speed, and at high yaw rates with operational rotor speed. Both of these critical conditions were omitted by Olsen and Coleman in Reference 5, which may give the mistaken impression that teeter spring restraints are not very useful. In their absence, strong hydraulic teeter dampers or centrifugal regulated teeter stops must be used to avoid stop bumping at high V/ $\Omega$ R ratios (e.g., during start-up). Both of these alternatives are prone to maintenance problems. 


\section{Recommendations and Conclusions}

Since this study began in 1980 , one commercial manufacture of large wind turbines has implemented some of the concepts described in this report. The Italian prototype $2.0-\mathrm{MW}, 60-\mathrm{m}$ (183-ft) diameter Gamma 60, designed by Glid Doman, is now operating in Italy. This turbine uses variable speed and yaw control of a fixed-pitch, two-bladed teetered rotor in an upwind configuration. The design of this larger machine is derived from the Washington University and UTEP models. Details are discussed in Reference 6, in which Doman also points out that a teetered hub is almost a necessity if one wishes to reduce the number of rotor blades from three or more to two.

The distinguishing feature of these three turbines is that they use yawing of the rotor out of the wind, or furling, to control power and loads. Rigid rotors do not operate smoothly in yawed flow, and great effort is expended by the turbine designer to avoid yawed flow operation. Experience has shown, however, that the two-bladed teetered rotor operates smoothly in sizes ranging from

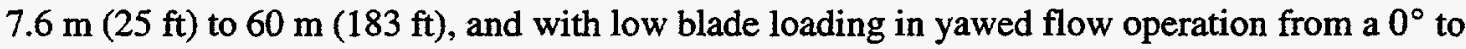
$90^{\circ}$ yaw angle, as long as stall is avoided and yaw rates are limited to reasonable values so that teeter-stop pounding is avoided.

For large wind turbines, surviving a storm can be a problem. In December 1993, three Wind Energy Group MS 3 two-bladed, teetered-rotor, variable-pitch wind turbines were shut down in storm force winds and subsequently lost their rotors, according to the newsletter Windirections (Vol. XIII, No. 3). However, as mentioned in the previous section, yaw-controlled turbine operation at an approximately $90^{\circ}$ yaw angle, when the rotor plane is almost edgewise to the wind direction, is the most benign method of storm survival. Because the gyroscopic loads from yaw rates of a teetered rotor are compensated by aerodynamic loads from teetering, high yaw rates for controlling the yaw angle in gusts are feasible and very effective at an approximately $90^{\circ}$ yaw angle, as long as teeter-stop contacts are avoided.

Both the Washington University and UTEP test turbines incorporate emergency shutdown using free yaw, as described in the section on Free Yaw for Shutdown and in Appendix 3. This important feature was not used on the Gamma 60 turbine. Because of the lateral offset between rotor axis and yaw axis, the rotor thrust provides a yawing moment. And as a result of the uptilt of the rotor axis, the rotor torque has a yaw-moment component in the opposite direction from that of the rotor thrust, which reduces loads on the yaw-drive system during power-on operation. The yaw-control system incorporates a clutch that is released when the generator is disconnected from the grid. The rotor then freely yaws at a limited rate under the influence of the rotor thrust to the quadrant between $90^{\circ}$ and $180^{\circ}$ yaw angle. If the blades have sufficient twist, the rotor will stop rapidly without mechanical breaking, by aerodynamic braking alone. Both at Washington University and at UTEP, the nacelle is aerodynamically balanced in such a way that, with stopped rotor, the nacelle remains in the yaw quadrant between $90^{\circ}$ and $180^{\circ}$ yaw angle, in which selfstarting of the rotor is not possible, even without a mechanical rotor brake.

As for a preference for either the upwind or downwind design, the experience at Washington University would tend to favor the latter. Both Washington University and UTEP use the downwind design. While an upwind design such as the Gamma 60 turbine requires an active yaw 
control for the entire wind speed range, a downwind turbine can operate in free yaw most of the time.

The constant-speed induction generator used at Washington University and at UTEP requires $0^{\circ}$ lateral offset between rotor and yaw axes, and 0 rotor axis uptilt angle for free yaw during poweron operation. The ESI-80 wind turbine uses this configuration. For any other combination of offset and uptilt, free yaw at $0^{\circ}$ yaw angle is only possible at one wind speed. With the $0.038-\mathrm{m}$ (1.5-in.) offset and the $8^{\circ}$ uptilt, free yaw was attempted at Washington University at a wind speed of about $8 \mathrm{~m} / \mathrm{s}(18 \mathrm{mph})$. The nacelle yawed to an angle where the power was negative and the generator was disconnected. At UTEP, the free-yaw attempt was successful at a wind speed of about $11 \mathrm{~m} / \mathrm{s}(25 \mathrm{mph})$, using $0.023-\mathrm{m}\left(0.9-\right.$ in.) offset and $9^{\circ}$ uptilt. The turbine ran smoother in free yaw and with smaller corrective yaw rates as compared to runs with the yaw-control system engaged.

This experience indicates that power-on free-yaw operation should be feasible with lateral offset and uptilt, if the rotor uses variable speed with torque proportional to the square of the rotor speed so that in steady state the rotor operates at a constant wind speed ratio. Such a rotor torque-speed relation was achieved in 1980 at Washington University by using a specially tuned alternator to provide this torque-speed characteristic. The same torque-speed relation is used up to rated wind speed for the Gamma 60 turbine, as described in Reference 6. Such variable rotor speed has the advantage of increased wind-capture efficiency at lower wind speeds, and of alleviating load fluctuations in turbulence by using the rotor inertia as short-term energy storage at higher wind speeds.

From the experience at Washington University and at UTEP, it would seem that a production wind turbine of larger size would use a teeter rotor with fixed-pitch blades that have appreciable blade twist, with lateral rotor axis offset, rotor uptilt, and a declutchable yaw drive to allow free-yaw wind following below rated power and free-yaw emergency shutdown. It would use a generator with its torque approximately proportional to the square of the RPM. For such a design, the yaw drive would only briefly be used for start-up by motoring to minimum RPM at an approximately $90^{\circ}$ yaw angle, after which free yaw would be established. Beyond rated wind speed, the yaw drive would again be engaged and operated by a rotor speed control to keep RPM and torque constant. Such a yaw angle controller, using a propeller speed governor, was successfully demonstrated in 1980 at Washington University with an alternator, which was tuned to obtain the desired torque-RPM relation (see the SERI report by Hohenemser and Swift in Reference 2 of Appendix 1). This type of yaw control, designed to keep RPM and torque approximately constant beyond rated wind speed, was apparently also successful for the Gamma 60 wind turbine, as discussed by Doman in Reference 6. This yaw control allows constant RPM and constant torque operation far beyond the rated wind speed for 0 yaw angle.

The variable-rotor RPM design requires careful attention to structural dynamics, more so than a fixed RPM design. The tower should have its first natural bending frequency below the minimum operating rotor rotational frequency. As mentioned by Doman in Reference 6, a downwind design could exhibit an aeroelastic tower bending-torsion instability if the nacelle center of gravity is too far off the yaw axis. The tower bending mode could then be excited by a component of the rotor thrust. Such tower instability was encountered with the UTEP tower which, due to the softness associated with a hydraulic tilting mechanism, had a 1 -per-second bending frequency versus the 2- 
per-second bending frequency of the otherwise similar but stable Washington University tower. The UTEP tower instability was eliminated by increasing the tower torsional stiffness. For free yaw, the instability could not occur, because tower bending and torsion are then uncoupled.

Another question that is related to structural dynamics is the effect of the large delta-three angle of the PCP rotor. It was originally selected in 1980 to avoid large teeter out-of-plane flap angles with their high in-plane dynamic loads. However, a high delta-three angle reduces yaw damping. UTEP researchers will conduct experiments on the question of the dynamic effects of delta three by comparing the dynamics of the present rotor with the dynamics of a similar rotor that has 0 delta three of the teeter axis.

Because several teeter rotors have been destroyed by teeter-stop pounding, the avoidance of this condition is important. The original Washington University rotor experienced teeter-stop pounding at low RPM, at high yaw rates, and in blade stall conditions. Later, the addition of teeter spring restraints and the limitation of yaw rates to about $20^{\circ}$ per-second avoided teeter-stop pounding. The teeter springs were particularly effective at low RPM during starting and stopping when the rotor behaved as if it were almost rigid. At higher RPM the teeter springs increased the yaw damping, which would be particularly important in free yaw. If conditions with severe blade stall are avoided, which is easily accomplished by yawing the rotor into the $0^{\circ}$ to $90^{\circ}$ yaw angle quadrant, mechanical teeter dampers are not needed to avoid teeter-stop pounding.

When upscaling a wind rotor with the same blade tip speed, the RPM is inversely proportional to the diameter ratio. The same is true of the admissible yaw rate. Based on the $20^{\circ}$-per-second yaw

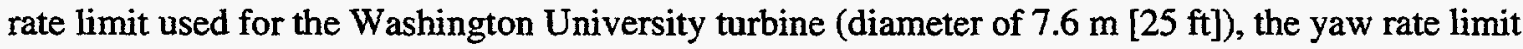
for the $60-\mathrm{m}(183-\mathrm{ft})$ Gamma 60 turbine should be $(20 \times 7.6 / 60)$, or $2.5^{\circ}$ per second. A smaller delta-three angle and different teeter stops may increase or decrease this limit.

When upscaling, the ratio of air density to structural material density would remain the same, the system weight would grow with the cube of the diameter ratio, torque and thrust would grow with the square of this ratio, and static stresses from flapwise loads and from centrifugal loads would remain the same. In-plane blade stresses from gravity ( 2 per revolution) would increase with the diameter ratio. Turbulence-induced stresses would be quite different because of the different ratio of turbulence length to diameter. Except for turbulence and gravity effects, structural dynamics, including aeroelastic instability and teeter-stop pounding margins, would be the same, because natural frequencies over the rotor frequency of rotation would remain unchanged. Thus, many aspects of the experience with the small-scale test rotors at Washington University and UTEP would be applicable to larger wind turbines of the same type.

It should be stated again that all tested and considered wind turbine configurations in this report had a rotor without full or partial span blade pitch variation, without aerodynamic blade tip brakes, without ailerons, without teeter dampers, and without a large mechanical rotor brake, all devices which increase complexity and maintenance of the wind turbine.

The following eleven general statements on teetered wind turbines summarize the experience at Washington University, together with the experiences of others:

1. A teeter rotor behaves quite differently from a rigid rotor and needs entirely different design and operational principles. 
2. Unlike rigid rotors, a teetered rotor can be yawed rapidly without gyroscopic moment resistance, because gyroscopic loads from yawing are compensated by aerodynamic loads from teetering. However, the yaw rate must be limited reliably to avoid teeter-stop pounding. (A tail vane stabilized upwind teeter rotor tested at Washington University between 1980 and 1986 proved to be a bad configuration, because the yaw rate depended on the turbulence response of the tail vane and could not be reliably controlled.)

3. In contrast to rigid rotors, teeter rotors can be smoothly operated in the entire yaw angle quadrant between $0^{\circ}$ and $90^{\circ}$. Power can be regulated within this yaw range from maximum to 0 power at $90^{\circ}$ yaw angle. Simultaneously, the thrust and teeter response also tend toward zero at $90^{\circ}$. Although blade pitch control for rigid rotors is more benign than active yaw control, for teeter rotors active yaw control is a natural-if the limitations on yaw rates are reliably ensured.

4. In free yaw a teetered rotor has negative yaw damping and is unstable when upwind of the tower. It has positive yaw damping and is stable when downwind. Free yaw up to rated wind speed is possible for a downwind design, if yaw rates can be limited and severe blade stall can be avoided, or adequate teeter damping is used.

5. Ignoring turbulence scaling effects, the teeter response to a non-dimensional yaw rate input, defined as the ratio of yaw rate to rotor speed, is independent of rotor size for rotors of equivalent Lock Number.

6. Teeter response, $\tau$, about the teeter pin is nearly independent of the $\delta_{3}$ angle used. This means that for a given input excitation, a rotor with high $\delta_{3}$ angle will have a reduced flapping response equal to $\tau \cos \delta_{3}$. Except for turbulence scaling effects, this charactenstic is independent of rotor size. The reduced flapping response will improve rotor operational characteristics in three ways: 1) tower clearance will be increased; 2) the rotor will run more smoothly; and 3) teeter-stop impact loads, if they occur, will be reduced. (The reduction in teeter-stop impact loads is the result of a reduction in kinetic energy associated with rotor pitching for the high $\delta_{3}$ rotor, as compared to pure rotor flapping for the zero $\delta_{3}$ rotor.)

7. A teeter rotor should not be subjected to severe blade stall without adequate damping. At least two turbine designs do operate teeter rotors in stall-the ESI-80 (now the AWT-26), and the Carter design. The AWT-26 uses mechanical dampers, whereas the Carter design uses elastomerics and soft, highly coned blades. The combination of severe blade stall and high yaw rates may be particularly damaging. Gyroscopic moments due to yaw rates produce a large teeter response that remains stable only as long as the rotor airfoils provide aerodynamic damping. If there is little or no damping, large teeter impacts result.

8. A teetered rotor is less sensitive to dynamic loading in downwind operation than a rigid rotor. Also, there may be an additional benefit if the rotor is yawed in such a way that the blade pair is out of the tower wake when the blades are vertical, as would be the case above rated wind speed for a yaw-controlled turbine. 
9. Use of an elastic teeter hinge restraint obviates the need for a teeter lockout device to prevent teeter-stop pounding at low RPM during starting and stopping. Teeter springs also increase yaw damping for upwind and downwind designs. A teeter spring P-value of 1.02 or 1.03 is reasonable to obtain this effect for small rotors. The spring stiffness scales with $\mathrm{R}^{3}$ for larger rotors, although the $\mathrm{P}$-value may have to be changed somewhat to compensate for turbulence scaling.

10. Blade coning is often used to enhance downwind wind-following characteristics and for centrifugal relief in some teetered rotors. The combination of teeter response with large blade-coning angles was not investigated, yet may be important. Further study must be done in this area.

11. Variable rotor speed operation for teetered rotors using yaw control may offer several new design opportunities. If rotor torque is selected proportional to the square of the RPM, a combination of rotor-shaft lateral offset and uptilt could be chosen that could allow downwind, free yaw, power on operation, below rated wind speed, and passive free-yaw shutdown at an approximately $90^{\circ}$ yaw angle for overspeed and loss-of-load protection. Above rated wind speed, rotor RPM could be easily controlled within rather narrow limits by a small active yaw drive that yaws the turbine out of the wind at higher wind speeds. At an upper RPM limit, the yaw control could be disconnected for an emergency free-yaw shutdown without the application of a rotor brake, as was described previously. This concept offers a simplified fixed pitch, free yaw, teetered-rotor design that avoids the complexities of large mechanical brakes or aerodynamic control surfaces for loss of load and overspeed control of the wind turbine. 


\section{References}

1. Swift, A.; Hock, S.; Thresher, R. Advanced Wind Turbine Performance and Cost Projections ... A Configuration Survey. AWEA Conference; Seattle, Washington, October 1992.

2. Stoddard, F.S. Analytical Method for Calculating the Yaw Moment and Evaluating the Yaw Stability of Horizontal Axis Wind Turbine. Seventh ASME Wind Energy Symposium, New Orleans, Louisiana, January 1988.

3. Glasgrow, J.C.; Miller, D.R.; Corrigan, R.D. Comparison of Upwind and Downwind Rotor Operations of the DOE/NASA 100-KW MOD-O Wind Turbine. DOE CONF-810226, Wind Turbine Dynamics Workshop; Cleveland, Ohio, February 1981.

4. Swift, A.H.P.; Craver Jr., W.L.; Wu, C.K.; Herrera, J.M. "A Versatile Teetered Rotor Test Bed." Proceedings of Windpower'93, 12-16 July 1993, San Francisco, California. Washington, DC: American Wind Energy Association.

5. Olsen. T.L.; Coleman, C.C.J. "Parametric Study of Wind Turbine Loads Using Yawdyn." Proceedings of Windpower'94, 9-13 May 1994, Minneapolis, MN. Washington, DC: American Wind Energy Association.

6. Spera. D.. ed. Wind Turbine Technology. Chap. 10, New York: ASME Press. 


\section{APPENDIX 1}

SERI/STR-217-3002

January 1987

Analysis and Test Results for an Improved Constant Speed Passive Cyclic Pitch Wind Turbine

Final Subcontract Report K.H. Hohenemser 


\section{Analysis and Test Results for an Improved Constant Speed Passive Cyclic Pitch Wind Turbine}

\section{Final Subcontract Report}

K. H. Hohenemser

Department of Mechanical Engineering Washington University

St. Louis, Missouri

January 1987

SERI Technical Monitor: C. Shepherd

Prepared under Subcontract No. XE-2-02054-01

Solar Energy Research Institute

A Division of Midwest Research insiltute

1617 Cole Boulevard

Golden, Colorado 80401-3393

Prepared for the

U.S. Department of Energy

Contract No. DE-AC02-83CH10093 


\section{NOTICE}

This report was prepared as an account of work sponsored by the United States Government. Neither the United States nor the United States Department of Energy, nor any of their employees, nor any of their contractors, subcontractors, or their employees, makes any warranty, expressed or implied. or assumes any lega! liability or responsibility for the accuracy. completeness or usefulness of any information. apparatus. product or process disciosed. or represents that its use would not infringe privately owned rights.

\section{Printed in the United States of America Available from: \\ National Technical Information Service \\ U.S. Department of Commerce \\ 5285 Port Royal Road Springfield. VA 22161}

\section{Price: Microfiche A01 \\ Printed Copy A04}

Codes are used for pricing all publications. The code is determined by the number of pages in the publication information pertaining to the pricing codes can be found in the current issue of the following publications. which are generally avaitable in most libraries: Energy Research AUstracts. (ERA): Government Reports Announcements and Index (GRA and I): Scienilfic and Technical Abstrac: Reports (S TAR): and publication. NTIS-PR-360 available from NTIS at the above adoress 


\section{PREFACE}

This report was prepared by Dr. K.H. Hohenemser of the Department of Mechanical Engineering, Washington University. The work described here was performed under subcontract XE-2-02054-01 for the Solar Energy Research Institute (SERI) and was sponsored by the Department of Energy. The subcontract began on March 15, 1982, and with subsequent amendments ended December 31, 1985. During this period, 11 Progress Reports were submitted to SERI.

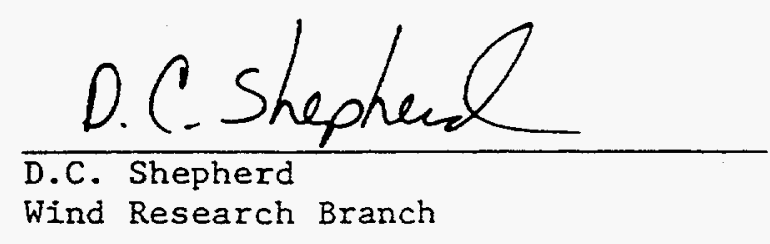

Approved for

SOLAR ENERGY RESEARCH INSTITUTE

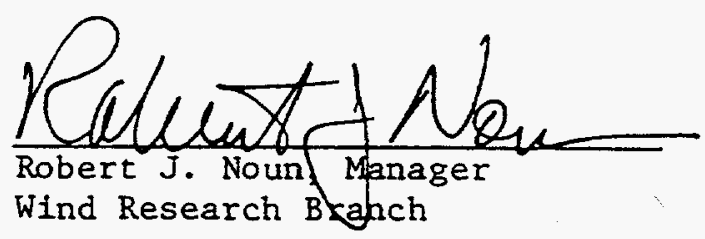




\section{SUMMARY}

The research was to contribute to answering the question whether conventional blade pitch control of wind turbines with its high initial and maintenance cost can be replaced by rotor yaw control. The necessary high yaw rates are only possible with hinged or teetered rotors whereby the passive cyclic pitch (PCP) teetered rotor was found to be particularly suitable. In a PCP rotor the teeter axis forms a small angle with the blade axis. The research with an improved constant speed PCP wind turbine driving an induction generator made use of the test equipment at Washington University's Tyson Research Center avaliable from a preceding study documented in the Final Report to SERI of December, 1981 (SERI/TR-1052-10). The atmospheric test equipment consisted of a horizontal wind turbine with vane controlled upwind two-bladed PCP rotor of 25 ft $(7.6 \mathrm{~m})$ diameter. The machine was mounted on a $60 \mathrm{ft}(18 \mathrm{~m})$ high Unarco Rhon SSV steel tower which was made tiltable for better access to the nacelle. The automatic rotor yaw control system was of a purely mechanical passive type. The rotor thrust which was laterally off-set from the yaw axis, in combination with a yawing component of the rotor torque due to uptilt of the rotor axis overcame at rated power the unfurling spring and furled the rotor with respect to the tall vane boom. The boom was attached to the nacelle by a pin located downwind of the yaw axis. Furling involved both nacelle rotation about the yaw axis and boom rotation about the pin. Due to the boom gravity moment, the boom pin Rulon bearings caused a large friction moment which resulted in imprecise delayed furling and unfurling.

In December, 1981 the boom pin was eliminated. The boom was instead supported by the yaw post and was moving together with the post. The nacelle, previously bolted to the yaw post, was now 90 degree rotatable about the yaw post with the help of two ball bearings. Thus tall vane boom yawing and nacelle furling were independent of each other and both functions involved litele friction. This design principle was retained throughout the report period and it corrected previously observed imprecise delayed furling and unfurling.

A number of further modifications were found to be desirable. The blade airfoil was extended toward the rotor center with high twist which greatly improved start-up. Another improvement in the same direction was achieved when the shaft mounted gearbox with belt driven generator was replaced by an integral gear-generator unit used in the "Proof-of-Concept" version of the PCP turbine which reduced the break-out torque to one fifth of the previous value. Some erratic yawing at low wind speed power-on operation was corrected by an increased tail vane area and a lengthened tail boom which also corrected two dynamic conditions. The mechanical damper characteristics were found to be decisive for a proper functioning of the furl control. Many damper configurations were tested. As predicted by the analysis, an elastic restraint of the teeter motion reduced the negative rotor yaw damping and allowed a lower mechanical damper force.

As predicted by the trim analysis, a proper unfurl spring setting produced a power-off rotor speed that peaked at 1.3 times power-on rotor speed at $20 \mathrm{mph}$ $(9 \mathrm{~m} / \mathrm{s})$ wind velocity. The autorotational rotor speed was lower at all other wind velocities. The PCP turbine was tested up to $60 \mathrm{mph}(27 \mathrm{~m} / \mathrm{s})$ gusts. Power-off rotor speed was kept within narrow limits even in severe turbulence. From the test results one can expect smooth low load storm survival. Low wind speed generator cut-in and high wind speed generator cutout were achleved by a digital controller in response to rocor speed without using wind speed information. Operation in deep stall was tested by 
increasing the drive train transmission ratio. It was found that torque peaked at twice the value predicted by the conventional prop code.

Power-on operation in severe turbulence, though much improved by parameter optimization, was still less than desirable because of furl and power fluctuations with the natural tail vane period of several seconds. This period should be lengthened by aerodynamic or mechanical means. Alternatively, a slower reacting wind following system (for example a yaw control side rotor) should be used instead of the tail vane. The parametric testing was done on a trial and error basis and was hampered by the lack of an analytical yaw control dynamics model. Such a model should be developed and verified by tests with the PCP turbine after slowing down the windfollowing system. Once a verified model was available, a generic study of torque and speed control by yawing of teeter rotors should be performed covering a spectrum of rotor parameters and control systems including active controls. The conclusion was that the PCP rotor continued to function very well up to high yaw rates and high wind velocities, but that the combination of the passive furl control system with a fast reacting wind-following tail vane caused some problems that could not be corrected as yet. 
1. Introduction $\ldots \ldots \ldots \ldots \ldots \ldots \ldots \ldots \ldots \ldots \ldots \ldots \ldots \ldots \ldots$

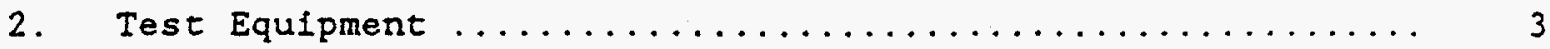

2.1 Experimental Turbine .................... 3

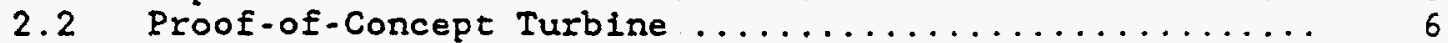

2.3 Furl Control system ...................... 8

2.4 Changes to the Experimental Turbine ............. 8

2.4.1 Instrumentation Changes .............. 11

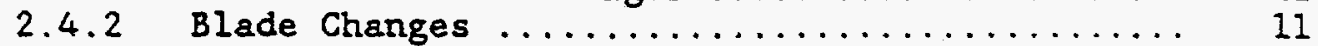

2.4.3 Tail Vane and Tall Boom Changes ........... 11

2.4.4 Transmission Ratio Increase ............. 13

2.5 Changes to the Proof-of-Concept Turbine ........... 13

2.5.1 Aluminum Disk on Shaft .............. 13

2.5 .2 Tension Teeter Springs ........................ 13

2.5.3 Emergency Shut-Down System ................ 13

2.5 .4 Vibration Shut-Down Switch .............. 14

2.5.5 Compression Teeter Springs .............. 14

$2.5 .6 \quad$ Rotor Brake ......................... 14

2.6 Changes to the Furl Control System $\ldots \ldots \ldots \ldots \ldots \ldots \ldots$

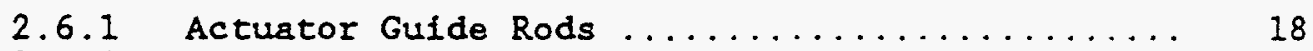

2.6.2 Rigid Damper-Actuator Coupling ............... 18

2.6 .3 Enfidine Damper ................... 18

2.6.4 Elastic Unfurl stop ................. 20

2.6.5 Damper Balancing Weight ............... 23

2.6.6 Actuator Furl Iimit Switch ............. 23

2.6 .7 Stiffer Unfuri Spring .................. 23

3. Analysis Data ........................... 25

3.1 Yaw Trim Analysis Results ................... 25

3.2 Analysis Results on Rotor Yaw Damping and Yaw Position stability ......................... 27

4. Test Data ........................... 33

4.1 Experimental Turbine ................... 33

$4.1 .1 \quad$ Analog Data .................... 33

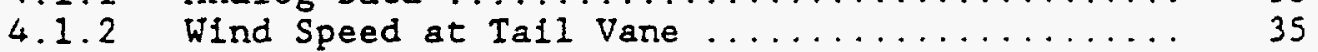

4.1.3 Statistical Data .................. 37

4.1 .4 Test with Stalled Blades ............. 39

4.2 Proof-of-Concept Turbine ................. 39

4.2 .1 Vibration Data .................... 41

4.2.2 Effects of Parameter Changes ............ 43

4.2.3 Statistical Performance Data ............. 45 
5. Conclusions ............................ 51

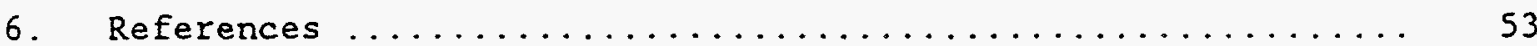


2-1 Side View of Configuration (a) Used 1980/81

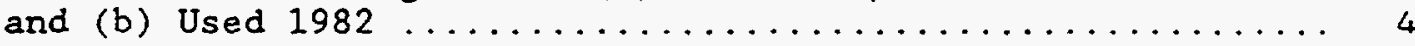

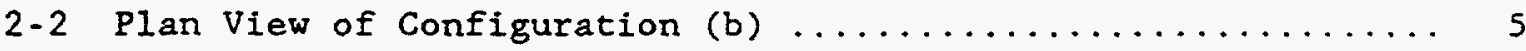

2-3 Plan View of Configuration with Gear-Generator Unit ...... 7

$2-4$ Plan View of Furl Control system $\ldots \ldots \ldots \ldots \ldots \ldots \ldots \ldots \ldots \ldots$

2-5 Blade Planform Before and After Modification $\ldots \ldots \ldots \ldots \ldots \ldots 12$

2-6 Tall Planform and Boom Before and After Modification $\because \ldots \ldots \ldots 12$

2-7 Teeter Springs Supporting Disk Assembly $\ldots \ldots \ldots \ldots \ldots \ldots \ldots 15$

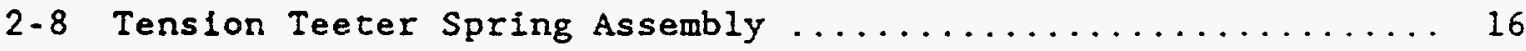

2,9 Schematlc of Electrical Control System ............. 17

2-10 Compression Teeter Spring Assembly ............... 19

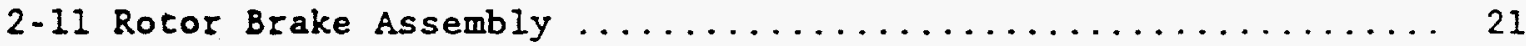

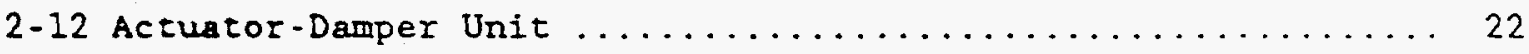

$2-13$ Clasped on Damper Balancing Weight $\ldots \ldots \ldots \ldots \ldots \ldots \ldots \ldots \ldots \ldots \ldots \ldots$

3-1 Equivalent Rotor Thrust Coefficient vs. Furl Angle ........ 26

3-2 Torque Coefficient vs. Speed Ratio ................ 26

3-3 Power-off RPM and Furl Angle From Trim Analysis
and From Test Data $\ldots \ldots \ldots \ldots \ldots \ldots \ldots \ldots \ldots \ldots \ldots \ldots \ldots \ldots \ldots \ldots \ldots \ldots$

3-4 Rotor Yaw Damping Moments and Non-Dimensional Hub
Moments vs. Teeter Spring Stiffness $\ldots \ldots \ldots \ldots \ldots \ldots \ldots \ldots$

3-5 Rotor Yawing Moment vs. Yaw Angle $\ldots \ldots \ldots \ldots \ldots \ldots \ldots \ldots \ldots \ldots$

4-1 Oscillograph Record for Yaw Oscillation,

4-2 Yaw Rate Distribution, November $12,1982 \ldots \ldots \ldots \ldots \ldots \ldots$

4-3 Bin Plots Taken, October 12, $1982 \ldots \ldots \ldots \ldots \ldots \ldots \ldots \ldots \ldots$

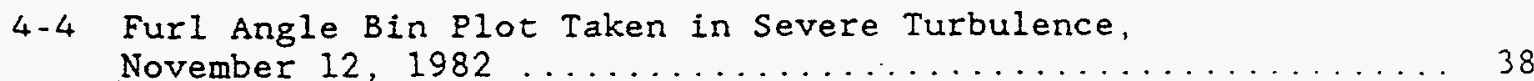

4-5 Torque Coefficient for Unfurled Operation
vs. Speed Ratio, January $15,1983 \ldots \ldots \ldots \ldots \ldots \ldots \ldots \ldots$ 
4-6 Blade Angle of Attack vs. Non-Dimensional Radius, NASA Model ............................... 42

4-7 Bin Plots for Electric Power Output and Furl

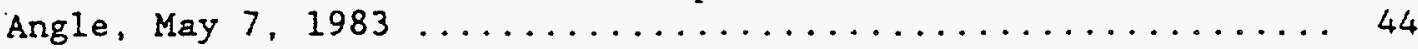

4-8 Bin Plots for Electric Power Output and Furl

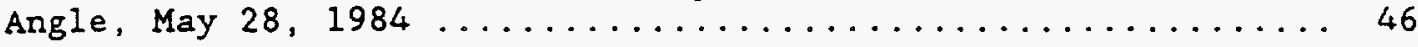

4-9 Bin Plots for Electric Power Output and Furl

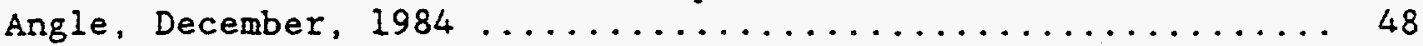

4-10 Furl Angle Bin Plots Without and With Data Preaveraging ..... 49 


\section{LIST OF TABLES}

Page

2-1 U.S. Motors Test Results ......................

2-2 Changes to Experimental Turbine .................. 24

2-3 Changes to Proof-of-Concept Turbine ............... 24

$2-4$ Changes to Furl Control system .................. 24

4-1 Damper Rate vs. Nacelle Yawing Frequency ............. 43

4-2 The Effect of Teeter Spring Stiffness on

Damper Rate and Furling Characteristics .............. 45 
NOMENCLATURE LIST

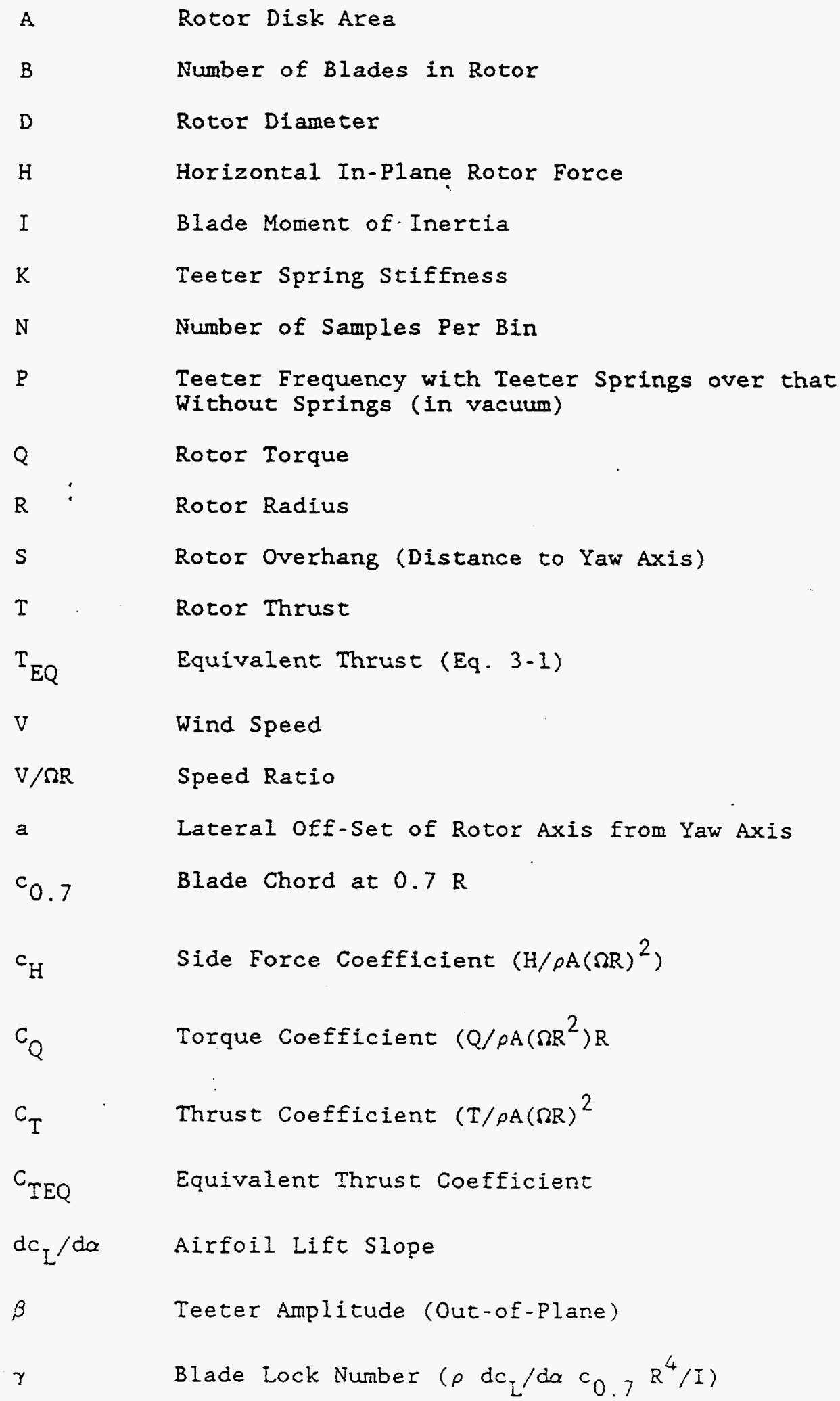




$\begin{array}{ll}\delta_{3} & \text { Angle Between Blade Axis and Teeter Hinge } \\ 7 & \text { Rotor Axis Uptilt Angle } \\ 6 & \text { Blade Pitch Angle } \\ \rho & \text { Air Density } \\ \sigma & \text { Rotor Solidity Ratio }\left(B c_{0.7} / \pi \mathrm{R}\right) \\ x & \text { Rotor Yaw Angle } \\ \Omega & \text { Rotor Angular Speed }\end{array}$


SECTION 1.0

INTRODUCTION

The horizontal axis wind turbine type under study incorporated the novel combination of two features; rotor passive cyclic pitch (PCP) variation and rapid rotor yaw angle variation to accomplish rotor speed and torque control by yawing. The wind turbine had a teetered rotor with $25 \mathrm{ft}(7.6 \mathrm{~m})$ diameter. It had a delta three angle of the teeter hinge $\left(\delta_{3}-67\right.$ deg) whereby the oscillation amplitude about the hinge axis was almost equal to the cyclic pitch amplitude about the blade axis. This type of rotor made rapid yaw rates possible without transferring gyroscopic or aerodynamic moments to the rotor hub and without causing excessive angular excursions of the blade tip path plane from the perpendicular to the rotor axis. Thus the hub could be easily yawed without resistance whereby the rotor plane followed the yawing motion of the hub almost instantaneously due to the aerodynamic servo action involved in the process. The experimental PCP turbine, Installed April 1980 at Washington University's Tyson Research Center, was first operated with manual yaw controls, see Ref. 1. Rotor yaw rates up to $15 \mathrm{deg} / \mathrm{s}$ were encountered leading to cyclic pitch amplitudes up to \pm 5 deg. The turbine was tested power-on at yaw angles of $0,15,30$ and 45 degrees, power-off up to 80 degfees. Rotor loads and vibrations remained small. The alternator was tuned in such a way that torque increased with the square of the rpm so that the rotor would operate at constant wind speed with optimal tip speed ratio.

Two automatic rotor yaw control systems, one active and one passive system, were developed and tested in 1981, Ref. 2. Both systems provided an effective rotor speed and torque limitation. The passive rotor yaw control was simpler and it was expected to be more reliable. Except for some preliminary testing of the active system, all research up to the present was done in the configuration having the passive rotor yaw control. In September 1981, the variable speed alternator was replaced by a constant speed induction generator. Constant speed power-on operation was retained throughout the subsequent tests. It was found that with the turbulence level usually encountered at Tyson, variable rotor speed did not increase the captured rotor energy vs. that for constant rotor speed. However, for comparable wind speeds and turbulence levels, the dynamic rotor loads and the torque variations were less for variable rotor speed.

During the $1980 / 81$ test perlod the tail vane boom was supported by the nacelle with the help of two Ruion bearings. This design caused excessive friction in the passive rotor yaw controls and led to substantial hysteresis effects with associated loss of energy capture. The wind turbine was then modified in December 1981 so that both the tail vane boom and the nacelle were independently supported by the yaw post with the help of ball bearings. The test and analysis results to be presented in the following are for this configuration involving negligible bearing friction for tail vane yawing and nacelle furling. 
SECTION 2.0

\section{TEST EQUIPMENT}

\subsection{EXPERIMENTAL TURBINE}

The Tyson test equipment as of November 1981 was described in Ref. 2 . Fig. 2.1 (a) shows a schematic side view of this turbine. The tail vane boom was supported by the nacelle 12 inch $(0.30 \mathrm{~m})$ downwind of the yaw post. Furling of the nacelle with respect to the tail boom involved the rotation of the nacelle about the yaw axis and a rotation of the tail boom about the furl pin. Since the furl pin rulon bearings were heavily loaded by the gravity moment of the tail vane and boom, furling of the nacelle caused a large frictional moment.

Fig. 2-1 (b) shows the side view of the turbine as modified in December 1981. Both nacelle and tail vane boom were supported by the yaw post. The tail vane boom was pinned to the yaw post and rotated together with it. The upper yaw post bearing was a self aligning seal Master thrust ball bearing with low friction. The lower yaw post bearing was a Rulon bearing. Due to the large distance between upper and lower yaw post bearings $(20$ inch, $0.50 \mathrm{~m})$, its load and friction moment was small. The nacelle was supported by the yaw post with the help of two self aligning Seal Master thrust ball bearings with low friction. The racelle rotated (furled) relative to the yaw post and tail boom by $90 \mathrm{deg}$. Thus the yawing motion of the tail vane boom and the furling motion of the nacelle in relation to the boom were independent of each other, and they both had low friction moments. The original configuration of Fig. 2-1 (a) used a steel box as the main structure of the nacelle. The modified turbine, Fig. 2-I (b), used instead a fiberglas composite bed plate. The rotor shaft supported by the bearing block and the shaft rounted gear box were same as before.

Fig. 2-2 shows the plan view of the modified experimental turbine of Fig. $2-1$ (b). The hollow rotor shaft supported by the bearing block carried at its downwind end a slip ring unit with 16 slip rings (omitted in Fig. 2-1 (a) and (b) ). The slip rings were connected through the hollow shaft to four strain gage bridges for measuring out-of-plane blade root bending moments, teeter motions and rotor torque. Other quantities measured were the rotor speed from a magnetic pickup signal, tail boom vertical and lateral bending, yaw post bending in two directions, axial bed plate acceleration, furl angle (the angle of the bed plate with respect to the yaw post), and generator current. The rotor axis was laterally off-set by 4.3 inch $(0.11 \mathrm{~m})$. The rotor overhang (distance to the yaw axis) was 32 inch $(0.81 \mathrm{~m}$ ). There were wedges between bearing block and bed plate seen in Fig. 2-I (b) to adjust the uptilt angle of the rotor shaft.

The single phase Gould induction generator (not seen in Figures 2-I and 2-2) was attached on top of the shaft mounted gearbox and was belt driven from the gear box. The transmission ratio between generator and rotor was normally 9.37 : 1 . It could be varied by exchanging pulleys and $V$-belt. The break-out rotor torque was quite high, about $10 \mathrm{ft}-1 \mathrm{~b}(13 \mathrm{Nm})$. There were rather high losses from the shaft mounted gearing system and from the generator belt drive. The test results are given in terms of the measured rotor torque and rotor speed. No effort was made to evaluate the transmission and electrical losses. 


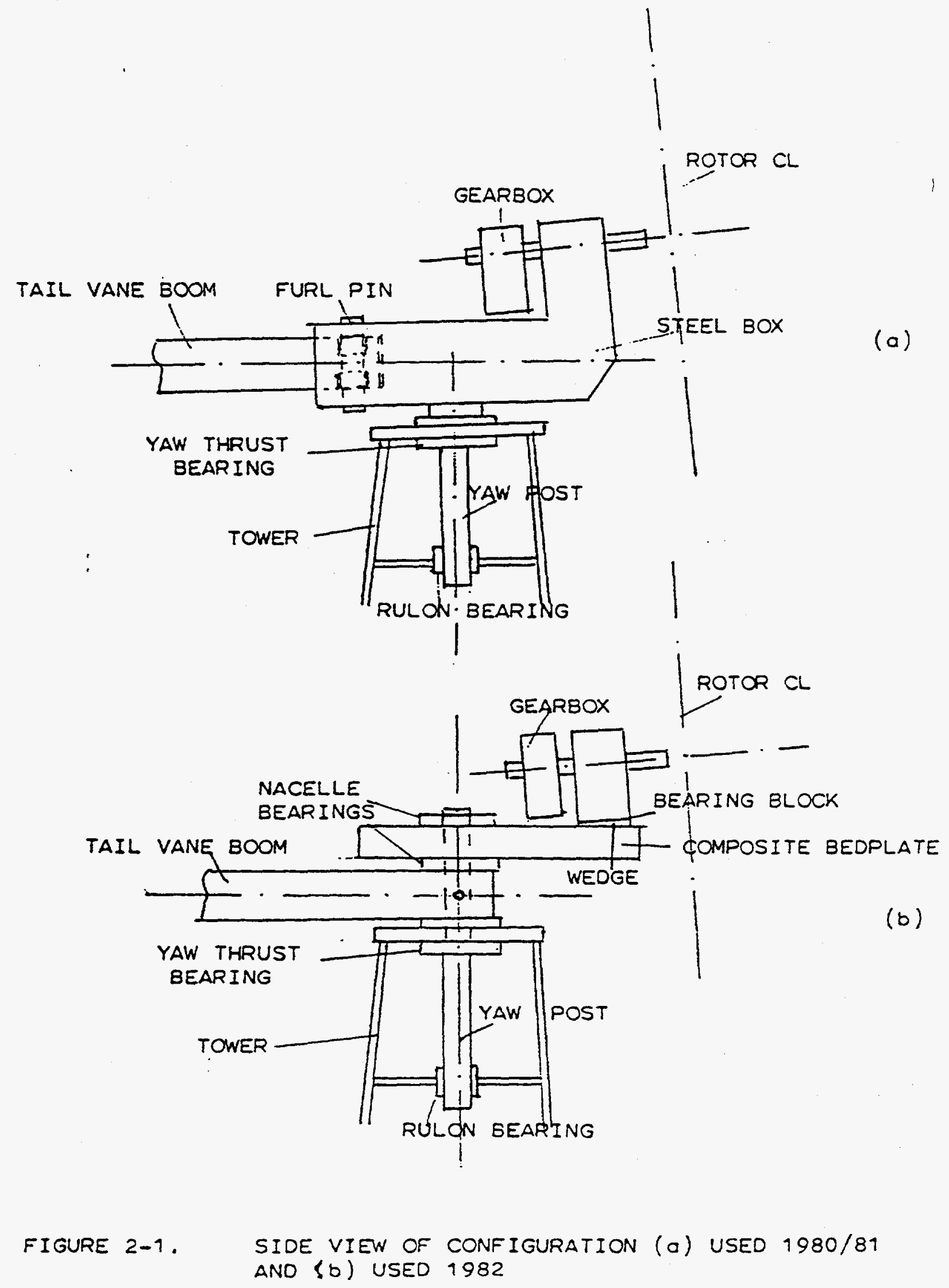




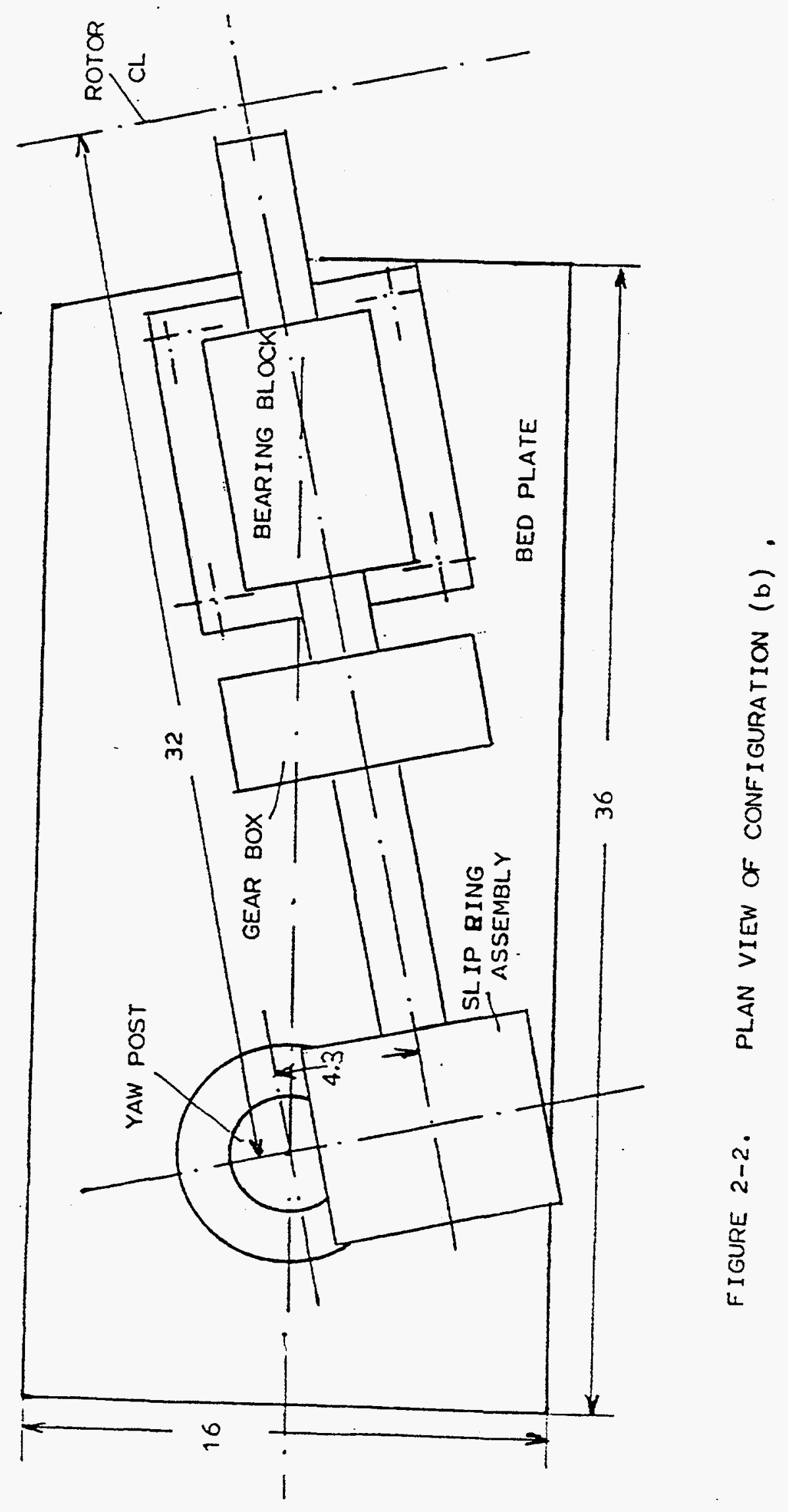




\subsection{PROOF-OF-CONCEPT TURBINE}

In April 1983, the experimental turbine was changed to a duplicate of the Proof-of-Concept turbine tested at the Rocky Flats Wind Systems Test Center. Fig. $2-3$ shows the plan view of this configuration with an integral geargenerator unit manufactured by U.S. Motors. This configuration was more compact than that shown in Fig. 2-2. The rotor overhang was reduced from 32 inch $(0.81 \mathrm{~m})$ to 27.5 inch $(0.70 \mathrm{~m})$. The transmission ratio of 9.21 was almost the same as before. The rotor axis lateral off-set from the yaw axis was also the same, 4.3 inch $(0.11 \mathrm{~m})$. The bed plate planform area was substantially smaller. The friction break-out torque was reduced from $10 \mathrm{ft}$ Ib $(13 \mathrm{Nm})$ to $2 \mathrm{ft}-\mathrm{Ib}(2.7 \mathrm{Nm})$ and made the wind turbine start at lower wind speed.

The rotor shaft of the new configuration was too short to install a slipring unit so that measurements in the rotating system were no Ionger possible. However, during the preceding test perlod a good correlation had been established between axial acceleration and out-of-plane blade root bending moments. This allowed the estimation of the blade root bending moment from the measured axial acceleration. The main blade loads had their origin in the blade coning mode which was subjected to $2 \mathrm{P}$ aerodynamic excitation. The blade coning mode amplitude was reflected in the axial $2 \mathrm{p}$ nacelle acceleration. Teeter stop impacts were also clearly recognizeable in the axial acceleration trace so that this important limit condition could be established from the acceleration measurements. For the Rocky Flats tests, telemetering equipment was used for measuring quantities in the rotating system.

The generator was used at Rocky Flats in the three phase mode. At Tyson it was used in. the single phase mode with a capacitance of $150 \mu F$ across one pair of phases. The three phases were conducted down to the instrument shed where capacltors were located. Tests had been conducted at U.S. Motors with the next larger unit of 50 increased rating (15 HP motor rating vs. $10 \mathrm{HP}$ for the installed unit). It had been found that single phase operation was more efficient if the generator was driven in the sense opposite so that it would start as a motor.

Special starting capacitors were used for the motoring test. The Electromatic digital controller had a two second minimum delay between generator cut-out and cut-in. During these two seconds the generator could run as a motor driven by the grid but in a direction opposite so that it would turn when started as a motor from stand still.

During the 1982 tests the digital controller operated a mechanical contacter which was quite noisy. After installing the Proof-of-Concept turbine, an attempt was made to replace the mechanical contactor by a solid state switch. Due to high cut-in currents, the protective circuits blew several times. The solid state switch was then removed and the mechanical contactor was reinstated. At first the capacitance across one pair of phases was kept connected after generator cut-out. This produced high and erratic currents from self excitation. The capacitance was then wired such that it was cut out together with the generator using the third switch of the three pole contactor. Now the cut-in current transient varied little and stayed in the range of 50 to 60 amps peak current. 


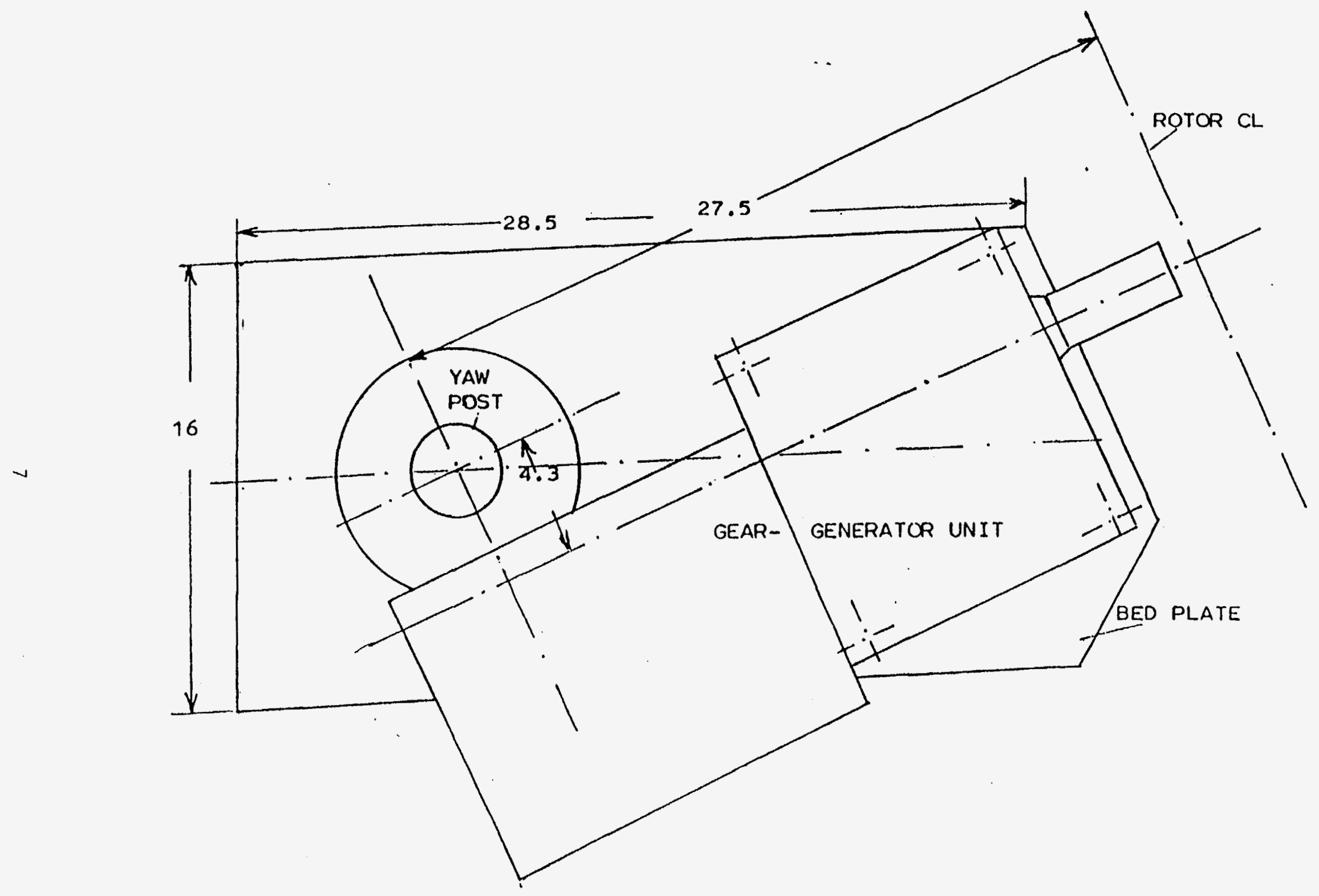

FIGURE 2-3. PLAN VIEW OF CONFIGURATION WITH GEAR-GENERATOR UNIT 
Table 2-1 shows the results of the U.S. Motors tests for the single phase and for the three phase mode of operation, both for 240 volt. The actually measured currents and powers were reduced by a factor of $2 / 3$ in order to apply to the units installed at Rocky Flats and at Tyson. The single phase data were taken in the mode where the generator is driven opposite to the direction it would start as a motor. The rotor power in $T a b l e ~ 2-1$ was determined with the assumption of a $0.1 \mathrm{KW}$ friction loss and a 48 gearing loss. It is seen that in the middle power range three phase operation yields 908 generator efficiency, single phase operation only, 858 generator efficiency. For the tests with the Corps machine the data in $\mathrm{Table} 2-1$ were used to determine electric power output from the measured current. This output checked well with an independent measurement from a power meter.

\subsection{FURL CONTROL SYSTEM}

Since the furl control system was the same both for the experimental and for the Proof-of-Concept turbines, there is no need to differentiate between these two configurations. Fig. 2-4 shows the plan view of the control system. Unfurl tension spring and actuator-damper unit were connected on the upwind side to the bed plate, on the downwind side to the tail boom. The electric actuator was not needed in normal operation and merely served to stop the rotor in case of an emergency or if the tower was to be lowered. Due to the lateral rotor axis off-set from the yaw axis, the rotor thrust produced a nacelle furling moment. As shown in Fig. 2-1 (b) the rotor axis was tilted upward. Since the rotor turned counter clockwise seen downwind, the driving rotor torque, due to this uptilt, contributed an unfurling moment. The uptilt angle of the rotor axis improved the rotor-tower clearance and allowed a small rotor overhang (distance to yaw axis) and a small nacelle moment of inertia. The power-on unfurling moment from torque compensated in part the difference between the high power-on and the low power-off rotor thrust moment at a given rotor speed. Without the rotor axis uptilt the power-off rotor speed would be excessive.

The main parameters of the furl control system were lateral rotor axis offset, rotor axis uptilt angle, unfurl spring rate and unfurl spring preload, the kinematic relation between unfurl spring extension and furl angle, and the mechanical damper characteristics. Except for the first, all of these parameters were varied. Each of these changes required the lowering of the tower to gain access to the nacelle. Since lowering of the tower during a high wind period was inadvisable, the testing of each set of parameters required a separate high wind period of which there were at the site only a few per year except in non-usable thunder storms. This explains why researching the dynamic control characteristics of the turbine was time consuming. Furthermore, there was no mathematical model available for predicting the effects of the parameters on the dynamic control characteristics so that parameter changes had to be made by trial and error.

\subsection{CHANGES TO EXPERIMENTAL WIND TURBINE}

During the atmospheric testing, deficiencies in the test equipment were found and changes were made to correct the deficiencies. In the following the changes are discussed separately for the experimental turbine, for the 
Table 2-1 U.S. Motors Generator Test Results

\section{Single Phase Generator, $240 \mathrm{~V}$ with 140 \& $\mathrm{f}$ Across Two Phases}

\begin{tabular}{llrlrlll} 
RPM & Amps & KW $_{\text {in }}$ & KW $_{\text {out }}$ & Effic. & PF & Rotor KW & Total Effic. \\
\hline 1868 & 50.6 & 12.0 & 8.7 & 0.72 & 0.75 & 12.6 & 0.69 \\
1860 & 45 & 10.7 & 8.0 & 0.75 & 0.77 & 11.2 & 0.71 \\
1853 & 39 & 9.5 & 7.3 & 0.77 & 0.80 & 10.0 & 0.73 \\
1845 & 34 & 8.0 & 6.4 & 0.80 & 0.82 & 8.4 & 0.76 \\
1838 & 29 & 6.7 & 5.6 & 0.82 & 0.84 & 7.1 & 0.79 \\
1830 & 23 & 5.3 & 4.5 & 0.85 & 0.86 & 5.6 & 0.80 \\
1824 & 18 & 4.1 & 3.5 & 0.85 & 0.85 & 4.3 & 0.81 \\
1816 & 13 & 2.9 & 2.5 & 0.85 & 0.84 & 3.1 & 0.81 \\
1808 & 7 & 1.5 & 1.1 & 0.73 & 0.66 & 1.7 & 0.65 \\
1807 & 5 & 0.6 & 0.15 & 0.25 & 0.14 & 0.7 & 0.21
\end{tabular}

Three phase Generator, $240 \mathrm{~V}$

\begin{tabular}{|c|c|c|c|c|c|c|c|}
\hline RPM & Amps & $\mathrm{KW}_{\text {in }}$ & $\mathrm{KW}_{\text {out }}$ & Effic. & $\mathrm{PF}$ & Rotor KW & Total Effic. \\
\hline 1863 & 33 & 12.0 & 10.7 & 0.88 & 0.81 & 12.6 & 0.85 \\
\hline 1855 & 29 & 10.7 & 9.5 & 0.89 & 0.81 & 11.2 & 0.85 \\
\hline 1848 & 26 & 9.5 & 8.4 & 0.89 & 0.81 & 10.0 & 0.85 \\
\hline 1841 & 25 & 8.0 & 7.1 & 0.90 & 0.79 & 8.4 & 0.85 \\
\hline 1834 & 19 & 6.7 & 6.0 & 0.90 & 0.78 & 7.1 & 0.85 \\
\hline 1827 & 16 & 5.3 & 4.8 & 0.90 & 0.75 & 5.6 & 0.85 \\
\hline 1821 & 13 & 4.1 & 3.7 & 0.90 & 0.70 & 4.4 & 0.84 \\
\hline 1814 & 11 & 2.9 & 2.5 & 0.87 & 0.55 & 3.1 & 0.81 \\
\hline 1806 & 9 & 1.5 & 1.0 & 0.72 & 0.30 & 1.7 & 0.59 \\
\hline 1802 & 8 & 0.6 & 0.2 & 0.33 & 0.06 & 0.7 & 0.28 \\
\hline
\end{tabular}




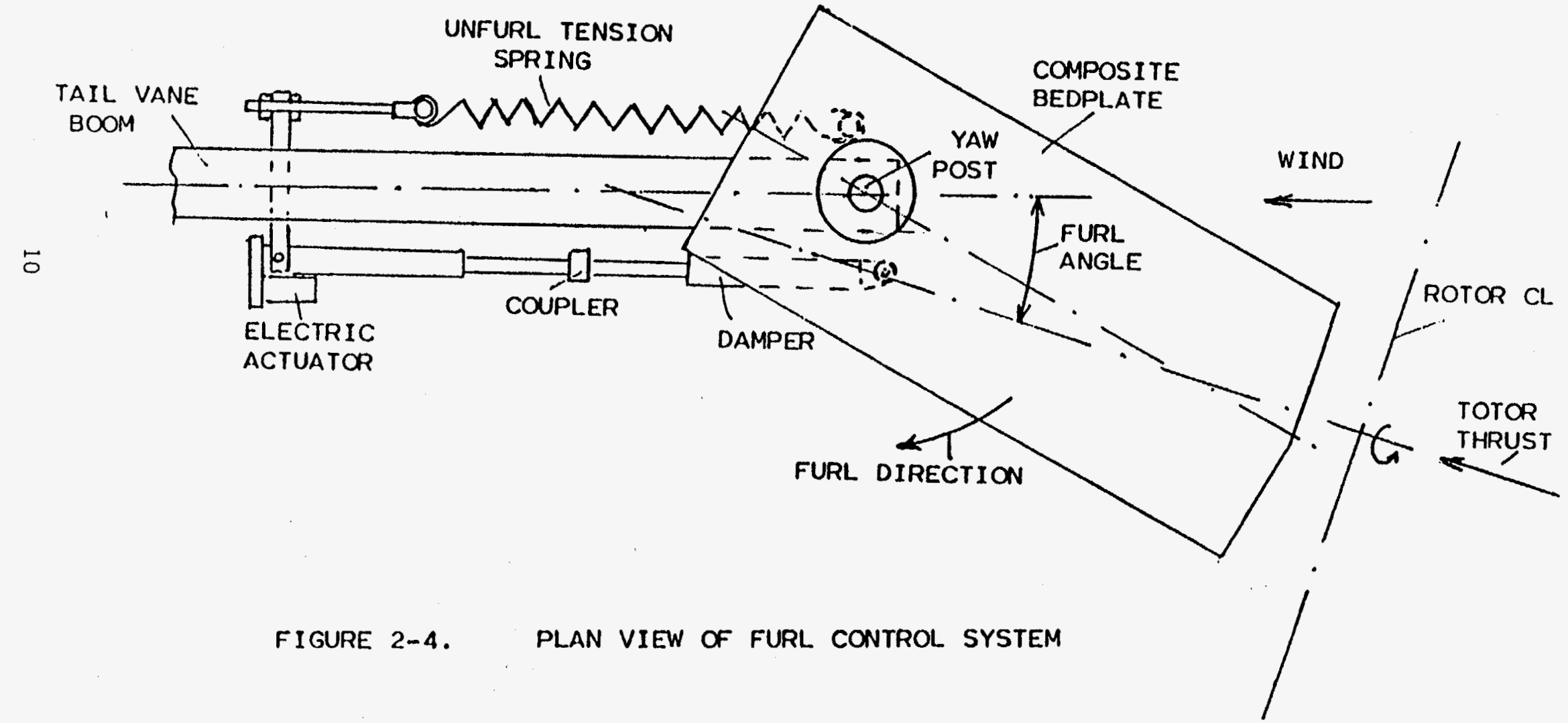


Proof-of-Concept turbine and for the furl control system common to both. The changes are summarized for these three cases respectively in Tables 2-2, 2-3, $2-4$.

\subsubsection{Instrumentation Changes}

In May 1982 a second anemometer was installed on top of the tail vane in order to obtain data on the effect of the rotor wake on the vane. In September 1982 a potentiometer pickup for the tail vane boom position relative to the tower was added. The yaw post rotation was transferred to a precision potentiometer with the help of double sprockets and a pinned drive belt. This instrument allowed to determine the total rotor yaw rate from nacelle furl and tail boom yaw measurements. Also in September 1982 the instrumentation was improved by changing the furl potentiometer to a strain gage flexure gliding in a spiral. This gave more reliable signals for the display instrument, for the oscillograph and for the computer.

\subsubsection{Blade Change}

In September 1982 the blades were modified as seen in Fig. 2.5. The added portion continued the leading and trailing edges to the station 23 inch $(0.16 \mathrm{~m})$ from rotor center. The twist increased within the added blade portion from $9 \mathrm{deg}$ to $16 \mathrm{deg}$, the chord increased from 12 to 14 inch (0.30 to $0.36 \mathrm{~m})$. The blade coning frequency was not affected by the addition and remained at $8.0 \mathrm{~Hz}$. The effect of the modification was a rotor start-up at substantially lower wind speed so that the previously used starting motor could be eliminated.

\subsubsection{Tail Vane and Tail Boom Changes}

Also in September 1982 a new enlarged tail vane and a longer tail boom were installed as seen in Fig. 2.6. The tail vane area was increased by a factor of 1.5 from $16 \mathrm{sq}$ ft to $24 \mathrm{sq}$ ft $\left(1.5 \mathrm{~m}^{2}\right.$ to $\left.2.25 \mathrm{~m}^{2}\right)$. The tail vane height was increased by a factor of 1.2 from 120 inch to 144 inch ( 3.0 to $3.6 \mathrm{~m}$ ). The mean tail vane chord was increased by a factor of 1.25 from 19 inch to 24 inch $(0.48 \mathrm{~m}$ to $0.61 \mathrm{~m})$. The boom length between yaw axis and vane trailing edge increased by a factor of 1.12 from 192 inch to 216 inch (4.9 to $5.5 \mathrm{~m}$ ). There were three reasons for the change. First, it had been observed that at low wind speed power-on, vane yawing was erratic which was interpreted as caused by the onset of vane stall. In other words, at low wind speed, the tail vane could not resist the furling moment of the rotor thrust. This condition was corrected by the larger tail. Second, the vertical tail natural frequency was rather close to the operational rotor speed so that quite large 1 P vertical tail excitation occurred. The modification lowered the natural vertical tail frequency from $180 \mathrm{CPM}$ to about $140 \mathrm{CPM}$ so that at the rotor operational speed of 195 RPM no visible 1 P vertical tail vibrations could be observed. Third, strong $4 \mathrm{P}$ torque oscillations together with $4 \mathrm{P}$ nacelle yaw oscillations had been observed at high power output. This condition was incerpreted as a combined blade in-plane and lateral tail boom mode coupled through the rotor shaft uptilt angle. The modified tail boom had a substantially lower lateral natural frequency which no longer coupled with the in-plane blade mode. 


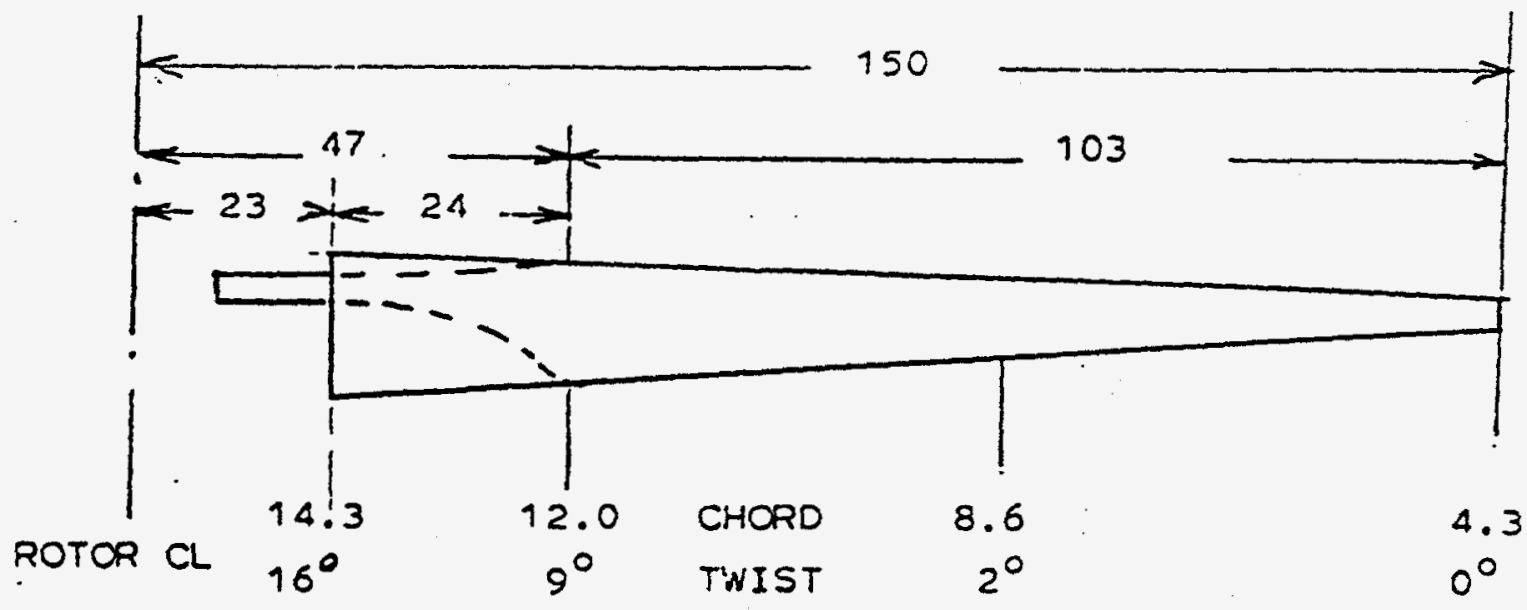

FIGURE 2-5.

BLADE PLANFCRM BEFORE ( DASHEO LINES) AND AFTER MOOIF ICATION, DIMENSIONS IN INCHES

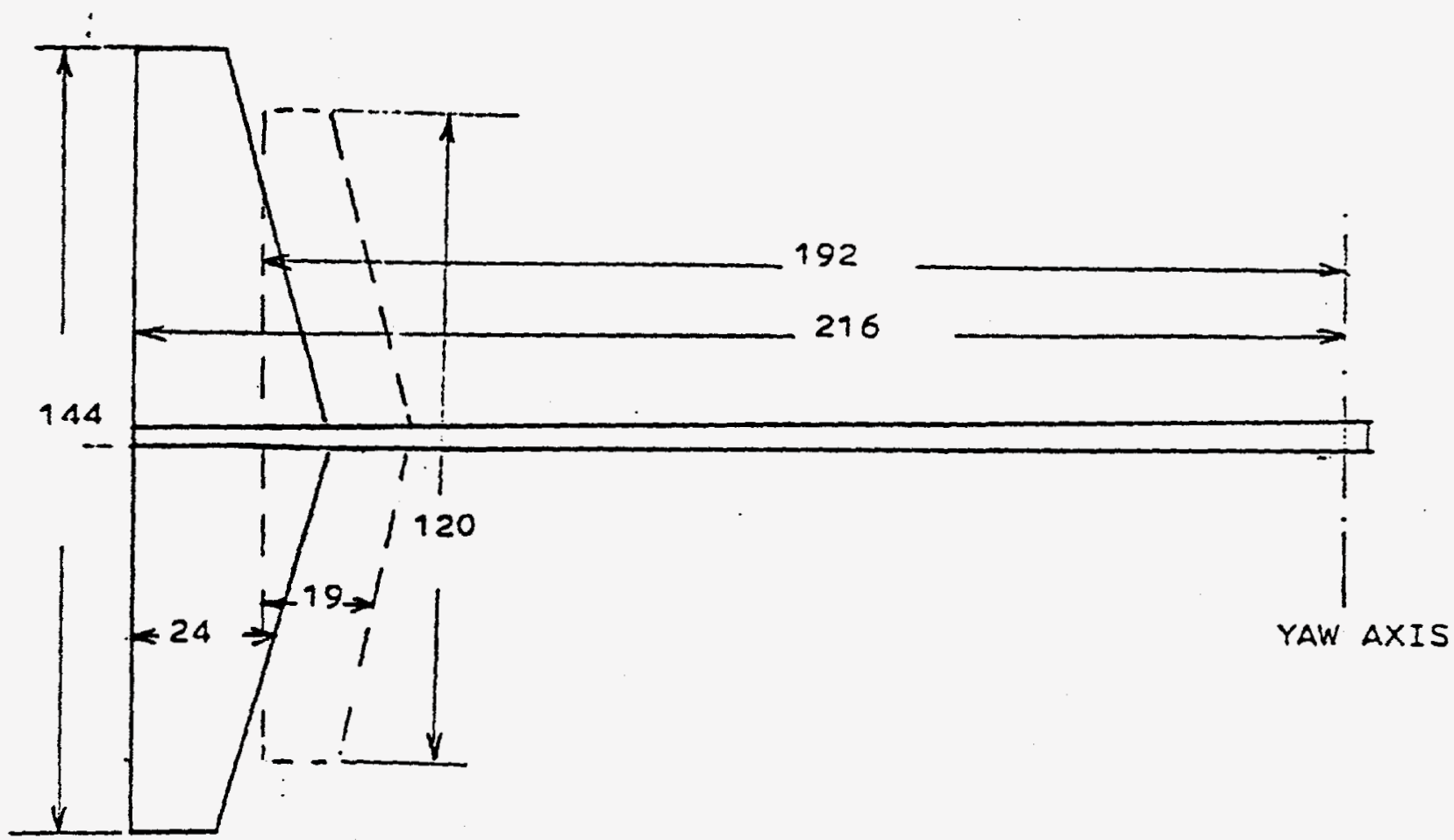

FIGURE $2-6$.

TAIL PLANFORM AND TAIL BOOM BEFORE ( DASHED LINES) AND AFTER MOOIFICATION, DIMENSIONS IN INCHES 


\subsubsection{Transmission Ratio Increase}

In November 1982 the transmission ratio between induction generator and rotor was changed from 9.37 : 1 to 12.5 : I by using a different size pulley in the belt drive. The purpose of this change was to study the stall characteristics of the rotor.

\subsection{CHANGES TO THE PROOF-OF-CONCEPT TURBINE}

AlI the changes to the experimental turbine discussed above (except for the change in transmission ratio) were carried over to the Proof-of-Concept turbines. The additional changes to this turbine made in 1983 to 1985 are discussed in the following subsections and summarized in $T a b l e ~ 2-3$. None of these changes were made to date to the Rocky Flats PCP turbine.

\subsubsection{Aluminum Disk on Shaft}

In April 1983 a 9 inch $(0.23 \mathrm{~m})$ diameter aluminum disk was mounted on the rotor shaft as seen in Fig. 2-7. The disk had a slight press fit and was also secured to the shaft by a key not shown in Fig. 2-7. A spacer was inserted beitween the disk and the cone of the taper lock that connected the hub to the shaft. The disk was used to support the teeter tension springs and later also the teeter compression springs and the friction pad of the rotor brake added in May 1985.

\subsubsection{Tension Teeter Springs}

The rotor hub was modified in May of 1983 by the addition of aluminum angles as seen in Fig. 2-8. The angles were bolted to the hub box by the four bolts holding the teeter bearing block inside the hub box as seen in the view along the rotor axis in the lower part of Fig. 2-8. Tension teeter springs were then mounted between the aluminum disk and the angles as shown in Fig. 2-8. Several sets of tension teeter springs were tested. Most of the tests were conducted with a set of teeter springs that gave an elastic restraint of

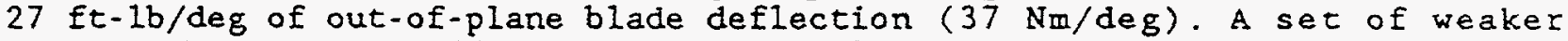
springs had little effect on the control characteristics. Stronger springs caused $1 \mathrm{P}$ nacelle excitation, presumably because of unequal spring preload which could not be removed since the spring lengths were not adjustable.

\subsubsection{Emergency Shut-Down System}

Fig. 2-9 shows a block diagran of the electrical system. The upper portion of the diagram contains the elements that were installed in september 1981 , namely circuit breaker, power contactor, digital controller, magnetic pick-up. The remaining components represent an emergency shut-down system which was designed and installed in March of 1984 in preparation for unattended turbine operation. The latching relay had two functions; first, to operate the power contactor, second to power the furl actuator in response tc one of four emergency signals indicating power loss, overspeed, overvoltage and excessive vibrations. The furl actuator could be switched either to the manual or to the automatic mode when the furl signal would be given by the latching relay. When the actuator was in the automatic mode, any of the four emergency signals would result in generator disconnect and in rotor furling. 
The power failure relay operated an adjustable timer which was set to about one second delay. When the power returned within one second, the latching relay would not trip, the generator would remain connected and the rotor would remain unfurled. The overspeed relay would receive its closing signal from the frequency-to-voltage converter which was receiving pulses with twice generator RPM from a magnetic pick-up. This pick-up was separate from that feeding the digital controller. The frequency-to-voltage converter also fed voltage proportional to rotor speed to the Vishay signal conditioner and from there to the RPM display instrument, to the oscillograph and to the computer. The latching relay remained tripped until an unlatching switch was operated. During unattended operation the circuit breaker tripped once because of generator overload and the machine was found in furled position with the rotor standing still. The overspeed shut-down was set to 10 overspeed. Actually, the functioning of the overspeed and the power failure relays and even the functioning of the electric actuator were not critical since the mechanical furl control system would prevent a dangerous overspeed. However, at power-off rotor speed in the vicinity of $20 \mathrm{mph}(9 \mathrm{~m} / \mathrm{s})$ wind velocity the blade coning frequency was in near resonance with $2 \mathrm{P}$ aerodynamic excitation. Several days of power-off operation might have reduced turbine life. The Rocky Flats PCP turbine had no emergency shut-down provisions and was not meant to operate unattended.

\section{$2.5: 4$ Vibration Shut-Down Switch}

The Select Controls vibration shut-down switch was installed in October 1984. When positioned parallel to the rotor axis, it was closed below $1.2 \mathrm{~g}$ and open above $1.2 \mathrm{~g}$. It was found that during generator cut-in a very brief acceleration peak occurred which occasionally tripped the acceleration switch. The switch had to be installed at an angle to the axial direction to make it less sensitive. Though normally the axial accelerations were not over $\pm 0.5 \mathrm{~g}$, the acceleration switch had to be desensitized to about $1.8 \mathrm{~g}$ in order to reliably prevent tripping from generator cut-in.

\subsubsection{Compression Teeter Springs}

In order to test higher teeter spring rates, a set of adjustable compression springs was added in May 1985 ( $F$ ig. 2-10). Adjustable tension rods were supported by the aluminum disk and carried on the upwind side of the hub box the compression springs which gave an elastic restraint of $35 \mathrm{ft}-\mathrm{lb} / \mathrm{deg}$ of out-of-plane blade deflection $(47 \mathrm{Nm} / \mathrm{deg})$. The tension teeter springs were left installed but their unequal preload could now be compensated by the adjustable preloads of the compression springs. The combined elastic restraint was $62 \mathrm{ft}-1 \mathrm{~b} / \mathrm{deg}(84 \mathrm{Nm} / \mathrm{deg})$. The teeter bearings and the rotor shaft were quite highly loaded by the combined teeter springs which should serve merely research purposes but should not be used for long time operation. The fatigue strength of the shaft and the allowable radial loads of the Rulon teeter bearings are adequate for long term operation of either of the tension or compression teeter springs alone.

\section{5 .6 Rotor Brake}

After the Corps terminated the support in December 1984 , continued testing depended on changing the wind turbine to a configuration for which no experienced help would be needed when raising and lowering the tower. This 


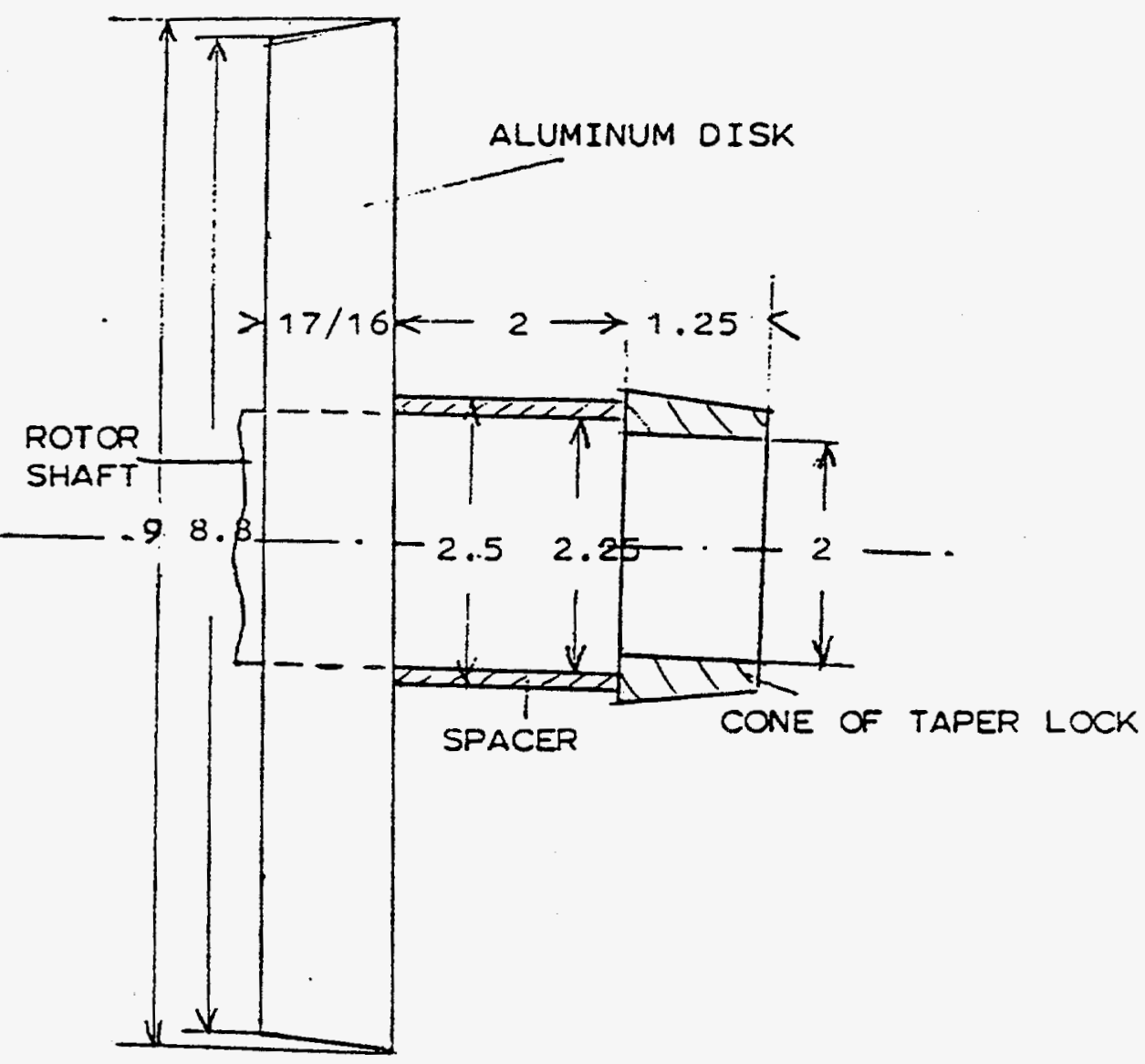

FIGURE 2-7.

TEETER SPRINGS SUPPORTING OISK ASSEMELY. $1 / 2$ SCALE 


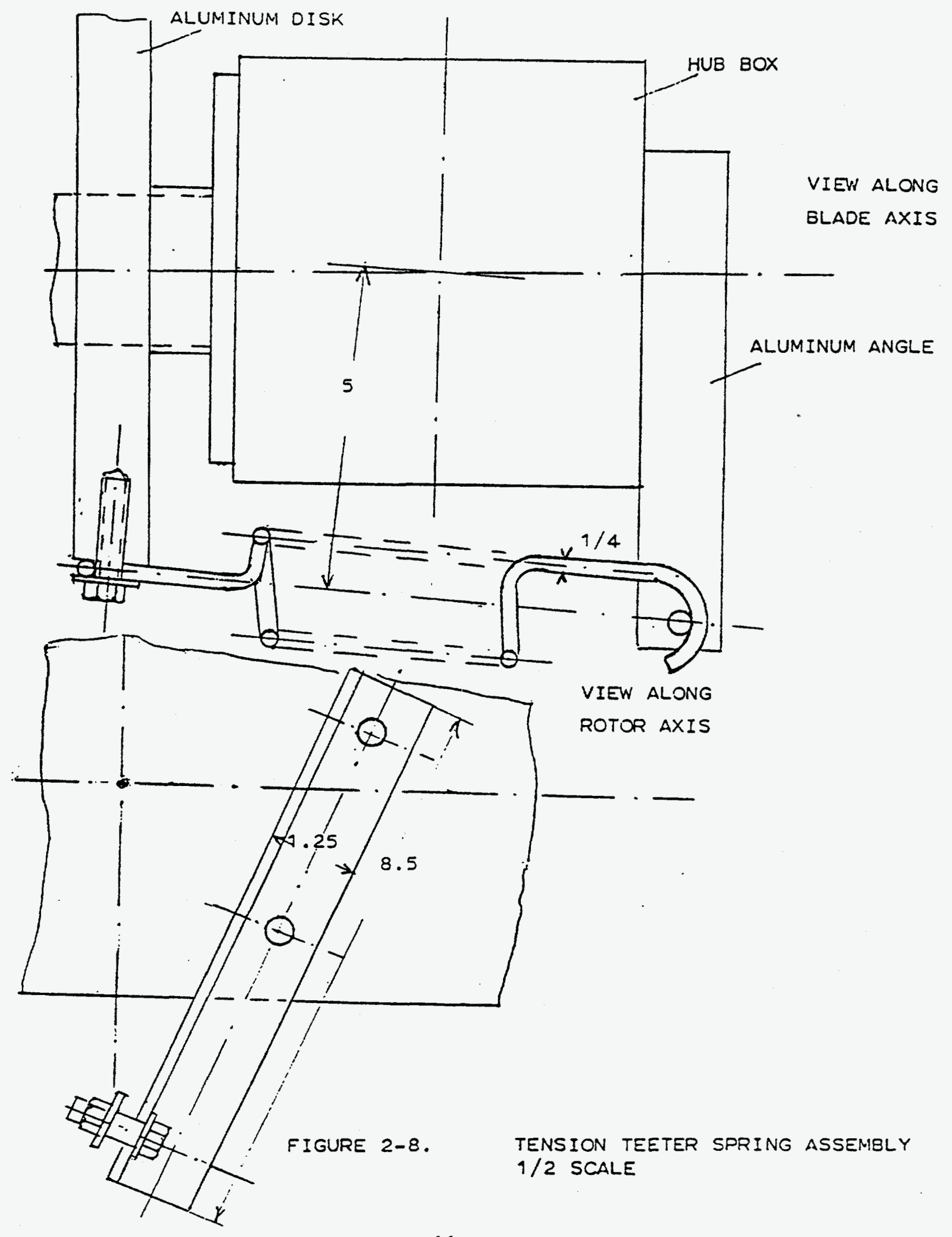




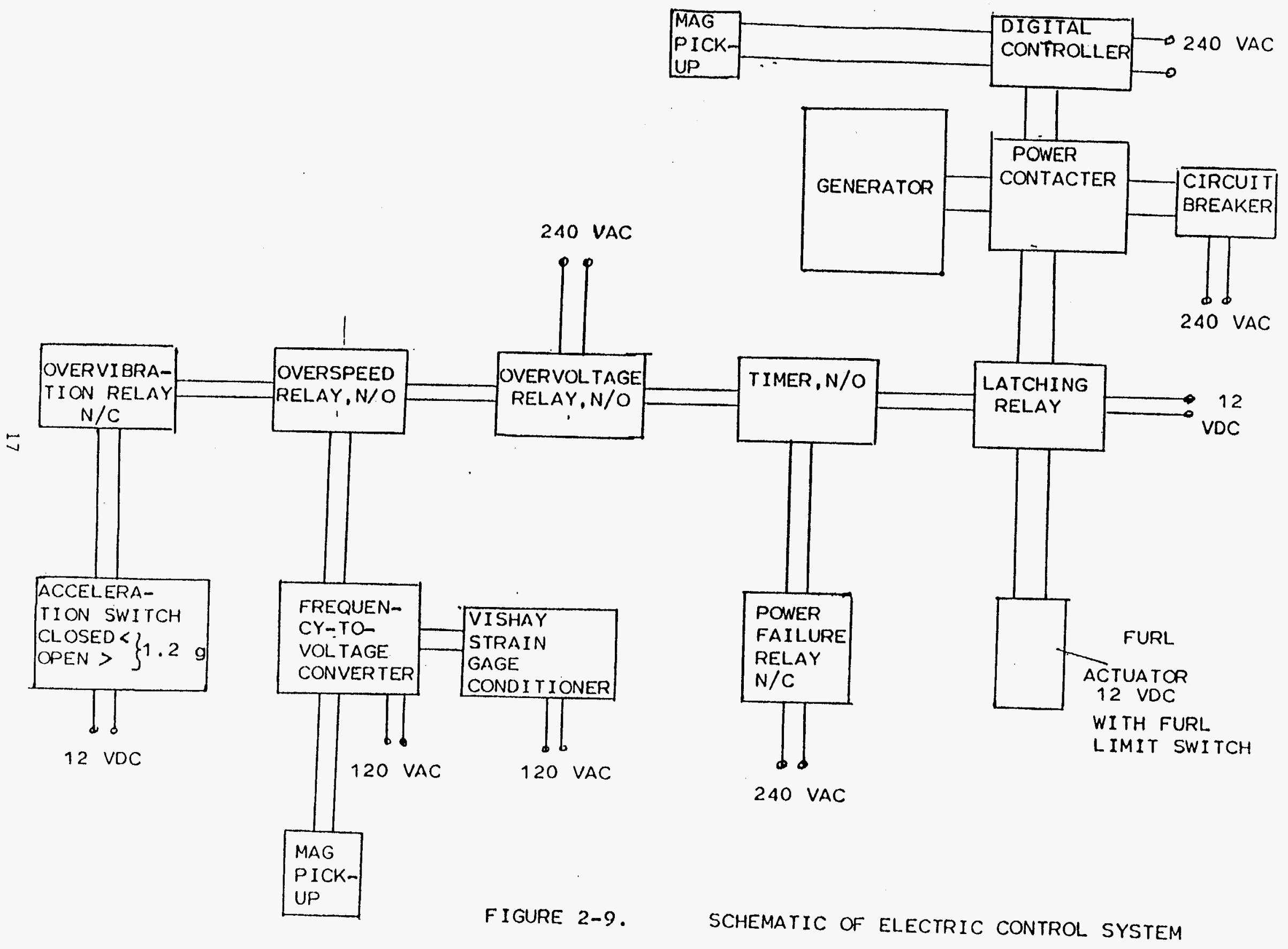


required the design, manufacturing and testing of a rotor brake to be able to raise and lower the tower in high winds. The brake was installed in May 1985 and tested in September 1985. As seen in Fig. 2-11, the brake pad was pressed by an electric actuator against the downwind side of the aluminum disk of Fig. 2-7. The walking beam carrying the brake pad was supported by one of the bolts that tie the gear-generator unit to the bed plate. The electric 12 VDC actuator had an adjustable slip clutch by which the force normal to the brake pad could be limited. The brake provided a rotor friction torque of $20 \mathrm{ft}-1 \mathrm{~b}$ $(27 \mathrm{Nm})$ which compared to $2 \mathrm{ft}-\mathrm{Ib}(2.7 \mathrm{Nm})$ of break-out friction torque without the brake. The brake made it possible to raise and lower the tower in winds up to $20 \mathrm{mph}(9 \mathrm{~m} / \mathrm{s})$.

\subsection{CHANGES IN FURL CONTROL SYSTEM}

The changes are summarized in Table 2-4.

\subsubsection{Actuator Guide Rods}

The modification to the electric furl actuator seen in Fig. 2-12 was made in January 1982. It had been observed that the actuator piston occasionally rotated about its axis by several degrees which changed the piston axial position. Guide rods were then added held by a clamp around the coupler and sliding in holes through another clamp around the actuator body. Due to the ball screw in the actuator,. the torsional moment tending to rotate the piston was small and the guide rods were capable to prevent such rotation. The guide rod clamps had to be adjusted such that even with fully extended actuator the guide rods vere still inside the guiding holes. Due to an adjustment error of the clatps, the guide rods were pulled out of the guide holes during unfurling in April 1984 resulting in a blockage of the actuator when trying to furl. The rotor kept turning for 24 hours in winds between 5 and $15 \mathrm{mph}$ so that a crane with bucket had to be rented to furl the rotor externally and stop it before lowering the tower.

\subsubsection{Rigid Damper-Actuator Coupling}

Originally, the actuator piston and the damper rods were connected by pin and clevis as shown in the assembly drawing of Ref. 2. In March 1982 this connection was replaced by a rigid coupler which prevented jack knifing of the unit when the compression from the damper during furling exceeded the tension force from the unfurl spring.

\subsubsection{Enidine Damper}

The control dynamics of the furl system was found to depend critically on the furl damper, and numerous damper versions were tested. The original damper designed and bullt by Washington University Technology Associates (WUTA) had an overflow reservoir that was in part filled with compressed air. The damper force at a given damper rate could be varied by changing a valve setting, but the force depended also on the reservoir air pressure. The damper had inear characteristics with the force proportional to the rate. Temperature had a large effect on the damper. For example, the damper rate under 40 ib force changed from $0.5 \mathrm{inch} / \mathrm{s}$ at $20 \mathrm{deg} F$ to 1.0 inch/s at $70 \mathrm{deg} F$. 


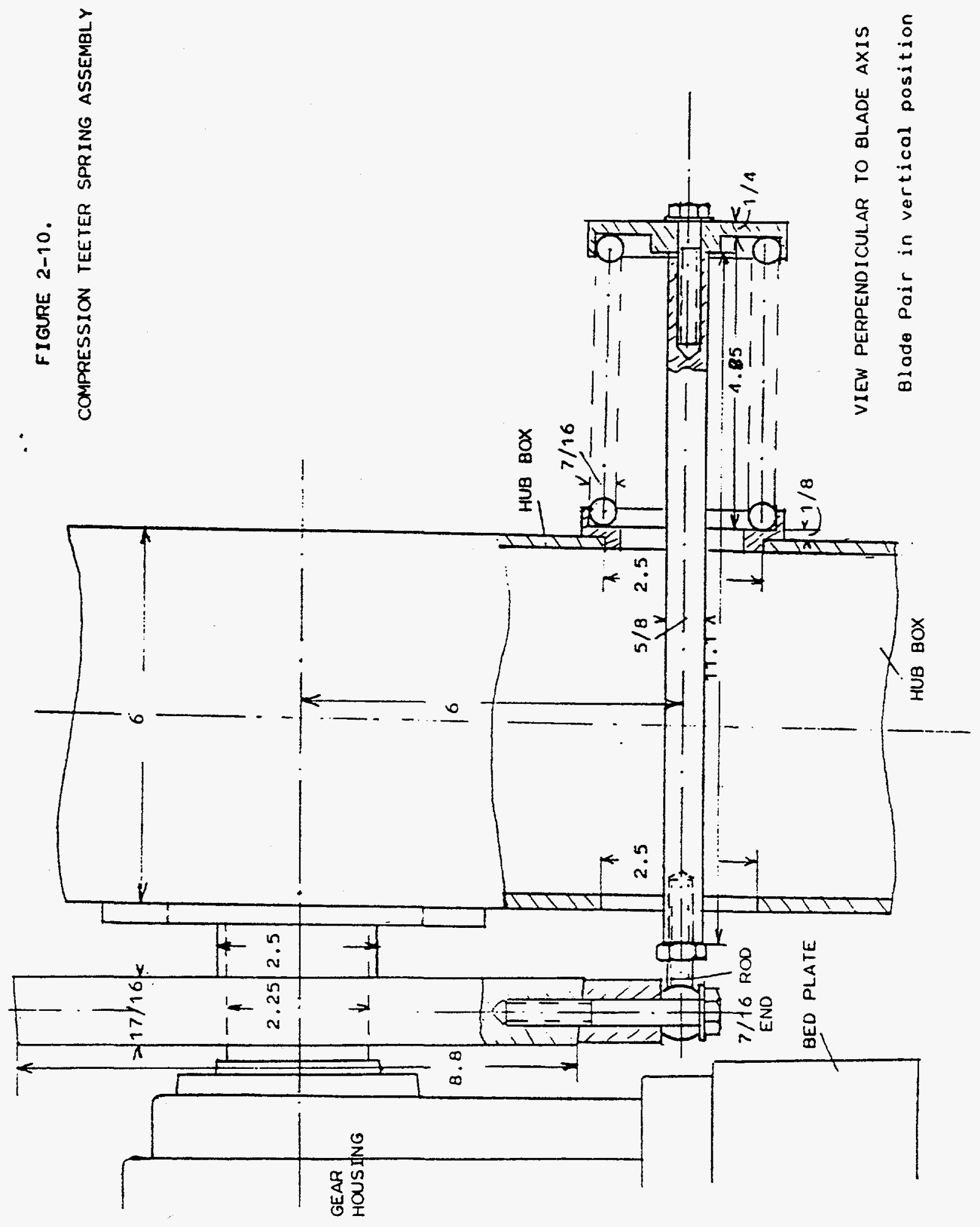


In June of 1982 a damper manufacturered by the Enidine Corporation was installed. It had a rubber sponge material in the cylinder that could soak up the hydraulic fluid displaced by the damper rod when it was retracted into the cylinder. The damper force was proportional to the square of the rate. The force was not adjustable. For a change of damper characteristics an insert containing the fluid passages had to be replaced which required drainage, disassembly, reassembly and refilling of the damper. The original Enidine damper had excessive break-out friction. The damper was returned to the manufacturer and the seals were replaced by 0 -rings which reduced the break-out friction with the piston in the middle range to about 10 lb (44 N). The modified Enidine damper was reinstalled at Tyson in December 1982. The damper, due to the special silicon based hydraulic fluid, retained its characteristics nearly independent of ambient temperature. The first insert produced at $50 \mathrm{lb}(222 \mathrm{~N})$ damper force a damper rate of $1.0 \mathrm{inch} / \mathrm{s}(0.025$ $\mathrm{m} / \mathrm{s}$ ). The same type of insert and the same type of o-rings were used later for the two Proof-of-Concept turbines. In the course of time, three further inserts were acquired and tested at Tyson with damper rates under 50 lb (222 N) force of $0.50 \mathrm{inch} / \mathrm{s}(0.013 \mathrm{~m} / \mathrm{s}), 0.70 \mathrm{inch} / \mathrm{s}(0.018 \mathrm{~m} / \mathrm{s})$ and $1.30 \mathrm{inch} / \mathrm{s}$ $(0.033 \mathrm{~m} / \mathrm{s})$.

The damper was taken off the turbine once and stored for several months in partially compressed position. After reinstalling the damper, it was found to have erratic damping characteristics. The manufacturer was called and gave the belated information that the damper should only be stored in extended position so not to damage the sponge rubber insert. After storing the damper for a few weeks in extended position and after topping the damper fluid, it functioned properly again. Fortunately, when instalied in the turbine, the damper was always in its extended or near extended position except during relatively short high wind periods.

\section{6 .4 Elastic Unfurl Stop}

Fig. 2-12 (a) shows the normal operating condition of the electric actuator with extended piston. Originally, there was no unfurl stop between bed plate and tail vane boom so that the unfurl limit was given by the fully extended damper. This was true also for the Rocky Flats PCP turbine. Unfurl impact forces went into the damper and into the clevis attaching the damper to the bed plate. As a consequence of these impact forces (and of a faulty clevis), the connection of the damper to the bed plate falled. The nacelle then performed oscillations between the furl and unfurl $11 \mathrm{mits}$ ( $87 \mathrm{deg}$ to $-15 \mathrm{deg}$ furl angle) with a period of 5.5 seconds and with a furl and unfurl rate of $50 \mathrm{deg} / \mathrm{s}$. The blade loads during these osclilations were not higher than before the fallure. Since the actuator was disconnected, the rotor had to be stopped manually after the winds dropped below cut-in with the help of the crane and bucket.

The Tyson Proof-of-Concept machine had a much more massive damper clevis taken from the preceding experimental turbine. It could accept the unfur 1 impact loads. A stronger damper clevis was also installed at Rocky flats. As a consequence of the clevis fallure, both machines, thet at Rocky Flats and that at Tyson, received in April 1983 an elastic unfurl stop between nacelle and tall vane boom so that the unfurl impact loads were absorbed by this stop rather than by the damper. Another important advantage of the unfurl stop was that now the damper piston could be placed in the unfurled position about 1.5 


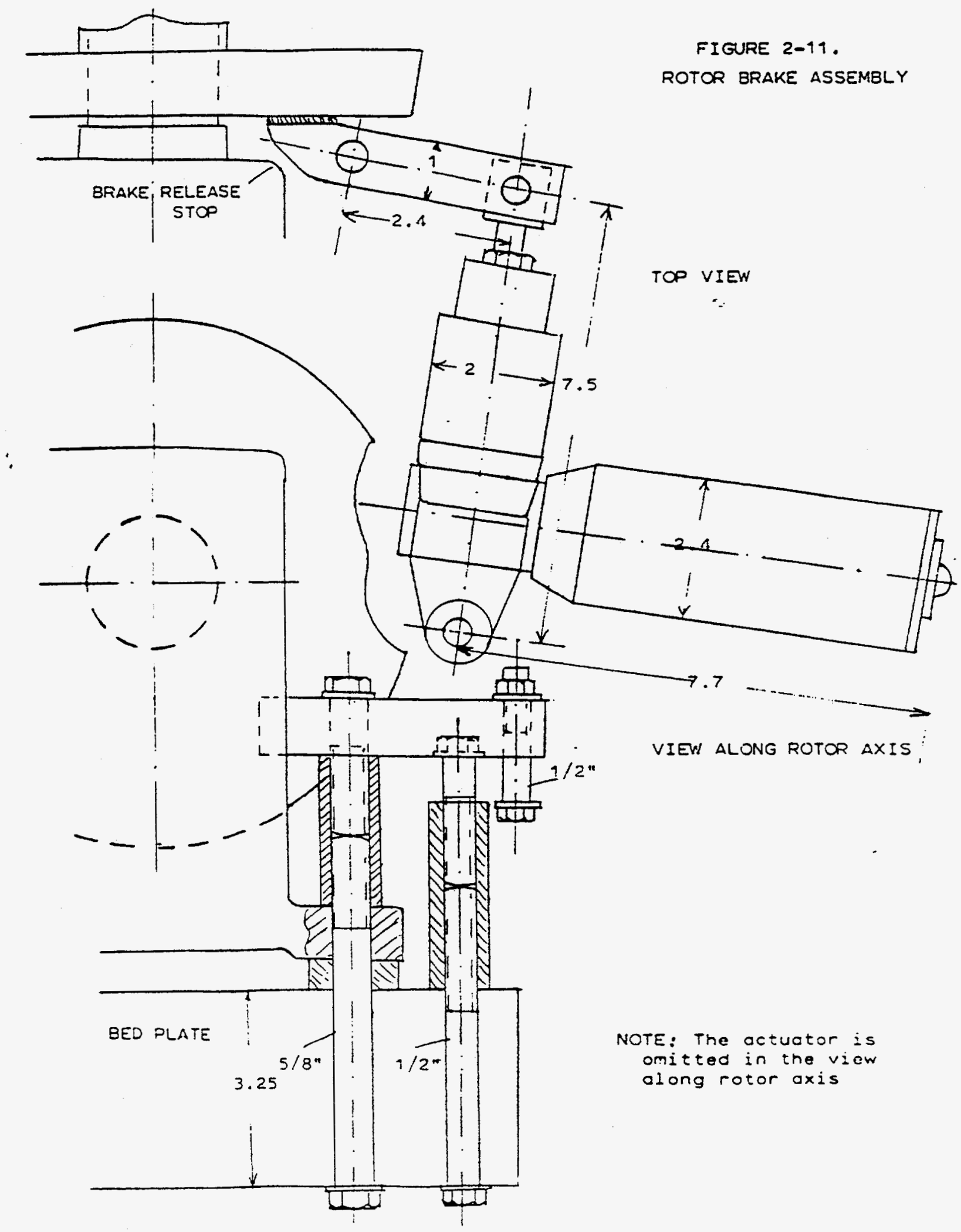



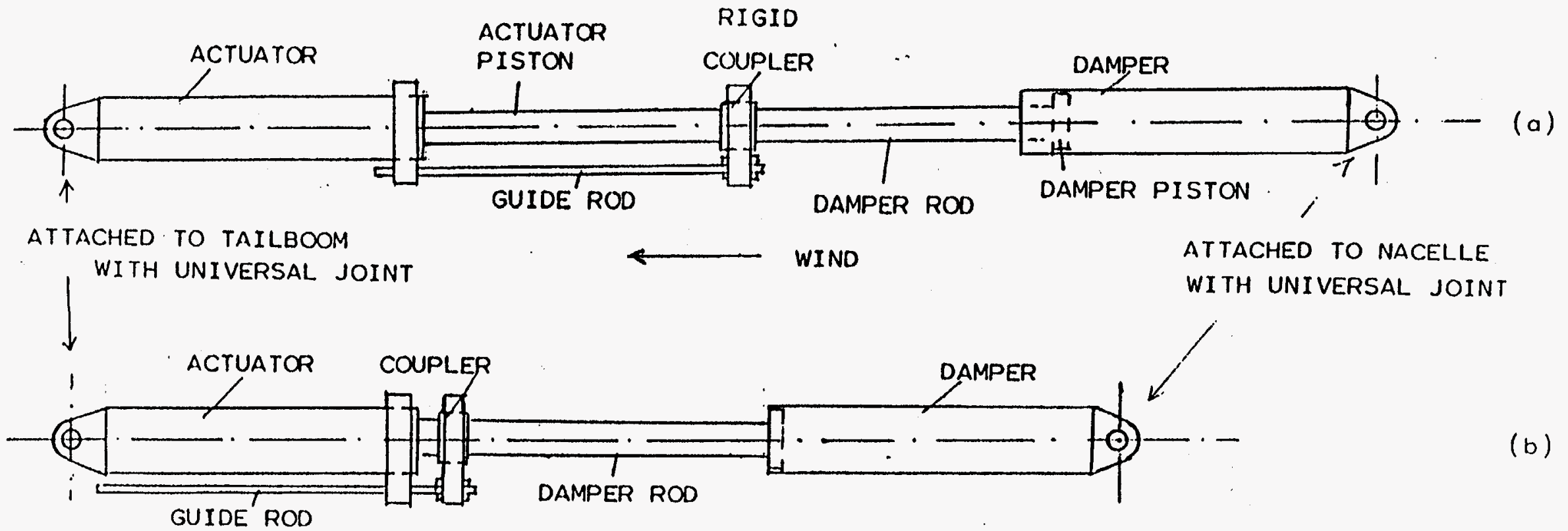

ATTACHED TO NACELLE WITH UNIVERSAL JOINT

$\begin{array}{ll}\text { FIGURE 2-12. ACTUATOR-DAMPER UNIT } & \text { (a) OPERATING CONDITION } \\ & \text { (b) EMERGENCY FURLED }\end{array}$

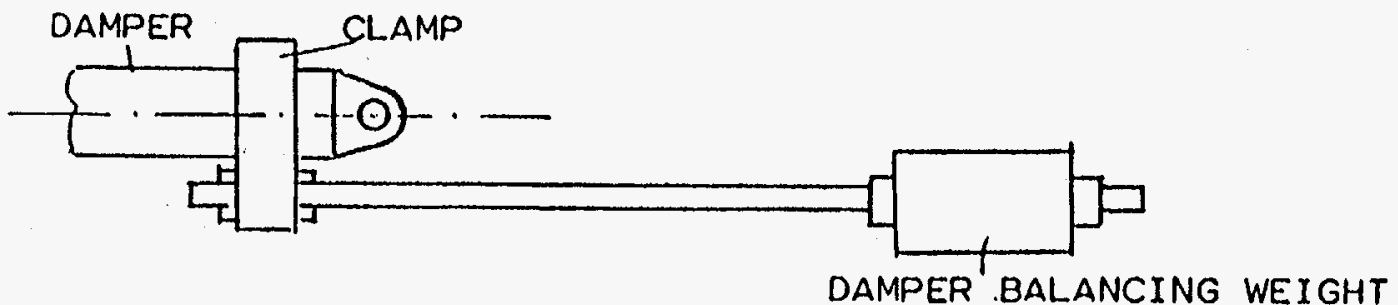

FIGURE 2-13. CLAMPED-ON DAMPER BALANCING WEIGHT 
inch $(0.038 \mathrm{~m})$ away from its fully extended iocation as seen in Fig. $2-12$ (a). This substantially reduced the damper break-out force.

During emergency furling with the actuator the damper rod had to be pulled out all the way as seen in Fig. 2-12 (b). The nacelle was furled to the furl stop, positioned at 87 deg furl angle. This brought the rotor to a stand still up to $30 \mathrm{mph}(13.4 \mathrm{~m} / \mathrm{s})$ wind speed. Whether the rotor will stand still at much higher wind speed when furled to this limit is not known.

\subsubsection{Damper Balancing Weight}

Due to the damper gravity bending moment, the damper break-out friction increased substantially when the piston came close to the fully extended position. In May 1983 the damper for the Tyson turbine, but not for the Rocky Flats machine, was balanced by a device shown in Fig. 2-13 balancing one half of the damper gravity moment about the nacelle attachment bearing. This measure together with placing the piston in the unfurled position 1.5 inch away from fully extended, reduced the damper break-out force in the unfurled condition from $100 \mathrm{lb}(445 \mathrm{~N})$ to $20 \mathrm{lb}(89 \mathrm{~N})$.

\section{$2.6,6$ Furl Limit Switch}

In April 1984 a furl limit switch was added which interrupted actuator power at contact with the furl stop. This limit switch was part of the automatic emergency shut-down equipment installed at Tyson for use during unattended wind turbine operation. The actuator had a slip clutch which allowed a few seconds of operation against the furl stop. However, powering the actuator for an extended period beyond stop contact would have burnt out the slip clutch.

\subsubsection{Stiffer Unfurl Spring}

In May 1984 the unfurl spring with $5.7 \mathrm{lb} /$ inch $(1005 \mathrm{~N} / \mathrm{m}$ ) was exchanged for one with $7.1 \mathrm{lb} /$ inch $(1250 \mathrm{~N} / \mathrm{m})$. The advantage of the stiffer spring was that spring preload adjustments were easier to make. Previously, the rod end had to be reversed for some of the tested high preload conditions which meant disconneting the spring. With the stiffer spring the rod end could remain in place for all spring preload adjustments. 
TABLE 2-2. Changes to Experimental Turbine

\begin{tabular}{lll} 
Date & \multicolumn{1}{c}{ Item } & \multicolumn{1}{c}{ Effect } \\
\hline $5-82$ & Anemometer on Tall Vane & Rotor Wake Measurement \\
$9-82$ & Tail Boom Position Indicator & Total Rotor Yaw Rate \\
$9-82$ & Furl Strain Gage Indicator & Greater Reliability \\
$9-82$ & Blade Airfoll Extension & Earlier Start-up \\
$9-82$ & Larger Tail Vane, Larger Boom & Erratic Yawing Avoided \\
$12-82$ & Increased Transmission Ratio & Blade Stall Study
\end{tabular}

TABLE 2-3. Changes to Proof-of-Concept Turbine (None Made to Rocky Flats PCP Turbine)

\begin{tabular}{lll} 
Date & \multicolumn{1}{c}{ Item } & \multicolumn{1}{c}{ Effect } \\
\hline $4-83$ & Aluminum Disk on Shaft & Supported Teeter Springs \\
$5-83$ & Tension Teeter Springs & Delayed Furling \\
$3-84$ & Emergency Shut-Down System & Unattended Operation \\
$10-84$ & Vibration Shut-Down Switch & Unattended Operation \\
$5-85$ & Compression Teeter Springs & Delayed Furling \\
$5-85$ & Rotor Brake & Tower Tilting in Wind
\end{tabular}

TABLE 2-4. Changes to Furl Control System

Date Item Effect

\begin{tabular}{lll}
\hline $1-82$ & * Actuator Guide Rods & No Actuator Piston Rotation \\
$3-82$ & * Rigid Damper Coupling & No Jack Knifing \\
$6-82$ & * Enidine Damper & Greater Reliability \\
$12-82$ & * Enidine damper O-Rings & Lower Break-Out Friction \\
$4-83$ & * Elastic Unfurl Stop & No damper Impact Loads \\
$5-83$ & Damper Balance Weight & Lower Break-Out Friction \\
$4-84$ & Furl Limit Switch & Unattended Operation \\
$5-84$ & Stiffer Unfurl Spring & Delayed Furling \\
& &
\end{tabular}


SECTION 3.0

ANALYSIS DATA

Though analysis was not a requirement of the subcontract, some analytic data will be given here since they serve to better understand the experimental data. The analysis was limited to the determination of yaw trim conditions and to the prediction of rotor yaw damping and rotor yaw position stability. A complete yaw control dynamics analysis has not as yet been performed. The analysis was based on a model developed in Ref. 3. A slow prescribed rotor yaw oscillation was analyzed and the rotor yaw damping was determined from the response. The model of Ref. 3 also allowed the determination of hub forces and moments as a function of steady yaw angle, thus making a yaw trim analysis possible. The yaw trim analysis results presented in the following were taken from Ref. 4, the rotor yaw damping results from Ref. 5.

\subsection{YAW TRIM ANALYSIS RESULTS}

The equivalent rotor thrust was defined by

$$
\therefore a T_{E Q}-(T a+H S-Q \eta)
$$

The aerodynamic furling moment was $T_{F Q} a$. Without the negative term - $Q \eta$ from rotor axis uptilt angle $\eta$, one would need for torque Iimitation a substantially higher unfurl spring moment. This would drive up the power-off rotor speed. For the selected value of $\eta-7 \mathrm{deg}$ the power loss from axis uptilt angle is small. If teeter springs were used, a fourth term was needed in the expression for $T_{F O}$. The following trim analysis results were obtained without the teeter sping term. In non-dimensional form and using the parameters of the experimental turbine Eq. 3-1 reads

$$
c_{\mathrm{TEQ}}-c_{\mathrm{T}}+7.8 c_{\mathrm{H}}-5.0 c_{\mathrm{Q}}
$$

Aerodynamically more meaningful are these coefficients when divided by the blade solidity ratio.

Fig. $3-1$ taken from Ref. 4 shows $\mathrm{c}_{\mathrm{TEO}} / \sigma$ vs. rotor furl angle for $200 \mathrm{RPM}$. The two sets of solid lines represent cotstant torque coefficient $c_{o} / \sigma$ and constant speed ratio $\mathrm{V} / \Omega R$. Estimates of the nacelle yawing moment without rotor were included in the determination of the horizontal force coefficient $c_{H}$. The dashed line represents the unfurling moment of the tension spring in terms of $c_{T E O} / \sigma$. The reduction in spring moment for furl angles over 60 deg was caused by the spring kinematics since the center-line of the tension spring had at high furl angles a smaller moment arm with respect to the furl axis than at medium furl angles. Trim balance was obtained when the aerodynamic furling moment was equal to the spring unfurling moment. Following the dashed line from left to right, it is seen that increasing wind speed caused increasing furl trim angles. Up to 40 deg furl angle and up to a speed ratio of 0.17 the rotor torque remained nearly constant. For higher wind speed the rotor torque diminished and reached zero at $V / \Omega R-0.31$. Due 


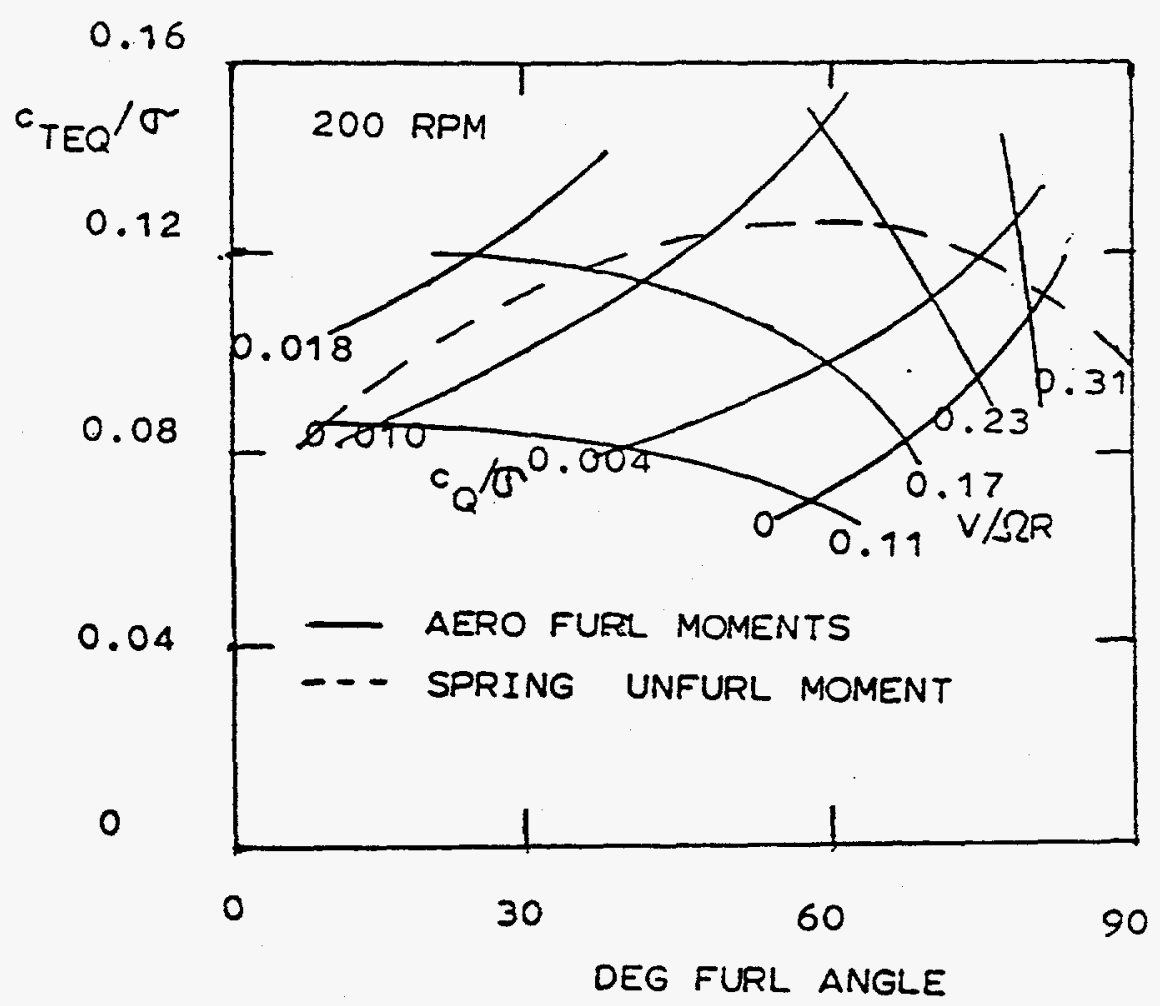

FIGURE 3-1. EQUIVALENT ROTOR THRUST COEFFICIENT VS. FURL ANGLE

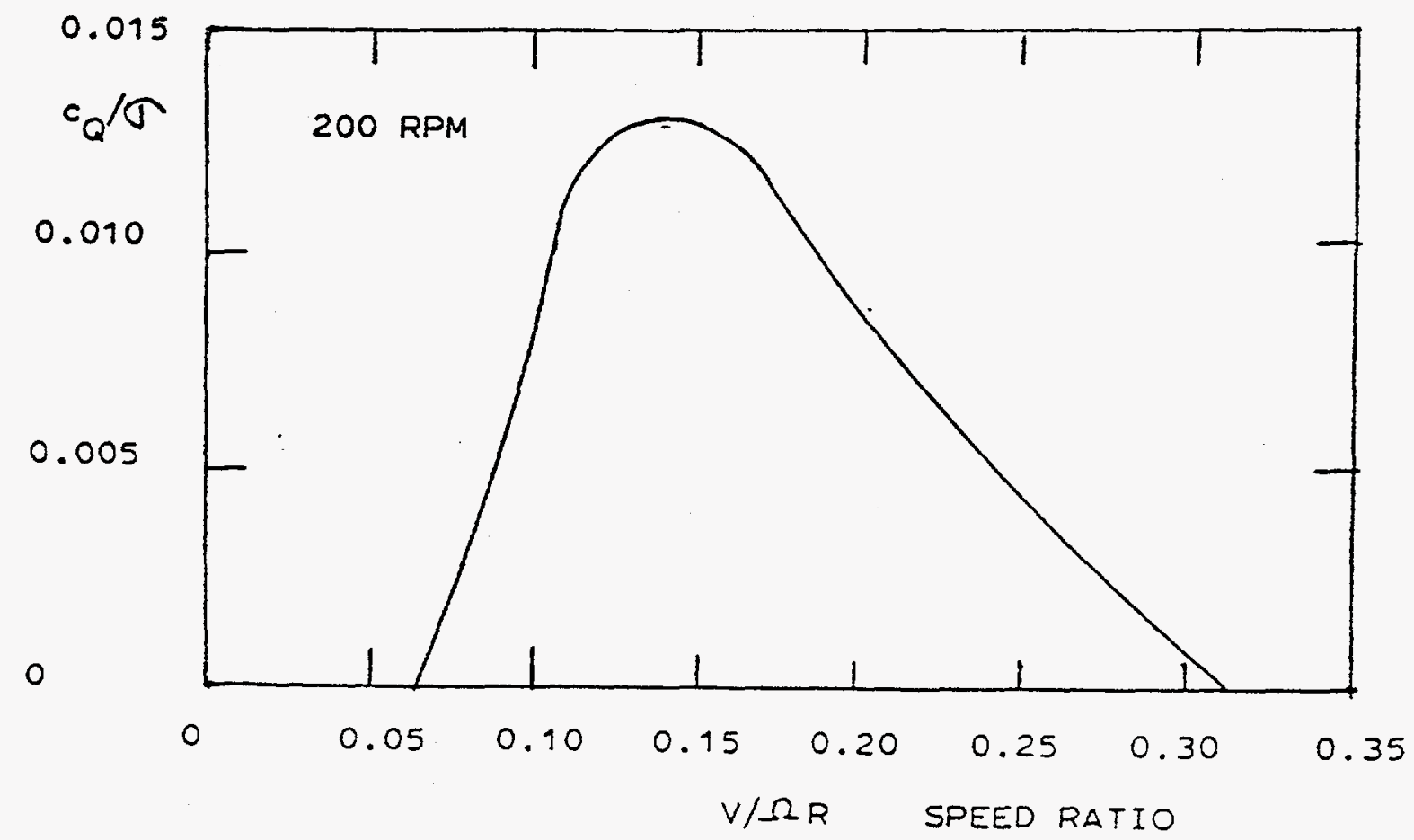

FIGURE 3-2. TORQUE COEFFICIENT VS. SPEED RATIO 
to the steep negative slopes of the lines of constant $V / \Omega R$ at high furl angles, the trim position at a given wind speed was always stable despite of the negative spring moment slope. This means that at a given wind speed an increase in furl angle was always associated with an unfurling restoring moment.

Fig. 3-2 shows at 200 RPM the trim values of the torque coefficient $c_{0} / \sigma$ vs. the speed ratio $V / \Omega R$. Generator cut-in speed was $V / \Omega R-0.07$ and cut-out speed was $V / \Omega R=0.31$. Fig. $3-3$ shows power-off $R P M$ and furl angle vs. wind speed from analysis (solid line) and from a test on April 3, 1982 (crosses). The test results will be discussed later. Maximum power-off RPM was reached at $20 \mathrm{mph}(9 \mathrm{~m} / \mathrm{s})$ wind speed. At $50 \mathrm{mph}(22 \mathrm{~m} / \mathrm{s})$ the rotor speed was down again to $200 \mathrm{RPM}$. Beyond $50 \mathrm{mph}(22 \mathrm{~m} / \mathrm{s})$ the RPM should drop below 200 .

It should be noted that the digital controller cut power out when the generator speed was below synchronous and cut power in when the speed was above synchronous. The grid disconnect at $V / \Omega R-0.31$ or $50 \mathrm{mph}(22 \mathrm{~m} / \mathrm{s})$ wind speed was, therefore, automatic without the necessity of any wind speed signal, the grid connection at $V / \Omega R-0.07$ or $11 \mathrm{mph}(5 \mathrm{~m} / \mathrm{s}$ ) was also automatic and needed no wind speed measurement. Due to fluctuating wind speed it was unavoldable that in the vicinity of the cut-in and cut-out velocities frequent on and off generator switches occurred. Due to the two seoond delay built into the digital controller this was acceptable though some motoring losses were involved.

\subsection{ANALYSIS RESULTS ON ROTOR YAW DAMPING AND YAW POSITION STABIIITY}

The analytical model developed in Ref. 3 was used in Ref. 5 to determine rotor yaw damping and rotor yaw position stabllity as a function of teeter spring stiffness. The latter was characterized by the paramecer $P$ which represents at a given rotor speed the teeter natural frequency with teeter springs over that without teeter springs, omitting aerodynamic effects. The paramter $P$ - 1 is nearly proportional to the teeter spring stiffness. For given teeter springs, $P$ is a function of rotor speed and becomes larger at lower rotor speed. The total teeter stiffness (without aerodynamic effects) is the sum of the spring stiffness and the centrifugal stiffness. At lower rotor speed the latter becomes less in comparison to the teeter spring stiffness so that the relative spring effect becomes larger.

The two upper graphs of Fig. $3-4$ show the results of the rotor yaw damping analysis for $\delta_{3}-0$ and $67 \mathrm{deg}$. The main parameters affecting the results are thrust coefficient $c_{T} / \sigma$, angular rotor speed $\Omega$. Lock number $\gamma$, rotor diameter $D$ and rotor overhang $S$. It was found that the rotor yaw damping moment was nearly proportional to the yaw rate. Thus only one yaw rate of $0.5 \mathrm{rad} / \mathrm{s}$ is shown in Fig. 3-4. The remaining parameters are listed on top of this figure. The yaw damping moment was assumed to be positive when directed opposite to the yaw rate. The mean spring hub moment is represented by the top dashed Iines of the upper two graphs and contributed to positive yaw damping. The yaw rate produced a tilting of the rotor tip path plane with associated thrust and torque vector tilting and with an associated horfzontal side force. For an upwind rotor all these effects produced a negative rotor yaw damping. The aerodynamic effects due to the nacelle without rotor were omitted for Fig. 3-4. It is seen that without teeter 

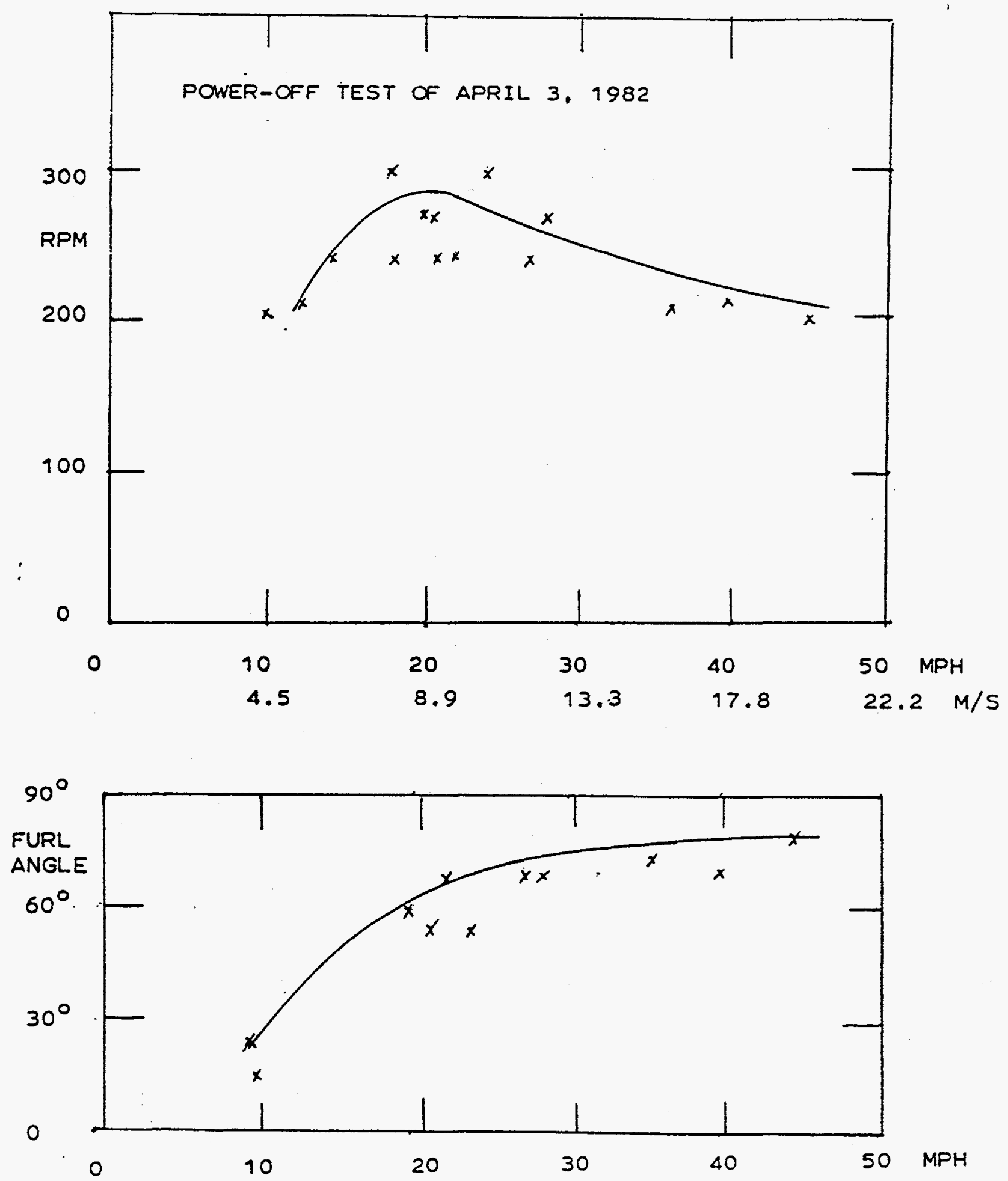

FIGURE 3-3. POWER-OFF RPM AND FURL ANGLE FROM TRIM ANALYSIS ( SOLID LINE) AND FROM TEST DATA 
springs $(P-1.0)$ the yaw damping moment was negative and that a certain $P$ value was needed to obtain zero yaw damping. For $\delta_{3}$ - 0 this value was $P=$ 1.035. For $\delta_{3}-67 \mathrm{deg}$ this value was $P-1.09$. The actual spring moment was the same in both cases as can be seen from the lower graph of Fig. $3-4$. K $\beta$ is the amplitude of the teeter spring moment, 2 I $\dot{x}$ is a reference moment used to non-dimensionalize $K \beta$. The line of zero yaw damping is horizontal which means that the teeter spring moment for zero yaw damping was independent of $\delta_{3}$.

At operational rotor speed the configuration with the tension teeter springs at Tyson $\left(\delta_{3}-67 \mathrm{deg}\right)$ had a value of $\mathrm{P}-1.022$ and with tension plus compression teeter springs a value of $\mathrm{P}-1.051$. Thus, according to the analysis, the rotor yaw damping was still negative with both sets of teeter springs. The results of a simplified analysis of the teeter amplitudes from rotor yaw rates were presented in Ref. 6 and compared with Rocky flats test results using the Proof-of-Concept PCP wind turbine which had no teeter springs. For low wind speed, analysis and test results were in reasonable agreement.

Fig. 3-5 taken from Ref. 5 shows for the same parameters listed in Fig. 3-4 the rotor yawing moment vs, steady yaw angle for two P-values ( 1.0 and 1.05$)$ and for two $\delta_{3}$ values ( 0 and $67 \mathrm{deg}$ ). Negative moments indicate negative position stability when the yawing moment tends to increase the yaw angle. At $\delta_{3}-0$, approximately neutral yaw position stability was obtained for $P$ 1.05 , a value which according to Fig. $3-4$ would also eliminate negative yaw damping. At $\delta_{3}-67 \mathrm{deg}$, a higher $\mathrm{p}$-value was needed. A value of $\mathrm{P}-1.09$ which removed negative rotor yaw damping should come close to removing also negative yaw position stability. At the maximum $P$-value achieved with the Tyson machine, $P=1.051$, Fig. $3-5$ shows negative rotor yaw position stability.

It should be noted that neither Fig. $3-4$ nor Fig. 3.5 included yawing moments from rotor axis lateral off-set and from rotor axis uptilt. For the rotor yaw damping data of Fig. 3-4 this should lead to only small corrections since neither the mean thrust nor the mean torque were much affected by the yaw rate. However, thrust and torque are greatly affected by rotor yaw angle so that including thrust off-set and torque vector up-tilt angle, Fig. 3-5 would change drastically. The trim analysis results shown in Fig. 3-1 included the moments of Fig. $3-5$ and indicated that for fixed tail vane yaw angle the nacelle yaw position stability was positive as explained in the preceding subsection. 


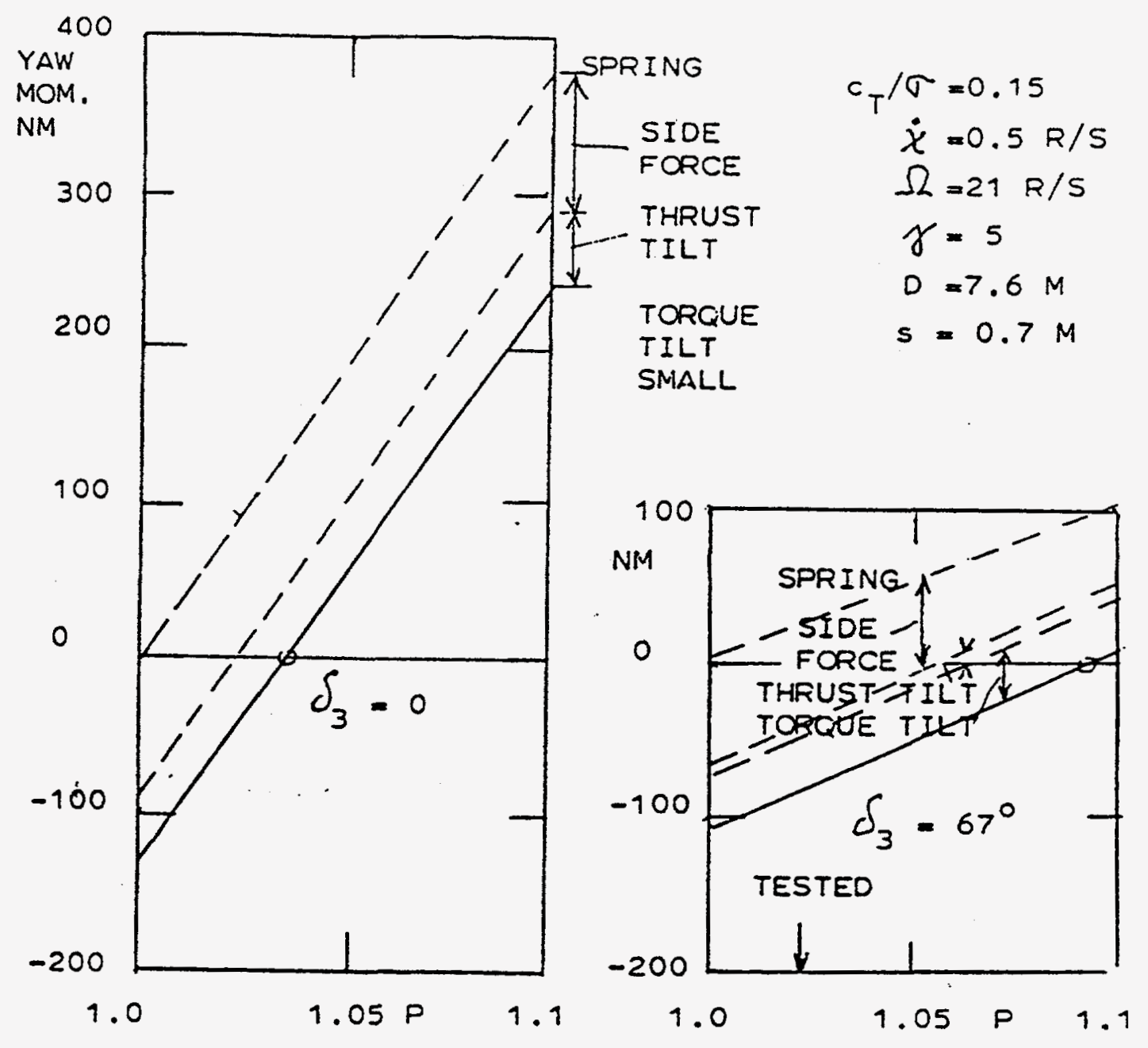

(a)

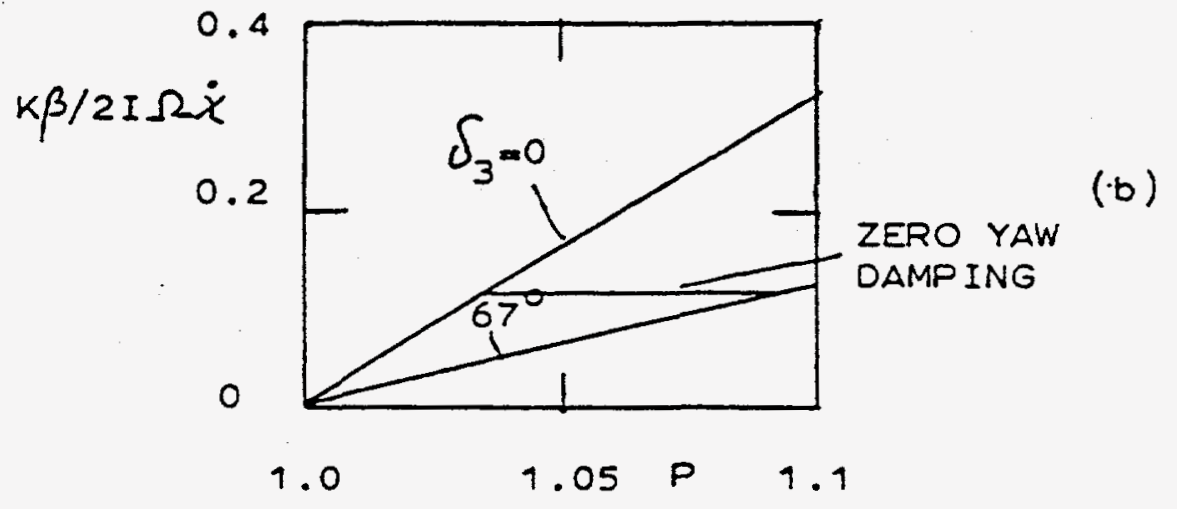

FIGURE 3-4. ROTOR YAW DAMPING MOMENTS (a) AND NON-DIMENSIONAL HUB MOMENTS (b) VS. TEETER SPRING STIFFNESS $P-1$ 


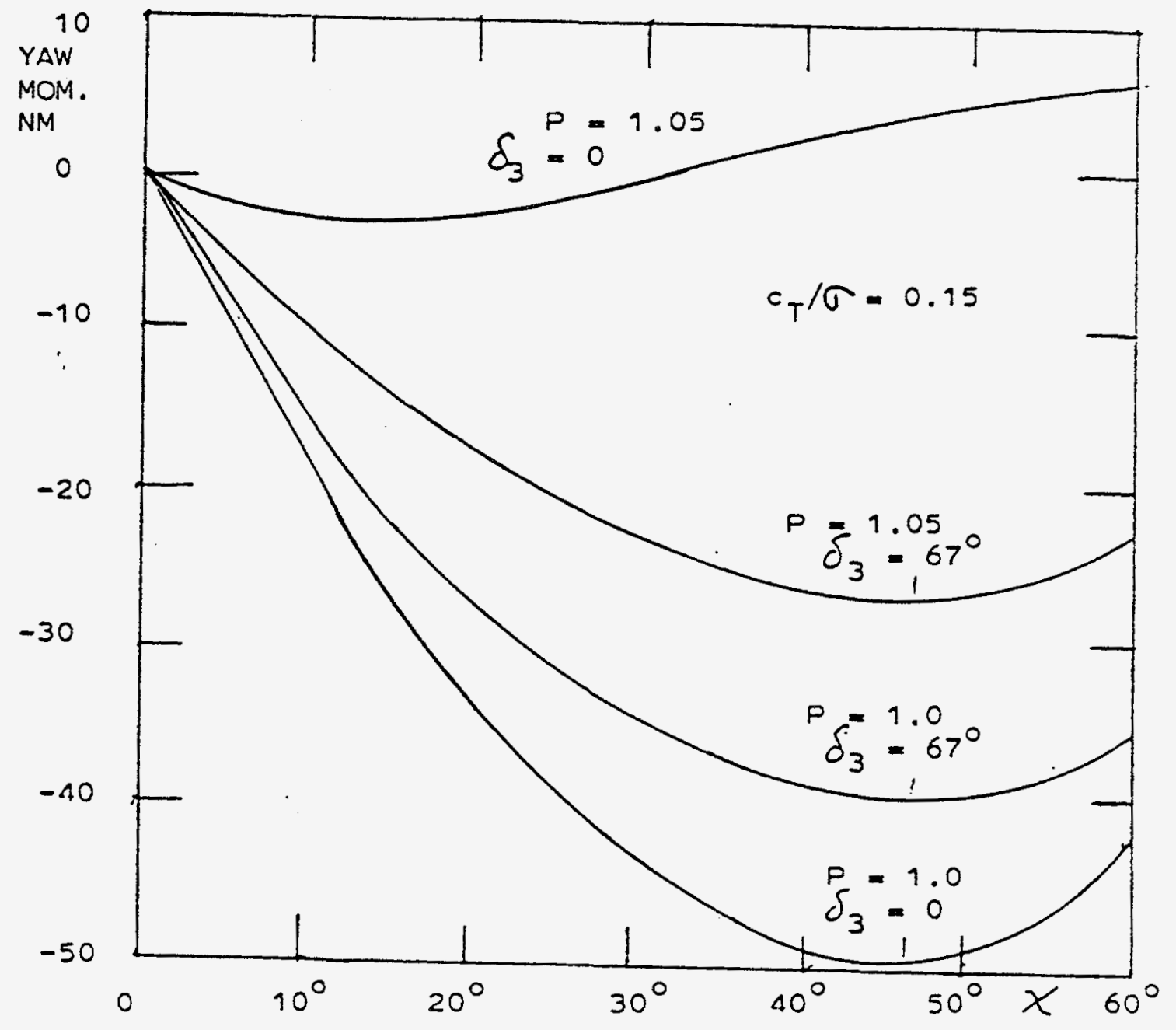

FIGURE 3-5. ROTOR YAWING MOMENT VS. YAW ANGLE 


\section{SECTION 4.0}

TEST DATA

The modified experimental wind turbine was tested for 24 days between January 1982 and January 1983. The number of tower raisings since May 1980 increased from 72 to 99 , an addition of 27 (not all ralsings were followed by a test). The number of operational hours since May 1980 increased from 141 to 190, an addition of 49 hours.

The Proof-of-Concept wind turbine was tested for 31 days between April 1983 and October 1985. The number of tower raisings since May 1980 was 127, an addition of 28 since installing the Proof-of-Concept turbine, the number of operating hours was 113 for this machine, of which 60 were unattended.

\subsection{EXPERIMENTAL TURBINE}

Móst of the 24 runs with the modified experimental turbine showed results that were affected by some mechanical deficiencies or by some inappropriate settings of parameters like furl angle range, uptilt angle of the rotor axis, spring preload, damper rate etc. The removal of the large furl bearing frictior by the modification to Fig. 2-1 (b) configuration had a very substani:ai effect and required a stiffer damper and a higher preload of the unfurl sp:ing. The furling motion lost its jerkiness and became smoother, though tri:ially there was excessive break-out friction of the Enidine damper. The early tests of the modified turbine showed severe instabilities from jack kntfing of the actuator-damper unit. The phenomenon was removed in several steps by first blocking the pin movement of the clevis between actuato: and damper and by finally inserting the rigid coupler shown in Fig. 2-12. The deficiencies caused by the original tail vane and boom (erratic yawing power-on at low wind speed, 1 p vertical tail resonance, 4 P bursts of rotor torque and nacelle vibrations at high power) were discussed in Section 2 and were corrected in September 1982 by installing a larger tail vane and a longer tail boom.

\subsubsection{Analog Data}

Power-off, the passive furl control system worked well and behaved approximately as predicted by the trim analysis. This can be seen in Fig. 3 . 3 where the power-off analytic trim values for RPM and furl angle are compared to test data taken on April 3, 1982. The wind was extremely turbulent and sometimes fluctuated between 20 and $50 \mathrm{mph}$ ( 9 and $22 \mathrm{~m} / \mathrm{s}$ ) within two seconds. Nevertheless, the furl angle and RPM variations were small even in severe gusts. The blade loads were also acceptable. From these tests benign storm survival in autorotation seems to be assured. 
FLOW ANGLE OF TAIL VANE $\pm 22^{\circ}$
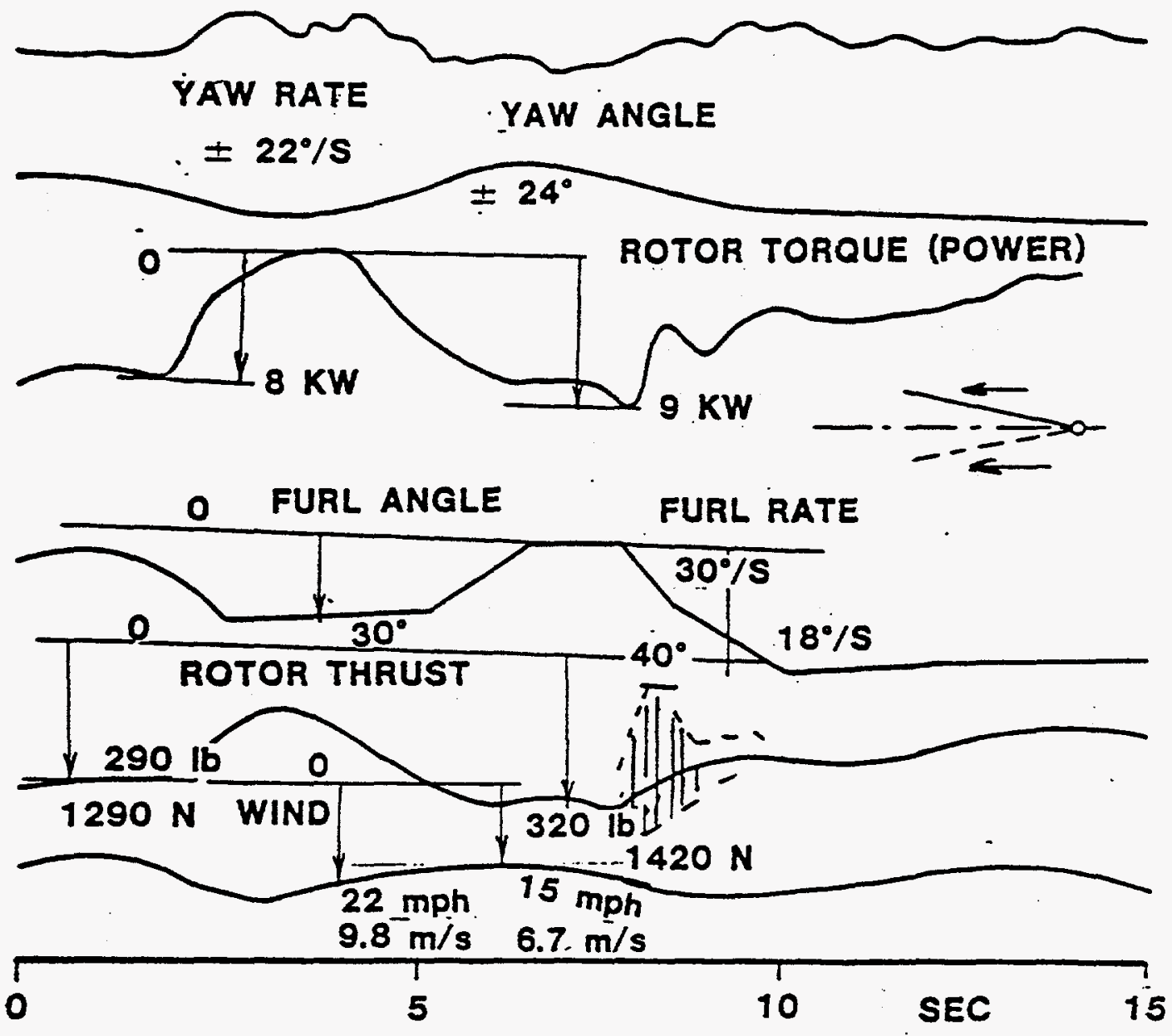

FIGURE 4-1. OSCILLOGRAPH RECORD FOR YAW OSCILLATION, OCTOBER 20, 1982 
The power-on behavior in turbulence was, however, less satisfactory. A typical power-on time history taken from Ref. 4 is shown in Fig. $4-1$ and was measured on october 20, 1982. The two top curves represent flow angle relative to the vane and vane yaw angle relative to the mast. They are in phase and have about the same amplitude indicating that the wind direction was approximately steady. The lowest curve represents the wind velocity measured $17 \mathrm{ft}(5.2 \mathrm{~m})$ below the rotor center. The wind speed oscillated between 15 and $22 \mathrm{mph}(6.7$ and $9.8 \mathrm{~m} / \mathrm{s}$ ) with a period of about 6 seconds which was the natural period of the tail vane. This explains the large tail vane yaw amplitude without wind direction change. The furl angle time history is somewhat uneven because the damper had at that time a large breakout friction force. However, it is clearly seen that on-set of furling occurred at the time of maximum yaw vane furl rate, and on-set of unfurling occurred at the time of maximum vane yaw rate in the unfurl direction. The rotor yaw angle change from combined tail vane yawing and rotor furling was \pm $50 \mathrm{deg}$ and explains the large fluctuations in rotor torque and rotor thrust. As mentioned before, according to the analysis, rotor torque and thrust are mainly a function of rotor yaw angle, not of rotor yaw rate. The rotor power varied between 0 and $9 \mathrm{~kW}$, the rotor thrust varied between 100 and $3001 \mathrm{~b}$ $(45,0$ and $1340 \mathrm{~N})$. In contrast, power-off tests showed that tail vane yawing and rotor furling were mostly uncoupled. Apparently, the variable rotor speed and the lower negative rotor yaw damping reduced the coupling between vane yawing and rotor furling.

Many parameter changes were tried to obtain a better power-on turbulence response. Neither changes in uptilt angle of the rotor axis in the range of 7 to 10.5 deg nor changes in the unfurl spring preload and in spring kinematics had an effect on the basic dynamic behavior, though the proper combination of spring preload and uptilt angle was important for the energy capture. The effects of teeter springs and of damper rates will be discussed later.

\subsubsection{Wind Speed at Tail Vane}

The test results shown in Fig. 4-1 were obtained with the larger tail vane and the longer tail boom. Except for the effects mentioned before, furl dynamics was not affected by this modification. Wind speed measurements with a second a nemometer on top of the tail vane installed in May 1982 have shown that unfurled power-on operation reduced the mean wind speed at the tail vane by a factor of 0.7 . With non-rotating furled rotor the tail vane anemometer indicated at $11 \mathrm{mph}(5 \mathrm{~m} / \mathrm{s})$ wind speed the same mean value as the $22 \mathrm{ft}(6.7$ M) Lower tower anemometer. For higher speed, the upper anemometer indicated a lower mean speed than the tower anemometer which amounted to a reverse wind speed gradient as compared to that in the earth's boundary layer. The reason was the potential flow perpendicular to the ridge on which the turbine was located. All tests were conducted in westerly winds which would produce this ridge effect. Due to this effect, the measured wind speeds in the test regime were higher than at the rotor center so that the performance data were conservative. The tail vane anemometer was not normally used and all data were correlated with the lower anemometer. 

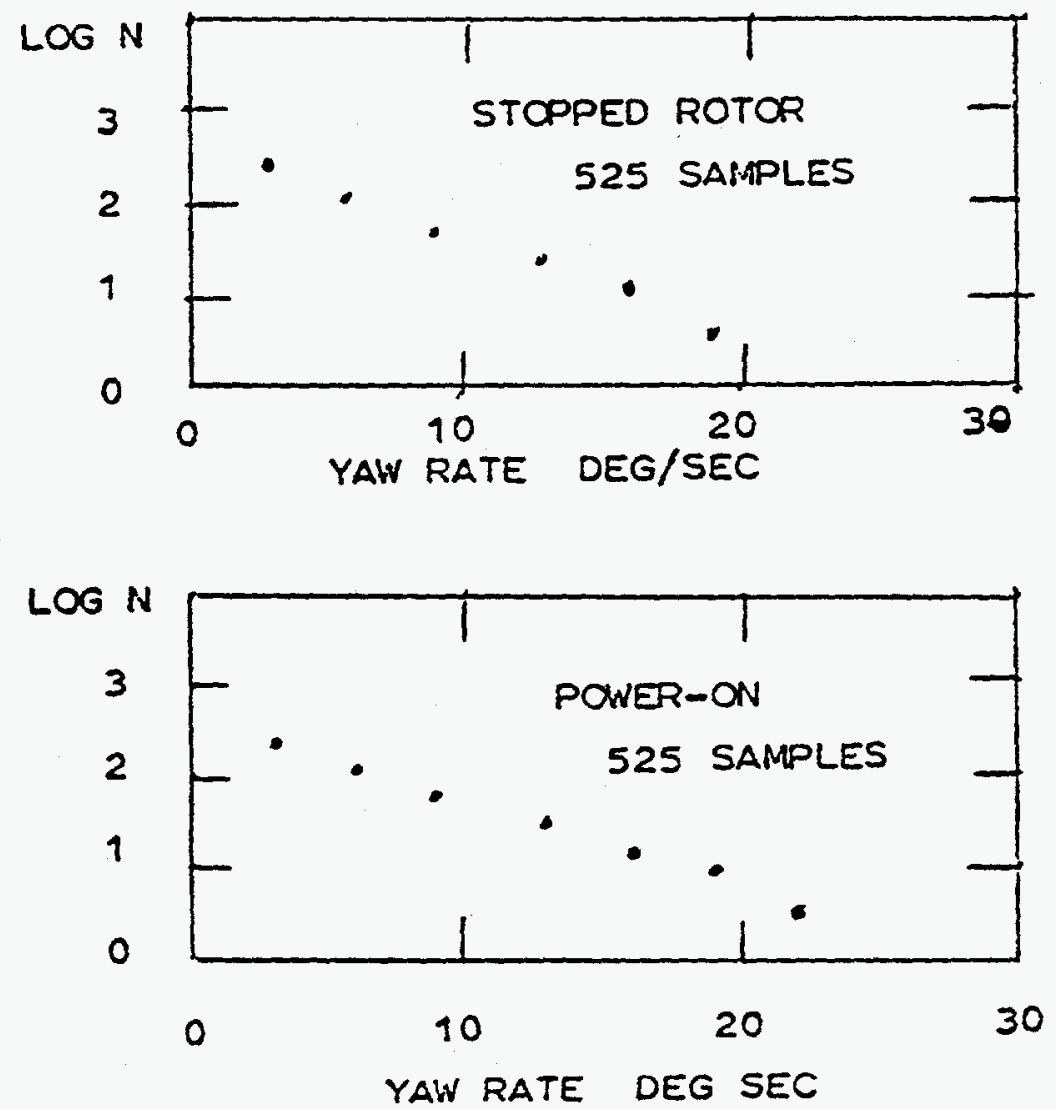

FIGURE 4-2. YAW RATE DISTRIBUTION, NOVEMBER 12.1982 


\subsubsection{Statistical Data}

While in the case represented by Fig. 4-I the periodic wind speed variations were the cause of the tail vane oscillations, statistically this appears to be a rare event as can be concluded from Fig. 4-2 also taken from Ref. 4 . On November 12, 1982, the yaw rate distribution of the tail vane was measured with stopped rotor and in power-on operation. The two distributions were almost the same. Thus the off-set rotor thrust seemed to have little effect on the yaw oscillations which were statistically mainly caused by wind direction changes.

A typical statistical evaluation of a test run made on October 10,1982 is shown in Fig. 4-3, also taken from Ref. 4. The left upper graph shows the wind speed distribution in terms of $\log N$ ( $N$ is the number of samples per wind speed bin). The other three graphs give means and standard deviations of furl angle, rotor power (computed from the measured rotor torque and rotor speed) and cyclic pitch amplitude for each wind speed bin. While this run was made in a condition of moderate turbulence, Fig. 4-4 shows the measured furl angle means and standard deviations for a high turbulence test on November 12, 1982. Both mean and standard deviation for the furl angle are substantially higher for the same wind speed bins.

The data shown in Figs. 4-3 and 4-4 made use of a machine language program for the Apple II computer. 128 samples were taken during one second about every three seconds and assigned to a wind speed bin from a single wind speed sample taken at the beginning of the sampling period. Mean and standard deviation for each wind speed bin were updated for each sample set. The problem with this method was that the measured wind speed at the anemometer site was not the average wind speed that the rotor experienced. In $\operatorname{Ref} .7$ i.t is shown that preaveraging of the data before application of the method of bins will low-pass filter the data and reduce the scatter in the bins. The correct preaveraging time is a function of the anemometer location and increases with axial, horizontal and vertical displacement from the rotor center. Also, due to the difference between a point wind speed measurement and the average wind speed over the rotor disk, a filtering effect will occur that $c$ an be simulated by a certain preaveraging time. If this time exceeds the correct time, as it usually does in wind systems performance measurements, meaningful data are discarded. If the preaveraging time is less than the correct time, the data contain turbulence inputs to the anemometer that are unrelated to the response of the wind energy system which is the case with the Fig. 4-3 and Fig. 4-4 data. Unfortunately, the computer input data had to be discarded after the means and standard deviations had been determined for each wind speed bin so that there was no way to afterwards correct the data for the effects discussed. However, oscillograph data were preserved and could be preaveraged later. The results of preaveraging will be discussed in Subsection 4.2.3. 

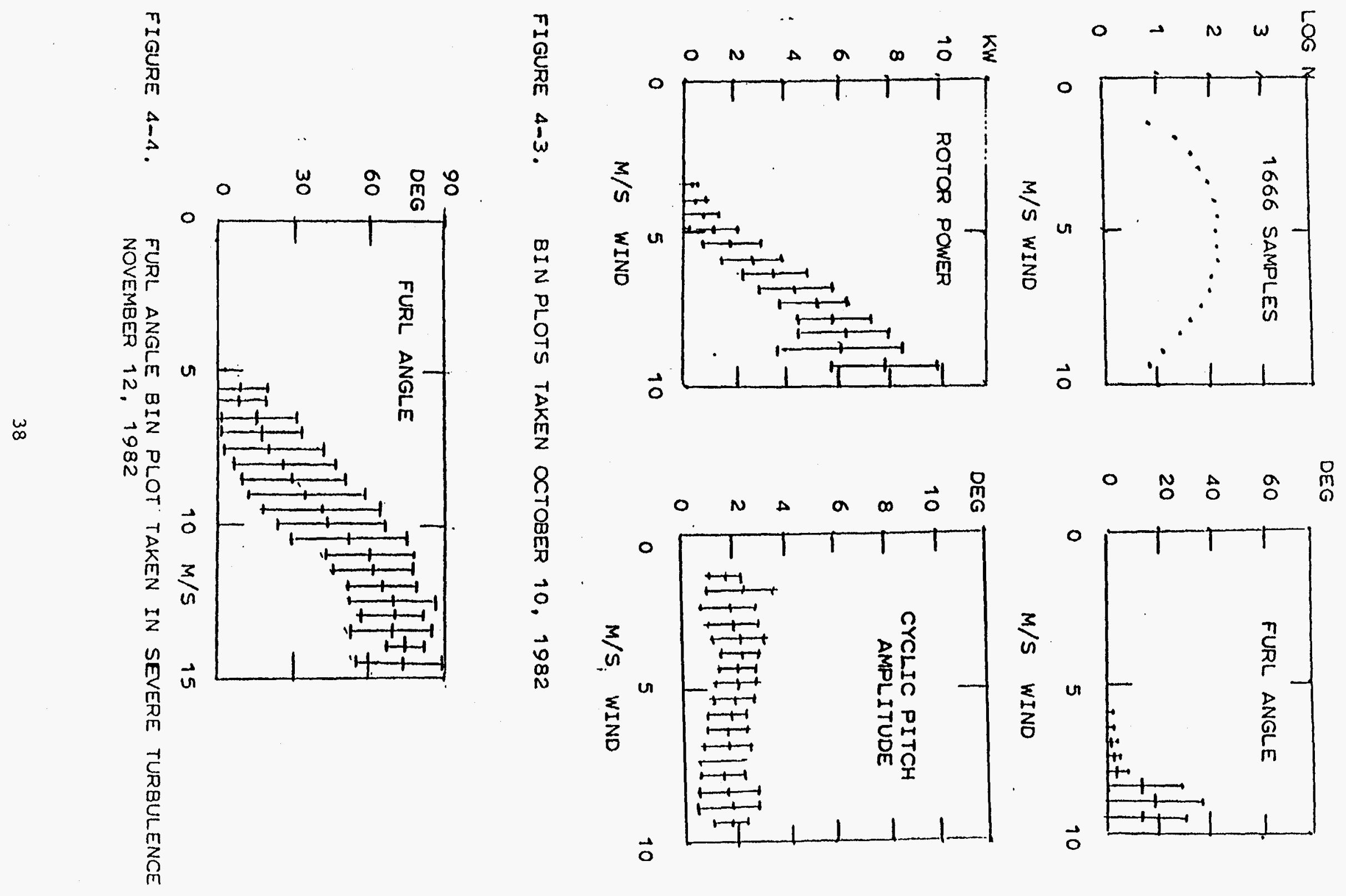


\section{1 .4 Tests with Stalled Blades}

In December 1982, the transmission ratio was changed from $9.37: 1$ to 12.5 : 1. At the same time the elastic teeter stops were narrowed from \pm 11 deg to \pm 5 deg of free travel to lower the impacts in case of blade stall. The damper was changed to give in the furl direction 50 more damping than in the unfurl direction. This led to a very low maximum furl rate of only $5 \mathrm{deg} / \mathrm{s}$ vs. a maximum unfurl rate of $20 \mathrm{deg} / \mathrm{s}$. On January 15,1983 the rotor reached the stall regime and strong teeter impact loads occurred. As a consequence, the teeter bearings suffered some wear, and the elastic teeter stops were damaged. Blade stall was delayed far beyond the expected limit. Fig. 4-5 shows the torque coefficient ${ }^{c}{ }_{Q} / \sigma$ vs. speed ratio $V / \Omega R$. The test points

represent mean values from a large number of analog data selected during periods of nearly steady wind speed. The dashed line was obtained from the prop code using two-dimensional airfoil data. Above $c_{Q} / \sigma=0.02$ this

analysis was in error by a large margin. The solid line was obtained with the NASA stall model described in Ref. 8. In agreement with the test results this model predicted more than twice the maximum rotor torque.

Fig. 4-6 shows the blade angles of attack obtained with the NASA model for four tipspeed ratios $\Omega R . V$. The tests were conducted up to $\Omega R / N-3$ where the entire blade is stalled. At $\Omega R / v-4\left(c_{Q} / \sigma-0.03\right)$ only the inner portion of the blade is stalled. The blade will be nearly unstalled at $c_{Q} / \sigma-0.02$ which should be considered a maximum value to be used in teetered rotors. This value corresponds to $7 \mathrm{~kW}$ rotor power at 12.5 transmission ratio, and to $17 \mathrm{KW}$ rotor power at 9.4 transmission ratio. Thus the lower gear ratio turbine with a maximum rotor power of $10 \mathrm{KW}$ (see Eig. 4-3) operated unfurled with a wide stall margin.

\subsection{PROOF-OF-CONCEPT TURBINE}

Many of the 29 test runs with the Proof-of-Concept turbine were also affected by equipment deficiencies and had to be repeated after corrections were made. The first four runs were needed to solve the problems of operating the three phase generator with single phase current, discussed in Subsection 2.2. The emergency shut-down system, particularly the vibration shut-down part, required many adjustment runs before it worked properly. The tower winch failed and had to be replaced. The hydraulic tower lifter failed severa? times and needed replacements. The electric actuator power unit accumulated water while the tower was down and had to be replaced several times and better sealed. The furl strain gage bridge failed and was replaced. The Vishay strain gage signal conditioner needed repair from time to time. The pinned belt driving the tail vane yaw potentiometer stretched and slipped off the sprockets so that an important piece of data was missing. Several times a suitable wind was not utilized because the Corps test engineer was not avail. able due to higher priority assignments. The first unattended run, Octobe: 19 to 22, 1984, was terminated because the anemometer and the furl indicator 


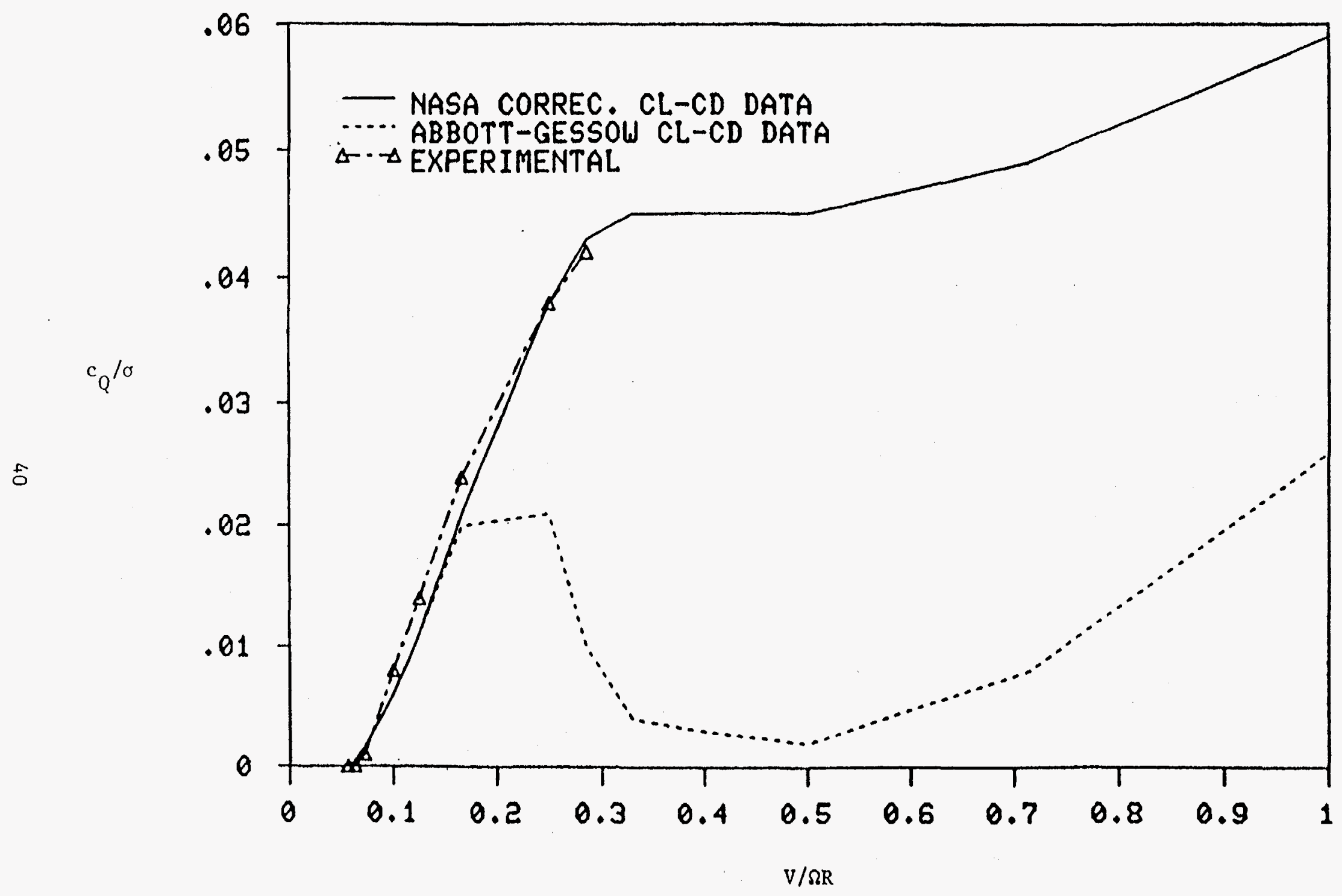

FIGURE 4-5. TORQUE COEFFICIENT FOR UNFURLED OPERATION VS. SPEED RATIO, JANUARY 15. 1983. PROP CODE DOTTED LINE. NASA MOOEL SOLID LINE 
failed. The second unattended run, October 24 to 27,1984 was terminated by the tripping of the circuit breaker from generator overload. Due to this overload condition it was decided not to continue the unattended runs. However, the tower was left in the raised position with furled rotor between November 17, 1984 and January 19, 1985. During these two months there was harsh winter weather with high storm velocities. Except for some instrument deterioration no damage was observed. The wire bundle inside the tower was not noticeably twisted.

\subsubsection{Vibration Data}

Vibration tests with raised tower and non-rotating turbine were conducted in october, 1983. Upon impact excitation of the blades, two natural frequencies were observed in the oscillograph trace of the bed plate accelerometer; 8.0 and $2.0 \mathrm{~Hz}$. The first was the blade coning frequency and it agreed with measurements made earlier with the rotor alone before installation on the tower. The second frequency was that of the fundamental tower bending mode which could also be observed as a 1 P resonance at 120 RPM during rotor start-up. It was not clear why a much lower blade coning frequency of $6.3 \mathrm{~Hz}$ had been determined at Rocky Flats.

It was found that the damper configuration had a large effect on nacelle vibrations. The damper force was proportional to the square of the damper rate so that the damper provided at high frequencies a rather rigid connection between nacelle and tail vane boom. The nacelle yawing oscillation, due to the uptilt angles of the rotor and generator axes, produced power-on rotor torque and generator current oscillations. Thus the nacelle yawing vibration was seen not only in the bed plate accelerometer trace but also in the generator current trace. The nacelle natural frequency could be best determined from the motion following an unfurl stop impact. The relation between the damper rate under $50 \mathrm{lb}(222 \mathrm{~N})$ force and the nacelle natural yawing frequency is presented in Table 4-1. The dates refer to the test runs with the four different damper inserts.

The frequency of rotor rotation at synchronous generator speed was $3.2 \mathrm{~Hz}$ so that the damper with 0.7 inch/s rate caused a $1 \mathrm{P}$ nacelle resonance which resulted in occasional large 1 p current oscillations up to \pm 6 amps. Efforts to detune the system by inserting rubber washers into the damper clevis mount were unsuccessful. The stiffer damper configuration with a rate of $0.5 \mathrm{inch} / \mathrm{s}$ was used only in April 1984 and resulted in a very low unfurl response leading to a substantial loss of captured energy. The lowest damper stiffness ( $1.3 \mathrm{inch} / \mathrm{s}$ rate) resulted in high furl rates and occasional large amplitude furl oscillations with a period of about six seconds which was the natural period of the tail vane in yaw. Thus the only practical damper settings were those with 1.0 and $0.7 \mathrm{inch} / \mathrm{s}$ rates under 50 ib force. of these two settings only the 1.0 inch/s rate provided a natural nacelle frequency that was not in resonance with $1 \mathrm{P}$ excitation. 


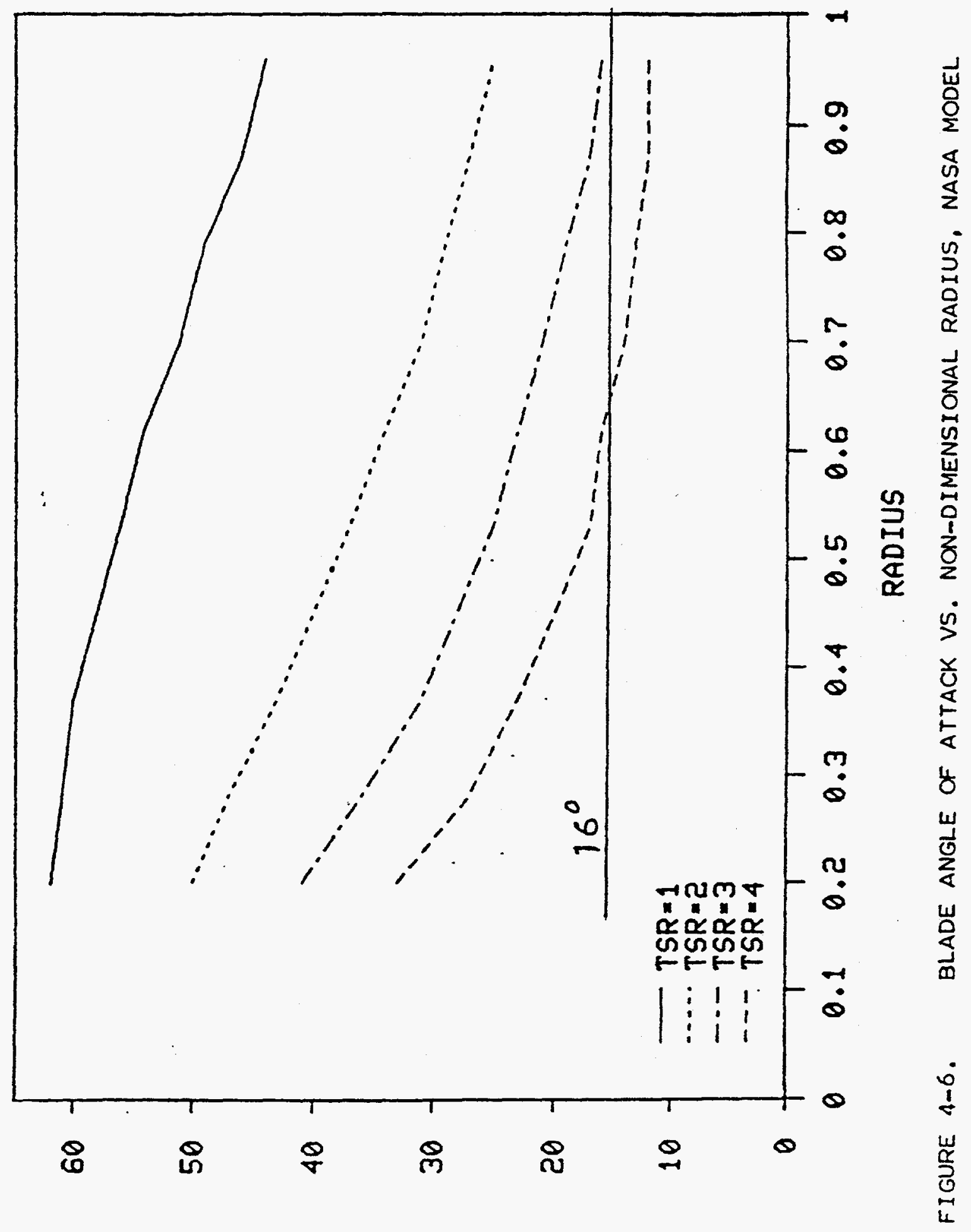

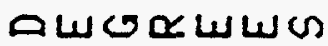


TABLE 4-1. Damper Rate vs. Nacelle Yawing Frequency

$\begin{array}{lll}\text { Damper Rate } & \text { Nacelle Yawing } & \text { Date } \\ \text { inch/s }(50 \mathrm{lb}) & \text { Frequency } \mathrm{Hz} & \end{array}$

$\begin{array}{lll}1.3 & 1.6 & \cdots \\ 1.0 & 2.5 & 5-19-83 \\ 0.7 & 3.2 & 5-2-83 \\ 0.5 & 3.8 & 5-28-84 \\ & 3-30-84\end{array}$

\subsubsection{Effects of Parameter Changes}

The evaluation of the various parameter changes for the Proof-of-Concept turbine was made on the basis of the furl characteristics in turbulence. Actually the rotor yaw angle rather than the rotor furl angle should have been used since thrust and torque at a given wind speed are a function of rotor yaw angle. One would need then the measurement of the wind direction with respect to the rotor. Available was only the wind direction at the top of the tall vane which, due to the rotor wake effect, was not the same as that at the rotor. However, in the mean, the tail vane boom assumed approximately the direction of the wind so that the mean rotor furl angle should be close to the mean rotor yaw angle.

For the furl response to turbulence one would like to have neither oversensitivity leading to large furl and power fluctuations, nor undersensitivity leading to a delay in response and a loss of energy capture. During the parametric testing both of these conditions were encountered. Increased teeter spring stiffness removed, according to the analysis, some of the negative rotor yaw damping and slowed the furl and unfurl responses. Reduced damper rates also slowed the furl response. Thus one could trade teeter spring stiffness against damper rates and vice versa. Table 4-2 gives some qualitative insight into the teeter spring and damper rate effects. The cited numbers are typical values of furl oscillation amplitudes and maximum furl rates in the wind region between 15 and $25 \mathrm{mph}$ ( 7 and $11 \mathrm{~m} / \mathrm{s}$ ). The last column shows whether the response was judged to be either over or undersensitive. The numbers in table 4-2 should be taken only as trend indicators, they have no absolute significance. It is seen from Table 4-2 that for each stiffening of the teeter springs at a given damper rate the trend is the same as for a reduction in damper rate at a given tester spring stiffness. 


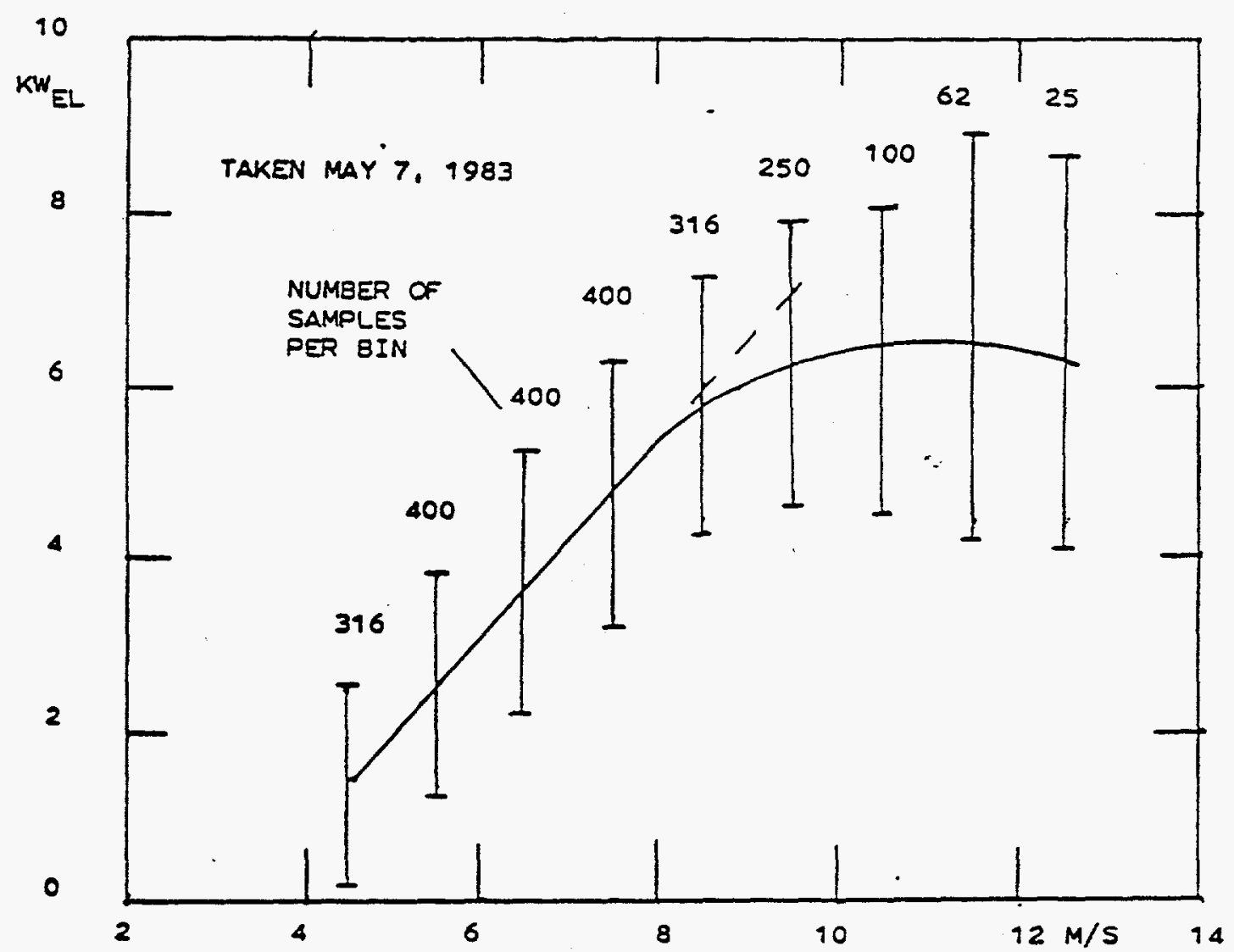

FPL

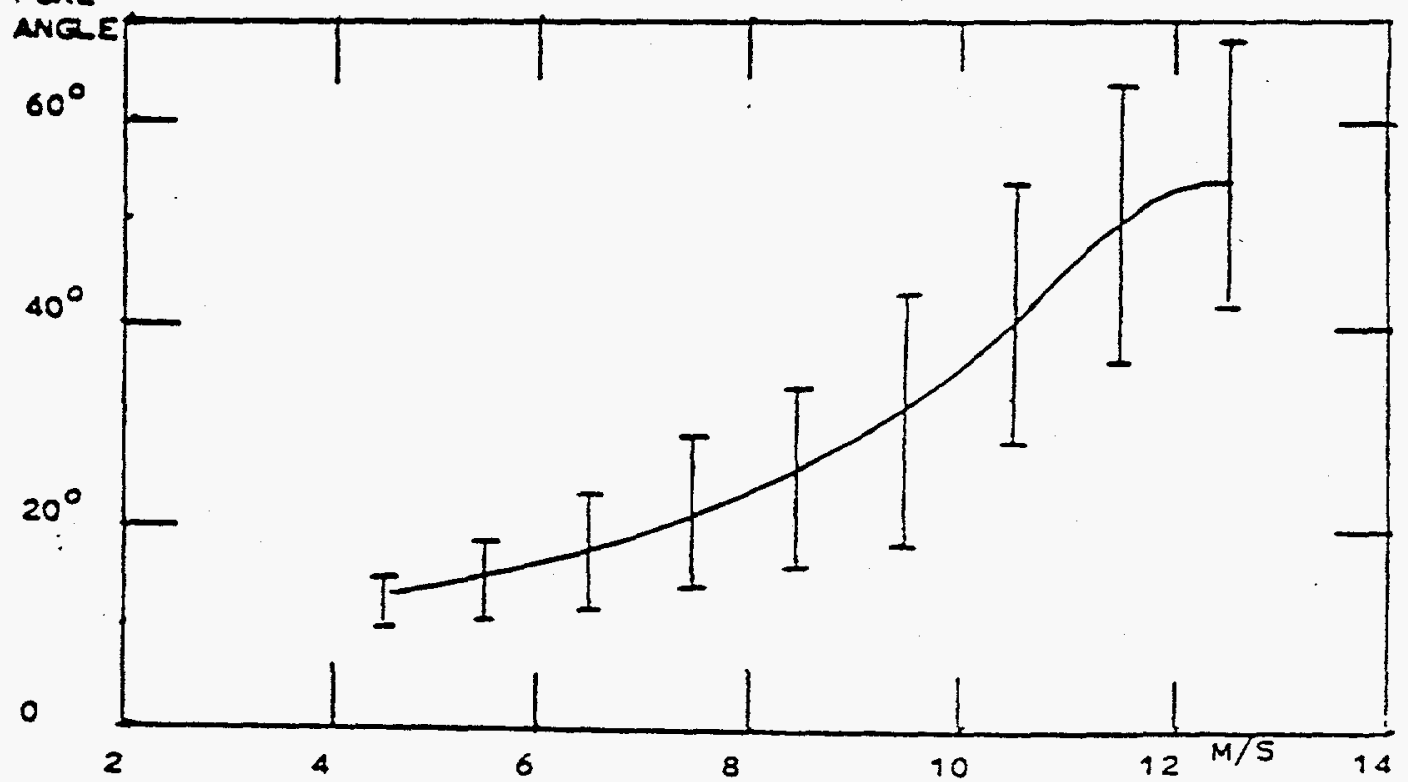

FIGURE 4-7. BIN PLOTS FOR ELECTRIC POWER OUTPUT AND FURL ANGLE, MAY 7, 1983 
TABLE 4-2. The Effect of Teeter Spring Stiffness on Damper Rate and Furling Characteristics

Date

Teeter Spring Damper Rate

Ft Ib/Deg inch/s

Furl Am-

Max Furl Over Under plitude Rate $\mathrm{o} / \mathrm{s}$ Sensitive

\begin{tabular}{cccccc}
\hline $5-2-83$ & 20 & 1.0 & $\pm 22^{\circ}$ & 23 & $*$ \\
$5-7-83$ & 27 & 1.0 & $\pm 13^{\circ}$ & 20 & \\
$5-19-83$ & 27 & 1.3 & $\pm 22^{\circ}$ & 25 & $*$ \\
$5-22-83$ & 45 & 1.3 & $\pm 17^{\circ}$ & 22 & $*$ \\
$4-6-84$ & 75 & 0.5 & $\pm 3^{\circ}$ & 6 & \\
$4-30-84$ & 27 & 0.5 & $\pm 6^{\circ}$ & 10 & $*$ \\
$5-28-84$ & 27 & 0.7 & $\pm 12^{\circ}$ & 18 & \\
$10-4-85$ & 62 & 0.7 & $\pm 6^{\circ}$ & 10 & \\
$?$ & 62 & 1.0 & $?$ & & $*$
\end{tabular}

The preload of the unfurl spring had to be changed a number of times. Due to different combinations of teeter spring stiffness and damper rate, the furling system became more or less sensitive to gusts. The unfurl spring load had to be adapted to the changing sensitivity to avoid generator overload or loss of energy capture. A good criterion for the proper unfurl spring adjustment was the maximum autorotational RPM as seen in Fig. $3-3$. This maximum should be at 250 to $270 \mathrm{RPM}$. In this range reasonable power-on characteristics were obtained.

\subsubsection{Statistical Performance Data}

Fig. 4-7 shows bin plots of furl angle and of electric power output for the test of May 7, 1983. The high turbulence level during the test caused high mean furl angles and a low maximum mean power output of $6.4 \mathrm{KW} E \mathrm{~L}$. Fig. 4.8 shows the result of a test conducted May 28, 1984. A stiffer unfurl spring had been installed and adjusted such that the spring unfurl moment over the entire furl angle range was larger by a factor of 1.25 as compared to the May 7, 1983 test shown in Fig. 4-7. The damper insert with the flow passages had been changed to obtain 1.4 times the damper force at a given rate $(0.7 \mathrm{inch} / \mathrm{s}$ or $0.018 \mathrm{~m} / \mathrm{s}$ under $501 \mathrm{~b}$ or $222 \mathrm{~N}$ force). The mean furl angle was for a given wind speed bin lower than before, the electric power output somewhat higher, particularly in the upper wind speed range. How much of this change 

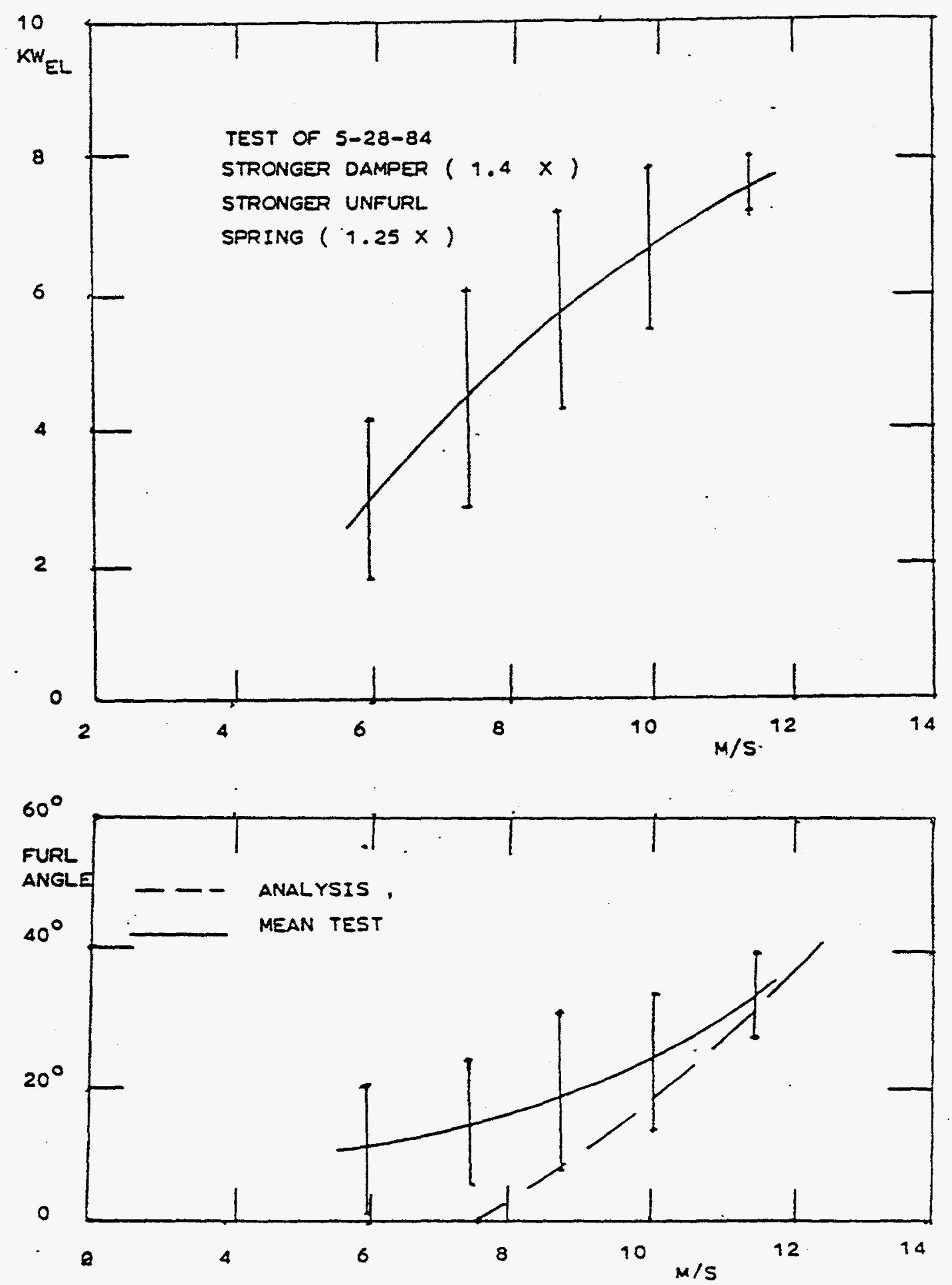

FIGURE 4-8. BIN PLOTS FOR ELCTRIC POWER OUTPUT AND FURL ANGLE, MAY 28, 1984 
was due to the stronger spring and damper and how much to a possibly lower turbulence level was difficult to judge. The dashed line in Fig. $4-8$ represents the analytical prediction of furl angle vs. wind speed taken from Fig. 3-1. The measured mean furl angle is higher than the predicted furl argle particularly for lower wind speed. Fig. 4-9 obtained on December 16 , 1984 shows a low turbulence case where the mean furl angle was lower and the electric power output was higher than for the test of 5-28-84 shown in Fig. 4-8. The mean electric power reached $9 \mathrm{~kW}$ and the upper standard deviation $10 \mathrm{~kW}$.

Following Ref. 7, the data from the tests of May 28, 1984 were reevaluated with a four second preaveraging time. Fig. 4-10 shows the effect of preaveraging on the furl angle. The upper graph, identical to that of Fig. 4-8, was the result of point samples, the lower graph was the result of preaveraged samples. Though the number of samples in each wind speed bin was rather small in both cases, the effect of preaveraging was clear. Not only the standard deviations were reduced but also the mean values. The associated mean electric power output for a given wind speed was somewhat increased when using preaveraging. The result obtained by preaveraging with a four second time interval should be more realistic than the result from point sampling, which was polluted by the high wind speed frequencies experienced by the anemometer but not by the rotor. Despite this improvement of the statistical data, the basic response to turbulence shown in $\mathrm{Fig}$. 4-1 cannot be smoothed by any method of data processing. It appears that the root cause of the furl and power fluctuations in turbulence is the fast responding tail vane oscillating in phase with the furl angle so that the rotor yaw rate was made up of the sum of tail vane yaw and rotor furl amplitudes. The obvious solution is to slow down the motion of the wind following element; for example, by replacing the tail vane with a slow acting yaw control side rotor. For an active yaw control system with a yaw gear drive the problem would not occur. 

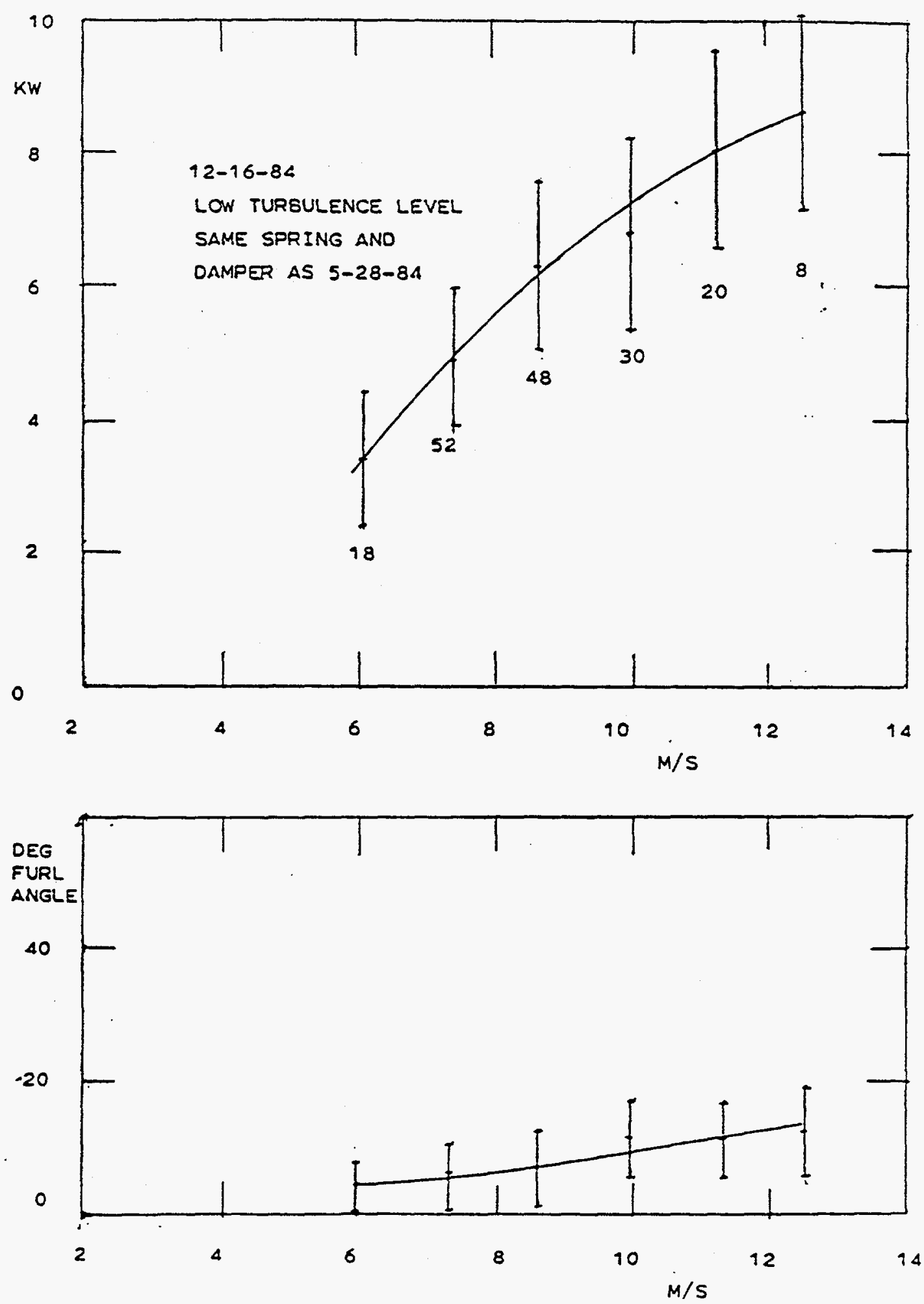

FIHURE $4-9$. BIN PLOTS FOR ELECTRIC POWER OUTPUT AND FURL ANGLE, DECEMBER 16,1984 

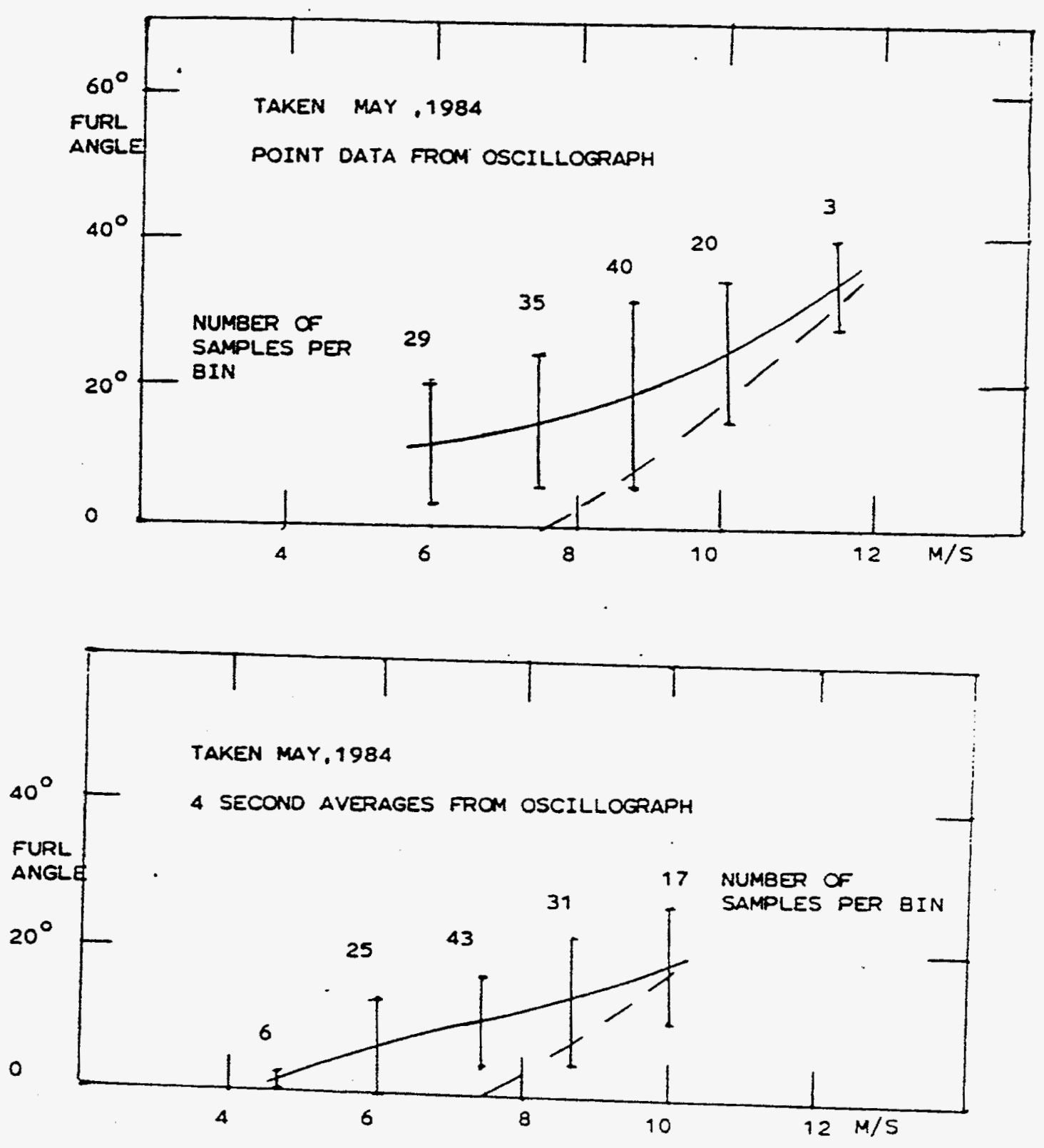

FI GURE $4-10$

FURL ANGLE BIN PLOTS WITHOUT ANO WITH DATA PREAVERAGING 
SECTION 5.0

CONCLUSIONS

Analysis and atmospheric experiments with a $25 \mathrm{ft}$ ( $7.6 \mathrm{~m})$ diameter tail vane stabilized PCP wind turbine having passive rotor furl control, conducted during the period of January 1982 to October 1985, allowed the following conclusions.

- The modification to independent yaw and furl controls was successful in eliminating delayed furling and unfurling from high bearing friction.

- The blade modification to high twist high chord root sections was successful in causing early start-up.

- The $50 \%$ increase in tail vane area and $12 \%$ increase in tail boom length was successful in eliminating erratic power-on low wind speed yawing and in correcting two dynamic conditions.

- Increasing the transmission ratio from 9.4 to 12.5 allowed operation in deep stall with strong teeter stop impacts. The torque was twice that predicted by the conventional prop code.

- The modification to the Proof-of-Concept turbine where the shaft mounted gear box and the belt driven generator were replaced by an integrated gear-generator unit, further reduced the start-up wind speed because of an $80 \%$ reduction of the break-out torque.

- The trim analysis predicted in agreement with the tests that the poweroff rotor speed would peak at $20 \mathrm{mph}(9 \mathrm{~m} / \mathrm{s})$ wind velocity and that it would drop off at lower and at higher wind speed. From tests with up to $60 \mathrm{mph}(27 \mathrm{~m} / \mathrm{s})$ gusts, benign storm survival in autorotation can be expected.

- The trim analysis predicted power-on lower furl angles than the measured means.

- Turbulence increased the standard deviations and the means of the furl angle. It decreased the mean electric powar output.

- The rotor yaw damping analysis predicted in qualitative agreement with the tests a reduction in negative rotor yaw damping with increasing teeter spring stiffness.

- Damper characteristics were found to strongly influence furl control dynamics. Damper rates of 0.7 to 1.0 inch $/ \mathrm{s}(0.018$ to $0.025 \mathrm{~m} / \mathrm{s})$ under $50 \mathrm{lb}(222 \mathrm{~N})$ force were optimal for teeter spring stiffnesses of 30 to $60 \mathrm{ft}-\mathrm{lb} / \mathrm{deg}$ (40 to $80 \mathrm{Nm} / \mathrm{deg})$.

- Optimal unfurl spring settings varied with furl friction, damper setting and teeter spring stiffness. Typlcal values were $150 \mathrm{lb}(667 \mathrm{~N})$ unfurled to $220 \mathrm{lb}(980 \mathrm{~N})$ furled.

- Preaveraging the test data before performing a bin analysis reduced the furl and power standard deviatlons, decreased the mean furl angle and increased the mean power output in a given wind speed bin. 
To answer in a more generic way the question whether rotor yaw control can be advantageously substituted for blade pitch control, the following points should be considered.

- A rotor yaw control dynamics analysis is needed for a teetered rotor including the effects of partial blade stall.

- The present PCP wind turbine is not well suited for verifying a rotor yaw control dynamics model because of the complex and unknown aerodynamic rotor-tail vane interaction.

- Slowing the response of the wind following element, for example by replacing the tail vane with a yaw control side rotor, should make the turbine suitable for verifying a rotor yaw control dynamics model which could then be used for a generic study of rotor torque and speed control by yawing. 
SECTION 6.0

REFERENCES

1. Hohenemser, K.H., Swift, A.H.P., and Peters, D.A., The Yawing of Wind Turbines with Blade Cyclic Pitch Variation. Final Report, SERI/TR-808515, December 1980.

2. Hohenemser, K.H., and Swift, A.H.P., The Investigation of Passive Blade Cyclic Pitch Variation Using an Automative Yaw Control System. Final Report, SERI/TR-1052-10, December 1981.

3. Swift, A.H.P., The Effects of Yawed Flow on Wind Turbine Rotors. D.Sc. Thesis, Washington University, May 1981.

4. Hohenemser, K.H., and Swift, A.H.P., Torque Control by Yawing of a Constant Speed Two-Bladed Wind Turbine with Passive Cyclice Pitch Varfation. Proceedings Sixth Biennial Wind Energy Conference and Workshop, Minneapolis/St. Paul, June 1983, pp. 277-287.

5.' Swift, A., Hohenemser, K., and Rangwala, S., The Effect of Hinge Spring Restraints on Two-Bladed Teetered Wind Turbine Rotors. ASME Wind Symposium IV, Dallas, Texas, February 1985.

6. Hansen, A.C., and Wright, A.D., A Simple Teetering Rotor Hub Design Model. Proceedings National Conference, American Wind Energy Association, Pasadena, California, September 1984, pp. 74-82.

7. Hansen, A.C., and Hausfeld, T.E., Correlation of Wind Turbine Power Output with Turbulent Winds. Draft SERI Report, February 1985.

8. Viterna, L.H., and Corrigan, R.D., Fixed Pitch Rotor Performance of Large Horizontal Axis Wind Turbines. Large Horizontal Axis Wind Turbine Workshop, Cleveland, Ohio, July 1981. 


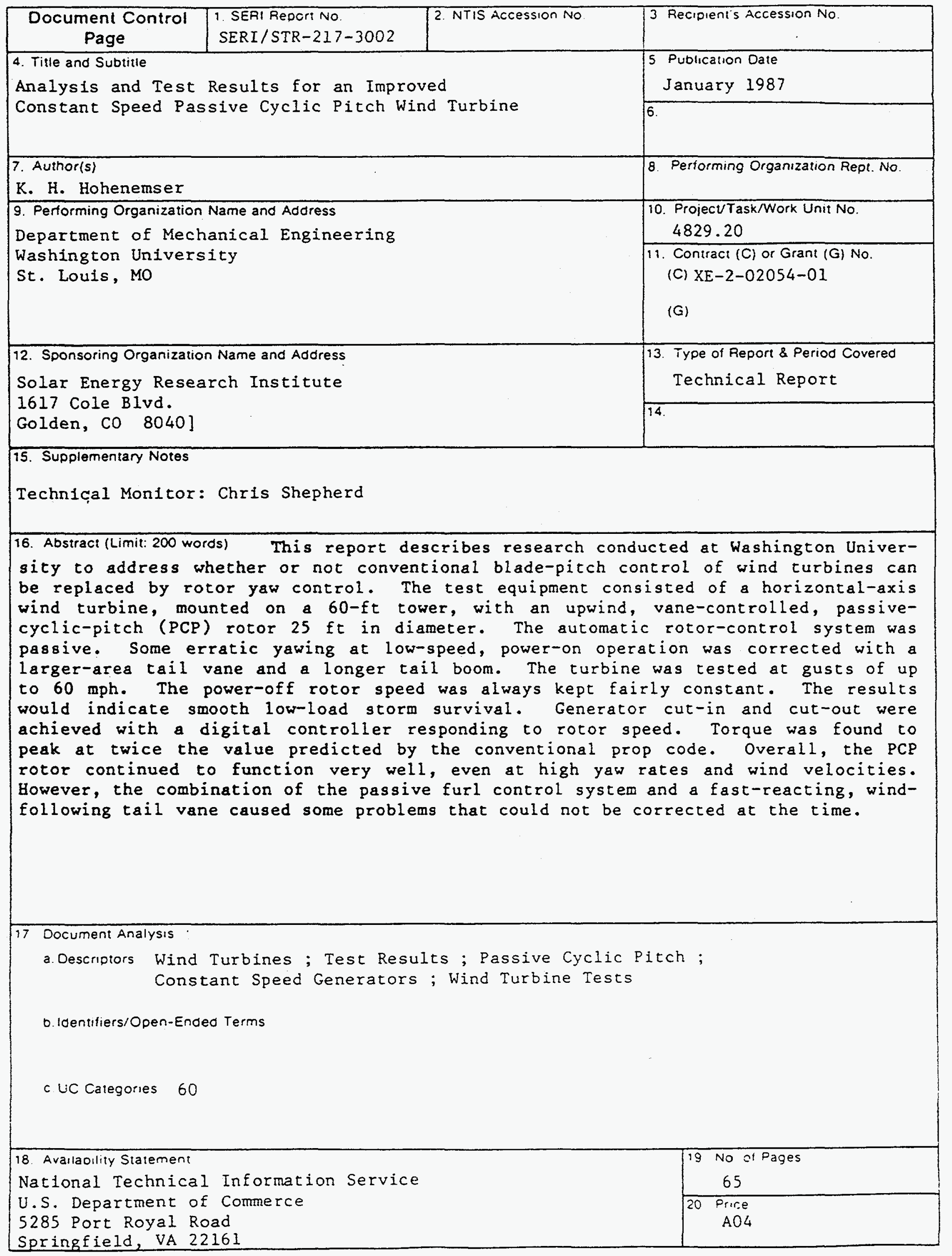




\section{APPENDIX 2}

Sixth ASME Wind Energy

Symposium, Dallas, Texas

February 1987

Wind Turbine Yaw

Dynamics Analysis for a

Teetered Rotor System

K.H. Hohenemser 


\section{WIND TURBINE YAW DYNAMICS ANALYSIS FOR A TEETERED ROTOR SYSTEM}

K. H. Hohenemser

Washington University

St. Louis. Missours

\section{ABSTRACT}

The wind turbine system studied limits torque and speed of a teetered fixed pitch upwind rotor by passive rotor yawing. A tail vane provides the reference for the downwind direction. The nacelle, coupled to the tail boom by a non-linear spring and damper. can furl from this direction between 10 and 90 degrees. Lateral off-set and up-tilt of the rotor axis provide rotor thrust and torque inputs to the furl mechanism. The system non-linearities are considered in computing trim equilibrium but are neglected in determining dynamic deviations from trim. The three main parameters contributing to system dynamics are the rotor aerodynamic yaw damping which is negative the tail vane yaw damping, and the damping action of the furl damper which couples the nacelle to the tail boom. While it is easy, by proper adjustment of the furl damper, to obtain a good response to wind velocity changes, wind direction fluctuations excite the lowly damped tail vane mode with large furl participation. To alleviate this mode without introducing a sluggish control response, a mechanical tail vane yaw damper is needed. The analysis results are in qualitative agreement with experimental observations of a $7.6 \mathrm{~m}$ diameter wind turbine of the type analyzed.

\section{NOTATION}

B

$D_{M}$

Number of blades in rotor

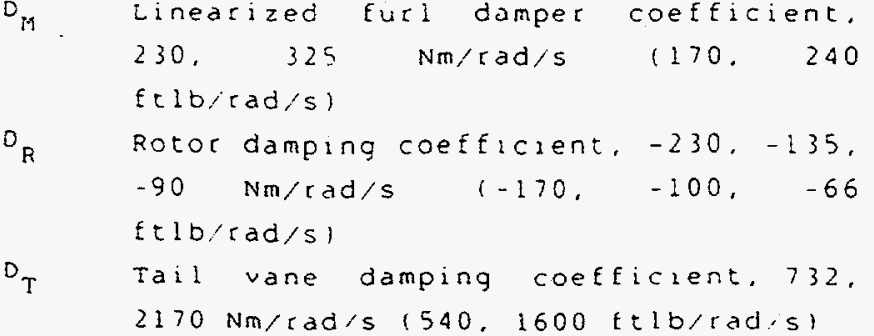

$\mathrm{H}$

I

$I_{N}$

$I_{T}$

$K_{E} \cdot K_{Y}$ $k_{1} \cdot k_{2}$

P

R

$S$

T

$T_{E Q}$

v

$V / R R$

c.7

$c_{0}$

$\sigma_{T}$

CTEQ
Horizontal in-plane rotor force

Blade moment of inertia

Nacelle moment of inertia, $49 \mathrm{kgm}^{2} / 3$ slugft ${ }^{2}$,

Tail vane moment of inertia, $945 \mathrm{kgm}$ $\left(700\right.$ slgft $\left.{ }^{2}\right)$

Factors in $E=k_{f} e^{\lambda t}, y=k_{y} e^{\lambda t}$

Ratios describing natural mode shapes Non-dimensional teeter frequency is vacuum, 1.00,1.03,1.05

Rotor torque

Rotor radius. $R=3.8(12.5 \mathrm{ft})$

Rotor overhang (distance to yaw axis) $0.70 \mathrm{~m}(27.5$ inch $)$

Rotor theust

Equivalent rotor thrust, e $T_{E Q}$ aerodynamic furl moment

wind speed, analysis is valid in rang. $9-13.4 \mathrm{~m} / \mathrm{s}$ ( 20 to $30 \mathrm{mph}$ )

Speed ratio

Blade chord at $0.7 \mathrm{~F}, 0.19 \mathrm{~m} 17$. inchl

Torque coefficient, $Q / O \pi R^{2}(Q R)^{2} R$ Thrust coefficient, $T / \Delta \pi R^{2}(Q R)^{2}$

Equivalent thrust coefficient taket with $T_{E Q}$

dc da Blade aliforl lift slope

$e$ Lateral off-set of rotor axis from ya: axis, 0.11 ( 4.3 inch)

Nacelle furl angle, 10 to 90 degrees trime 
\& Rotor angular speed

$r$ Blade Lock number, $\rho\left(\mathrm{dc}_{L} / \mathrm{d} \alpha\right) c_{0.7}$ $R^{4} / I, \quad r=5$

$90^{\circ}-\delta_{3}$ Angle between blade axis and teeter hinge, $\delta_{3}=67$ degrees

$\zeta$ Damping ratio

$n$ Rotor axis up-tilt angle, 7.0 degrees

$n_{1}, n_{2}$ General transients from initial unit deflection

$\lambda_{1} \ldots \lambda_{4}$ Eigenvalues

$\rho \quad$ Air density

- Rotor solidity ratio, 0.032

$\omega$ Natural Erequency

\section{INTRODUCTION}

In Reference 1 a rather comprehensive method is developed for analyzing the $y$ aw dynamics of a teetered rotor. Eight state variables are used: teeter angle and its rate, elastic coning angle and its rate, inflow, angular speed, and yaw angle and its rate. Dynamic inflow is assumed in accordance with Reference 2 which meanwhile has been extensively substantiated by successfully interpreting dynamic wind tunnel rotor tests. The elastic coning mode is assumed to be a straight line through the rotor center, a somewhat crude assumption which should have an effect on blade load prediction but which should hardly affect the yaw dynamics with its frequency which is an order of magnitude lower than the coning frequency. For the rotor considered here the coning frequency is $9 \mathrm{~Hz}$, the upper limit of the yawing natural frequency is about $0.3 \mathrm{~Hz}$. The blades are assumed to be unstalled, an assumption which can be checked by computing the angle of attack distribution along the radius and over the range of the azimuth angle. Yaw angle and yaw rate produce a rapid change of angle of attack with the frequency of rotor rotation. The dynamic stall angle of attack is thereby substantially increased over the steady stall angle of attack given in the profile section characteristics from wind tunnel testing. Even at very high yaw rates, up to $60 \mathrm{deg} / \mathrm{s}$, no indications of blade stall are observed during tests with the $7.6 \mathrm{~m}$ diameter rotor. The combinations of wind velocity and yaw angle, determined by the trim characteristics of the near constant speed rotor coupled to an induction generator, are such that the rotor becomes sufficiently unloaded at higher yaw angles so that blade stall is avoided. Thus the analysis method of Reference 1 which ignores blade stall, is applicable to the yaw dynamics of the tested rotor.

so far, the Reference 1 method of analysis has been applied to conditions where the rotor yaw angle and its rate are prescribed. This allows one to determine nacelle trim conditions in yaw, Reference 3 . and to compute the hub moments and forces during a periodic yaw oscillation. Reference 4. To add the nacelle yaw angle and its rate as the 9 th and 10 th state variable, and to couple the nacelle to the tail boom requiring an 11 th and 12 th state variable is straight forward in principle. However, this approach leads to a large increase in complexity of an already complex program since each blade element is affected by the unknown nacelle and tail vane motions. In a "global" program such as that of Reference 1 it is also difficult to retain a clear insight into the main parameters affecting the dynamic behavior of the system. The approach taken here is to use the results of the trim analysis of Reference 3 together with the results of the rotor damping analysis of Reference 4 to establish a set of two nonlinear differential equations for the tail vane yaw angle and for the nacelle furl angle. The equations are then linearized for the vicinity of a trim condition as is the usual procedure in helicopter and airplane flight dynamics. The system dynamics is then studied with the linearized equations.

\section{SYSTEM DESCRIPTION}

Fig. 1 shows a schematic top view of the system to be analyzed. The wind speed $V$ gives the reference direction. The tail vane is deflected from the v-direction by the yaw angle $y$,positive when counter-clockwise in the top view. The nacelle centerline is deflected from the tail vane direction by the furl angle $f$,positive when counter-clockwise in the top view. The tail vane yaw and nacelle furl axes are concentric which is the same as in the experimental machine. The rotor axis is laterally off-set from the $y$ aw axis by the distance, e, so that the rotor thrust $T$ gives a furling moment tending to increase the furl angle $f$. The rotor axis is titled up by the angle $n$ (not seen in the top view of Fig. 1) so that the yaw component of the driving rotor torque tends to decrease the furl angle $\mathrm{f}$. In Fig. 1 the rotor turns clockwise seen down-wind. For a counterclockwise turning rotor, the lateral off-set e must be in opposite direction to that shown in Fig. 1. The positive furl angle $f$ is then in the clockwise direction. The equations of motion remain the same if also the positive $y$-direction is reversed. The experimental wind turbine has a counter-clockwise turning rotor seen down-wind and $e$ and $f$ have opposite signs vs. those shown in Fig. 1 . The main consideration is that the rotor thrust provides a furling moment while the furl component of the rotor torque gives an unfurling moment. This relation is necessary in order to obtain a small spread between power-on and power-off rotor speed.

The $7.6 \mathrm{~m}$ diameter wind rotor drives, via a 9.2:1 transmission system, an induction generator which keeps the power-on rotor speed practically constant between 195 and $200 \mathrm{rpm}$, the latter occurring at a rated electric power of $8 \mathrm{~kW}$. Fig. 2 shows the schematic plan-view of the gear-generator unit mounted on the bedplate. The dimensions are in inches. The rotor overhang $S$ is quite smali, 27.5 inch or $0.70 \mathrm{~m}$. The nondimensional lateral rotor axis off-set from the yaw axis is $e / R=4.3 / 150=0.029$. The rotor up-tilt angle, not shown in Eig. 2 , is $n=7.0 \mathrm{deg}$. These and other data needed in 
the analysis are given in the section "Notation."

Fig. 3 shows the schematic top view of the furl control system. The unfurl tension spring connects the tail vane boom with the bedplate carrying the gear-generator unit shown in Fig. 2. Another connection between these two components is given by the coupled linear damper and electric actuator. The latter is not used in normal operation and merely serves to shut down the machine by furling it if so required. Due to the $80 \mathrm{deg}$ relative rotation of the tail vane boom with respect to the bedplate, both the unfurl spring and the damper have, in terms of the furl angle, non-linear characteristics. Eurthermore, the damper force increases with the square of the rate of Iinear displacement.

\section{NACELLE FURL TRIM ANALYSIS}

Results of the trim analysis for $200 \mathrm{rpm}$ rotor speed are taken from Reference 3 . There they are presented in the form of the equivalent thrust coefficient $c_{\text {Teg }} / \sigma$ vs nacelle furl angle for constanteQ torque coefficients $c_{\sigma} / \sigma$ and for constant speed ratios V/QR, see Fig. 4. The equivalent thrust $T_{F O}$ is the force which gives the total aerodynaffec furling moment when multiplied by the off-set e. In Reference 3 the following expression is used

$$
\text { e } T_{E Q}=e T+S H-n Q
$$

where $H$ is the rotor and nacelle side force, positive when tending to increase the furl angle, and where $S$ is the overhang of the rotor. Without the negative term ne from rotor axis up-tilt angle $n$ one would need a substantially higher unfurl spring moment for torque limitation. This would drive up the power-off rotor speed. For the selected value of $\eta=7 \mathrm{deg}$, the power loss from rotor axis up-tilt is small. The maximum power-off rotor speed occurring at 20 mph wind velocity is about $30 \%$ above power-on rotor speed. In determining the trim values in Eig. 4, some minor terms resulting from elastic teeter hinge restraint and from delta three effects were neglected. These terms are fully developed in Reference 4 where, however, the much larger effects of lateral rotor axis off-set $e$ and rotor axis up-tilt angle $\eta$ are not included.

Estimates of the nacelle yawing moment without rotor are included in the computation of the side force $H$. The dashed line in $F$ ig. 4 represents the unfurling moment of the tension spring plotted with negative sign. The reduction in spring moment for furl angles over 60 deg, despite higher spring tersion, is caused by the spring kinematics. Trim balance is obtained when the aerodynamic furling moment is equal to the spring unfurling moment. Following the dashed 1 ine from left to right, it is seen that increasing wind speed causes increasing furl trim angles. Up to 40 deg furl angle and up to a speed ratio of 0.17 the rotor torque remains nearly constant. For higher wind speed the torque diminishes and reaches zero at a speed ratio of 0.31 . Due to the steep necative slopes of the lines of constant speed ratio $V / Q R$ at high furl angles, the trim position at a given wind speed is always stable despite the negative spring moment slope. This means that at a given wind speed an increase in furl angle is always associated with an unfurling restoring moment.

Fig. 5 shows the static furl stability derivative $d(c / \sigma) / d f$ per radian, which is positive when the equivalent thrust coefficient decreases with increasing furl angle. Fig. 5 also shows the associated wind velocity in mph. These values were taken from Fig. 4 along the dashed line. It is seen that between 20 and $30 \mathrm{mph}$ the static furl stability is nearly constant and increases with higher wind speed. The value of $\mathrm{d}\left(\mathrm{c}_{\mathrm{TEO}} / \sigma\right) / \mathrm{df}=0.07 \mathrm{will}$ be used in the followitg analysis. This amounts, in dimensional units, to a furling moment gradient of $50 \mathrm{ftlb} / \mathrm{rad}(68 \mathrm{~N} \mathrm{~m} / \mathrm{rad})$.

NACELLE FURL DYNAMICS FOR STEADY TAIL VANE POSITION

Experience has shown that the furl control mechanism is closely coupled to the tail vane motions so that wind direction changes and the tail vane response to these changes can have a large effect on furl angle and power output. It is, therefore, of interest to first study the functioning of the furl mechanism in the absence of this coupling. It is assumed that the tail vane remains in a fixed position and absorbs the moments from tension spring and furl damper without deflection, for example due to a large inertia. An initial deflection from furl equilibrium of 15 deg $(0.26$ rad) is stipulated and the transient of the furl angle to neutral is computed. The furl differential equation for $f$ in radians reads

$$
\ddot{\mathrm{f}} \mathrm{I}_{\mathrm{N}}+D(\dot{\mathrm{f}})+50 \mathrm{f}=13 \mathrm{ftlb}
$$

$D(\dot{f})$ is the non-linear damping function, 50 ftlb/rad is the static furl stability at 200 $\mathrm{rpm}$ corresponding to $d\left(c_{\mathrm{TE}} / \sigma\right) / \mathrm{df}=0.07$ taken from Fig. 5 between $\left\{Q^{2}\right.$ and $30 \mathrm{mph}$, and $13 \mathrm{ftlb}$ is the restoring furl moment for 15 deg deflection from neutral. $D(f)$ contains two contributions, one from the aerodynamic rotor damping in yaw, the other from the mechanical damper.

Expressions for the rotor yaw damping are derived in Reference 4. In the absence of blade stall, this damping is linear and depends, among other quantities, on the teeter spring restraint. Because of the upwind rotor location, the aerodynamic rotor yaw damping is negative which means that the yawing moment proportional to the yaw rate has the same direction as the yaw rate and tends to increase this rate. Adding teeter springs reduces the absolute yaw damping value. However, in order to achieve zero or positive yaw damping, unrealistically heavy teeter springs are required. A certain moderate amount of teeter spring restraint is desirable also in order to avoid teeter stop impacts at low rotor speed. A measure of the teeter spring stiffness is the ratio $P$ of the teeter frequency with spring restraint over that without spring restraint, both frequencies to be taken at operational rotor speed in vacuum. $\quad P=1.0$ indicates the 
absence of teeter springs. The experimental turbine has been operated with $P=1.00,1.03$ and 1.05. From Reference 4 one can compute for this wind turbine the following yaw damping values $D_{R}$ valid for a thrust coefficient of $c / \sigma^{R}=0.15$. The mechanical damper moment has been varied during the tests over a wide range. Two frequently used damper settings will be considered here.

Damper Moment $11800 \dot{\mathrm{f}}^{2}+7.2$ (sign $\dot{\mathrm{f}}$ ) ftlb

Damper Moment $2900 \dot{\mathrm{f}}^{2}+7.2$ (sign $\dot{\mathrm{f}}$ ) $\mathrm{ftlb}$

These expressions ignore the kinematics of the damper-actuator unit and are approximately valid for 20 to 70 deg furl angle. The minimum furl angle in normal operation is set at 10 deg in order to avoid the initial range between 0 and $10 \mathrm{deg}$ which is quite ineffective in changing rotor torque. The two mechanical damper characteristics listed in Eq. 3 correspond respectively to $0.7 \mathrm{inch} / \mathrm{s}$ and $1.0 \mathrm{inch} / \mathrm{s}$ linear damper rate under 50 ib of damper force. The second term in Eq. 3 represents the average friction of the damper which is independent of the rate but changes with the sign of the furl rate.

Summarizing the various conditions to be analyzgd and dividing Eq. 2 by $I_{N}=36$ slugft, we obtain

$$
\begin{gathered}
\left.\left.\ddot{\mathbf{f}}-\begin{array}{l}
4.7 \\
2.8
\end{array}\right\} \dot{\mathrm{f}}+\begin{array}{r}
50 \\
25
\end{array}\right\} \dot{\mathrm{f}}^{2}+0.2(\operatorname{sign} \dot{\mathrm{f}})+1.4 \mathrm{f}= \\
0.36 \mathrm{rad} / \mathrm{s}^{2}
\end{gathered}
$$

The numbers -4.7 and -2.8 correspond to respectively $P=1.00$ and 1.03 . The value $P$ $=1.05$ is here omitted in the analysis but will be used later for the coupled system analysis. Fig. 6 shows the non-linear mechanical damping for settings 1 and 2 and the linear rotor damping for $P=1.00$ and 1.03 , but with negative sign. The actual damping is the difference between the mechanical damping of curves 1 and 2 and the rotor damping for $P=1.00$ and 1.03 . It is seen that the combination of damper setting 2 with the rotor without teeter springs, $\mathrm{P}=$ 1.00, yields zero or less furl damping over a wide range of furl rates. This combination was initially tested but gave unsatisfactory results with wide fluctuations of furl angle and torque. The combination of setting 2 with the weak teeter springs, $P=1.03$, results in a great improvement since now the entire furl rate range shows good damping. The combination of mechanical damper setting 1 with the rotor without teeter springs, $P=$ 1.00 , was never tested but should have resulted in a comparable improvement.

The non-linear equations 4 have been numerically integrated with a predictorcorrector iteration loop. using a time interval of 0.2 seconds. The results are shown in Fig. 7. As could be anticipated from inspecting Fig. 6 , the combination of the weak mechanical damper with the rotor without teeter springs, curve 1 in Fig. 7 , leads to a large overshoot of the neutral position, while both combinations of the weak mechanical damper with a rotor having teeter springs, $P=1.03$, and the strong mechanical damper with a rotor having no teeter springs, $P=1.00$, result in no overshoot. reads

The substitute linear equation for Eq. 4

$$
\ddot{\mathbf{f}}+2 \zeta(1.4)^{1 / 2} \dot{\mathrm{f}}+1.4 f=0.36
$$

For a damping ratio of $r<1.0$ one obtains as solution a damped oscillation with $-\tau+\omega i$. For curves 1 and 2 in Fig. 7 the linear approximations $-0.25 \pm 1.17 i$ and $-0.95 \pm$ 0.63 i apply respectively. The linear responses are within the range shown in Fig. 7 quite close to the non-linear responses and have, therefore, not been included in Fig. 7 . In summary one can conclude from this study with fixed tail vane position that for any given teeter hinge spring stiffness one can select a mechanical damper setting which will avoid overshoot in the transient from an initial deflection. For the substitute linear system the damping ratio should be somewhat but not too much below critical damping.

TAIL VANE YAW DYNAMICS FOR STEADY NACELLE FURL POSITION

It is of interest, before analyzing the coupled tail vane and nacelle motions, to look at the tail vane dynamics for constant furl angle. For unstalled tail vane this is simple since the equation of tail vane motion is linear. In the range between 20 and 30 mph and with the rotor standing still the motion is described approximately by

$$
700 \ddot{y}+540 \dot{y}+700 y=0 \mathrm{ftlb}
$$

$D=540 \mathrm{ftlb} / \mathrm{rad} / \mathrm{s}$ is the tail vane damping cofficient from which the negative rotor damping must be subtracted when the rotor is operating. With the rotor damping values of rable 1 one obtains

$$
\left.700 \ddot{y}+\begin{array}{l}
370 \\
440 \\
474
\end{array}\right\} \dot{y}+700 y=0
$$

The three damping values $370,440,474$ refer respectively to the three values $P=1.00$, $1.03,1.05$. The complex frequencies are given in Table 2. It is seen that the damping ratio for constant furl angle varies substantially with $P$. It is independent of wind speed and rather low. In the next section it will be shown that the damping ratio of the oscillatory mode will be further lowered by coupling with the furl mechanism.

COUPLED NACELLE FURL AND TAIL VANE YAW DYNAMICS

The two Iinearized homogeneous differential equations for nacelle furl angle and tail vane yaw angle (Fig. 1) read

$$
\begin{gathered}
36 \ddot{\mathrm{f}}-\left\{\begin{array}{r}
170 \\
100 \\
66
\end{array}\right\}(\dot{\mathrm{y}}+\dot{\mathrm{E}})+\left\{\begin{array}{l}
240 \\
170
\end{array}\right\} \dot{\mathrm{f}}+50 \mathrm{f}=0 \\
\mathrm{ft} 1 \mathrm{~b} \\
700 y+540 y+700 y-\left\{\begin{array}{l}
240 \\
170
\end{array}\right\} \dot{\mathrm{f}}=0
\end{gathered}
$$


or have been used before. Three coupling terms are omitted in Eq. 8 since, as compared to the retained coupling terms, they have a small effect on system dynamics. Neglected are the inertial coupling term $36 \mathrm{y}$ in the first equation, the change of rotor furling moment with $y$ in the first equation which from Fig. 4 is in the velocity range considered about $15 \mathrm{y}$, and the effect of the unfurl spring on the tail vane in the second equation which is essentially a constant term balanced by a constant tail vane angle increment. The remaining two coupling terms are $\left\{\begin{array}{r}170 \\ -100 \\ 66\end{array}\right\} \dot{y}$ in the first equation and $\left\{\begin{array}{r}-240 \\ 170\end{array}\right\}$ f in the second equation. Physically this means that the nacelle furl response is affected by the tail vane yaw rate due to the negative rotor damping in yaw, and that the tail vane response is affected by the furl rate due to the mechanical damper attached to the tail boom. Fig. 3 .

We will first determine the eigenvalues and eigenmodes of $\mathrm{Eq}$. 8 and then compute typical transients from an initial unit deflection in nacelle furl angle and in tail vane yaw angle. Table 3 gives in the first five rows the eigenvalues for five of the possible six combinations of rotor and mechanical damping possible from Eq. 8 , omitting the unstable case $D_{B}=-170, D_{M}=$ 170. In all cases there are tho real and one conjugate complex pair of eigenvalues. Note that the period of the oscillatory mode for the coupled system is close to the period of the tail vane mode in table 2 .

As Table 3 in comparison to rable 2 shows, the oscillations of the coupled mode are even less damped than for the pure tail vane mode. Also, an increase in oscillatory damping goes together with a decrease in the smaller of the two real eigenvalues, and thus with a more sluggish control response. This dilemma can only be overcome by largely increasing the tail vane damping. As the last row shows, as compared to the same case with normal tail vane damping, the damping ratio of the oscillatory mode is more than trebled, while the absolute value of $\lambda_{2}$, though smaller, is still adequate.

The solutions of Eq. 8 are of the form $=k_{f} e^{\lambda t}, y=k$ e $e^{\lambda t}$. By writing Eq. 8 for each of the eigenvalues, one can solve for the mode shape ratios $K_{f} / K_{y}$. In case of the conjugate complex pair of eigenvalues, this ratio will in general be complex valued. It was found, however, that $f$ and $y$ oscillate nearly in phase, finding which agrees with the experimental evidence. In the following the mode shape ratio $K_{f} / K$ will be approximated by a real numbel also for the conjugate complex eigenvalue.

we will first define an aperiodic and a periodic transient from initial unit deflections and then, by appropriate superposition, derive the transients for $f(0)$ $=1, y(0)=0$, and $y(0)=1$ and $f(0)=0$. The general aperiodic transient is given by

$\eta_{1}(t)=\left[\lambda_{1} /\left(\lambda_{1}-\lambda_{2}\right)\right] e^{-\lambda_{2} t}-\left[\lambda_{2} /\left(\lambda_{1}-\lambda_{2}\right)\right] e^{-\lambda_{2} t}$
This function satisfies the conditions $n_{1}(0)$ $=1.0, \mathrm{dn} / \mathrm{dt}=0$ for $t=0$. The transient is mainly determined by the exponential function with $\lambda_{2}$ since the exponential function with $\lambda_{1}$ decays rapidiy in comparison to that for $\lambda_{1}$. We will allocate a tansient to $n_{\text {using }}$ $\lambda_{2} \ll \lambda_{1}$. The general periodic transtent is given by

$n_{2}(t)=e^{-\tau t} \omega^{-1}(\zeta \sin \omega t+\omega \cos \omega t)$

This function also satisfies the conditions $n_{2}(0)=1.0, \mathrm{~d} n_{2} / \mathrm{d} t=0$ for $t=0$. These $t w o$ general transients are shown in Figs. 8 to 10 for three sets of eigenvalues from Table 3 . The modal shapes for each transient are given by the ratios $k_{1}=k_{f} / k_{y}$ for $n_{1}, k_{2}=k_{f} / k_{y}$

The case $f(0)=1, y(0)=0$ can now be easily determined by the following superposition of the two general transients.

$f(t)=\left[k_{1} /\left(k_{1}-k_{2}\right)\right] n_{1}-\left[k_{2} /\left(k_{1}-k_{2}\right)\right] n_{2}$

$y(t)=\left[1 /\left(k_{1}-k_{2}\right)\right]\left(n_{1}-n_{2}\right)$

Eqs. 11, in addition to giving $f(0)=1, y(0)$ $=0$, also satisfy the definitions of $k$ and $\mathrm{K}_{2}$ so that for $n_{2}=0, f(t) / y(t)=k_{1}$, for $n_{1}$ $0, f(t) / y(t)=k$. The case $y(0)=1, f(0)$ $\bar{I} O$ is found by - feplacing in Eq. $11 \mathrm{~K}_{1}$ by $\mathrm{K}_{1}$ 1 , and $\mathrm{K}_{2}$ by $\mathrm{K}_{2}$. For the case of ${ }^{1} \mathrm{Fig.}$ which has been the "normal" configuration of the experimental wind turbine, the specific transients in terms of the general transients are given in Table 4 and these transients are shown in Figs. 11 and 12 .

It should be noted that these expressions are approximations since $k$ is taken for $\lambda_{2}$ while $n_{1}$ includes a $\lambda_{1}$ term, and since the complex valued nature ${ }^{1}$ of $k$, was neglected. From Table 4 and Figs. 11 and 12 it is seen that an initial unit deflection in furl angle leads to a near aperiodic transient combined with little tail vane motion. However, for an initial unit deflection of the tail vane, the oscillatory mode prevails with strong participation of the furl angle. only by largely increasing the tail vane damping can the oscillatory motion of tail vane and of furl angle be alleviated as Fig. 10 vs Figs. 8 and 9 shows.

The conclusion that the natural tail vane damping is insufficient to avoid large furl and yaw responses to wind direction fluctuations is confirmed by a frequency response analysis made for the case $P=1.05$, $D_{M}=170, D_{T}=540$. Fig. 13 shows the nondimensional ${ }^{T}$ sum of nacelle furl and tail vane yaw amplitude vs. frequency. The lower curve is for a periodic Eluctuation of the wind velocity of $25+5 \mathrm{mph}$. The upper curve is for a periodic Eluctuation of the wind direction by +0.4 radians. The dynamic response to wind velocity excitation is smaller than the static response, while the wind direction excitation gives a high resonance peak at $0.16 \mathrm{kz}$.

CORRELATION OF ANALYSIS WITH EXPERIMENTAL OBSERVATIONS

Due to the various simplifications of the analysis a direct comparison with test results is not possible. However, the 
predicted trends with a variation of parameters can be correlated with observed trends. Table 5 gives some qualitative insight into the effects of teeter springs and damper settings. The cited numbers are typical values of furl oscillation amplitudes and maximum observed furl rates in the wind speed region between 20 and $30 \mathrm{mph}$ and at typical turbulence levels usually encountered at these wind speeds. The sensitivity column indicates whether the responses were judged either over or under sensitive. The numbers in Table 5 should be taken as trend indicators, they have no absolute significance. The damper rate at 50 ib damper force varies between 0.5 and 1.3 inch/s. In all modifications except that for the last row, furl amplitudes and maximum furl rates increase or decrease together which means that a suppression of furl excursions leads to a sluggish control response. A maximum furl rate of $18 \mathrm{deg} / \mathrm{s}$ is considered desirable. The last row refers to a configuration with mechanical tail vane damping. The mechanical damping moment is adjustable up to 205 ftlb $(277 \mathrm{~N} \mathrm{~m})$ and is constant independent of yaw rate. The numbers in Table 5 apply to a test with maximum yaw damping. The additional yaw damping reduces the furl oscillations without cutting down on sensitivity. Fig. 14 visualizes the data of Table 5 .

The observations expressed in Table 5 and Fig. 14 confirm the trend of the analysis expressed in Figures 8 to 12 and in Table 4. While the tail vane yaw damper which makes use of a commercially available electric brake driven from the tower by chain and sprockets, was very successful in alleviating furl angle excursions without slowing down the furl response, this solution may not be practical as a permanent instaliation. However, the analysis and testing of the machine with mechanical tail vane damper point to an important requirement in the design of larger wind turbines with power regulation by yawing. The yaw control system operating on the yaw gear drive must not only allow fast yaw responses (this is only feasible with a teetered rotor) but must also be well damped in order to handle the effects of wind direction fluctuations.

\section{CONCLUSIONS}

The yaw dynamics of a tail vane stabilized wind turbine with upwind teetered rotor driving a constant speed induction generator with torque limitation by a passive furl control system is analyzed and the following conclusions are derived.

1. A non-linear trim analysis shows stable trim conditions in the entire furl range. with increasing wind speed the furl angle increases gradually. The driving rotor torque first remains constant, then diminishes so that blade stall is avoided. After power loss the rotor speed does not rise more than $30 \%$ and becomes less at higher wind speed.

2. A non-linear nacelle Eurl dynamics analysis with fixed tail vane position shows that despite the negative rotor yaw damping a control response of the passive furl control system without overshoot can be obtained by properly selecting the setting of the mechanical furl damper.

3. The tail vane yaw dynamics analysis for steady nacelle furl angle shows an oscillatory response with low damping ratio.

4. The coupled nacelle furl and tail vane yaw dynamics is analyzed with linearized system equations. The oscillatory mode is even less damped than for the tail vane alone. Adding teeter hinge springs or increasing the furl damper stiffness improves the damping ratio of the oscillatory mode but slows down the control response. The oscillatory mode is hardly excited by wind speed changes but strongly excited by wind direction changes with strong participation of the nacelle furl angle. The only way to alleviate this mode is to largely increase the tail vane damping.

5. The trends uncovered by the analysis correlate well with those obtained by tests with a $7.6 \mathrm{~m}$ diameter wind turbine of the type analyzed. The addition of teeter springs and the application of stiffer furl damper settings does reduce the nacelle furl fluctuations but with a penalty of reduced control sensitivity. Only the addition of a mechanical tail vane yaw damper in the form of a commercially available electric brake significantly reduces the furl fluctuations without reducing control sensitivity. This experience, when applied to larger teetered wind turbines with power regulation by rotor yawing, calls for a fast acting but close to critically damped yaw control system.

\section{REFERENCES}

1. Swift, A. H. P., "The Effects of Yawed Flow on wind Turbine Rotors," D. SC. Thesis, Washington University, May 1981 .

2. Pitt, D. M. and D. A. peters. "Theoretical Prediction of Dynamic Inflow Derivatives," Proc. 6 th European Rotocraft Forum, Bristol, England, Sept. 1980 .

3. Hohenemser, K. H. and A. H. P. Swift, "Torque control by Yawing of a constant speed Two-Bladed wind Turbine with Passive Cyclic Pitch variation," Proc. 6 th Biennial wind Energy Conf. Minneapolis, MN, June $1-3,1983$, pp. 277 $-287$.

4. Swift, A., $K$. Hohenemser, and $S$. Rangwala, "The Effect of Hinge spring Restraint on Two-Bladed Teetered wind Turbine Rotors," ASME Wind Symposium IV. Dallas, TX, Feb. 1985.

The tests 1 isted in Table 5 , were sponsored in part by the Solar Energy Research Institute (SERI) in Golden, colorado, and in part by the U. S. Army Corps of Engineers, District of st. Louis. 
Table 1 Rotor Damping

\begin{tabular}{l|lllll}
$P$ & 1.00 & 1.00 & 1.03 & 1.05 \\
\hline$D_{R}$ ftlo/rad/s & $\mid-170$ & $\mid$ & -100 & $\mid$ & -66
\end{tabular}

Table 2 Damping Ratio and Frequency of rail Vane

\begin{tabular}{lll} 
P & Complex Freguency \\
\hline 1.00 & 1 & $-0.26 \pm 0.96 i$ \\
1.03 & 1 & $-0.31 \pm 0.95 i$ \\
1.05 & 1 & $-0.34 \pm 0.94 i$
\end{tabular}

Table 3 Eigenvalues for $\mathrm{Eg} .8$

\begin{tabular}{|c|c|c|c|c|c|c|c|c|}
\hline $\mathbf{P}$ & $\mathbf{D}_{\mathbf{R}}$ & $\mathrm{D}_{\mathrm{M}}$ & $D_{T}$ & $\lambda_{1}$ & $\lambda_{2}$ & $\lambda_{3}, \lambda_{4}$ & 1 & Transient \\
\hline $\begin{array}{l}1.00 \\
1.03 \\
1.05 \\
1.03 \\
1.05 \\
1.03\end{array}$ & $\begin{array}{l}-170 \\
-100 \\
-\quad 66 \\
-100 \\
-\quad 66 \\
-100\end{array}$ & $\begin{array}{l}240 \\
240 \\
240 \\
170 \\
170 \\
170\end{array}$ & $\begin{array}{r}540 \\
540 \\
540 \\
540 \\
540 \\
1600\end{array}$ & $\begin{array}{l}-2.21 \\
-3.91 \\
-4.64 \\
-1.57 \\
-2.43 \\
-2.52\end{array}$ & $\begin{array}{l}-0.57 \\
-0.34 \\
-0.30 \\
-0.83 \\
-0.56 \\
-0.44\end{array}$ & $\begin{array}{r}0 \pm 1.051 \\
-0.26 \pm 0.99 \\
-0.31 \pm 0.95 \\
-0.18 \pm 1.03 \\
-0.29 \pm 1.01 \\
-0.67 \pm 0.90\end{array}$ & $\begin{array}{ll} & \\
i & 1 \\
i & 1 \\
i & 1 \\
i & 1\end{array}$ & $\begin{array}{l}\text { Fig. } 9 \\
\text { Fig. } 8 \\
\text { Fig. } 10\end{array}$ \\
\hline
\end{tabular}

Table 4 Transients $f(t)$ and $y(t)$

\begin{tabular}{|c|c|c|c|c|c|c|}
\hline$f(0)$ & $y(0)$ & $\mathrm{D}_{\mathrm{M}}$ & $D_{T}$ & $P$ & $f$ & $Y$ \\
\hline 1 & 0 & 170 & 540 & 11.03 & $0.75 n_{1}+0.25 n_{2}$ & $0.14\left(n_{2}-n_{1}\right)$ \\
\hline 0 & 1 & & & & $1.34\left(n_{2}-n_{1}\right)$ & $0.11 n_{1}+0.89 n_{2}$ \\
\hline
\end{tabular}

Table 5 Experimental Furling Characteristics

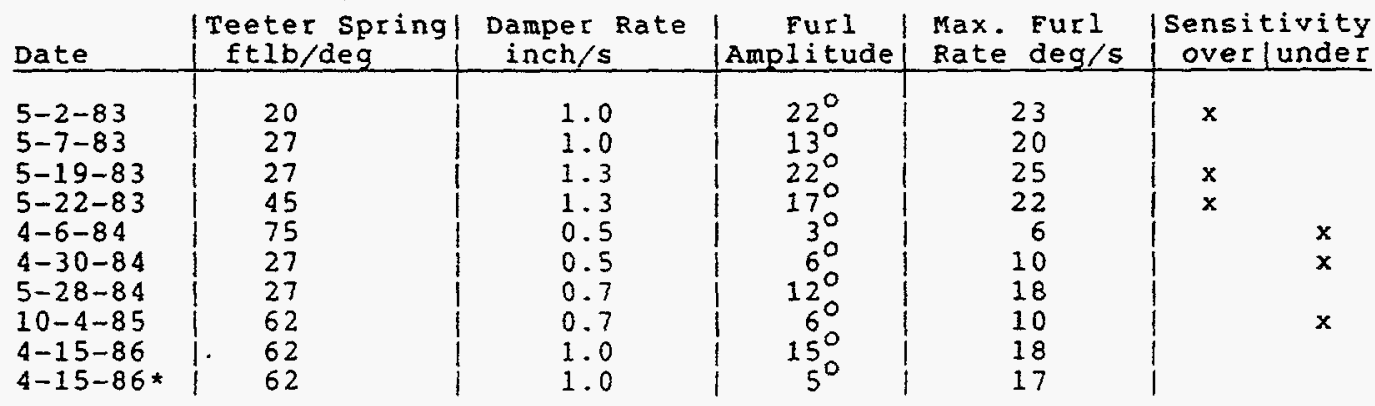

*The second test on 4-15-86 was conducted with full tail vain yaw damping. Linearized for $0.3 \mathrm{~Hz}$ and +7.5 deg yaw amplitude, one obtains $D_{T}=1600 \mathrm{ft} 1 \mathrm{~b} / \mathrm{rad} / \mathrm{s}$. 


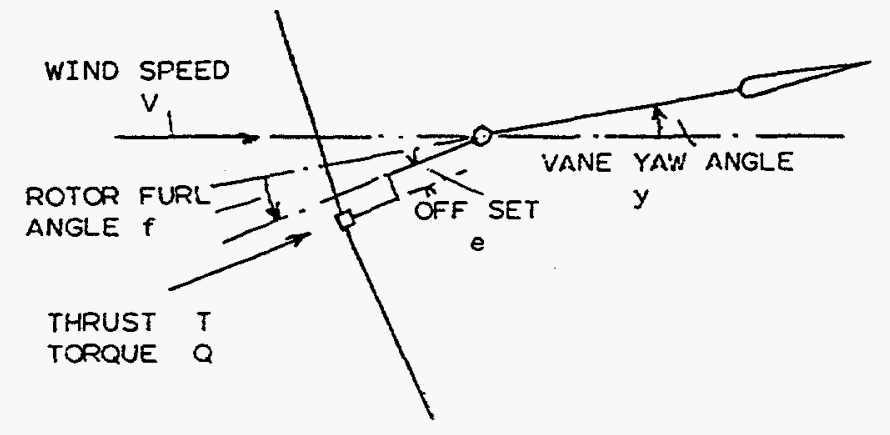

Fig. 1 Schematic top view of wind turbine

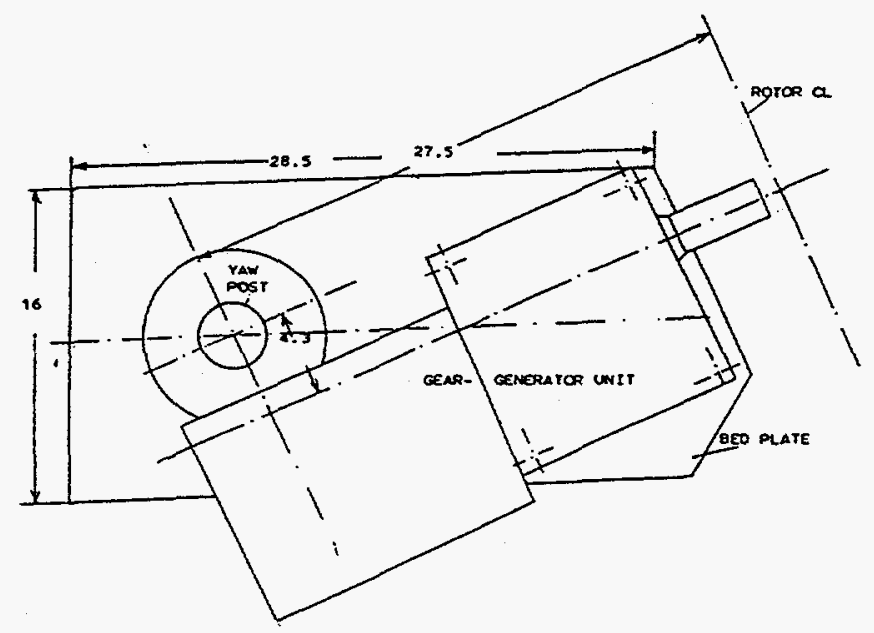

Fig. 2 Top view of gear-generator on bedplate

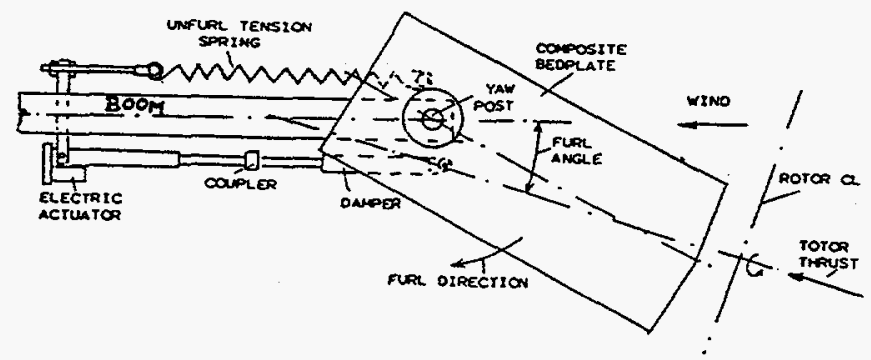

Fig. 3 Top view of furl control system

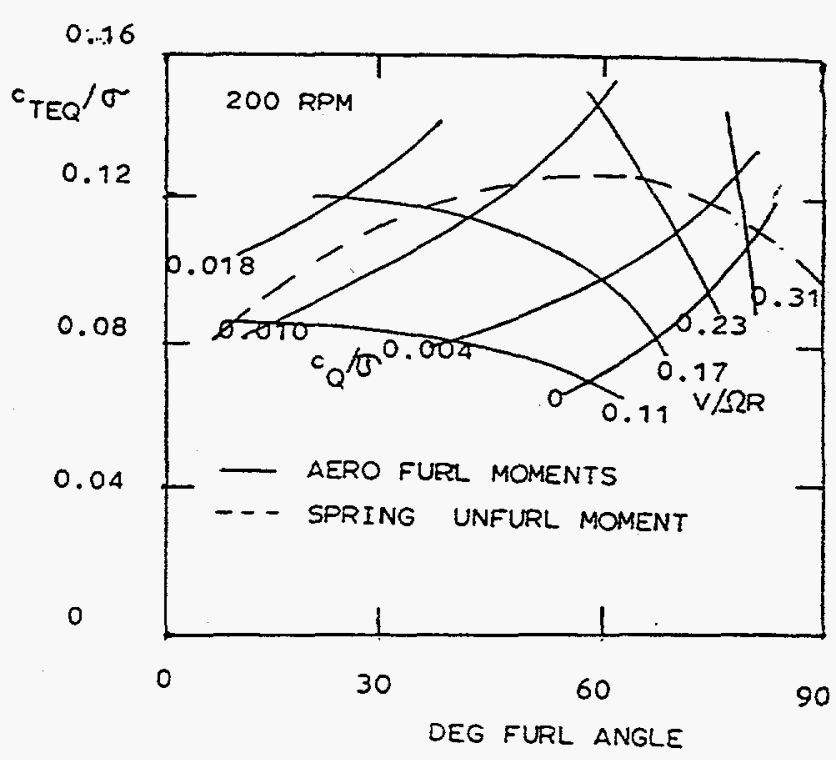

Fig. 4 Equivalent rotor thrust coefficient vs furl angle

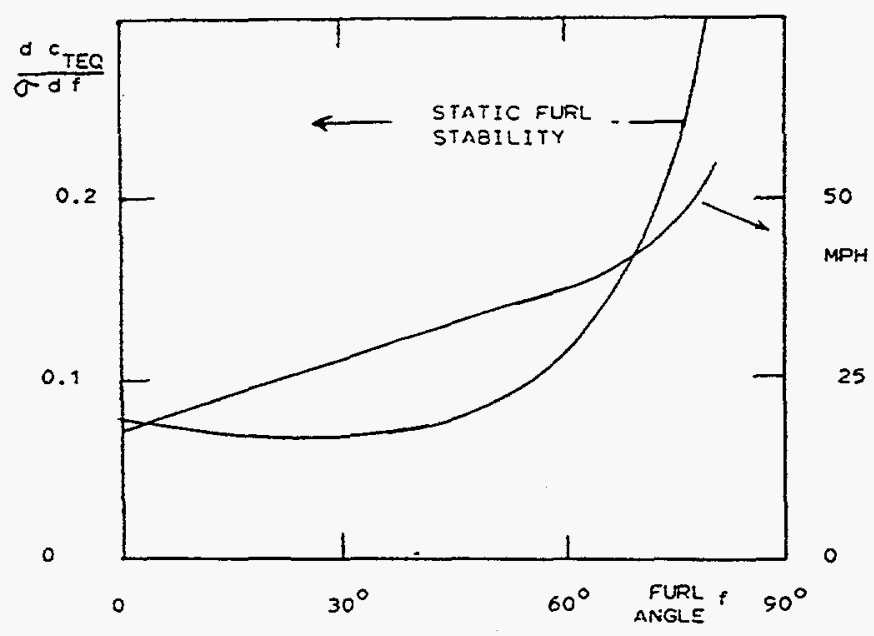

Fig. 5 Furl stability derivative and wind speed vs furl angle 


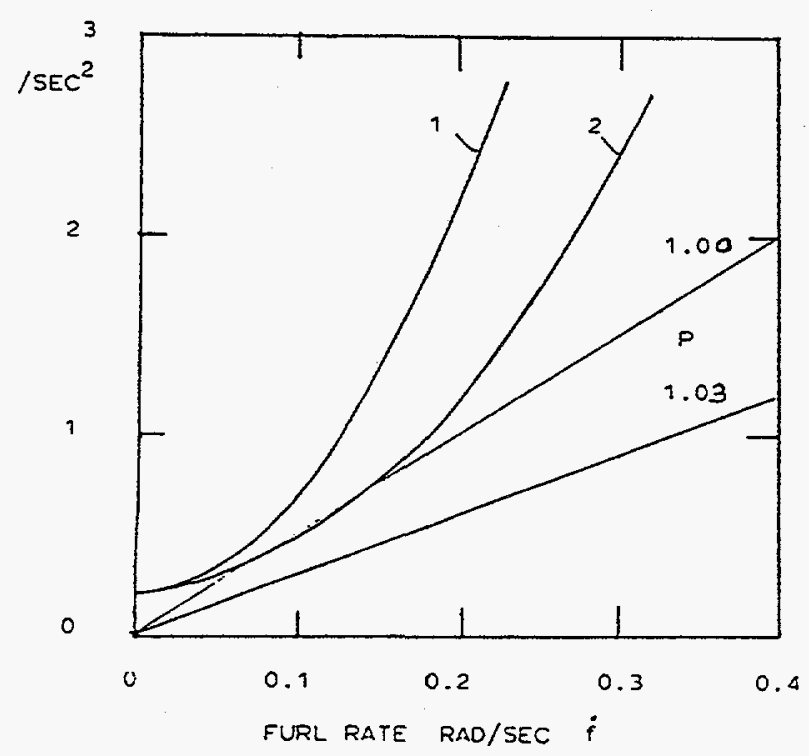

3. 6 Damping terms in eq. 4, Graph 1;0.2 $+50 \mathrm{f}$, Graph $2 ; 0.2+25 \mathrm{f} ; \mathrm{Graph}$
$\mathrm{P}=1 ; 4.7 \mathrm{f}, \mathrm{Graph} \dot{\mathrm{P}}=1.03 ; 2.8 \mathrm{E}$

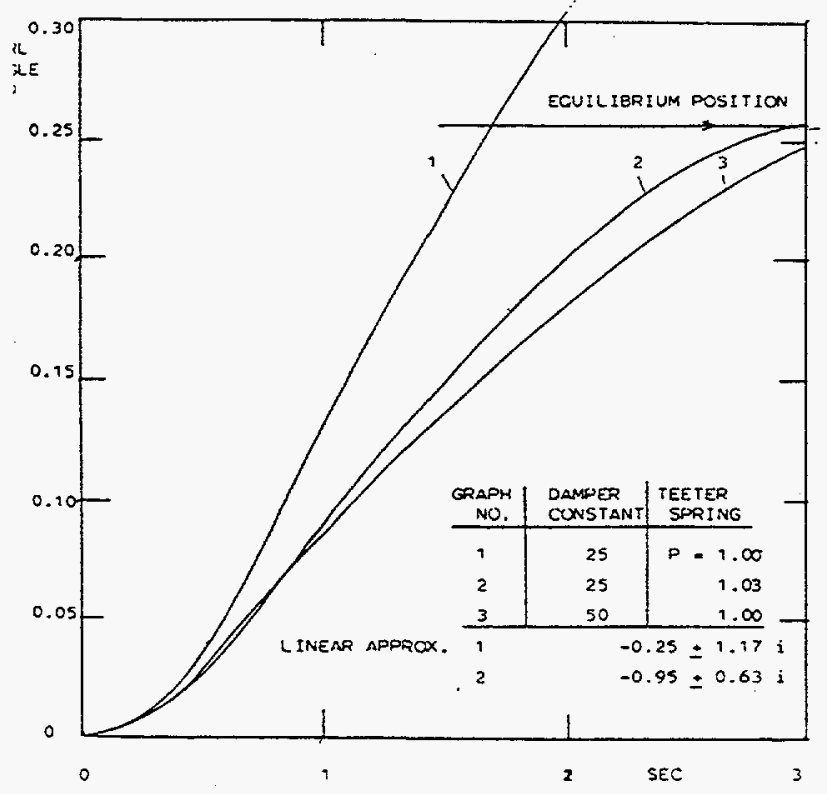

9. 7 Furl angle transients from initial furl angle of 0.26 ad

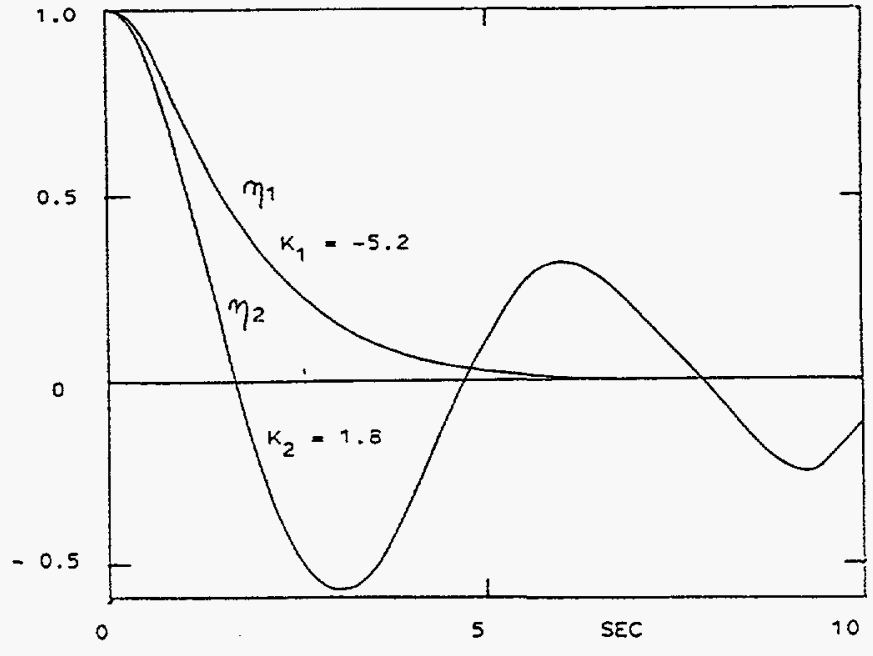

Fig. 8 General transients for $\mathrm{P}=1.03, \mathrm{D}_{\mathrm{M}}=$ $170, D_{T}=540$, amplitude ratios $K_{f} M_{K}$
$=-5.2$
1.8
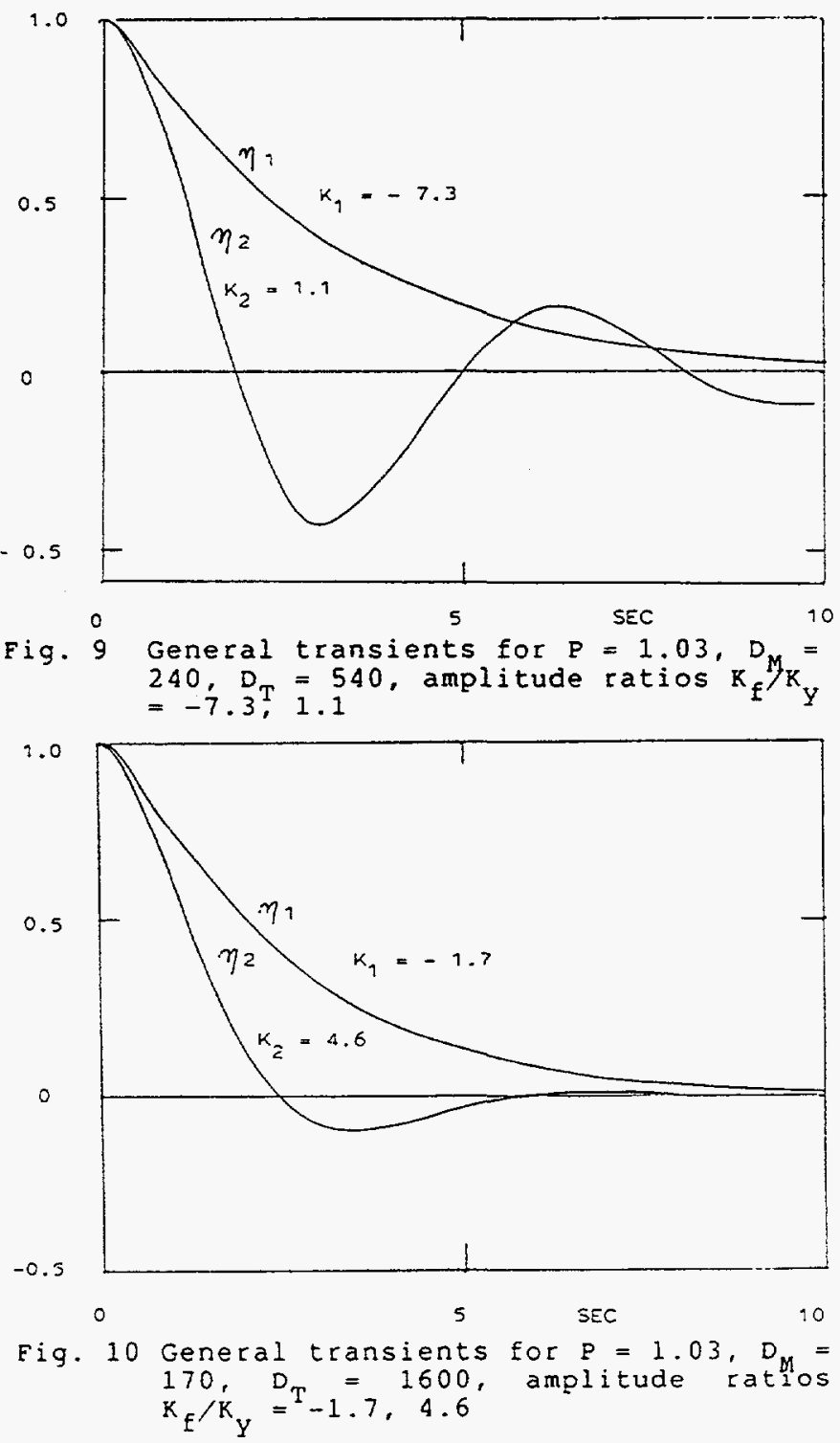


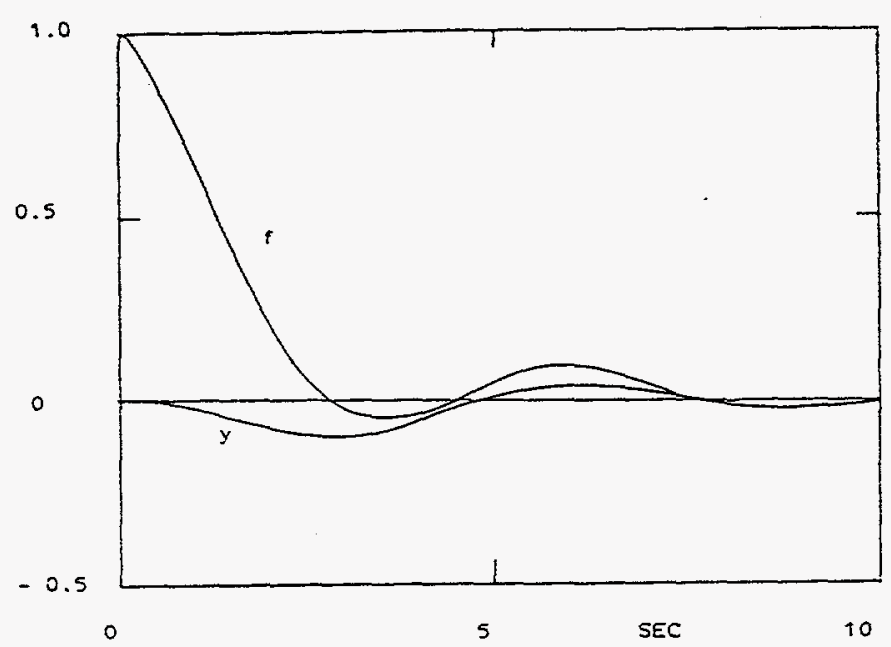

Fig. 11 Transients from initial unit furl angle for $\mathrm{P}=1.03, \mathrm{D}_{\mathrm{M}}=170, \mathrm{D}_{\mathrm{T}}=$

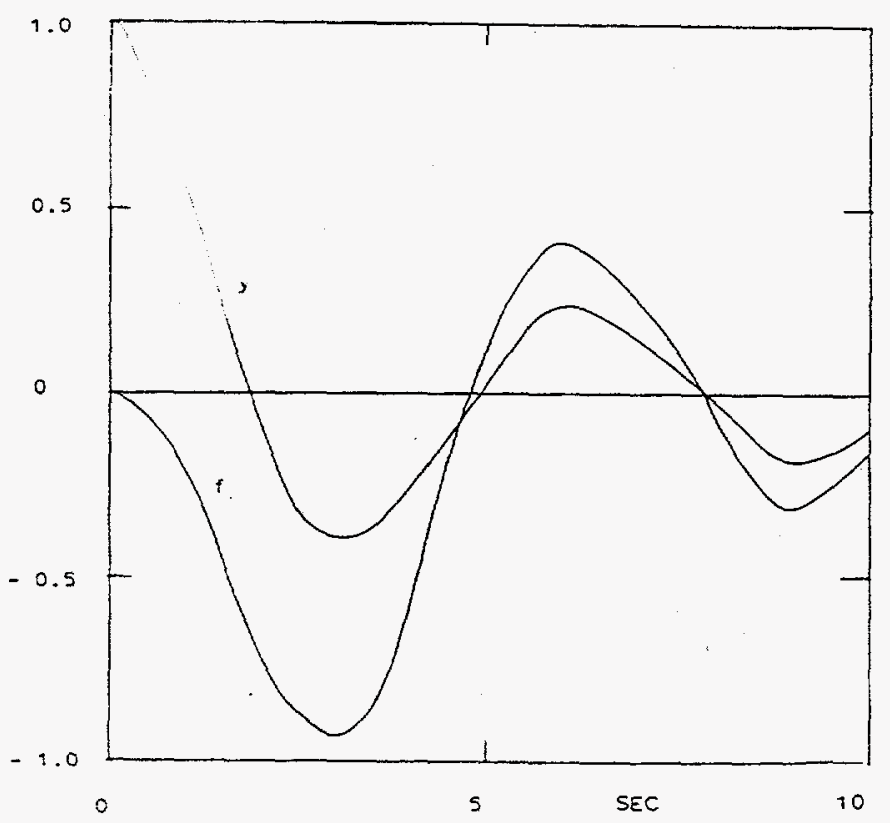

Fig. 12 Transients from initial unit yaw angle for $P=1.03, D_{M}=170, D_{T}=$

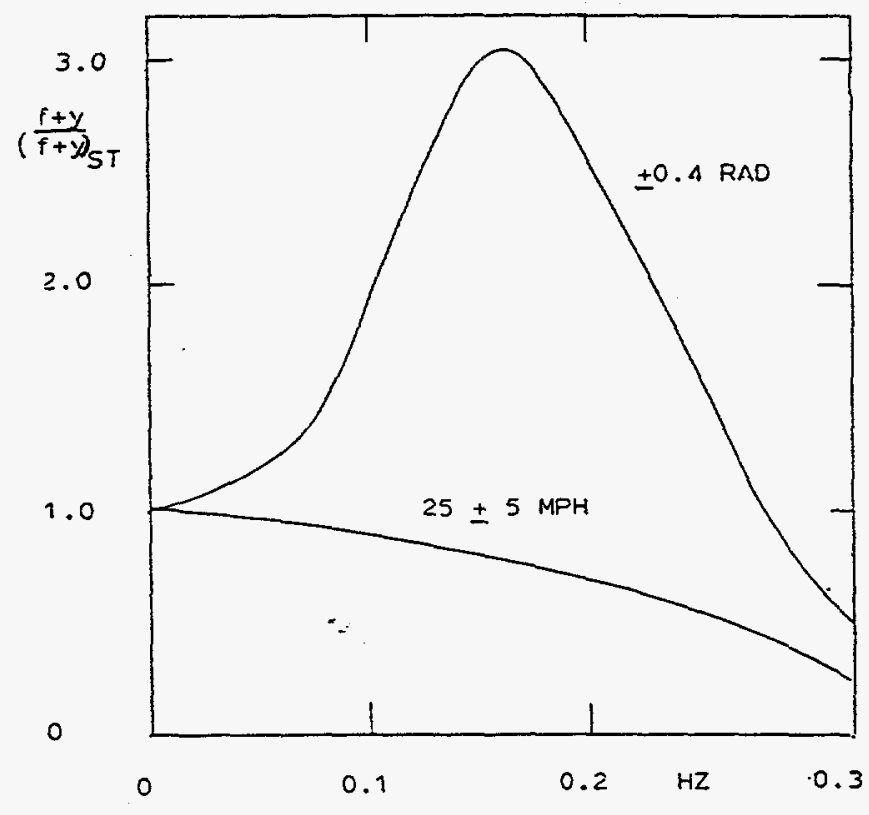

Fig. 13 Frequency responses for rotor yaw angle $(f+y)$ to wind speed and to wind direction oscillations for $P=$ $1.05, \mathrm{D}_{\mathrm{M}}=170, \mathrm{D}_{\mathrm{T}}+540$

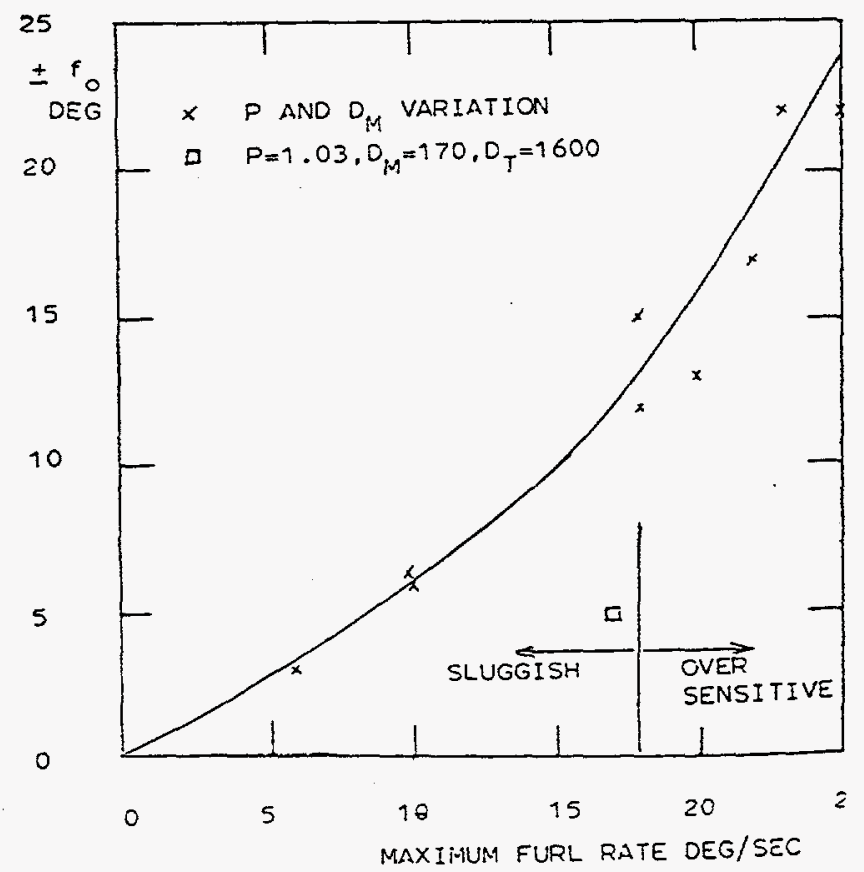

Fig. 14 Experimentally determined qualitative furling characteristics from Table 5 


\section{APPENDIX 3}

Seventh ASME Wind Energy

Symposium, New Orleans, Louisiana

January 1988

Wind Turbine Shut-Down

by Self Yawing

K.H. Hohenemser 
WIND TURBINE SHUT-DOWN BY SELF YAWING

K. H. Hohenemser

Washington University

St. Louis, Missouri

\section{ABSTRACT}

There is a need to safely shut down a wind turbine in response to an emergency signal, without using the control system or a rotor brake, since these components themselves are subject to failure. It is shown that for a teetered upwind turbine such a shut-down can be accomplished by self yawing if the rotor axis is laterally off-set from the yaw axis. The active yaw control system has a clutch which is disengaged in response to an emergency signal whereby the generator power is simultaneously switched off. In case of a fault in the wind turbine or in the electric grid, the turbine then yaws itself to the 90 degree angle position where the rotor is aerodynamically braked to a stand still or to a near stand still. The analysis shows benign transients with moderate over-speed peaks though teeter stop bumping may occur. Initial tests with a 7.6 m diameter teetered fixed pitch rotor confirm the predicted self yawing characteristics.

\section{NOTATION *}

H Rotor horizontal in-plane force, N

I Flapping moment of inertia for one blade, $54 \mathrm{Nm}$

The numbers refer to the experimental wind turbine used for the self yawing tests.

$I_{N}$ Nacglle yawing moment of inertia, $62 \mathrm{~N}$ m $s^{2}$

$\mathrm{K}$ Elastic teeter hinge stiffness, $2480 \mathrm{~N}$ $\mathrm{m} / \mathrm{rad}$

Me Yawing moment from thrust off-set, $T e$ $\mathrm{N}$ m

$M B_{C}$ yawing moment Erom rotor plane side tilt, $T \beta_{C} S / 2 \mathrm{~N} m$
${ }^{M}$ Yawing moment from teeter spring, $K \beta_{c} / 2 \quad N m$

$M_{H}$ Yawing moment from $\mathrm{H}$-force, $\mathrm{H} S \mathrm{~N}$ m

$M \quad$ Yawing moment from yaw friction, $N$ m

Q Rotor torque, $\mathrm{N} \mathrm{m}$

R Rotor radius, $3.8 \mathrm{~m}$

$\mathrm{s} \quad$ Rotor overhang, $0.7 \mathrm{~m}$

I Rotor thrust, $N$

$v \quad$ Wind speed, $\mathrm{m} / \mathrm{s}$

$C_{0.7}$ Blade chord at $0.7 \mathrm{R}, 0.19 \mathrm{~m}$

$c_{Q}$ Rotor torque coefficient, $Q / \rho \pi R^{2}(\Omega R)^{2}$ R

$C_{T}$ Rotor thrust coefficient, $T / Q \pi R^{2}(Q R)^{2}$

$c_{L \alpha} \quad$ Lift slope of blade airfoil, 5.6

CDO Blade airfoil profile drag coefficient

e Lateral rotor axis off-set, $0.106 \mathrm{~m}$

t Time

$\alpha \quad$ Blade airfoil angle of attack

B Rotor tip path plane side tilt angle

$\bar{B}_{S} \quad$ Rotor tip path plane uptilt angle

$\bar{B}$ Tqtal rotor plane tilt angle, $\left\langle\beta_{S}^{2}+\right.$ $\left.\mathrm{B}_{\mathrm{C}}\right)^{1 / 2}$

$\bar{\beta}_{C} \bar{\beta}_{s}$ Rotor tip path plane tilt angles per unit yaw rate, $s$

$r$ Blade Lock number, $c_{L_{\alpha}} \circ c_{0.7} R^{4} / I=5.0$

$\delta_{3}$ Delta three angle of teeter hinge, 67 deg 


Air density, $1.2 \mathrm{~kg} / \mathrm{m}^{3}$
$\sigma \quad$ Rotor solidity ratio, $2 \mathrm{c}_{0.7^{/ \pi R}=0.032}$
$\phi \quad$ rotor axis uptilt angle, 7 deg
$x \quad \begin{aligned} & \text { Rotor yaw angle from upwind position, } \\ & \text { clockwise in top view }\end{aligned}$
$\dot{X} \quad$ Rotor yaw rate, $\mathrm{s}^{-1}$
$\ddot{X} \quad$ Yaw acceleration, $\mathrm{s}^{-2}$
$\& \quad$ Angular rotor speed, initially $21 \mathrm{~s}^{-1}$
$\dot{\&} \quad$ Rotor acceleration, $\mathrm{s}^{-2}$

Note: Yawing moments are positive when acting in positive yaw angle sense

\section{INTRODUCTION}

Larger wind turbines are using a sophisticated system of automatic shut-down after some faults in the turbine or in the electric grid have been signalled by the emergency system. Such a shut-down must be possible even if the fault is in the turbine control system which usually accomplishes start-up and shut-down. For example, one employs a pressurized hydraulic fluid reservoir capable of a turbine shut-down in the case of a failure in the hydraulic pressure supply system for the turbine controls. This reservoir is, of course, of no use if the failure is in the control system itself rather than in its power supply. Thus there is a need for an emergency shut-down system which does not use the turbine control system or a rotor brake since these components themselves can fail. The subject of this paper is a method of emergency shut-down for a upwind horizontal axis teetered wind turbine which has an active yaw control system. In the analysis and tests the blade pitch angle was fixed. though the method is not necessarily limited to fixed pitch wind turbines. Shut-down is accomplished totally by self yawing, requiring neither blade feathering, nor the functioning of the active yaw control system, nor aerodynamic, nor a mechanical brake.

The self yawing process to be studied here is different from the downwind or upwind self alignment used in previous wind turbine types. Rather than at zero or 180 deg yaw angle, the equilibrium yaw position is at 90 deg yaw angle where the rotor plane is edgewise to the wind so that the rotor will decelerate and come to a stand still or near stand still. The proposed method of wind turbine shut-down by self yawing has been studied for a teetered rotor because this rotor type is capable of rapid yaw rates. The method may not work for rigid rotors because of their low yaw rates and because of their entirely different yawing characteristics. Test results on shut-down by self yawing were obtained after modifying the $7.6 \mathrm{~m}$ diameter teetered fixed pitch upwind turbine at washington University's
Tyson Research Center near st. Louis, Missouri, whereby the tailvane and the passive furl control system were replaced by an active yaw control with a remotely operated clutch.

SYSTEM DESCRIPTION

Eig. 1 shows rotor yaw angles in the upwind quadrant, $x<90$ deg, and in the downwind quadrant, $X>90 \mathrm{deg}$. The yaw gear includes a clutch which can either be remotely released or can slip beyond a certain predetermined yawing moment. The rotor axis is laterally off-set from the yaw axis $Y$. After release or slippage of the clutch, the rotor is self yawing under the influence of the yawing moment from the off-set thrust. In the upwind quadrant, the thrust moment tends to increase the yaw angle. In the downwind quadrant the thrust tends to decrease the yaw angle. A yaw trim equilibrium position will be obtained at 90 deg yaw angle provided the nacelle minus rotor yawing moment is made zero for this position.

The rotor axis has a built-in uptilt angle and the rotor turns in a direction such that the yaw component of the rotor torque gives at normal operation, a yawing moment opposite to that of the rotor thrust. If seen downwind the yaw axis is left of the rotor axis, the rotor must turn clockwise. If the yaw axis is to the right of the rotor axis, the rotor must turn counter-clockwise as shown in Fig. 1. The rotor axis off-set and uptilt angle are preferably selected such that in the main wind speed range the yawing moments from rotor thrust and from rotor torque balance. This minimizes the required yaw motor power. Beside reducing the yaw motor power, the rotor axis uptilt angle has another beneficial effect, namely to keep the rotor overhang and the nacelle inertia small. in any kind of abnormal behavior--excessive vibrations, overvoltage, overcurrent etc.-the generator is automatically disconnected

from the electric grid so that self yawing into the 90 deg yaw angle position of the rotor axis is only required power-off. The question then arises whether after a sudden loss of rotor power, an orderly transition to the 90 deg yaw angle position without excessive overspeed and without excessive teeter amplitudes can be expected.

OUTLINE OF ANALYSIS

The purpose of the analysis is to study the power-off self yawing dynamics of a wind turbine with the features shown in Fig. 1 . The yaw dynamics analysis model of Reference 1 could be used for this purpose if some limitations were removed. Presently this analysis is limited to a prescribed yawing motion and is not applicable to the case of self yawing. In Reference 2 the model of Reference 1 was used to determine yawing moments from steady yaw deflections and from steady yaw rates. Here simple approximations for estimating rotor yawing moments will be derived. The data needed for the analysis of the experimental wind turbine are given in the Notation.

Though the principle of the estimates given here is straight forward, the details are hard to follow. With such a drastically simplified analysis one would expect only the establishment of trends but not quantitative 
correct results. The analysis was performed rather elaborate modification of the wind turbine in preparation of the shut-down tests by self yawing. A critique of the approximations made in the analysis will be given in the subsequent section.

The steady state rotor characteristics are taken from Reference 3 Fig. 2-1. They were computed for near zero blade pitch angle with the classical method of Reference 4 using a profile drag function of

$$
c_{\text {DO }}=0.010+0.5 \alpha^{2}
$$

typical of many airfoils up to the stall limit. Though the actual blade is twisted and tapered, the analysis assumes an untwisted untapered blade with a chord equal to that at $0.7 \mathrm{R}$. Spot checks with the more elaborate analysis showed adequate agreement for the purpose of a yaw analysis. The results are shown here in a different form from that used in Reference 3. Fig. 2 gives for five speed ratios $V / Q R=0.08$ to 0.24 the thrust coefficient $c_{\mathrm{T}} / \sigma$ between zero and 180 jeg yaw angle. The thrust is zero at 90 deg yaw angle and reverses beyond 90 deg, seen from the same side of the rotor. Expressed in a different way, this means that the rotor thrust always has a component in the wind iirection. Within the range shown in Fig. 2 there is no blade stall. For higher values Jf the thrust coefficient the straight lines vill flatten their slope because of partial slade stall.

For these same five speed ratios Fig. 3 jives the torque coefficient $c / \sigma$ between iero and 180 deg yaw angle. Posilive values if $\mathrm{c}_{0} / \sigma$ indicate a driving torque, negative ralues a braking torque. It is seen that raking torque is available for $V / Q R=0.08$ setween 60 and 120 deg yaw angle. For higher peed ratios the yaw angle range for braking orque gets much smaller. For $V / Q R=0.24$ he braking range is only between 82 and 98 leg yaw angle. For a yaw angle somewhat ifferent from 90 deg, the rotor speed will low down to a small value, but at a given ind speed the rotor may not stop completely - that a weak rotor brake is required for btaining rotor stand still while the wind is lowing and to prevent a restart, should the acelle drift away from the 90 deg yaw osition.

Fig. 4 shows the relationship between orque coefficient $c / \sigma$ and the absolute alue of the thrust colfficient $c / \sigma$ which is alid for all speed ratios and for all yaw ngles. This relationship will be used to stimate in-plane rotor forces.

For the yaw dynamics analysis the ollowing assumptions are made which, by omparison with the elaborate yaw dynamics sdel of Reference 1 are found to yield iasonable accuracy.

1. The steady state conditions of Figs. 2 and 3 are also valid in the presence of yaw rates or of teeter amplitudes.

2. Only first harmonic teetering is considered, representing rotor plane side tilt and uptilt. The rotor thrust is tilted on the average to the side by one-half of the blade teeter angle in the blade horizontal position.
3. The horizontal rotor force, called Hforce, is on the average equal to onehalf of the H-force for the vertical position of the blade pair.

4. Fot the vertical position of the blade pair, the increment in thrust on the upper blade from the gyroscopic moment causes an increment in torque according to Fig. 4.

5. Side tilt angles and H-forces from yaw angle are neglected as compared to those from yaw rates.

6. Blade twist and blade coning are neglected.

7. Self yawing to shut-down is only studied power-off, not power-on, where shut-down can be achieved by the yaw motor.

The rotor tip path plane side tilt angle $B$ and the uptilt angle $B$ associated with yw rate $x$ can be found by solving the following linear equations, see for example Reference 5

$$
\begin{aligned}
& \left.\quad(K / 2 I Q)(8 / \gamma)+\tan \delta_{3}\right) \beta_{c}+\beta_{s}=X / Q \\
& \left.-\beta_{c}+\left(K / 2 I Q^{2}\right)(8 / \gamma)+\tan \delta_{3}\right) \beta_{c}=-(16 / \gamma) \chi / Q
\end{aligned}
$$

with the rotor data given in the Notation, $\delta$ $=63 \mathrm{deg}, r=5.0, \mathrm{~K}=2480 \mathrm{~N} \mathrm{~m} / \mathrm{rad}, I=54 \mathrm{~N}$ $m s^{2}$, one obtains the tilt angles per unit yaw rate $\bar{\beta}=\beta / \chi, \bar{\beta}_{s}=\beta / X$ vs rotor angular speed \& seen in ${ }^{\prime}$ Fig. $\xi$. For known yaw rates $X$, the two yawing moments from thrust and from teeter springs can now be determined.

$$
\begin{aligned}
& M_{B_{C}}=T \beta_{c} 0.35 \times \mathrm{N} \mathrm{m} \\
& M_{S}=-1240 \bar{\beta}_{c} \times \mathrm{N} \mathrm{m}
\end{aligned}
$$

The angles $\beta_{\beta}$ and ${ }_{\beta}$ must be measured in radians rathef than in ${ }^{s}$ deg. Note that with the sign convention of the Notation, a positive yawing moment turns the nacelle clockwise seen in the top view and has the same direction as the positive yaw angle. Positive yaw damping requires, for positive clockwise yaw rate, a negative sign of the

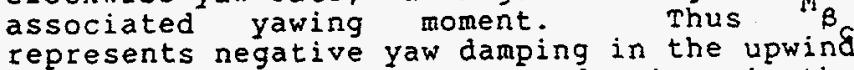
quadrant but positive yaw damping in the downwind quadrant where the sign of $T$ is reversed, see Fig. 2. In contrast, the teeter spring yawing moment $M_{S}$ is for positive $\chi$ always negative and cont ${ }^{\prime}$ ibutes to the rotor yaw damping.

In addition to the two yawing moments from tip path plane side tilt angle 6 ' expressed in eg. (3) and (4), there is the yawing moment from thrust off-set $e$

$$
M_{e}=T e
$$

Power-on there are several more yawing moments to consider, the most important one from the rotor axis uptilt angle

$$
M_{\phi}=-Q \phi
$$

For the selected thrust off-set and sense of rotation it opposes the thrust moment $M$. In Reference 2 it is shown that two further yawing moments are generated by the transmission of the torque from the rotor to the shaft, one proportional to the product $Q B$, the other proportional to $\beta_{C} Q$ tan $\delta_{3}$. Ackording to assumption 7 , none of these yawing moments are of concern since during 
self yawing no torque is transmitted to the shaft. Instead, the rotor torque is totally absorbed by the rotor inertia.

It remains to derive a simple estimate for the H-force with the yawing moment

$$
M_{H}=\mathrm{H} S
$$

According to assumption 5, only the yaw rate related $\mathrm{B}$-force will be needed. For the vertical position of the blade pair, Fig. 6 , the torque is replaced by the opposing forces Q/1.4 R located at the $0.7 \mathrm{R}$ stations. The thrust is replaced by the parallel forces $T / 2$ located at the $0.7 \mathrm{R}$ stations. For a clockwise yaw rate seen from the top as indicated in Fig. 6, the blade pait exhibits the gyroscopic moment 4 IRX which increases the thrust of the upper blade by

$$
\Delta T=4 I Q X / 1.4 R
$$

The thrust of the lower blade is decreased by the same amount. According to assumption 4, the torque increment from this thrust increment can be obtained from the slope of the torque-thrust relation shown in Fig. 4. The horizontal in-plane forces for the upper and the lower blade are additive, however, the average over one-half revolution is only one half of the horizontal force on the blade pair in the vertical position. Thus the Hforce from yaw rate is estimated by the expression

$H=\Delta Q / 1.4 R=(4 I \Omega X / 1.4 R)(\Delta Q / 1.4 R) /(\Delta T / 2)$

with

$$
\Delta Q / \Delta T=R d c_{Q} / d c_{T}
$$

one finally obtains with eq. (7) the estimate for the yawing moment from the H-force

$$
M_{H}=S 4 I \&\left(d c_{Q} / d c_{T}\right) X / R
$$

The derivation is given and Fig. 6 is shown for the upwind position of the rotor. In the frontal view the horizontal in-plane force is then to the left and the yawing moment of eq. (11) has the same sign as the yaw rate, that means the damping is negative. For the downwind position, the sense of the yawing moment from $x$ is reversed as one can see if one redraws Fig. 6 for downwind operation when $\&$ and $T$ have their sign reversed. Formally this can also be concluded from eq. (11) since $d c^{\prime} / d c_{T}$ will be negative for $x>$ 90 deg, see Flgs. ${ }_{2}$ and 3 .

Ali aerodynamic terms are now defined. Rotor thrust and torque are the steady state values and depend only on yaw angle $X$, speed ratio $V / \Omega R$ and rotor speed $Q, F i g s .2$ and 3. The driving torque is entirely absorbed by the rotor inertia so that

$$
\dot{Q}=Q / 2 I
$$

Mechanical yaw friction will be included according to

$$
M_{F}=-\operatorname{sign} \times 160 \mathrm{~N} \mathrm{~m}
$$

The yaw rate varies according to

$$
\dot{x}=\left[M / I_{N}\right.
$$

where the summation extends over the five moments from eqs. (3), 4), (5), (11), (13).

Note that with decresing angular rotor speed \& the two yaw damping terms from Eqs (3) and (11) decrease in absolute values as compared to the yaw damping Eq (4) from the teeter spring. At low rpm the teetered rotor behaves more and more like a rigid rotor with its large yaw damping.

\section{CRITIQUE OE ANALYTICAL METHOD}

The assumptions made to obtain a simple estimate of wind turbine shut-down by self yawing of the rotor, will be evaluated in this section. Assumption 1--rotor thrust and torque are the steady state values for a given rotor speed-are very well substantiated by the analytical model of Reference 1 . However, this model neglects blade stall effects. Assumption 2--only first harmonic teetering is considered--is certainly adequate for yaw dynamic studies. The higher harmonics influence the blade loads and vibrations, but not the rather slow yawing motions. The assumption that the rotor thrust tilts on the average with one half the teeter angle of the blade in horizontal position is proven lead to only small errors as compared to the elaborate Reference 1 analysis. Assumption 3--that the H-force is on the average equal to one half the H-force for the vertical position of the blade pair, is also well substantiated in Reference 2 . The estimation of the H-force accorcing to assumption 4 with the help of Fig. 4 is good for zero delta three angle, but in error for 67 deg delta three angle, where the H-force, according to Reference 2 , is only $2 / 3$ of that for zero delta three. The reason is that the blade pitch angle in the vertical blade position is not equal to the average pitch angle on which Fig. 4 is based. Thus the estimate of the rotor damping - negative in the upwind quadrant positive in the downwind quadrant is for the rotor with $\delta_{3}=67$ deg clearly on the high side. Assumption 5--the neglect of the side tilt angle and H-force from yaw position, is justified by the much larger effect of lateral thrust off-set. Assumption 6--the neglect of blade twist, is reasonable in the upwind quadrant but may lead to a larger error in the downwind quadrant because the adverse twist facilitates blade root stall. The neglect of the coning angle is justified because of the stiff blades of the experimental rotor and the absence of a built-in coning angle. Possible errors in the foregoing analysis are believed to arise from the neglect of partial blade stall and of teeter stop bumping. There is a need to extend the analysis of References 1 and 2 into the region of partial blade stall and of teeter stop impacts.

NUMERICAL DATA

The numerical data in this section apply to the experimental wind turbine after its modification to test shut-down by self yawing, so that a comparison between analytical and test data would be possible. 
The wind speed is $10 \mathrm{~m} / \mathrm{s}$. The rotor speed $\&$ vs yaw angle and the steady state yawing moment in autorotation are shown respectively in Figs. 7 and 8 . The dimensionless rotor axis off-set for the Tyson rotor is $e / R=0.028$. Due to the high rotor speed $Q$, the yawing moments are very large and rapidly increasing on both sides of the 90 deg yaw position. There is a strong static yaw stability with the yaw trim position at 90 deg yaw angle. To relieve the yaw motor of the Me-load in normal poweron operation, a smaller value of $e / R$ is desirable. The value of $e / R=0.01$ gives at $10 \mathrm{~m} / \mathrm{s}$ wind speed power-on a value of $M$ which about balances the yawing moment $M$ of eq. (6) from the 7 deg uptilt angle of the rotor axis.. As Fig. 7 indicates, there is only a small yaw angle range on each side of the 90 deg value where the rotor will come to a complete stand-stili.

Next, a transient is computed from an upwind position of $x=10$ deg to the 90 deg yaw angle trim position. At time $t=0$ the rotational speed is $Q=21 \mathrm{rad} / \mathrm{s}$. The initial value of $10 \mathrm{deg}$ is selected because between zero and 10 deg yaw angle, thrust $T$ and torque $Q$ vary very little. A numerical stepwise integration of eqs. 12 and 14 is performed with a time step of $1 / 4 \mathrm{~s}$. Three cases are,presented in Fig. $9, e / R=0.028$ without and with a yaw friction moment of 160 $N m$, and $e / R=0.01$. The upper graph, extending over 4 seconds of the transient, shows a well behaved yaw angle time history. The middle graph shows the rotor speed transients. Without the yaw friction, the overspeed is below $20 \%$, including the yaw friction the maximum overspeed is about $30 \%$. The lowest graph shows the teeter amplitude transients. It is seen that for the cases without the yaw friction, teeter stop bumping would occur. Thus, the friction is desirable though the overspeed will be higher and the nacelle will come to rest at less than 90 deg yaw angle. The rotor will not come to a complete stand still and a weak brake is required.

It should be noted again that the self yawing transient is only needed in case of a fault in the machine or in the electric grid. Since this can be expected to be a relatively infrequent event, rather high short term blade and hub loads from teeter stop bumping could be tolerated. The numerical analysis applies to a stiff rotor with rather low lock number. Larger rotors can have softer blades and a higher lock number so that the results for the experiment rotor may not directly

apply to much larger wind turbines. As a comparison to shut-down by self yawing shutdown using the yaw motor is shown in Fig. 10. The nacelie is first yawed with the maximum yaw rate of $0.5 \mathrm{rad} / \mathrm{sec}$ until the power has decayed to zero. The yaw rate is then gradually reduced and the rotor speed gradually drops to zero. The lower graph of Fig. 10 shows the teeter amplitude which is now well below the stop bumping limit.
TEST CONFIGURATION

The following is a brief description of the equipment used for an initial test on wind turbine shut-down by self yawing. For this test the available wind turbine had to be rather drasticaliy modified. The configuration of the $7.6 \mathrm{~m}$ diameter tail vane stabilized teetered upwind turbine at Washington University's Tyson Research Center as of May 1985 is described in Reference 6 . In the spring of 1986 a mechanical tail vane damper was added consisting of a commercially available electrically operated brake located on the tail vane boom and driven from the tower by chain and sprockets. Analysis and test results with this mechanical tail vane damper are given in Reference 7. In the spring of 1987, the passive nacelle yaw control system shown in Fig. 3 of Reference 7 was removed together with the tail vane and most of the tail boom. It was replaced by a rigid connection between nacelle and truncated tail boom and by an electrically powered yaw drive with remotely adjustable electrically operated slip ciutch. The 90 VDC yaw motor, the $60: 1$ worm gear drive and the clutch are located on the truncated tail boom, see Fig. 11. The yawing moment is transferred to the tower by the same 5.3:1 chain drive previously used to drive the electrically operated brake. The nacelle slip yawing moment can be remotely adjusted between zero and $220 \mathrm{~N} \mathrm{~m}$. The nacelle yaw rate can be remotely adjusted between zero and $0.5 \mathrm{rad} / \mathrm{s}$.

While it is planned to install automatic controls for the yaw motor, the test reported here was accomplished with manual yaw motor rate control. The position of the wind vane located on the truncated boom (see Fig. 11) is displayed near the yaw motor controller together with nacelle position and rotor speed, see Fig. 12 . These three signals together with four other signals from a generator power meter, from a generator current meter, from an anemometer and from a nacelle accelerometer are recorded on a strip chart. Wind following is achieved manualiy with the yaw motor rate controller whereby the vane position display indicates the rotor yaw angle. Adjustment of the yaw slip clutch moment is achieved by the clutch controller located adjacent to the yaw motor rate controller. see Fig. 12. When the generator over-current circuit breaker trips or grid power fails, a relay opens the yaw slip clutch circuit and the nacelle yawing moment goes to zero, whereupon the nacelle self yaws to the 90 deg yaw angle position and the rotor gradually comes to a standstill. Thus an error in operating the yaw motor rate controller or a grid power failure lead to an automatic shut-down of the wind turbine which does not require a power source or an actuator.

INITIAL TEST RESULTS

Initial test results on wind turbine shut-down by self yawing are shown in $F$ ig. 13 which compares the analytic yaw transient after power cut-off with the test transient. The analytic graph is for $\mathrm{e} / R=0.028$ and zero yaw friction. The initial speed ratio for the analysis and test is $V / \Omega R=0.08$. Thus the wind speed for the two yaw transients shown in Figs. 9 and 13 is not the 
same. Teeter stop bumping, neglected in the analysis, did occur during the test. As clearly indicated by the nacelle acceleration trace, there were 6 stop impacts with a frequency of two per rev over a period of one second indicated in Fig. 13. The teeter stop impacts presumably reduce the negative yaw damping in the upwind quadrant and reduce the yaw rate. Except for minor deviations, the two yaw transients determined from analysis and test agree well with each other. Only one graph is shown for the rotor speed since the deviations between analysis and test result are quite small. The teeter amplitude is not measured. However, the period of teeter stop impacts from the analysis agrees with that from the tests. A comparison between Figs. 9 and 13 shows that higher wind speed produces higher yaw rates, greater overspeed and more intense teeter stop bumping. Introducing yaw friction alleviates teeter stop impacts but increases the overspeed so that a trade-off will be required. It is planned to conduct further shut-down tests by self yawing in the

presence of higher wind speed and with lower thrust off-set $e / R$.

Though the initial tests, confirming the analysis, look promising, there is still much more analytical work, design work and testing to be done before the concept of emergency shut-down by self yawing can be applied in the field. One question is the effect of nacelle aerodynamics on the shut-down process, another, what the yaw dynamics will be after shut-down. The truncated boom shown in Fig. 11 was designed to balance the yawing moment of the standing rotor when its axis is crosswise to the wind. After shut-down by self yawing, the rotor axis remained crosswise to the wind for a considerable, but then drifted slowly either toward the upwind or the downwind position. Such a behavior may be entirely satisfactory even at high wind speed. Another more basic question is whether power control of a fixed pitch rotor by active yawing, which has been proven very undesirable for rigid rotors, is a useful concept for teetered rotors. This question requires a lot more attention.

CONCLUSIONS

1. An upwind horizontal axis teetered wind turbine with a lateral off-set of the rotor axis from the yaw axis has a power-off yaw trim position at 90 deg yaw angle where the rotor is edgewise to the wind direction and will shut itself down.

2. For a self yawing autorotating teetered rotor the yaw damping in the quadrant between zero and 90 deg angle is negative, in the quadrant between 90 and 180 deg yaw angle it is positive

3. After disengaging the yaw drive and the rotor generator load, such a wind turbine will yaw itself from the upwind operating position to the 90 deg yaw angle position where it will come to a stand still or near stand still.
4. A simplified analysis and tests show benign transients with moderate overspeed. Without yaw friction teeter stop bumping occurs during a brief period. According to the analysis this could be avoided by a proper choice of rotor axis off-set and yaw friction.

5. Initial wind turbine shut-down tests by self yawing prove the feasibility of this concept for the type of machine tested. The yaw and rotor speed transients and the periods of teeter stop impacts from test and analysis are in close agreement.

\section{REFERENCES}

1. Swift, A. H. P., "The Effects of Yawed Flow on wind Turbine Rotors," DSC Thesis, washington university st. Louis, Missouri, May 1981.

2. Swift, $A$. Hohenemse $r, K$. and Rangwala, S.. "The Effects of Hinge spring Restraints on Two-Bladed Teetered wind Turbine Rotors," Fourth ASME wind Energy Symposium, Dallas, Texas, February, 1985 .

3. Hohenemer, K. H., and swift, A.H.P. "The Investigation of Passive Cyclic Pitch variation Using an Automatic

Control System," SERI/TR-1052-10, May, 1982

4. Gessow, A. and Myers, G.D. Aerodynamics of the Helicopter. Macmillan, New York, 1952

5. Perkins, F. W., and Jones, R., "The Effect of Delta Three on a Yawing HATW Blade and on Yaw Dynamics," Wind Turbine Dynamics DOE COnf-810226, 1981 , pp. 295-299.

6. Hohenemser, K. H., "Analysis and Test Results for an Improved Constant speed Passive Cyclic pitch wind Turbine" SERI/STR-217-3002. DE87001135, Jan. 1987 .

7. Hohenemser, K. H. "Wind Turbine Yaw Dynamics for a Teetered Rotor system", Sixth ASME wind Energy Symposium, Dallas, Texas, February, 1987, pp. 1928. 

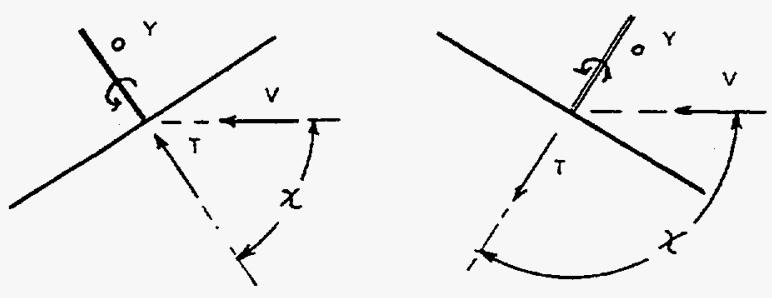

Fig. 1 Schematic Top Views at Yaw Angle less and more than 90 deg. $Y=$ Yaw Axis, $T=$ Thrust, $V=$ Wind Speed

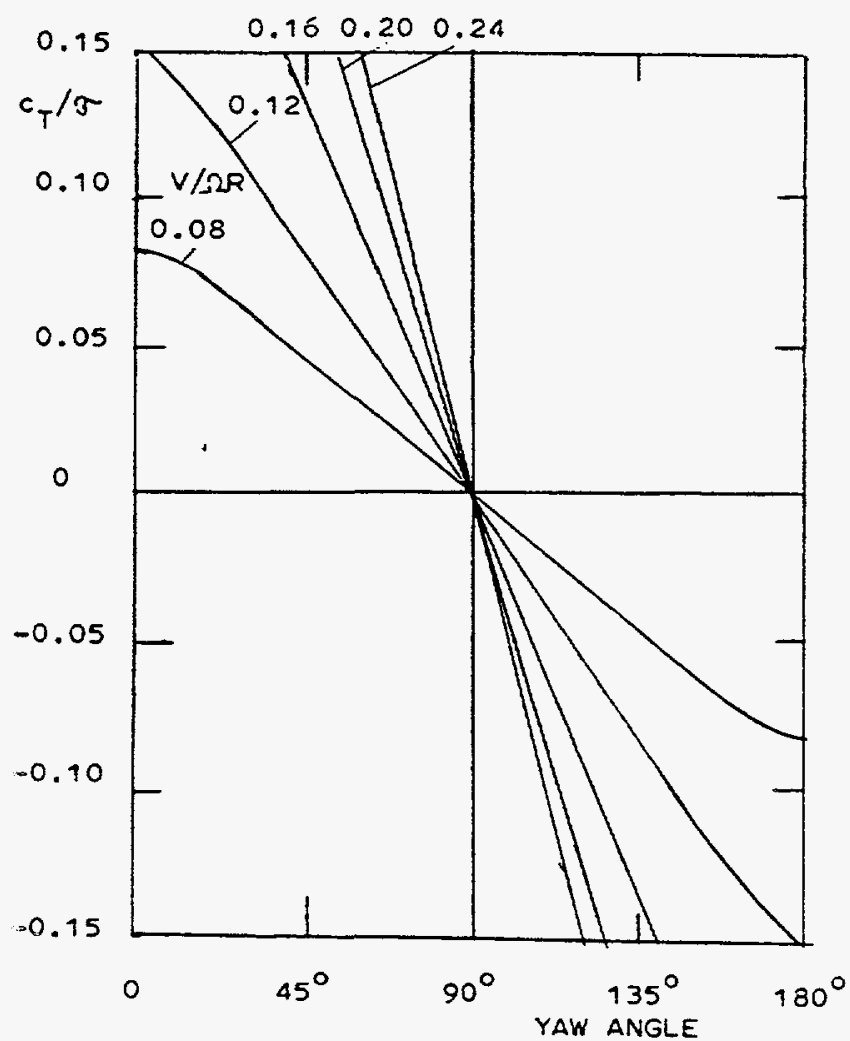

Fig.2 Thrust Coefficient vs. Yaw Angle for Five Speed Ratios

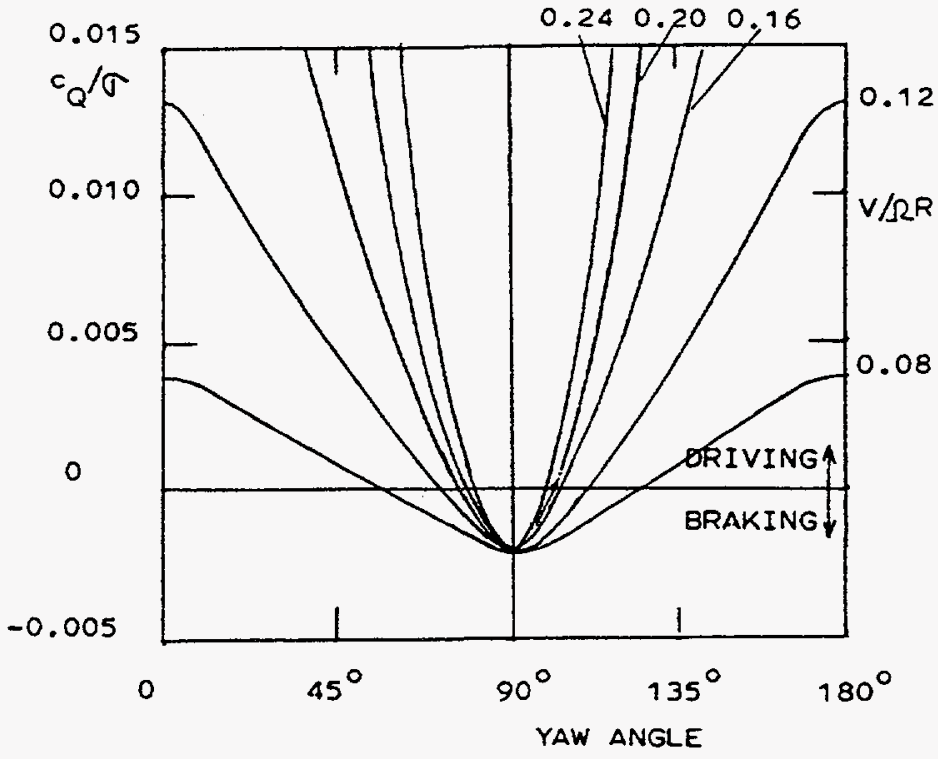

Fig.3 Torque Coefficient vs. Yow Angle for Five Speed Ratios

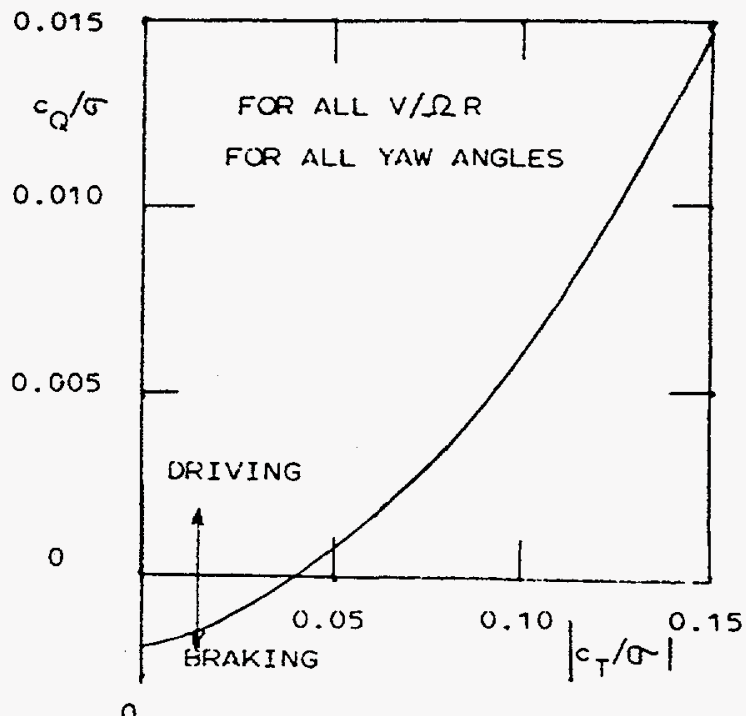

Fig.4 Torque Coefficient vs. Absolute value of Thrust Coefficient 


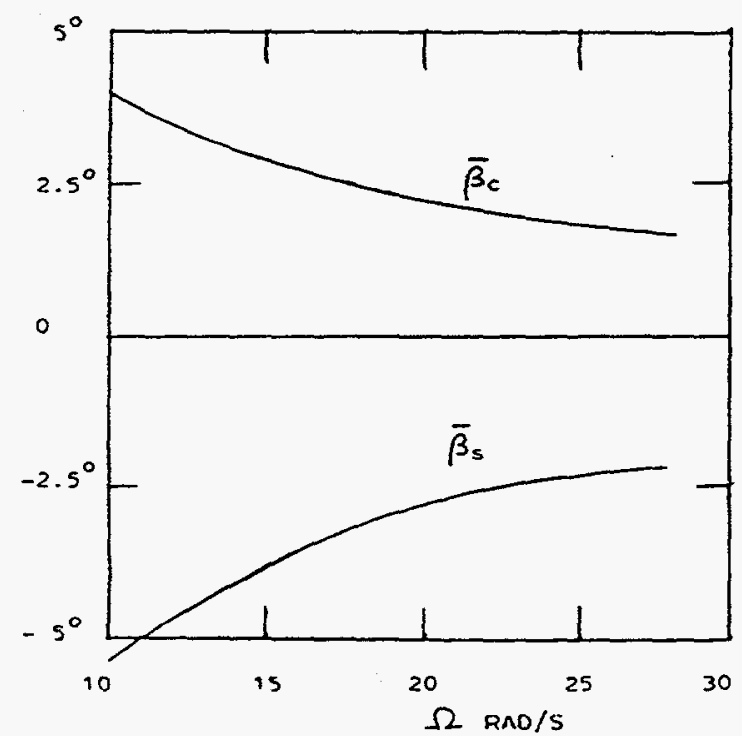

Fig.5 Side $T_{1}$ lt Angle $\bar{\beta}_{c}$ and $U_{p} T$ ilt Angle $\bar{\beta}_{s}$ Der unit Yow Rote vs. Angular Rotor soeed $\Omega$

$(Q+\Delta Q) / 1+5$
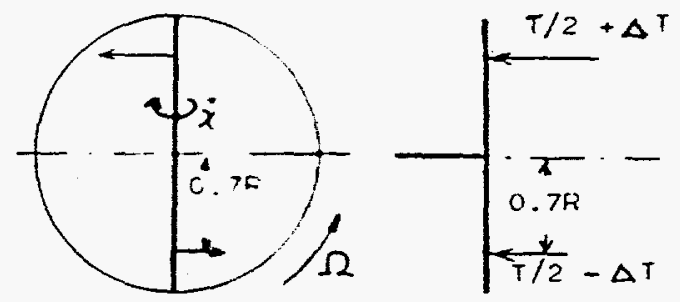

$(0-\Delta C) / 1.42$

Fig.6 Frontal and Side Views of Rotor with Non-Uniform Thrust and Torque from Gyroscopic Moment

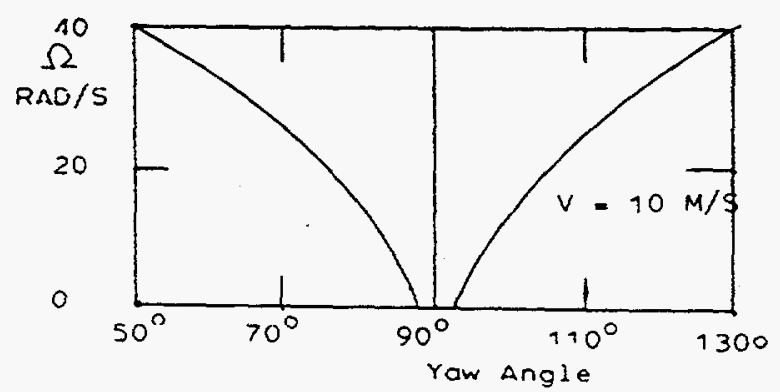

Fig.7 Power-off Angular Rotor Speed vs. Yow Angle

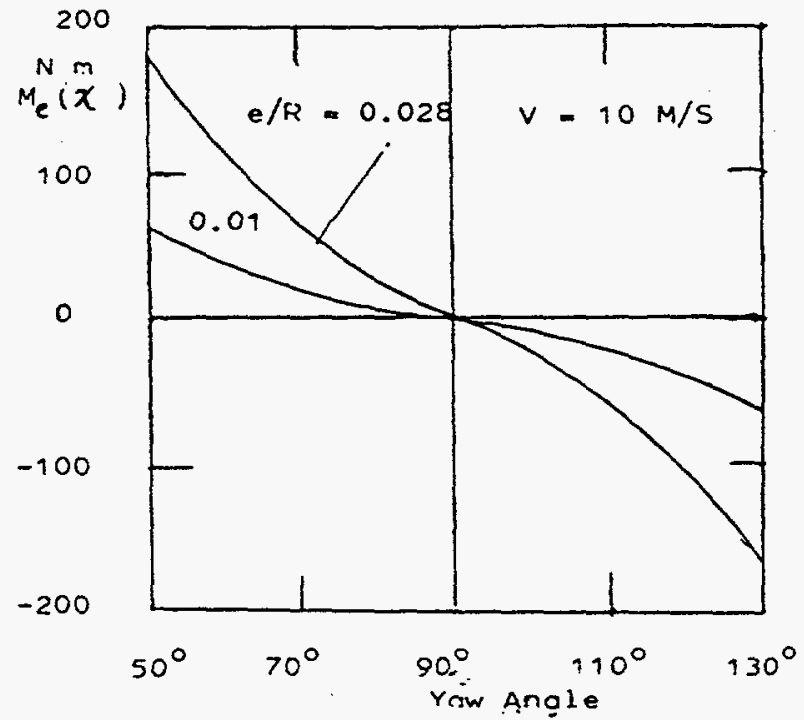

Fig. 8 Power-off Yowing Moment vs. Yow Angle
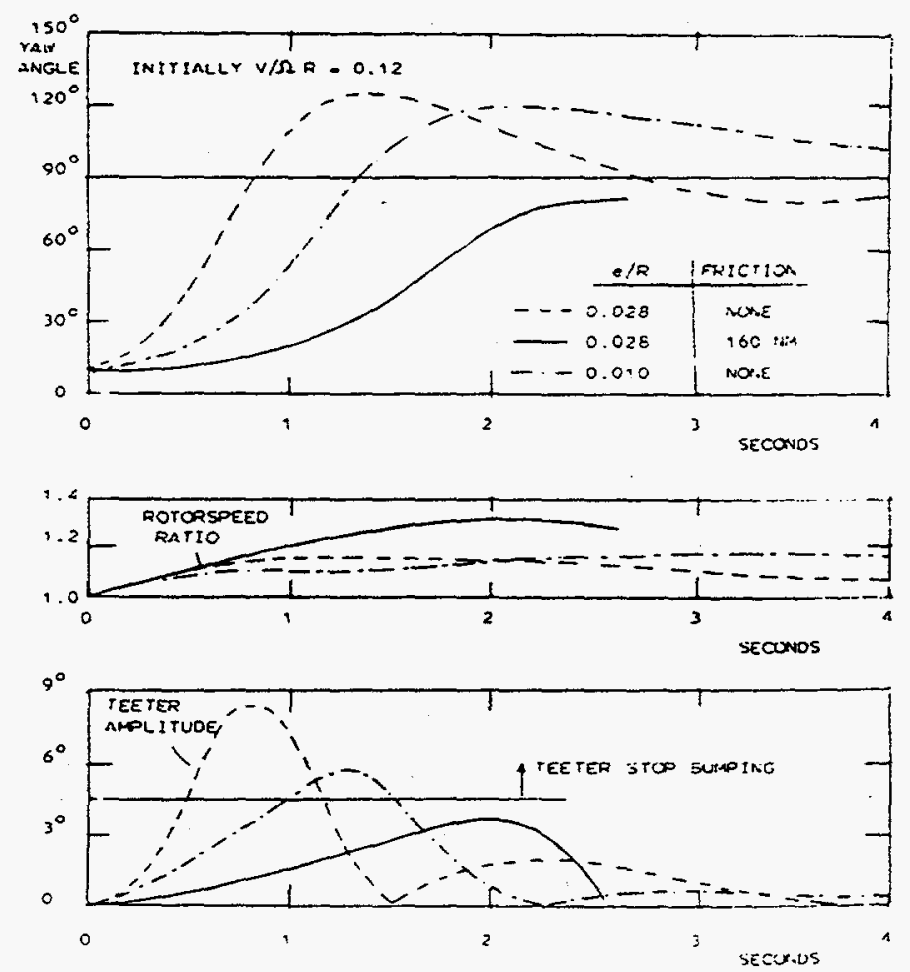

Fig. 9 Power-off Shut-Down by Self Yowing 

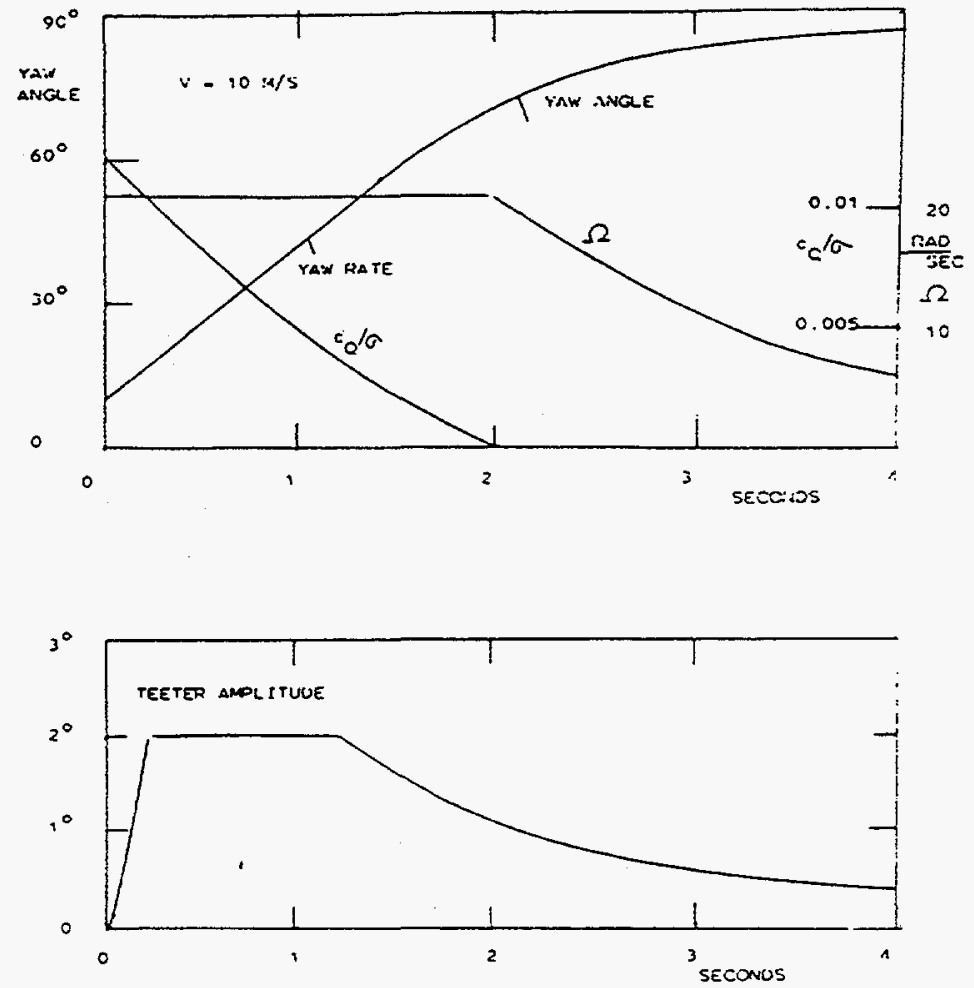

Fig. 10 Power-on Shut-Down with Yow Motor

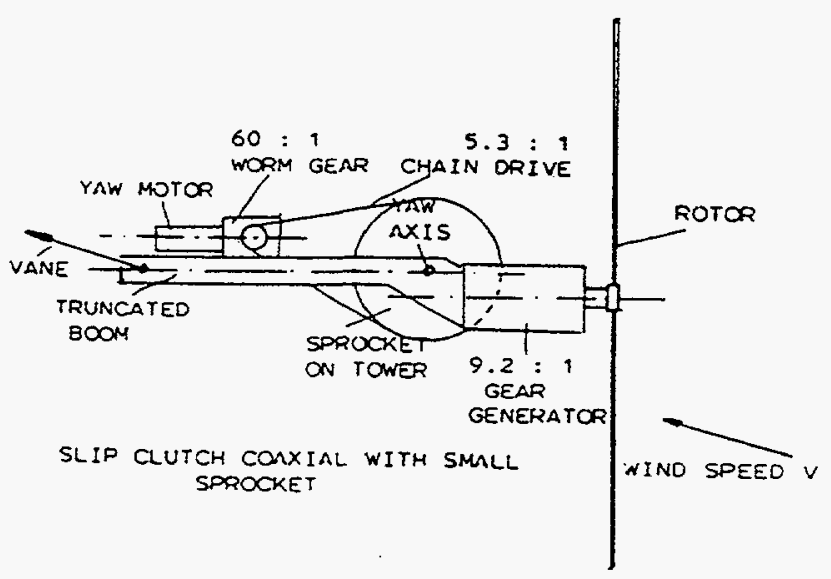

Fig.11 Schematic Plan View of Experimental wind Turbine
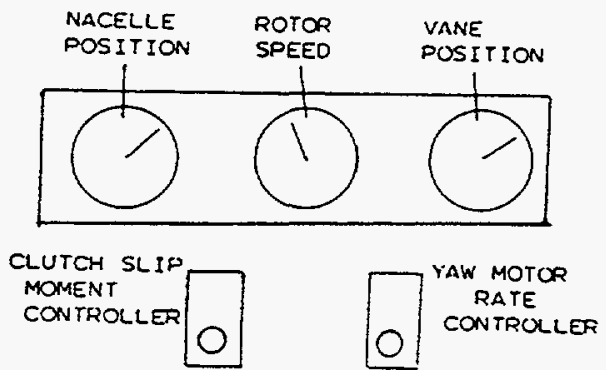

Fig.12 Display and Control Panel
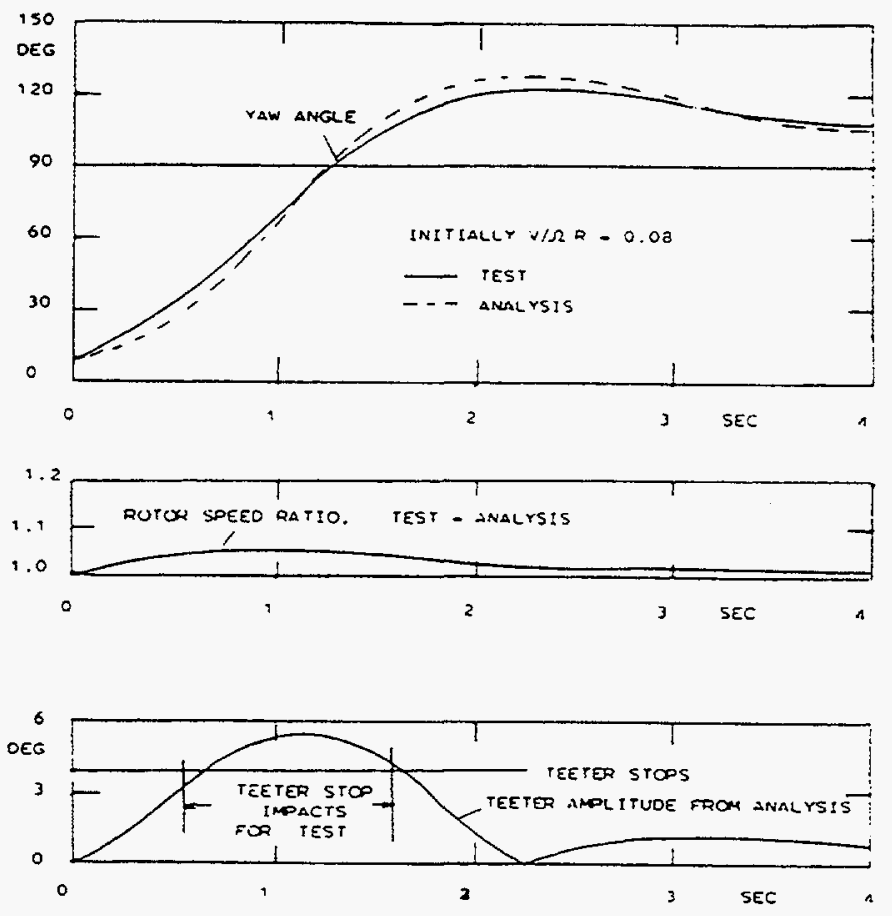

Fig.13 Comparison of Analytical and Test Dato 


\section{APPENDIX 4}

Tenth ASME Wind Energy

Symposium, Houston, Texas

January 1991

Power Regulation by Active Yaw Control for a Teetered Wind Rotor

Extended Abstract

K.H. Hohenemser 


\title{
POWER REGULATION BY ACTIVE YAW CONTROL FOR A TEETERED WIND ROTOR
}

\author{
Kurt H. Hohenemser \\ Washington University \\ St. Louis, Missouri
}

\section{Extended Abstract}

A new type of control system for a fixed pitch teetered wind rotor was studied by analysis and atmospheric testing. Active yaw control was used both for wind following and for power regulation. Experiments with the active yaw control began November 1988, using a facility at Washington University's Tyson Research Center. The upwind teetered rotor of 7.6 meter diameter with a delta three angle of the teeter axis of 67 degrees had previously been tested in a variety of yaw control configurations. They all had in common a freely swinging tail boom with a vertical tail surface at its end. This work, reported in Ref.1, led to the conclusion that the tail vane-rotor aerodynamic interference prevented a generic study of rotor yawing and required the replacement of the tail vane by direct means of active yawing.

Before testing the electro-mechanical yaw control, an automatic emergency shutdown system by purely passive yawing was provided. Analysis and test results for emergency shutdown were reported in Ref.2 which also gave a description of the 300:1 yaw gear drive. The 90 volt DC yaw motor was speed controlled by a Boston Gear Ratiotrol System RG-1 in proportion to a milliamp signal of up to \pm 12 volt. The circuitry of the yaw rate signal generator. designed and built at Washington University. is shown in Fig.1. There were three signal sources arranged in series: a negative volt input producing a negative yaw rate of the nacelle, a positive volt input producing a positive yaw rate when the pilot vane indicated a negative deviation from zero of the nacelle yaw angle, and a second positive volt input triggered by a generator overcurrent which disconnected the yaw angle input. The yaw rate signal passed a RC filter with no overshoot having a time constant of one second. The generator current signal and the nacelle yaw angle signal also passed through RC filters before operating the triggers. Between the yaw angle and the current relay there was a vane action cut-out switch which allowed, when open, operation with constant nacelle position except for overcurrent corrections.

The control dynamics analysis was based on quasi-steady relations both for the generator input power vs. generator current equation and for the rotor power vs. yaw angle equations. This assumption was justified by the slow build-up and decay of the yaw rates enforced by the yaw rate filter and by the limitation of the yaw rates to + 12 and -8 degrees per second. Fig. 2 shows the result of such an analysis for the transient from a $25 \%$ overcurrent of $50 \mathrm{amp}$ to the current trigger setting of 40 amp at a windspeed of 24 miles per hour (10.7 meters per second). The right hand scale gives the corresponding yaw angles.

The trigger lag $t_{L}$ indicates the delay in the reversal of the yaw rate after the trigger setting of 40 amp has been crossed by the generator current. The $25 \%$ overcurrent is corrected within 1.1 seconds. The equilibrium condition shows a limit cycle with a 1.5 second period. Amplitude and period of the limit cycle were found to be sensitive to the trigger lag $t_{L}$, both increasing with increasing lag. The amplitude of the limit cycle - not its period - also increased with wind speed. As will be shown in the full paper. these characteristics are in agreement with observations. The trigger lag was essentially determined by the current signal filter which must be designed such that it does not distort control system produced current limit cycles in the order of one $\mathrm{Hz}$ frequency and yet suppresses once per rotor rev current oscillations of $3.2 \mathrm{~Hz}$ frequency. They are turbulence related and 
increase with aerodynamic effects of blade surface pollution.

Though the results of the very simple quasisteady yaw control analysis agreed surprisingly well with test results obtained during moderate wind fluctuations around 24 miles per hour wind speed, this theory cannot be expected to remain valid for much higher wind speed and for intense turbulence. One can conclude from the work that the Tyson wind turbine in its present configuration is well suited for generic yaw control studies including the substantiation of dynamic yaw codes, if provisions were made to vary the delta three angle of the teeter axis from 67 degrees to lower values and if downwind rotor operation could be added.

\section{References}

1 Hohenemser, K.H.,"Analysis and Test Results for an Improved Constant Speed Passive Cyclic Pitch Wind Turbine," SERI/STR 217. 3002. DE 87001135 . January 1987.

2 Hohenemser. K.H.,"Emergency Shutdown of Wind Turbines by Self Yawing". Seventh ASME Wind Energy Symposium, New Orleans, Louisiana, January 1988, pp 23-31.

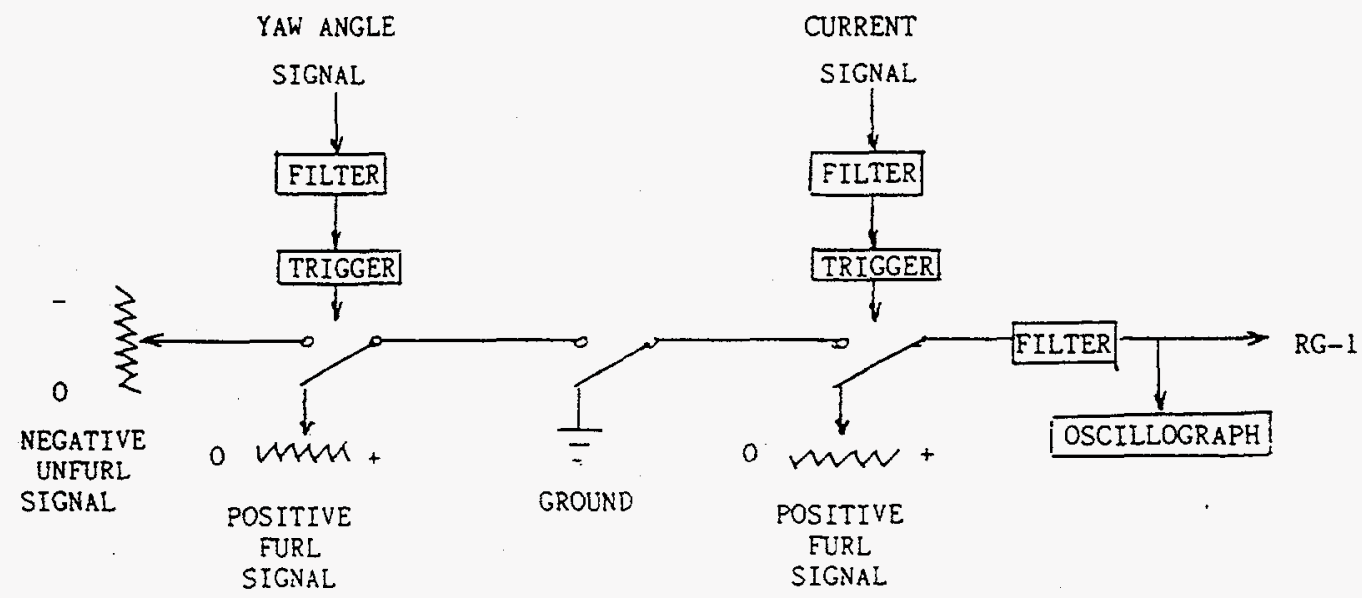

Fig. I Schematic of Yaw Rate Signal Generator Circuitry 


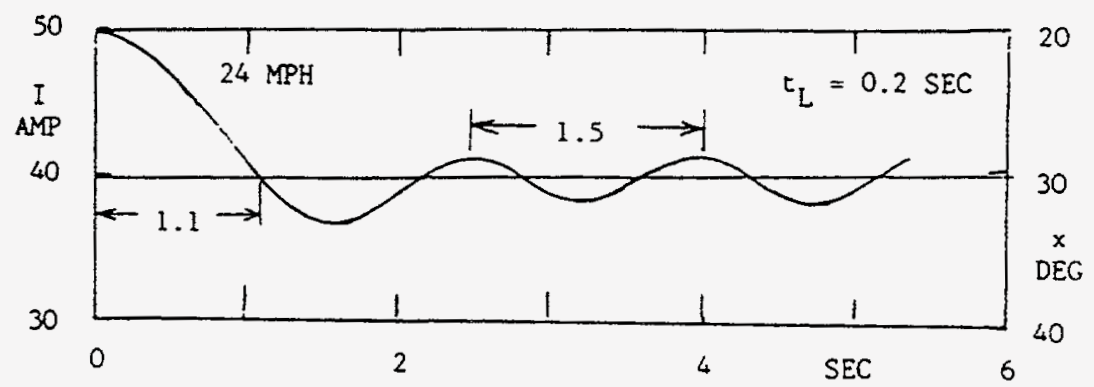

Fig. 2 Computed Response to $25 \%$ Overcurrent at $24 \mathrm{MPH}(10.7 \mathrm{~m} / \mathrm{s})$ Wind Speed 


\section{APPENDIX 5}

ASME Journal of Solar Energy

Engineering, Vol. 106, pp 171-176 May 1984,

On the Design of

Horizontal Axis Two-Bladed

Hinged Wind Turbines

Hohenemser, K.H. and Swift, A.H.P. 
K. H. Hohenemser

Washington University. St. Louis. Mo

\author{
A. H. P. Swift \\ University of Texas \\ El Paso, Texas
}

\section{On the Design of Horizontal Axis Two-Bladed Hinged Wind Turbines}

Hinged two-bladed wind turbines are not necessarily free of disturbing vibrations. The combination of elastic or built-in blade coning with blade flapping about a conventional teeter hinge produces periodic blade angular velocity variations in the blade tip path plane with associated vibrations and dynamic loads. The paper discusses and evaluates various hinge configurations for two-bladed rotors and shows why the conventional teeter hinge leads to nonuniform blade angular velocity in the blade tip path plane. The solution to this problem adopted for two-bladed helicopter rotors, though complex, could be of interest for large wind turbines. A much simpler solution, calling for the suppression of blade flapping by passive blade cyclic pitch variation produced by a strong negative pitch-flap coupling, was found to be practical for upwind tail vane stabilized two-bladed wind turbines.

\section{Introduction}

Though two-bladed wind turbines have lower first cost as compared to three or more bladed turbines, they are usually avoided for medium and small size units because their technology is less well understood by wind turbine designers. For this reason the following discussion of the design alternatives for two bladed wind turbines appears to be useful. Because a rigid blade-hub attachment can cause in two-bladed rotors severe two per revolution vibrations, such wind turbines are often hinged to the hub. As will be explained later, a conventional teeter hinge with an axis perpendicular to the blade axes will produce in the blade tip path plane periodic blade angular velocity variations if the blades have either an elastic or built-in coning angle, and if the blade pair, under the influence of yaw deflections, yaw rates or nonuniform inflow, performs flapping motions about the teeter hinge.

There are three methods available to avoid or to alleviate the periodic blade angular velocity variations associated with convisional flapping or teeter hinges; the addition of blade lag hinges, a floating hub design using a central universal hub hinge, and suppression of blade flapping by passive blade cyclic pitch variation, produced by a strong negative pitchflap coupling. The first two methods involve some complications. Lag hinges cause self-excited coupled lag and rotor support vibrations (mechanical instability) unless substantial blade lag motion damping is added. A floating hub is unstable unless an active blade cyclic pitch mechanism is added which provides a cyclic pitch feedback when the rotor tilts. The three hinge design methods to achieve in the blade tip path plane a nearly steady blade angular velocity will be described and evaluated in detail. Though some analytical results will be used, the discussion will be essentially of a qualitative nature.

Both in the helicopter and wind turbine literature there are numerous papers on the analysis of hinged rotors with pitchflap coupling. The present paper is not aimed at refining these

Contributed by the Solar Energy Division and presented at the Sixth Annual Technical Conference of the ASME Solar Energy Division, Orlando, Florida, April 18-21, 1983. Manuscript received by the Solar Energy Division September 16. 1983 . analytical methods but rather at evaluating design alternatives for smoothly running two-bladed hinged wind turbines.

\section{Collective and Cyclic Blade Pitch Variation}

A change in blade pitch angle is attained by rotating the blade about its longitudinal axis. Ignoring aeroelastic effects and higher harmonic cyclic pitch variations, the change in blade pitch from a reference plane is given by the sum of two terms.

$$
\theta=\theta_{o}+\theta_{C} \cos \left(\Omega t+\phi_{\theta}\right)
$$

The collective pitch variation $\theta_{0}$ at a given time $t$ is the same for all blades. The second term in equation (1) describes the cyclic pitch variation in terms of its amplitude $\theta_{C}$ and its phase angle $\phi_{\theta}$, which is different for different blades. The amplitude $\theta_{C}$ at a given time is the same for all blades. For a two-bladed rotor the phases of the blades differ by $180 \mathrm{deg}$. $\theta_{o}$ and $\theta_{C}$ are time functions. Collective and cyclic pitch can be imposed on the blades by a control mechanism. This is called active blade pitch variation. Collective and cyclic pitch can also be varied by passive means under the influence of aerodynamic and inertia forces. Active controls involve hydraulic or electric actuators and usually require electronic controls, all of which are subject to component malfunctions. Passive controls are simpler and more reliable except possibly under icing conditions. In propeller and wind turbine terminology, collective blade pitch variation is called blade feathering or unfeathering. Cyclic pitch variation is not used in propellers nor in most wind turbines. In a hinged rotor the blade tip path plane may assume a position which is different from the plane perpendicular to the shaft axis. The cyclic pitch control mechanism could be adjusted such that the cyclic pitch amplitude is zero in the plane perpendicular to the shaft axis. As the blade tip path plane tilts, a cyclic pitch amplitude with respect to the tilted plane develops which tends to restore the tilt angle to zero. This effect is used to stabilize a floating hub with a universal center hinge to be described later. 


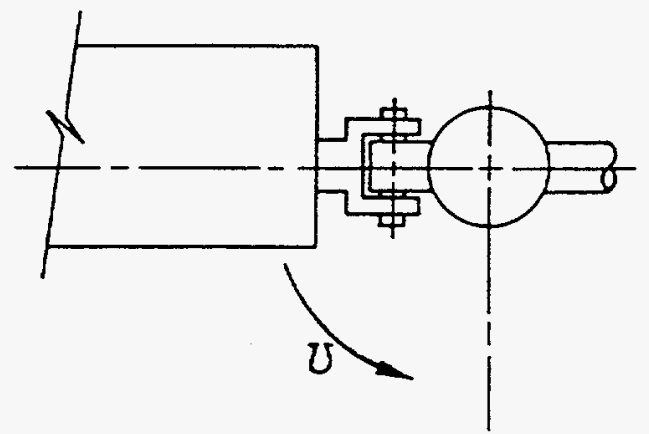

Fig. 1 Flap-coning hinge: axial view

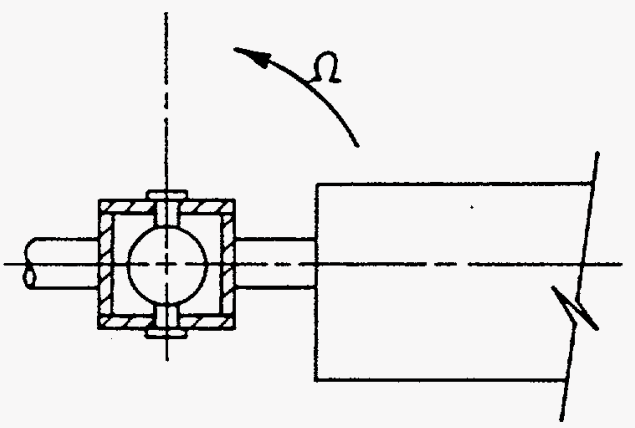

Fig. 2 Flap or teeter hinge: axial view

\section{Blade Coning and Flapping}

If blates are hinged to the hub with hinges perpendicular to the blade axes and positioned in the plane perpendicular to the rotor axis, see Fig. 1, and if aeroelastic effects and higher harmonics are ignored, the change in angular blade deflection about the hinge from a reference position is given by the sum of two terms.

$$
\beta=\beta_{o}+\beta_{F} \cos \left(\Omega t+\phi_{F}\right)
$$

The blade coning angle $\beta_{o}$ is at any given time the same for all blades. The second term in equation (2) describes blade flapping in terms of the flapping and amplitude $\beta_{F}$ and the phase angle $\phi_{F}$, which is different for different blades. The flapping amplitude at a given time is the same for all blades. In a two-bladed rotor the phase angles for the two blades differ by $180 \mathrm{deg} . \beta_{o}$ and $\beta_{F}$ are time functions. If the two blades are rigidly connected to the hub and can swivel about a teeter hinge, see Fig. 2, then only blade flapping is possible and no change in coning angle occurs except for aeroelastic effects. However, there may be a built-in fixed coning angle. In the literature the sum of what is called here coning and flapping, namely the right-hand side of equation (2), is usually denoted as flapping angle. The harmonic term would then be called cyclic flapping. Since the word flapping has the connotation of a periodic motion and not of a steady state, it seems that the definition of flapping given here is more ap-
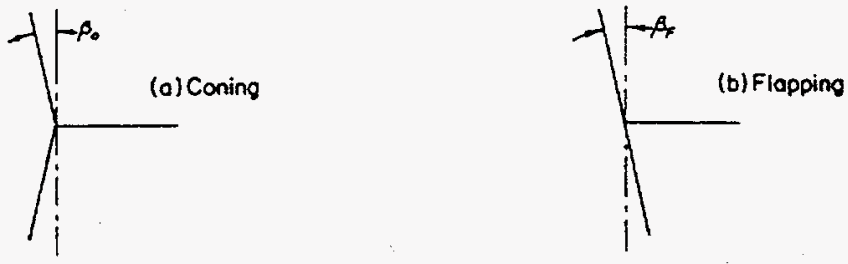

Fig. 3 Separate coning and happing, rotor side views
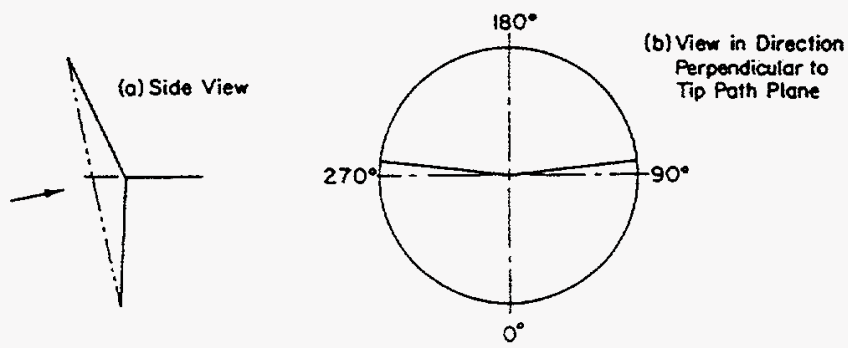

Fig. 4 Combined coning and flapping

propriate. It also shortens the text. Figure $3(a)$ shows the schematic side view of a rotor with the blades coned by the angle $\beta_{o}$. Figure $3(b)$ shows the schematic side view of a rotor where the blades flap with the amplitude $\beta_{F}$ in such a phase that for $t=0,2 \pi / \Omega, 4 \pi / \Omega$ etc. for $\phi_{F}=0$, a blade is in the upward position. The blades then rotate with a tip path plane, which is inclined downward. Figure $4(a)$ and $4(b)$ show what happens when the separate coning and flapping indicated in Fig. $3(a)$ and $3(b)$ are superimposed. When the blades are in the horizontal position their projections on a vertical plane are parallel to the rotor axis. Therefore, the blades when in the horizontal position cannot participate in the blade tip path plane tilting motion. Seen in the direction perpendicular to the blade tip path plane (arrow in Fig. $4(a)$ ), one has the view shown in Fig. $4(b)$. The two opposite blades, when in the horizontal position, form an angle with each other given by twice the product of coning and flapping angle, while they are aligned in the vertical position. In the blade tip path plane the blade tips move with nonuniform angular velocity, this velocity being larger for the lower portion and smaller for the upper portion of the tip path. These in-plane oscillations produce in-plane oscillatory blade loads and a two per revolution vertical excitation of the rotor support.

In order to obtain an estimate of the oscillatory in-plane force, a simple blade model is assumed here, consisting of a massless bar carrying a single point mass $m$ located at the radial distance $r$ from the rotor axis. In a frame of reference rotating with the angular speed $\Omega$, the in-plane oscillation in the blade tip path plane is from the geometry of Figs. 3 and 4

$$
\Delta \psi=\beta_{o} \beta_{F} \exp (i \Omega t)
$$

with the rate

$$
\Delta \dot{\psi}=\beta_{o} \beta_{F} \Omega i \exp (i \Omega t)
$$

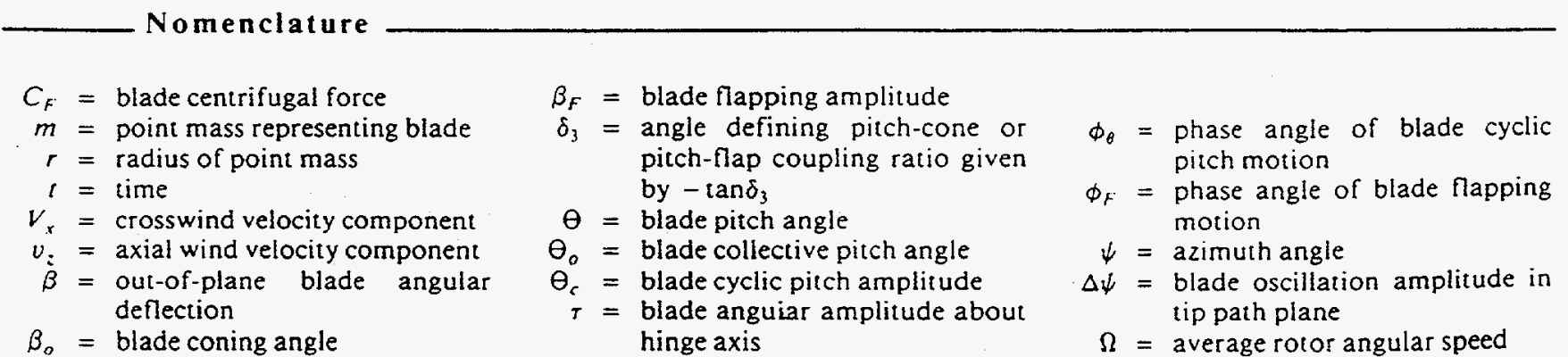


and with the acceleration

$$
\Delta \ddot{\psi}=-\beta_{o} \beta_{F} \Omega^{2} \exp (i \Omega t)
$$

The blade centrifugal force is

$$
C_{F}=m r(\Omega+\Delta \dot{\psi})^{2}
$$

At the azimuth angles 90 and 270 deg (see Fig. $4(b)$ ), the amplitude, rate, and accelerations are

$$
\Delta \psi=\beta_{o} \beta_{F}, \Delta \dot{\psi}=0, \Delta \ddot{\psi}=-\beta_{\circ} \beta_{F} \Omega^{2}
$$

At these azimuth angles there is acting on the rotor support an upward component of the blade centrifugal forces of magnitude

$$
2 m r \Omega^{2} \beta_{0} \beta_{F}
$$

and an upward component of the inertial forces of the same magnitude.

Upforce at horizontal blade position $=4 \mathrm{~m} r \Omega^{2} \beta_{o} \beta_{F}$

At the azimuth angles 0 and $180 \mathrm{deg}$ amplitude, rate and accelerations are

$$
\Delta \psi=0,|\Delta \dot{\psi}|=\beta_{o} \beta_{F} \Omega, \Delta \ddot{\psi}=0
$$

At $\psi=0$ deg the rotational speed is $\Omega+\beta_{o} \beta_{F} \Omega, \psi=180 \mathrm{deg}$ the rotational speed is $\Omega-\beta_{o} \beta_{F} \Omega$. Thus the centrifugal force at both blades has a downward component

Downforce at vertical blade position $=4 \mathrm{mr} \Omega^{2} \beta_{o} \beta_{f}$

Comparing equations (9) and (11) it is seen that in a frame of reference tied to the nonrotating rotor support the vertical force varies with the frequency $2 \Omega$ and with the amplitude $4 \mathrm{~m} r \Omega^{2} \beta_{o} \beta_{F}$. The force amplitude is $4 \beta_{o} \beta_{F}$ times the average blade centrifugal force. For example, if $\beta_{0}=\beta_{F}=0.1$, the force amplitude is 4 percent of the mean blade centrifugal force which amounts to a sizeable 2 per revolution vertical excitation of the rotor support. The oscillatory force need not be in the vertical direction as for the case of Figs. 3 and 4 . If flapping represents a blade tip path plane tilt about an axis other than the horizontal, the in-plane oscillatory force will have a different direction.

The preceding discussion was based on a description of the blade motion in the blade tip path plane. The analysis is usually performed in a reference system which rotates uniformly about the rotor axis. The blade centrifugal force then varies because of a variation of the distance of the blade mass from the rotor axis, and Coriolis forces appear because of the rate of change or this distance. The result is the same as that found here. The description of the blade motion in the blade tip path plane seems to be easier to grasp, since the Coriolis force concept is avoided.

The conclusion is that rotors with hinges as shown in Fig. 1 which are subject both to blade coning and blade flapping have a dynamic problem. Cierva, who began his autogyro development in the 1920's with a rotor according to Fig. 1, experienced blade failures from the high Coriolis forces and then added lag hinges, see Fig. 5, which are still used in most rotorcraft. Lag dampers are needed to prevent dynamic lag motion instability. The problem indicated by Fig. 4 not only arises in Fig. I type of rotors where the blades are free to cone, but it also occurs in rotors with teeter hinges, Fig. 2, if the blades have a built-in coning angle or if they are aeroelastically coned. The Bell Helicopter Company began its teetering rotor development with a configuration according to Fig. 2. It later adopted a universal hub hinge or floating hub arrangement, Fig. 7, which is now incorporated in all twobladed rotorcraft. As mentioned before, a noating hub requires an active cyclic pitch mechanism to stabilize the rotor tilt angle. This mechanism is shown in Fig. 7 and will be described in detail later. Utrich Huetter began his two-bladed. $100 \mathrm{~kW}$ wind turbine development in the $1950 \mathrm{~s}$ with a wind rotor according to Fig. 2, whereby the blades had a sub-

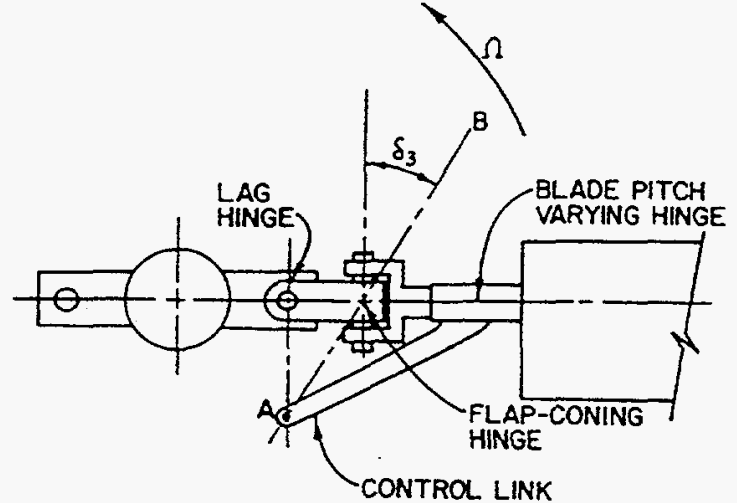

Fig. 5 Fixed hub with lag, flap-coning and pitch hinges: axial view

stantial built-in coning angle. Apparently he encountered difficulties, since in his U.S. patent (1) he applies the Bell Helicopter solution with the universal flapping hinge and with the active cyclic pitch variation to horizontal axis wind turbines.

The MOD-2 configuration with its two-bladed upwind rotor is, despite of its teeter hinge, relatively free of the problem indicated in Fig. 4. The reasons are that the blades have no built-in coning angle, that due to the high bending stiffness of the steel blades elastic coning is small, and that the yaw rate from the yaw gear drive is also small. With aluminum, fiberglass, or wooden blades, elastic coning can be considerable so that even without built-in coning angle Coriolis forces from combined coning and flapping can be significant.

One way to alleviate this condition is to elastically restrain the blade teeter motion, resulting in a semirigid, blade-hub connection. Another way is to aerodynamically restrain the blade teeter motion by using passive blade cyclic pitch variation produced by a strong negative pitch-flap coupling. Blade flapping is then effectively suppressed. Before discussing passive blade cyclic pitch variation in more detail various mechanisms to achieve aerodynamic pitch-cone and pitch-flap coupling will be described.

\section{Pitch-Cone and Pitch-Flap Coupling}

Figure 5 shows a schematic axial view of a blade-hub attachment frequently used for rotorcraft. The blade can be rotated about its longitudinal axis (blade pitch varying hinge) via a control horn and a control link extending parallel to the rotor axis and attached to the control horn at point $\mathrm{A}$. There is a flap-coning hinge in a horizontal plane, same as in Fig. 1, and there is a blade lag hinge parallel to the rotor axis. This hinge enables the blade to cancel the in-plane oscillations seen in Fig. $4(b)$ so that the blades rotate uniformly in the tip path plane. Since for a given control position point $A$ is fixed, the blade cones and flaps about the oblique axis $A-B$ that is inclined with respect to the flap-coning hinge by the angle $\delta_{3}$. Thus coning by the angle $\beta_{o}$ will produce a negative collecrive pitch change $\theta_{0}=-\beta_{0}$ tan $\delta_{3}$. Flapping with the amplitude $\beta_{F}$ will produce a cyclic pitch amplitude $\theta_{C}=-\beta_{0} \tan \delta_{3}$ The pitch-cone coupling ratio $\theta_{C} / \beta_{0}$ is $-\tan \delta_{3}$. The pitchcone coupling is quite effective in alleviating the cotor thrust increase from gusts, even if $\delta_{3}$ is only moderate. In contrase. the pitch-flap coupling has little effect on the rotor characteristics, unless large values of $\delta_{3}$ are selected. The effects of pitch-flap coupling are undesirable for rotorcraft since they reduce the rotor angular damping which is important for good rotorcraft flight characteristics. For this reason, rotorcraft have moderate values of $\delta_{3}$ of 15 to 30 deg.

Figure 6 shows a schematic axial view of a rotor type wirich allows the combination of a large pitch-cone coupling ratio with a small or zero pitch-flap coupling ratio. There is a 


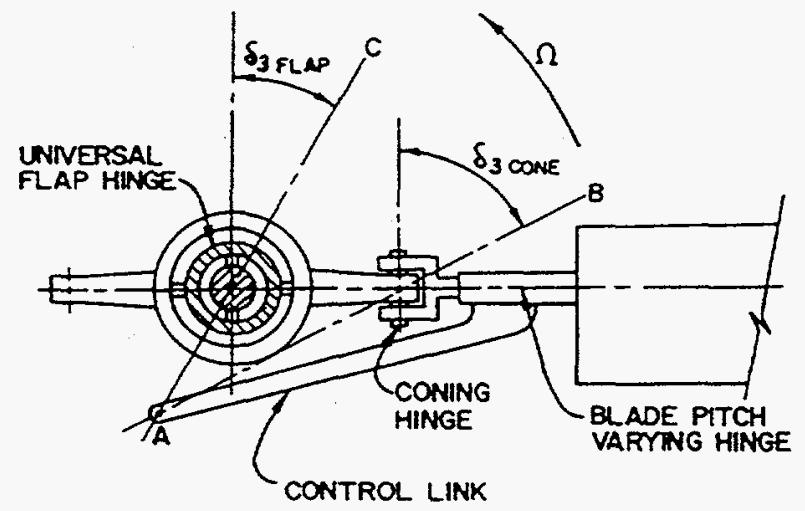

Fig. 6 Floating hub with coning and pitch hinges: axial view

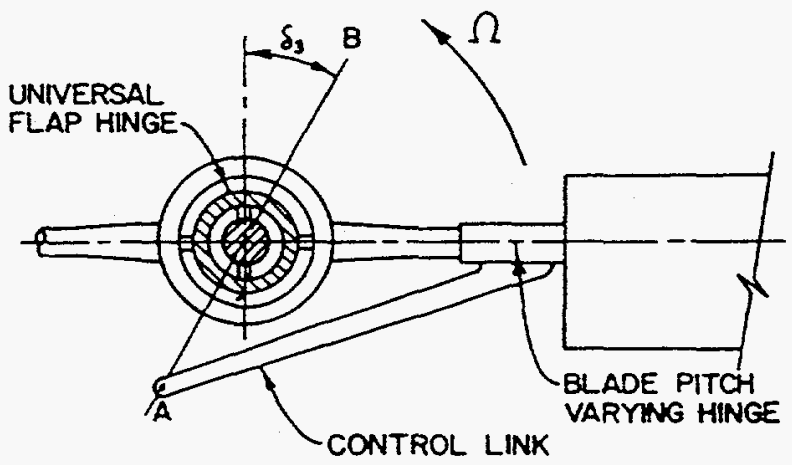

Fig. 7 Floating hub with pitch hinges: axial view

universal flap hinge in the rotor center (floating hub) and pure coning hinges further out. The blade is controllable about its longitudinal axis. Blade pitch is controlled via a control horn and a control link attached at point A. Coning takes place about the axis $A-B$ with a large $\delta_{3}$ angle. The pitch-cone ratio $\theta_{0} / \beta_{0}=-\tan \delta_{3 \text { CONE }}$ is large. Flapping takes place about the axis $A-C$, whereby the pitch-flap ratio $\theta_{C} / \beta_{F}=-\tan \delta_{3 F L A P}$ is small. The universal flap hinge allows the coned rotor to tilt so that the in-plane oscillations shown in Fig. 4 are avoided. The rotor type shown in Fig. 6 was analyzed aerodynamically in (2) and dynamically in (3). It was applied to the XV-1 Convertiplane developed in the 1950s. Due to the large pitch-cone coupling ratio this rotorcraft was gust insensitive. Due to the universal hub hinge the rotor ran smoothly with low vibration level. During cruising flight the rotor was unloaded by the fixed wing and the universal flapping hinge was blocked. The rotor then had not only a large pitch-cone coupling ratio but also a large pitch-flap coupling ratio. The rotor was accurately speed controlled by rotor angle of attack changes. Flapping was effectively suppressed so that the rotor followed rapid changes in pitch or roll without resistance. It was the experience with this rotor type which suggested its application in a simplified form to wind turbines.

A similar rotor type, however, without the coning hinges, is shown in Fig. 7. This rotor lacks pitch-cone coupling and has a small pitch-flap coupling ratio $\theta_{C} / \beta_{F}=-\tan \delta_{3}$. The universal flap hinge allows the use of a built-in coning angle without producing the in-plane oscillations in the blade tip path plane shown in Fig. 4. As mentioned before, the Fig. 7 rotor type has been incorporated in all modern two-bladed helicopters and has also been proposed for wind turbines in [1]. Though this rotor has excellent operating characteristics, it is rather complex and costly even more so than the lag hinge rotor of Fig. 5. The main reason for the complexity is the incorporation of the cyclic pitch feedback when the rotor tilis. It is conceivable that for large wind turbines this rotor type

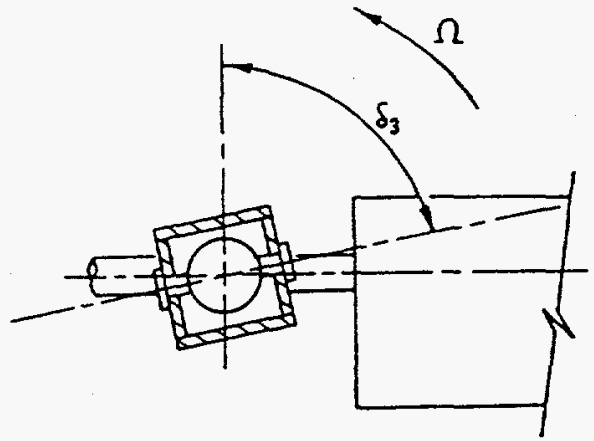

Fig. 8 Rotor with passive blade cyclic pitch variation: axial view (large pltch-flap coupling ratio)

may become of interest, since it allows a yaw control by purely aerodynamic means and thus avoids a yaw gear drive.

In wind turbines with rotor speed and torque control by yawing, an active cyclic blade pitch control is not needed. Without the active cyclic pitch control mechanism, the universal flap hinge in the hub center is not usable since the rotor plane could then wander off without aerodynamic feedback. The rotor with passive cyclic pitch variation shown in Fig. 8 combines the simplicity of the teeter rotor, Fig. 2, with the operational smoothness of the much more complex floating hub rotor of Fig. 7. The pitch-flap coupling ratio $\theta_{C} / \beta_{F}=-\tan \delta_{3}$ is very high so that flapping is largely suppressed and replaced by passive cyclic pitch variation. Due to the suppressed flapping, the in-plane amplitude shown in Fig. 4 is small, particularly if built-in coning is avoided and aeroelastic coning is kept moderate by reasonably stiff blades. The rotor shown in Fig. 8 could not be used in conventional rotorcraft, since it lacks blade pitch control and since the suppression of flapping also suppresses rotor damping. When applied to the vane stabilized wind turbine, the lack of an active pitch control and of rotor damping is not detrimental. Rotor speed and torque control can be accomplished by furling, and the tail vane provides the yaw damping. A twobladed passive cyclic pitch self-furling wind turbine of $7.6-\mathrm{m}$ (25-ft) dia has been tested in the atmosphere and was found to be running smoothly in the entire yaw angle range up tc 85 deg and at yaw rates up to $1 \mathrm{rad} / \mathrm{s}$. Experimental results for the test rotor are presented in [4]. Some analytical results will be presented in the following section.

\section{Effect of Pitch-Flap Coupling on Blade Flapping}

For the rotor type shown in Fig. 8, the effect of $\delta_{3}$ on the blade flapping amplitude for a steady yaw angle and for a steady yaw rate has been determined using the dynamic yaw analysis of [5]. Blade stall effects were neglected, while actually the inner portion of the retreating blade can be stalled. As compared to test results, the analytical values of flap and cyclic pitch amplitudes are smaller; however, the trend with $\delta_{3}$ established by the analysis is correct. In Figs. 9 and 10, the symbol $\tau$ denotes the amplitude of the angular motion about the hinge. It is compared to the flap amplitude and to the cyclic pitch amplitude. At $\delta_{3}=0$, which represents the teeter rotor of Fig. 2, the cyclic pitch amplitude is zero and $\tau$ equals the flapping amplitude. At $\delta_{3}=70 \mathrm{deg}$, the flapping amplitude is small and $r$ is almost equal to the cyclic pitch amplitude. Thus $\delta_{3}=70$ deg results in a hinge motion which represents almost pure cyclic pitch with little flapping, providing the rationale for the designation "rotor with passive cyclic pitch variation." For the normally used range of $\delta_{3}$ between 15 and $30 \mathrm{deg}$, flapping has not decreased much from its value for the teeter rotor, $\delta_{3}=0$. In order to ef fectively suppress napping, one has to select a $\delta_{3}$ angle of about $70 \mathrm{deg}$. The amplitude $\tau$ of the angular motion about the hinge does not change much with $\delta_{3}$. Thus the required 


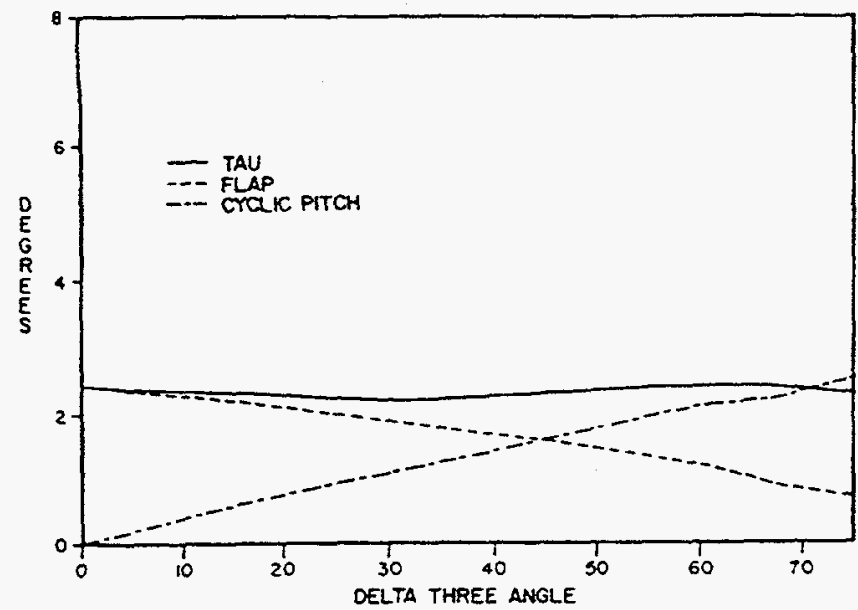

Fig. 9 Blade deflection angles versus delta three angle, steady-state yaw angle of $60 \mathrm{deg}$

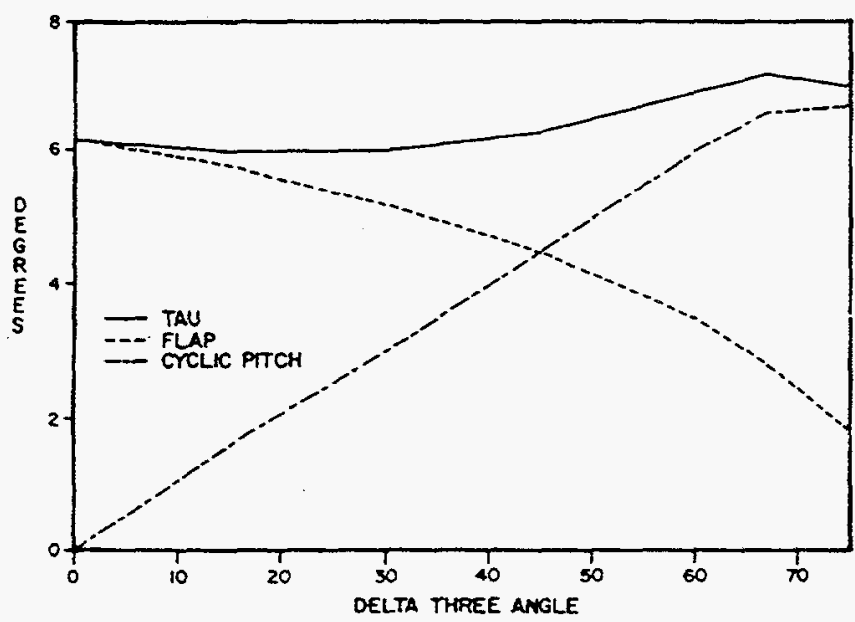

Fig. 10 Blade dellection angle versus delta three angle, dynamic yaw between 56 and $65 \mathrm{deg}$ at $30 \mathrm{deg} / \mathrm{s}$

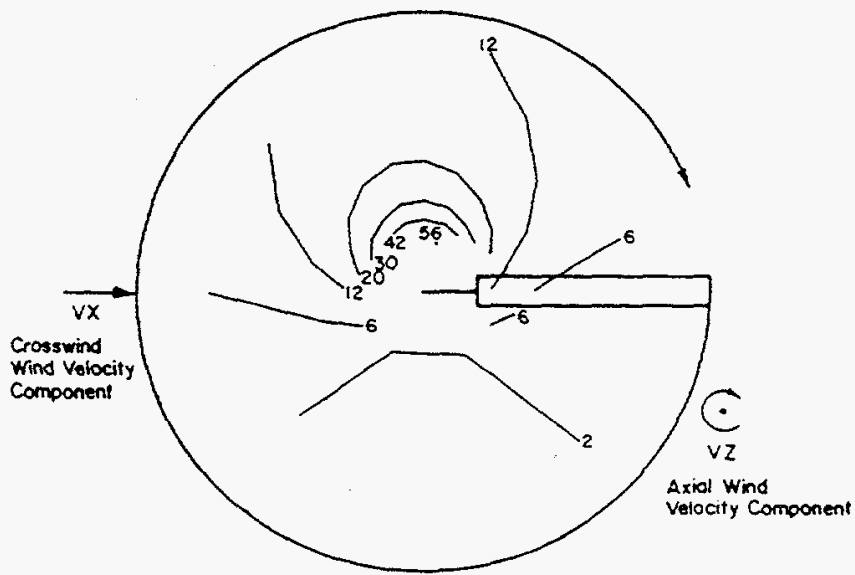

Fig. 11 Angle of attack profile for case of Fig. 10, delta three $=0$ deg

hinge motion between limiting stops is about the same for the rotor with blade passive cyclic pitch variation as for the teeter rotor, though the flapping limits are much lower.

The results presented in Figs. 9-12 refer to the test rotor described in [4] for an angular rotor speed of $\Omega=21 \mathrm{rad} / \mathrm{s}$ and a wind velocity of $18 \mathrm{~m} / \mathrm{s}(40 \mathrm{mph})$. Figure 9 assumes a steady yaw angle of $60 \mathrm{deg}$. Figure 10 assumes a steady rate of yaw of $30 \mathrm{deg} / \mathrm{s}$ for a yaw angle between 56 and $65 \mathrm{deg}$. This yaw rate increases $\tau$ from about 2.5 to $7 \mathrm{deg}$. The $\delta_{3}$ angle has little effect on rotor performance. The rotor power output is about $9.5 \mathrm{~kW}$ throughout the $\delta_{3}$ range. Figures 11 and 12

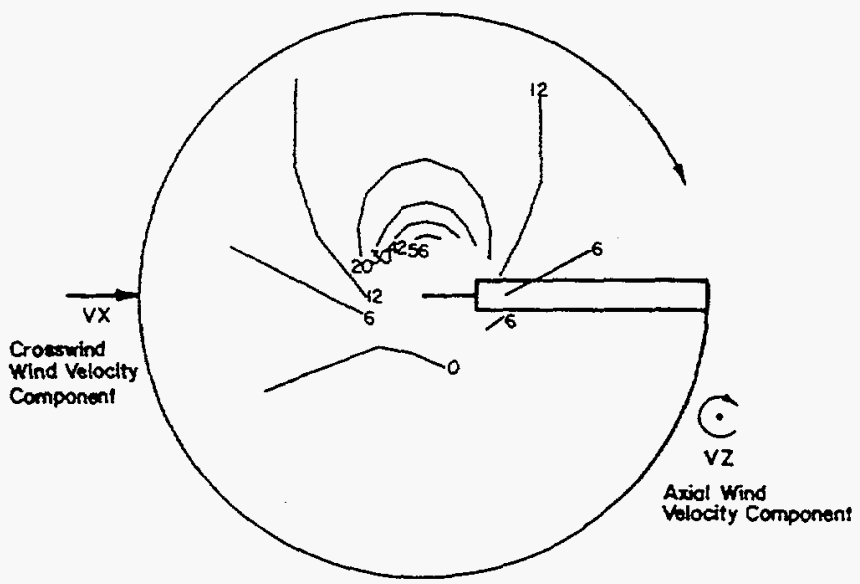

Fig. 12 Angle of attack protile tor case of Fig. 10, delta three $=67 \mathrm{deg}$

show for the yaw rate case of Fig. 10 the angle of attack profiles for $\delta_{3}=0$ and $\delta_{3}=67 \mathrm{deg}$, respectively. The profiles are approximately the same. The suppression of flapping according to the analysis, has little effect on the aerodynamic rotor characteristics. Test results obtained with teeter rotors and reported in [6] and [7] should be approximately applicable to rotors with passive blade cyclic pitch variation. For example, the effect of yaw rate on the teeter amplitude should be about the same as its effect on the cyclic pitch amplitude. The effect of blade stall on the teeter amplitude should be similar to its effect on the cyclic pitch amplitude. However, the suppression of lapping has a large effect on the yaw stability of a wind turbine, as will be explained in the next section.

\section{Effect of Pitch-Flap Coupling on Yaw Stability}

A teeter rotor, if located upwind of the yaw axis, has a negative contribution to yaw stability; a positive yawing moment is associated with a positive yaw angle. The yaw instability is generated by a rotor side force driving the nacelle in the direction in which the rotor is yawed. The rotor yaw instability must be overcompensated by the tail vane. The yaw damping from an upwind teeter rotor is also negative; a positive yaw rate produces a positive yawing moment. The negative yaw damping of the teeter rotor must be overcompensated by the positive tail vane damping. Since the tail vane is located in the rotor wake and operates in a flow field that is turbulent and has, as compared to the free stream, a substantially reduced velocity, it is quite difficult to design a tail vane with adequate yaw stability and yaw damping to overcompensate the negative contributions from the teeter rotor. In this respect the rotor with passive blade cyclic pitch variation is of some help. Because of the suppression of napping, the amounts of negative yaw stability and negative yaw damping contributed by the rotor are smaller than for the teeter rotor, so that it is easier to design for adequate tail vane effectiveness. With the analysis method of $[5]$, it has been found that for the 7.6-m-dia test turbine mentioned before a $\delta_{3}$ angle of 67 deg reduces the negative yaw stability and negative yaw damping contributions of the rotor by about 50 percent. The automatic rotor furl system, which does not benefit from the aerodynamic tail vane damping. must be mechanically damped. The rotor overhang-its distance upwind of the yaw axis-should be made as small as possible. Due to the suppression of flapping, the overhang can be reduced as compared to a teeter rotor without reducing the blade-mast interference margin.

\section{Other Applications of Passive Cyclic Pitch Variation}

While blade passive cyclic pitch variation has been tested 
for a wind turbine with rotor speed and torque control by yawing, other useful applications are possible. For example, a wind rotor that is located downwind of the mast and that is designed to self-align with the wind direction, needs substantial blade coning. If a teeter hinge is used, combined coning and flapping with its detrimental effects occur during rapid wind direction changes which the rotor is incapable of following immediately. The temporary yaw angles as well as the yaw rates will cause flapping. The vertical boundary layer also will cause flapping. Suppression of flapping by passive blade cyclic pitch variation would appear desirable. The usual $\delta_{3}$ angles of 15 to $30 \mathrm{deg}$ will have little effect. One needs to use $\delta_{3}$ angles of about $70 \mathrm{deg}$, an approach which has never been tried prior to the SERI project [4]. Self-aligning wind turbines must be stopped at high wind velocities. The blades will then bounce between the stops which limit the flapping motion. With passive blade cyclic pitch variation, the flapping motions between stops are much smaller than for the teeter rotor. This will improve the interference margin between blades and mast and will reduce the blade loads from stop impacts. The passive cyclic pitch feature could also be used for rotors with feathering blade controls if one desires an independent shutdow's by rapidly yawing the rotor out of the wind. The large Mapping amplitudes of a teeter rotor during this procedure would be suppressed by the passive cyclic pitch feature.

\section{Summary and Conclusions}

The following conciusions can be drawn for two-bladed wind rotors.

1 A teeter roto: with built-in or aeroelastic coning angle is not suited for operator at high yaw angles or at high yaw rates because simulianeous coning and flapping causes high in-plane blade forse and high 2 per revolution excitation of the rotor suppor:

2 One was is avoid in-plane blade oscillations from combined coning and napping is to add damped blade lag hinges as is done in most helicopter rotors.

3 Another way to avoid in-plane oscillations from combined coning and flapping is to use a universal flapping hinge (floating hub design). This requires blade pitch control. The combination of a universal central flapping hinge with blade pitch control is used in modern two-bladed helicopters. It has been proposed also for wind turbines. Though the dynamic performance is good, such a rotor is complex and costly.
4 A simple solution of the problem encountered with teeter rotors is to suppress flapping by a large pitch-flap coupling with a $\delta_{3}$ angle of about 70 deg. The amplitude of the angular motion about the hinge is then almost equal to the cyclic pitch amplitude which justifies the term "passive blade cyclic pitch variation." A two-bladed rotor with this feature is as simple and as rugged as a teeter rotor.

5 As a result of suppressed flapping, the yaw instability and negative yaw damping of an upwind teeter rotor is reduced. The performance of a teeter rotor, thrust, torque, and power output are not affected by passive blade cyclic pitch variation.

6 A moderate pitch-flap ratio with a $\delta_{3}$ angle between 15 and $30 \mathrm{deg}$ as it is usually applied in helicopters has little effect on flapping and is all but useless for its suppression.

7 The suppressed flapping resulting from passive blade cyclic pitch variation appears to be warranted in other wind turbine configurations in addition to those with rotor speed and torque control by yawing.

\section{Acknowledgments}

The results in this paper were obtained under a subcontract of the Solar Energy Research Institute (SERI) to Washington University Technology Associates.

\section{References}

1 Huettet, U., US Patent No. 4.201.514, May 6. 1980.

2 Hohenemser. K., "A Type of Lifring Roror With Inherent Stability." J. Aeron. Sc. Vol. 17, No. 9. Sept. 1950, po. 555-564.

3 Hohenemser, $K$, and Perisho, $C$. H., "Analysis of the Vertical Flight Dynamic Characteristics of a Lifting Rotor with Floating Hub and Off-Sei Coning Hinges," J. Amer. Helic. Soc. Vol. 3. No. 4. Oct. 1958, pp. 20-33.

4 Hohenemser, K. and Swift, A. H.P. "The Investigation of Passive Blade Cyclic Pirch Variation Using an Automatic Yaw Control System." Final Report, SERI/TR-1052-10, Dec. 1981

5 Swift, A. H. P. "The Effects of Yawed Flow on Wind Turbine Rotors." Doctor of Science dissertation, Washington University, Sever Institute of Technology, May 1981.

6 Glasgow, J. C. Pfanner, H. G., and Westercamp, E. J., "The Response of a $38-\mathrm{m}$ Horizontal Axis Teetered Rotor to Yaw," Large Horizontal Axis Wind Turbines, A Workshop held at Cleveland, Ohio, July $28-30,1981$.

7 Glasgow, \&. C., and Corrigan, R. D., "Siall Induced Instability of a Teetered Rotor," Large Horizontal Axis Wind Turbines. A Workshop held at Cleveland, Ohio, July 28-30, 1981. 


\section{REPORT DOCUMENTATION PAGE}

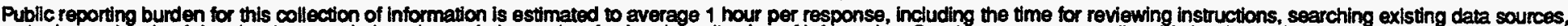

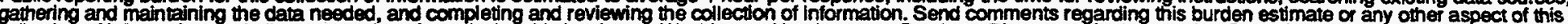

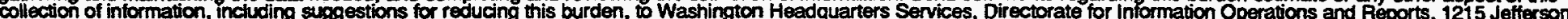

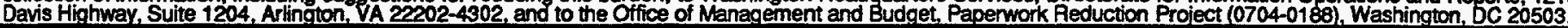

1.

2. REPORT DATE October 1995

3. REPORT TYPE AND DATES COVERED Subcontract Report

4. TITLE AND SUBTITLE

Analysis and Test Results for a Two-Bladed, Passive Cycle Pitch, Horizontal-Axis Wind Turbine in Free and Controlled Yaw

6. AUTHOR(S)

Kurt H. Hohenemser

7. PERFORMING ORGANIZATION NAME(S) AND ADDRESS(ES)

Kurt H. Hohenemser

2421 Remington Lane

St. Louis, MO 63144

9. SPONSORINGMONITORING AGENCY NAME(S) AND ADDRESS(ES)

National Renewable Energy Laboratory

1617 Cole Blvd.

5. FUNDING NUMBERS

C: XE-2-02054-01

TA: WE517060

Golden, CO 80401-3393

8. PERFORMING ORGANIZATION REPORT NUMBER

10. SPONSORINGMONITORING AGENCY REPORT NUMBER

TP-442-7391

DE95009291

11. SUPPLEMENTARY NOTES

NREL Technical Monitor: C. Shepard

12a. DISTRIBUTION/AVAILABILITY STATEMENT National Technical Information Service U.S. Department of Commerce 5285 Port Royal Road Springfield, VA 22161

12b. DISTRIBUTION CODE

UC-1211

13. ABSTRACT (Maximum 200 words)

This report surveys the analysis and tests performed at Washington University in St. Louis, Missouri, on a horizontal-axis, two-bladed wind turbine with teeter hub. The introduction is a brief account of results obtained during the 5-year period ending December 1985 . The wind tunnel model and the test turbine $\left(7.6 \mathrm{~m}\right.$ [25 ft] in diameter) at Washington University's Tyson Research Center had a $67^{\circ}$ delta-three angle of the teeter axis. The introduction explains why this configuration was selected and named the passive cycle pitch (PCP) wind turbine. Though the analysis was not limited to the PCP rotor, all tests, including those done from 1986 to 1994, were conducted with the same teetered wind rotor. The blades are rather stiff and have only a small elastic coning angle and no precone.

Between September 1979 and December 1985, the work was sponsored under various subcontracts by the Solar Energy Research Institute (SERI), now the National Renewable Energy Laboratory. The Final Subcontract Report of January 1987, included here as Appendix 1 , summarizes the analysis and atmospheric test results obtained during this period. This updated Final Subcontract Report also includes analysis and atmospheric test results obtained after SERI sponsorship was terminated.

14. SUBJECT TERMS

horizontal axis wind turbine OF REPORT Unclassified
18. SECURITY CLASSIFICATION OF THIS PAGE Unclassified
19. SECURITY CLASSIFICATION OF ABSTRACT Unclassified
15. NUMBER OF PAGES

16. PRICE CODE UL 